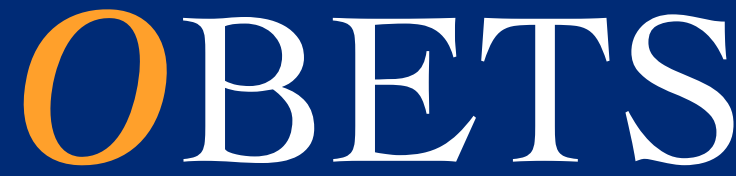

Revista de Ciencias Sociales

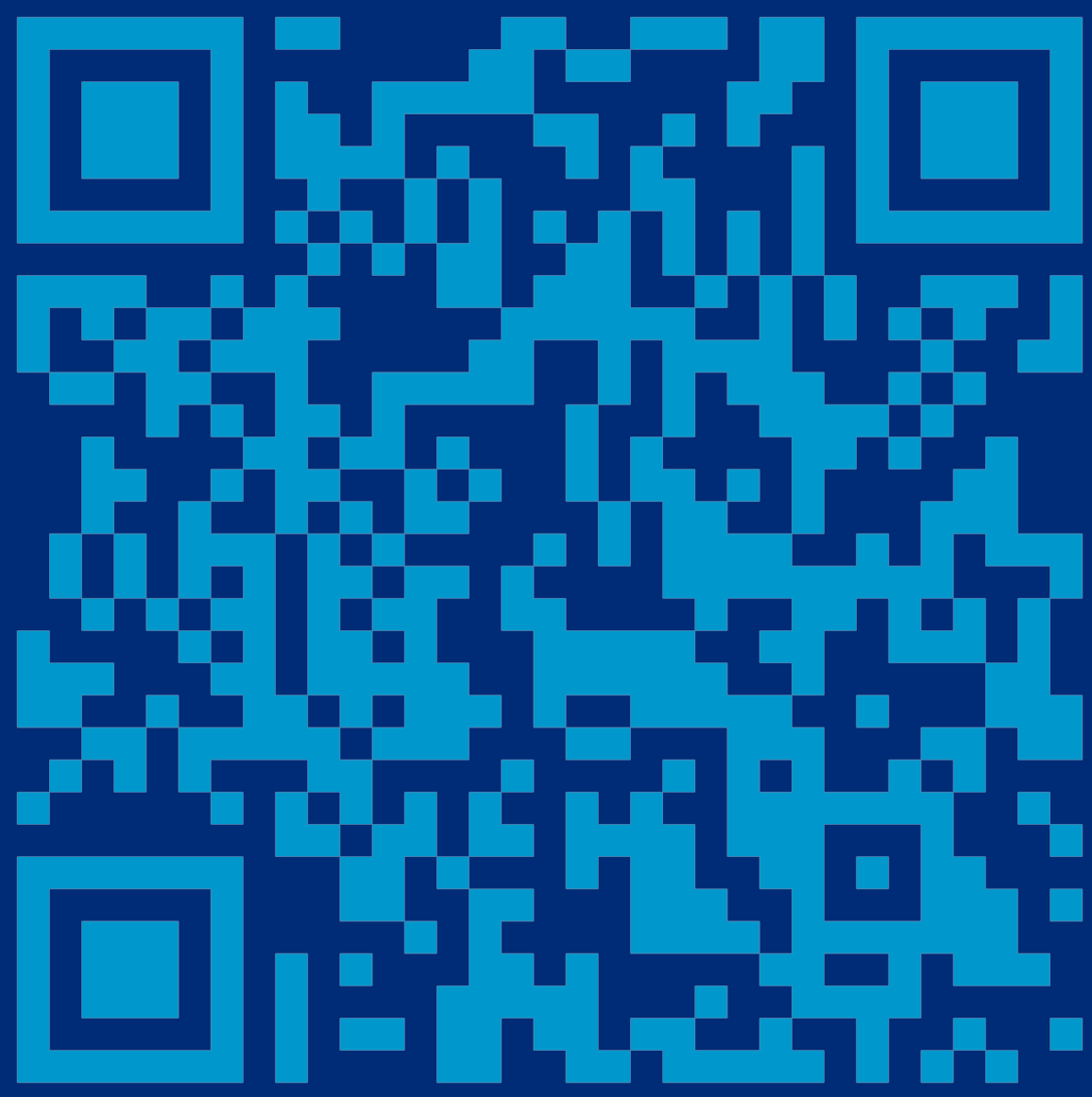

\title{
Julio-diciembre 2016
}

Instituto Interuniversitario de Desarrollo Social y Paz Universidad de Alicante

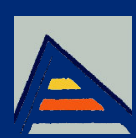

Universitat d'Alacant Universidad de Alicante 



\section{OBETS}

Revista de Ciencias Sociales 



\section{OBETS}

REVISTA DE CIENCIAS SOCIALES

PUBLICACIONES DE LA UNIVERSIDAD DE ALICANTE 
El presente número de la revista ha obtenido una ayuda del Vicerrectorado de Investigación, Desarrollo e Innovación de la Universidad de Alicante

Publicaciones de la Universidad de Alicante

Campus de San Vicente s/n

03690 San Vicente del Raspeig

Publicaciones@ua.es

http://publicaciones.ua.es

Teléfono: 965903480

Fax: 965909445

(C) de la presente edición: los autores

OBETS. Revista de Ciencias Sociales.

Editada por IUDESP.

Instituto Interuniversitario de Desarrollo Social y Paz.

Universidad de Alicante.

Periodicidad: Semestral

http://revistes.ua.es/obets

Email: revistaobets@ua.es

ISSN: 2529-9727

e-ISSN: 1989-1385

Depósito legal: A-885-2008

DOI: $10.14198 /$ OBETS

Diseño de portada: candela ink. / O. Santacreu

Composición:

Patricia Barbero

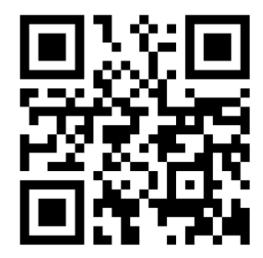

Los contenidos están bajo una licencia Creative Commons Reconocimiento 4.0 España.

Los contenidos pueden copiarse, distribuirse o comunicarse públicamente, bajo las siguientes condiciones generales: Reconocimiento. Debe reconocerse los créditos de la obra de la manera especificada por el autor o el licenciador (pero no de una manera que sugiera que tiene su apoyo o apoyan el uso que hace de su obra). Los términos de la licencia disponibles on-line en: http://creativecommons.org/licenses/by/3.0/es/ 
OBETS, Revista de Ciencias Sociales es una revista de investigación de periodicidad semestral editada por el Observatorio Europeo de Tendencias Sociales (OBETS), grupo de investigación integrado en la sede de la Universidad de Alicante (España) del Instituto Interuniversitario de Desarrollo Social y Paz (IUDESP). Dirigida a profesionales, investigadores/as, estudiantes, profesorado y público general interesado en la investigación académica en el campo de las Ciencias Sociales, comenzó a editarse en 2008.

La revista tiene como objetivo la difusión de estudios de naturaleza académica que contribuyan al mejor conocimiento de la sociedad contemporánea. En este sentido está abierta a la publicación de resultados de investigación empírica, metodológica o teórica de ámbito nacional e internacional. La revista abarca un amplio abanico de temas inscritos en el ámbito de la Sociología y Ciencias Sociales, como estudios de opinión pública, metodología, demografía, estructura y cambio social, ciencia política, teoría sociológica, antropología o psicología social. Los trabajos se publican en español, inglés, italiano, portugués o valenciano/catalán.

La revista está integrada en RUA, Repositorio Institucional de la Universidad de Alicante y cumple con el estándar de metadatos Dublin Core (http://www.dublincore.org) y con el protocolo OAI-PMH (Open Archives Initiative-Protocol for Metadata Harvesting: http://www.openarchives.org) para la transmisión de contenidos en Internet. Cuenta también con el DOI 10.14198/OBETS. A través de su página web y del RUA la revista ofrece opciones de acceso a contenido por títulos, autores, palabras claves o fecha.

A fin de alcanzar el mayor nivel de calidad posible en los trabajos publicados, todos los artículos se someten al arbitraje por pares académicos, considerando tanto la novedad de los resultados como el rigor metodológico en los diseños de investigación y análisis. El equipo editorial de OBETS. Revista de Ciencias Sociales no se hace responsable, en ningún caso, de la credibilidad y autenticidad de los trabajos. Del mismo modo, las opiniones y hechos expresados en cada artículo son de exclusiva responsabilidad de sus autores/as y OBETS. Revista de Ciencias Sociales no se identifica necesariamente con ellos. 
Incluida en:

\begin{tabular}{|l|l|}
\hline SCOPUS & $\begin{array}{l}\text { Base de datos bibliográfica de resúmenes y citas de artículos } \\
\text { de revistas científicas editada por Elsevier }\end{array}$ \\
\hline ESCI & $\begin{array}{l}\text { Emerging Sources Citation Index - Producto de la Web of } \\
\text { Science (WoS) editada por Thomson Reuters }\end{array}$ \\
\hline DICE & $\begin{array}{l}\text { Base de datos para la difusión y calidad editorial de las } \\
\text { revistas españolas de humanidades y ciencias sociales y } \\
\text { jurídicas }\end{array}$ \\
\hline ISOC & $\begin{array}{l}\text { ISOC - Base de datos del Centro de Información y } \\
\text { Documentación Científica (CINDOC) del CSIC }\end{array}$ \\
\hline CIRC & Clasificación Integrada de Revistas Científicas \\
\hline RESH & $\begin{array}{l}\text { Sistema de valoración integrada de revistas españolas de } \\
\text { Humanidades y Ciencias Sociales }\end{array}$ \\
\hline LATINDEX & $\begin{array}{l}\text { LATINDEX-Catálogo. Sistema regional de información en } \\
\text { línea para revistas científicas de América Latina, el Caribe, } \\
\text { España y Portugal }\end{array}$ \\
\hline DOAJ & DOAJ - Directory of Open Access Journals \\
\hline REDIB & $\begin{array}{l}\text { Red Iberoamericana de Innovación y Conocimiento } \\
\text { Científico }\end{array}$ \\
\hline DIALNET & $\begin{array}{l}\text { Portal de difusión de la producción científica iberoamericana } \\
\text { impulsado por la Universidad de La Rioja }\end{array}$ \\
\hline MIAR & MIAR: Matriu d'informació per a l'avaluació de revistes \\
\hline CiteFactor & CiteFactor: Academic Scientific Journals \\
\hline SJIF & SJIF Scientific Journal Impact Factor \\
\hline ULRICH'S & ULRICH'S Periodicals Directory \\
\hline RECOLECTA & $\begin{array}{l}\text { RECOLECTA: Recolector de Ciencia Abierta de la FECYT } \\
\text { y del Plan Estratégico REBIUN 2007-2010 }\end{array}$ \\
\hline SCIRUS & SCIRUS - Buscador de información científica \\
\hline SHERPA/RoMEO & $\begin{array}{l}\text { Políticas de copyright de las editoriales y autoarchivo. } \\
\text { University of Nottingham. }\end{array}$ \\
\hline DULCINEA & $\begin{array}{l}\text { Dulcinea - Proyecto coordinado por el Ministerio de } \\
\text { Educación y Ciencia para identificar y analizar las } \\
\text { políticas editoriales de las revistas científicas españolas }\end{array}$ \\
\hline
\end{tabular}




\section{EQUIPO EDITORIAL}

\section{Consejo de redacción}

\section{Dirección:}

Oscar Antonio Santacreu Fernández - IUDESP. Universidad de Alicante, España Secretaría:

Francisco José Francés García - Departamento Sociología II. Universidad de Alicante, España

\section{Secretaría técnica:}

María Carmen Albert Guardiola - Unidad Técnica de Calidad. Universidad de Alicante, España

Vocales:

- Mercedes Alcañiz Moscardó - Universitat Jaume I de Castellón, España

- Cristino Barroso - Universidad de La Laguna, España

- Mario Alejandro Guillén García - Programa Interdisciplinario de Población y

Desarrollo Local Sustentable (PYDLOS), Universidad de Cuenca, Ecuador

- Nina Rother - BAMF. Alemania

- Natalia Ix-Chel Vázquez González - Facultad de Ciencias Políticas y

Administración Pública. Universidad Autónoma del Estado de México, México

\section{Comité científico}

- Alberto Acosta Espinosa - Facultad Latinoamericana de Ciencias Sociales (FLACSO), Ecuador

- Antonio Alaminos Chica - IUDESP. Universidad de Alicante, España

- José Beltrán Llavador - Dpto. Sociología y Antropología Social, Universidad de Valencia, España

- Gianfranco Bettin - Università degli Studi di Firenze, Italia

- Fermín Bouza Álvarez - Universidad Complutense de Madrid, España

- José Manuel Canales Aliende - Dpto. de Estudios Jurídicos del Estado, Universidad de Alicante, España

- Vidal Díaz de Rada - Universidad Pública de Navarra, España

- Guillermina Díaz Pérez - Universidad Autónoma del Estado de México

- Mariano Fernández Enguita - Universidad Complutense de Madrid, España

- Margarita Latiesa Rodríguez - Universidad de Granada, España

- María Asunción Martínez Román - Dpto. Trabajo Social y Servicios Sociales. Universidad de Alicante, España

- Beatriz Padilla - Instituto Universitário de Lisboa (ISCTE-IUL), Lisboa, Portugal

- Andrea Pirni - University of Genova, Italia

- Ettore Recchi - Università degli Studi 'G. d'Annunzio' Chieti e Pescara, Italia

- M'hammed Sabour - University of Eastern Finland, Finlandia

- Pedro Sánchez Vera - Universidad de Murcia, España

- Sylvie Strudel - Université Panthéon-Assas, Paris, Francia

- José María Tortosa Blasco - IUDESP. Universidad de Alicante, España

- Anna Triandafyllidou - European University Institute, Florencia, Italia; ELIAMEP, Atenas, Grecia 


\section{ESTADÍSTICAS 2016}

Durante el año 2016 se han recibido un total de 72 artículo y 3 reseñas de libros. Durante el mismo año se ha concluido la evaluación externa (revisión por pares de forma anónima) de 52 artículos $(72,2 \%)$ estando el resto en proceso de evaluación $(27,8 \%)$.

De los 52 artículos evaluados, 19 han sido aceptados (36,5\%), de los cuales $13(68,4 \%)$ fueron remitidos a sus autores/as a fin de incorporar las modificaciones propuestas por las evaluaciones. Cada artículo ha sido revisado por una mediana de 2 revisores/as. Cada revisor/a ha evaluado una mediana de 1 trabajo.

En 2016 el tiempo medio de espera de los artículos aceptados (desde su recepción hasta su aceptación definitiva) ha sido de 224 días (mediana 217), y el tiempo medio entre aceptación y publicación ha sido de 80 días (mediana 50).

Tabla 1. Resumen estadísticas 2016

\begin{tabular}{l|c|c}
\hline \multirow{2}{*}{ Artículos } & \multicolumn{2}{|c}{ Artículos originales } \\
\cline { 2 - 3 } Recibidos & Número & Porcentaje \\
\cline { 2 - 3 } & 72 & \\
\hline Pendientes & 20 & $27,7 \%$ \\
\hline Evaluados, de los cuales: & 52 & $72,2 \%$ \\
\hline - Rechazados & 33 & $63,5 \%$ \\
\hline - Aceptados, de los cuales & 19 & $36,5 \%$ \\
\hline -- Aceptados con modificaciones & 13 & $68,4 \%$ \\
\hline
\end{tabular}

Tabla 2. Tiempos del proceso editorial

\begin{tabular}{l|c}
\hline Tiempos entre & Artículos originales \\
\hline & 2016 . Días \\
$\mathrm{M} / \pm \mathrm{DS} / \mathrm{Me}$ \\
\hline Recepción/aceptación & $223,7 / 81,9 / 217$ \\
\hline Aceptación/publicación & $80,5 / 76,4 / 50$ \\
\hline
\end{tabular}

Nota: $M / \pm D S / M e=$ Media/Desviación Estándar/Mediana 


\section{INDICE}

ARTÍ́CUlOS . . . . . . . . . . . . . . . . . . . . . . 381

Jorge Francisco Aguirre Sala

La prevención comunitaria del delito a través de la gobernanza local .

The community crime prevention through local governance

\section{Robert Arnau Roselló}

Cooperativas independientes entre la exhibición cinematográfica

y la gestión cultural: el cine ciudadano en la periferia de la industria

Independent cooperatives between film exhibition and cultural management: citizen cinema at the industry's periphery

\section{Liberto Carratalá Puertas}

¿La democracia es un sistema dependiente de valores como el conformismo y la obediencia? Un estudio comparado sobre las valoraciones que jóvenes y adultos españoles hacen de la democracia . . 441 Is democracy a dependent value such as conformity and obedience? A comparative study on the assestments that young and adult spanish do of democracy

\section{Ricardo Gaete Quezada}

Percepción de los dirigentes estudiantiles universitarios sobre la responsabilidad social universitaria 461

Perception of college student leaders about university social responsability

\section{Emilio M. Martínez Gutiérrez}

Donde la ciudad se escribe. Prensa, urbanización y cultura en Robert E. Park . . . . . . . . . . . . . . . . . . . . . 487 Where the city is written. Robert E. Park: on press, urban growth and culture 
Jhoner Perdomo, Luis Daniel Álvarez, Sary Levy-Carciente, Mauricio Phélan

La integración regional latinoamericana a partir de las oportunidades para el progreso .

The latin american regional integration based on its opportunities for progress

Francisco Alberto Vallejo Peña y Juan Herrera Ballesteros

University internships in Spain: what is missing for its stakeholders? .................................. 547

Prácticas de empresa universitarias en España: ¿qué echan de menos los protagonistas?

NOTAS DE INVESTIGACIÓN 567

Javier Carreón Guillén, Miguel Bautista Miranda, Cruz García Lirios, Guillermina Hernández Romero, Francisco Rubén Sandoval Vázquez y Gabriel Pérez Crisanto

Confiabilidad y validez de un instrumento que mide percepciones de salud ocupacional en migrantes de Huehuetoca, estado de México

Reliability and validity of an instrument that measures perceptions of occupational health in migrant Huehuetoca, state of Mexico

CRÍTICA DE LIBROS 583

Antonio Alaminos Fernández

Antonio Alaminos Chica, Francisco José Francés García,

Clemente Penalva Verdú y Óscar Antonio Santacreu Fernández

Análisis multivariante para las Ciencias Sociales I. Índices de

distancia, conglomerados y análisis factorial . . 585

NORMAS EDITORIALES E INSTRUCCIONES PARA

COLABORACIONES

EDITORIAL STANDARDS AND INSTRUCTIONS FOR

CONTRIBUTORS 
ARTículos ARTICLES 



\title{
LA PREVENCIÓN COMUNITARIA DEL DELITO A TRAVÉS DE LA GOBERNANZA LOCAL ${ }^{1}$ THE COMMUNITY CRIME PREVENTION THROUGH LOCAL GOVERNANCE
}

\author{
Jorge Francisco Aguirre Sala \\ Universidad Autónoma de Nuevo León, México \\ jorge.aguirres@uanl.mx
}

\begin{abstract}
Cómo citar / Citation
Aguirre Sala, Jorge Francisco (2016). "La prevención comunitaria del delito a través de la gobernanza local". OBETS. Revista de Ciencias Sociales, 11(2): 383-418. doi:10.14198/OBETS2016.11.2.01
\end{abstract}

\section{Resumen}

El objetivo de este estudio es mostrar el mayor número de comunes denominadores en cuatro prácticas latinoamericanas exitosas de la prevención del delito. El análisis se hizo con una metodología cualitativa, de índole de diseño teórico y codificación axial. El marco teórico vinculó la participación ciudadana con la gobernanza para sintetizar las perspectivas social, ambiental y situacional de la prevención en el modelo comunitario. Los datos se recolectaron en indicadores de procesos y no de impacto. En los resultados destacan: la asociación entre ciudadanos y autoridades, la gestión de derechos sociales y el empoderamiento ciudadano a través del presupuesto participativo.

Palabras clave: participación ciudadana; gobernanza local; prevención del delito; seguridad pública.

\section{Abstract}

The objective of this study is to show the most number of common denominators in four successful Latin American practices in crime prevention. The analysis was done with a qualitative methodology of theoretical design nature and axial coding. The theoretical framework links the citizen participation with governance to synthesize the social, environmental and situational pre-

\footnotetext{
${ }^{1}$ Investigación elaborada con los apoyos económicos y académicos otorgados por el Instituto de Investigaciones Sociales de la Universidad Autónoma de Nuevo León y el programa de estímulos correspondiente al expediente \#14051 del Consejo Nacional de Ciencia y Tecnología (CONACYT) de la República Mexicana.
} 
vention prospects in the Community model. Data were collected on process indicators rather than impact indicators. The main results are: the association between citizens and authorities, the management of social rights and citizen empowerment through participatory budget.

Key words: citizen participation; local governance; crime prevention; public security.

\begin{abstract}
extended
The objective of this study is to show the most number of common denominators in four successful Latin American practices in crime prevention. The analysis was done with a qualitative methodology of theoretical design nature and axial coding. The theoretical framework links the citizen participation with governance to synthesize the social, environmental and situational prevention prospects in the Community model.

Consequently some distinctions are made: a) the conceptual differentiation of citizen participation: electoral and non-electoral participation. Within the non-electoral participation is: conventional participation, unconventional and disruptive. b) The types of crime prevention are distinguished: social, environmental and situational. The community prevention is exposed as a synthesis of the above. These are contrasted with models Broken Windows and Zero Tolerance. c) Governance and citizen participation to approach to the notion of governance through its historical development, comparing their characteristics with those of governability is performed. While in state governability mediates or colonizes institutionalization of citizen participation, at the governance citizen participation in public affairs is directly and brokering state formulas given in cooperatives; where new forms of regulation that require negotiation are present prevails and coordination. The state governability is vertical, even in procedures, weightings and agendas public consultations, while democratic governance seeks horizontality through deliberative consensuses that are not subject to hierarchical layers. In governability also it notes that the State assigns the conditions must have community networks (through regulations that constitute the structure and function of the Citizens Councils), in contrast to the governance of social networks have greater symmetry between citizens and the State. Also in the state governability it has the prerogative to take action and defining public policies; in contrast, governance seeks cooperation and to the delegation of state actions. The realization of the common good and the general interest is not in the state monopoly and is located in the interaction of government, the private sector and citizen participation. It also warns of the potential risks of governance to the scopes of neoliberalism.

The cases analyzed correspond to locations: Diadema, Brazil; The League of Emergency, Chile; Bogota, Colombia and Tlalpan, Mexico, in the form of local governance. Each was studied in the respective periods of application of their prevention programs: from 2000 to 2004 for Diadema; 2001-2003 for the League; 1993-2002 and 2007 to 2008 for Bogotá; 2010-2013 for Mexico.

Data were collected on process indicators rather than impact indicators. The
\end{abstract}


sources of information are documentaries and also come from in-depth interviews.

In the case of Brazil highlights the publication on Public Security from Prefeitura de Diadema (2006). The Chilean documentary information comes from Dammert and Lunecke (2004) and Candina (2006). For information from Colombia highlights the UN-Habitat program of the Mayor of Bogotá (2008), the corporate strategy of the National Police of Colombia (2010) and Angarita (2014). The information Tlalpan, in Mexico, comes from the Electoral Institute of the Federal District (2013). Latin America data come from Dammert (2005) and the United Nations Office on Drugs and Crime (2011). The main depth interviews were conducted with Ms. Karen Rosa Montiel Avila, police first rank and instructor at the University of Security Sciences in Mexico, who graduated from the School of Investigations Police of Chile; Dr. Benito Torres Escalante, specialization coordinator at the University of Security Sciences, who also given information and criteria for frame of reference in his work (Torres, 2005); Lieutenant Gerardo Gonzalez Espirícueta, actually retired member of Mexican army; Subcomisario Melquicedec Parra, actually retired member of the National Police of Colombia.

In the Diadema case of successful community prevention actions are listed: The creation of a municipal department of social policy and public security, public geo-referenced information for the registering of criminal activities, crime monitor jointly by authorities and citizens, the Municipal Council for Security and Crime Prevention, the definition of social and environmental policies aimed at school projects, campaigns delivery of firearms, thoughtful collection of toy weapons made by children and drug and alcohol awareness aimed at teenagers and young people. A comparative table between traditional police and community policing is showing, according to public perception.

In the League of Emergency case, from Chile, the outstanding actions were established under the following "lines": generate a more enjoyable environmental for neighbors' coexistence, opportunities for participation and dissemination of rights, expanding opportunities for recreation and expression. In Bogotá case the constant were: disarmament plan, rehabilitation of urban spaces, creating security fronts, family police stations, police professionalization for preventive surveillance and security pacts. In Colombian case also highlights the National Plan for Community Policing Quadrants, created by the National Police and executed with the table of minimum action required (TAMIR), among which are: networking citizens-police to give advice and weekly visits schools on issues of resistance and drug abuse, Schools of Public Safety, networks of support and solidarity and support networks and communications approaches to youth gang, older adults population in vulnerable conditions and "Civic youth Police".

A comparative table shows with most important common denominators. In Brazil, Chile, Colombia and Mexico cases there are a parallelism between the programs of community crime prevention and procedures of participatory budgeting. 
There are equivalences between the participatory budgeting process and community crime prevention: participatory budgeting starts with an approach from authorities to citizens at the moment the information, the upcoming implementation of the sharing mechanism and the corresponding call to present projects. This rapprochement is equivalent to contact and call for meetings with the public security authorities and the communities where intervention programs are generated in crime prevention.

Secondly, the preparation and presentation of projects in both processes is performed under the formula of governance: communication networks are established inter-organization, negotiation, and inter-institutionalization to design projects that complement each other government activities and those of the citizens. In both cases the projects are focused on solving problems and to this extent comply with "the reconstruction of the social control of the territory by those who live"; definition adopted for community crime prevention. As essential elements have community involvement, guidance for troubleshooting and decentralization.

Third, specific demonstrations planned in both processes have individualized matches: from the identification and registration of the participants, through their training, development of workshops, evaluation and certification of technical, legal and economic viability of the activities, formalizing agreements and commitments, to monitoring and recording of the actions themselves.

Conclusions show process indicators as evaluative elements for programs community crime prevention. Process indicators are: counting the number attending meetings and planning of the various programs counting interviews with government officials and participatory citizens, number of campaigns of all types of informants and reports of actions to recover and / or rehabilitate urban spaces, activities to protect environmental or situational prevention to people and goods through alarms, fences, lighting, etc.

Some negative aspects of community prevention are shown also: the criminalization "strange"; any differences are considered dangerous.

A further aspect to reassess in the governance of community prevention is the role of citizens delegate command and gender role inside the internal control of the police forces. This dimension opens a future line of research. In general, the criteria for successful programs in community crime prevention through local governance, are rooted in seven factors: 1) innovation, which includes citizen initiatives that, sometimes, never are imagined by the authorities; 2) the precision of the impact, that is, targeting to specific problems; 3) the association between individual citizens and groups with authority; 4) management, seeking the exercise and defense of social rights and the follow up complaints; 5) sustainability through technical, financial and legal viability of the projects approved by the Participatory Budgeting; 6) citizens or officials committed; and finally 7) empowerment of any member of the community (children and immigrants), not just citizens.

As a final corollary is clear that citizen participation cause maximum freedom with a minimum of punitive exercise of control institutions. Public security is harmonized with the legal security of each citizen. And undoubtedly contemporary community crime prevention through local governance with vanguard 
instruments of citizen participation, confirm Beccaria's wise thesis: "It is better to prevent crimes than to punish them".

\section{INTRODUCCIÓN}

La seguridad ciudadana es una responsabilidad ineludible para todo gobierno. Sin embargo, en muchas ocasiones las condiciones organizacionales, estructurales y económicas impiden al Estado garantizar la seguridad pública y concomitantemente otros derechos básicos como el derecho a la salud, la educación y las oportunidades laborales. En esas circunstancias los gobiernos permiten o promueven iniciativas privadas o ciudadanas bajo la tutela del Estado para elevar los niveles de salud, educación y empleo. La seguridad no ha sido la excepción. Pero el uso de la fuerza pública es un derecho exclusivo del Estado, por ende, una de las estrategias gubernamentales consiste en establecer propuestas de prevención comunitaria del delito con la coparticipación de la ciudadanía bajo el esquema de la gobernanza.

Por lo anterior, el objetivo capital de este estudio estriba en analizar y hallar los elementos que constituyen un común denominador en las prácticas exitosas de la prevención comunitaria del delito ejercida por la gobernanza de tipo local. Ello supone que la prevención comunitaria del delito, a través de la gobernanza local, exige un alto y constante nivel de institucionalización de la participación ciudadana. Para comprender dicho fenómeno se explica, como marco teórico, las diferenciaciones conceptuales de la participación ciudadana y la noción de gobernanza guiadas a la prevención del delito. Desde este marco teórico se establecer la metodología para el análisis que permite hallar los comunes denominadores de la prevención en los casos exitosos a escala local. El análisis y los hallazgos de los elementos comunes proveen recomendaciones focalizadas que permitirán elevar la calidad de la seguridad pública. Dichos elementos no proveen datos para establecer correlaciones con la disminución de las tasas delictivas y obtener evidencias con los indicadores de impacto. No obstante, los elementos comunes resultan ilustrativos como indicadores de procesos e indicadores operativos.

\section{METODOLOGÍA}

Para obtener el mayor número de comunes denominadores en las prácticas exitosas de la prevención del delito, se efectúa un análisis con metodología cualitativa de índole de diseño teórico fundamentado (Hernández-Sampieri, Fernández-Collado y Baptista, 2006: 687 y ss.). Inicialmente se conceptualiza la prevención bajo tres enfoques: la perspectiva social, ambiental y situacional. 
Las tres propuestas pueden sintetizarse en la prevención comunitaria, siguiendo el proceso metodológico de "codificación axial" de Strauss y Corbin (1990). Ello permite ligar la prevención comunitaria a la gobernanza. Establecido ese vínculo, se sigue la metodología cualitativa de teorías sustantiva o de rango medio (Glaser y Strauss, 1967) para aprovechar la codificación selectiva y axial de la función sintetizadora 'prevención comunitaria-gobernanza' con los niveles primarios (población general) y secundarios (población de victimizadores) de prevención, pues en ellos puede involucrarse la participación ciudadana. Se excluye el nivel terciario (victimarios), que corresponde a los procesos penales de readaptación y rehabilitación para evitar las reincidencias de los infractores, porque la participación ciudadana no tiene potestad directa para intervenir en dichos procesos.

La muestra de las prácticas exitosas se delimita a cuatro experiencias latinoamericanas reconocidas por la comunidad de expertos y académicos en materia de seguridad. Aunque ningún caso fue posible galardonarlo con el premio "Gobernarte" del Banco Interamericano de Desarrollo, porque el premio se estableció a partir del año 2013. Sin embargo, Brasil, Colombia y México son los países permanentemente coincidentes entre los premiados y la muestra aquí elegida los incluye sumando un caso de Chile. Se prefiere la muestra latinoamericana porque, al adoptar la prevención comunitaria, se excluyen los modelos de origen anglosajón conocidos como Broken Windows y Zero Tolerance, que también se contrastan en el marco teórico.

Los casos de la muestra conciernen a escalas municipales para guardar consistencia con el modelo comunitario y corresponden a Diadema, Brasil; La Legua de Emergencia, Chile; Bogotá, Colombia y Tlalpan, México. Cada uno se estudió en los respectivos períodos de aplicación de sus programas de prevención: 2000 a 2004 para Diadema; 2001 a 2003 para La Legua; 1993 a 2002 y 2007 a 2008 para Bogotá; 2010 a 2013 para México.

La recolección de datos se establece para los indicadores de procesos y de operativos y, por no tratarse de una metodología cuantitativa, se excluyen los de impacto. Ello obedece al propósito de destacar las intervenciones de participación ciudadana en vinculación con la gobernanza contra el delito e ilustrar las propuestas, estrategias y tácticas, más allá del mero registro estadístico (exactamente como sucede en la georreferenciación preventiva del delito). Las fuentes de información son documentales y también provienen de entrevistas a profundidad.

La información documental se halla consignada en la bibliografía basada en el establecimiento, publicación y divulgación de resultados de los programas. Para el caso de Brasil destaca Kahn (2004) y la publicación sobre seguridad 
pública de la Prefeitura de Diadema (2006). En el ámbito chileno la información documental procede de Dammert y Lunecke (2004) y Candina (2006). Para Colombia destacan como fuentes informativas el programa UN-Habitat de la Alcaldía de Bogotá (2008), la estrategia institucional de la Policía Nacional de Colombia (2010) y Angarita (2014). La información general de México tiene sus fuentes en el manual del gobierno municipal de Puebla (2012) y Hernández y Zepeda (2015). De Tlalpan los datos proceden del Instituto Electoral del Distrito Federal (2013). De Latinoamérica en general los datos provienen de Shaw (2001), Dammert (2005) y la Oficina de Naciones Unidas contra la droga y el delito (2011). De entre las entrevistas a profundidad destacan las participaciones de la Lic. Rosa Karen Ávila Montiel, policía de primer rango e instructora de la Universidad de Ciencias de la Seguridad en México, quien es egresada de la Escuela de Policía de Investigaciones de Chile; la participación del Dr. Benito Torres Escalante, coordinador de especializaciones en la Universidad de Ciencias de la Seguridad, de quien también se ha tomado información y criterios de marco referencial a partir de su obra (Torres, 2005); del teniente en retiro del ejército mexicano Gerardo González Espirícueta; y la participación del Subcomisario Melquicedec Parra, actualmente miembro en retiro de la Policía Nacional de Colombia. Del resto de las entrevistas a profundidad se agradece la disposición de todo el personal militar, policial y de trabajo social que participó.

Los resultados, discusión y conclusiones se exponen según le metodología de Hernández-Sampieri, Fernández-Collado y Baptista, (2006: 731-734). Los resultados se exhiben por el modelo desarrollado de prevención comunitaria que incluye la prevención social, ambiental y situacional en una matriz que despliega a cada localidad de la muestra. También por la metodología narrativa que hace referencia a los niveles de intervención. Las discusiones se presentan por la metodología concerniente a las cuestiones futuras que deben ser analizadas. Las conclusiones se presentan validando la exigencia de institucionalizar la participación ciudadana.

\section{MARCO TEÓRICO: LA PARTICIPACIÓN CIUDADANA Y LA GOBERNANZA EN LA PREVENCIÓN DEL DELITO}

Si la participación ciudadana no incrementara la calidad de vida, -y con ella la calidad de la seguridad ciudadana y pública-, carecería de sentido. Particularmente la participación ciudadana puede incrementar la calidad de vida al abocarse a disminuir los actos delictivos comunitarios o llamados del "fuero común". Los quehaceres ciudadanos serían ridículos si, como indica el reputado constitucionalista norteamericano Ackerman: "la vida política no es más 
que una de muchas diversiones en la continua búsqueda de la felicidad" (1999: 207). Cuando se trata de la seguridad ciudadana y de la prevención delictiva, la participación ciudadana no es una fiesta, ni siquiera un divertimento en la vida política.

Si se adopta la clasificación de Martí I Puig, Ortega y Somuano (2011) que categorizan las participaciones ciudadanas en electorales y no electorales para hacer hincapié en que éstas últimas incluyen a la participación convencional, la no convencional y la disruptiva, (ampliando la distinción conceptual establecida por Barnes y Kaase (1979)) entonces se aceptará que la participación no electoral convencional es la más apropiada para la prevención del delito en gobernanza. La participación no convencional (mítines, caravanas, peticiones, reparto de volantes) y la disruptiva (ocupación de plazas y edificios públicos, bloqueos, intentos violentos de derrocamiento) muestran insatisfacción y rechazo hacia el sistema político y el estatus quo. En contraste, la participación convencional (actividades comunitarias, contacto con las autoridades, militancia en organizaciones civiles, conformación de comités o comisiones ciudadanos, etc.) valoran positivamente la organización política y social y se adhieren a sus reglas (Vallès, 2000) y, por ello mismo, desean proceder dentro de la legalidad y procuran que todos los miembros de una comunidad también así lo hagan de manera permanente. Es decir, la participación convencional apunta a desarrollar sus actividades estableciendo procedimientos de manera institucional, sobre todo para adquirir una estructura organizacional y los medios para entrar en contacto con las administraciones gubernamentales en las cuales todavía depositan amplia credibilidad (Ganuza y Francés, 2015).

La participación ciudadana convencional institucionalizada tiene como propósito influir en el gobierno, con interacciones ante y con el Estado planteadas desde ambos lados de la interacción (Organization for Economic Cooperation and Development (OECD), 2011). Busca superar los obstáculos de facto que impiden al Estado cumplir con la misión de garantizar la seguridad pública. Tal es la cooperación de la gobernanza local en la prevención comunitaria del delito. La participación ciudadana convencionalmente institucionalizada en los procesos de gobernanza es el último cabo de buena esperanza por el cual los ciudadanos no han perdido la confianza de influir, -estructural y por tanto, permanentemente-, en asuntos gubernamentales que generan mayor calidad en la seguridad ciudadana y pública. En contraste, la participación no convencional y la disruptiva, en relación al delito, paradójicamente incurren en violaciones al orden público o la ley. Ambas, en más de una ocasión se denigran al tomar la justicia por propia mano y cuando ello ocurre, la mayoría de las veces las situaciones desembocan en linchamientos y otros actos de bar- 
barie colectiva. Por ende, la participación ciudadana de tipo convencional -institucionalizada a través de la gobernanza local-, constituye la esencia de las movilizaciones que pueden elevar la calidad de la seguridad ciudadana a través de la prevención comunitaria del delito.

Si se deslinda la participación ciudadana convencional de las actividades que muestran insatisfacción con la organización política, entonces se comprenderá que la acción ante el Estado se transforma en interacción con el Estado y no en enfrentamientos. A ello debe llamársele gobernanza y concebirse, en buena parte, como una instrumentación del poder ciudadano en el gobierno. La noción de gobernanza en sí misma ha sido ambigua por las circunstancias de su nacimiento histórico, pues se planteó también en relación al desarrollo económico y los vínculos con el mercado. El Diccionario de la Real Academia Española de la Lengua incluyó una nueva definición de gobernanza en su $21^{\mathrm{a}}$ edición. Así, gobernanza es el "arte o manera de gobernar que se propone como objetivo el logro de un desarrollo económico, social e institucional duradero, promoviendo un sano equilibrio entre el Estado, la sociedad civil y el mercado de la economía". A pesar de los vínculos con los poderes de facto,-como el mercado neoliberal que la hacen vulnerable a los intereses de grupos hegemónicos-, la gobernanza apunta a un nuevo gobierno que abandona el férreo control monopólico por parte del Estado. Por tanto, no sigue al pie de la letra la jerarquía de las escalas gubernamentales, sino que opera en interacción de redes autónomas con estructuras y procesos de información, enlace y co-decisión. Puede decirse entonces que:

"la gobernanza está constituida por las normas y reglas que pautan la interacción en el marco de redes de actores públicos, privados y sociales interdependientes en la definición del interés general en entornos complejos y dinámicos. La gobernanza se asocia a una mayor implicación de actores no gubernamentales en el diseño e implementación de las políticas públicas y, al fin y al cabo, en la definición del interés general" (Cerrillo, 2005: 9)

En consecuencia, la gobernanza posee mayor capital social y capacidad de participación ciudadana que la mera gobernabilidad. Busca nivelar la asimetría de poder que los partidos políticos autoritarios cooptaron al convertirse en bloques herméticos y cuya misión se redujo a la eficacia de la contienda electoral. Ello les conllevó un alejamiento de las capacidades ciudadanas en el ámbito local, vinculo que es necesario para resolver las cuestiones públicas en la escala comunitaria, aplicar soluciones desde los intereses y recursos de ciudadanos particulares y disolver conflictos concretos a través del consenso. Es decir, los partidos políticos han quedado rebasados por no permitir el ejercicio del poder en las escalas allende a sus fronteras, en variadas esferas de alta complejidad donde no son los únicos actores sociales y por no poseer alcance transversal. 
Otras distinciones entre la gobernabilidad y la gobernanza se deducen a partir del ensayo de Paniagua, Borunda y Camargo (2012) y la compilación de los 10 textos de referencia fundacional que realizó Cerrillo (2005). Mientras que en la gobernabilidad se impone la institucionalización estatal que mediatiza o coloniza la participación ciudadana, en la gobernanza la participación ciudadana en asuntos públicos es directa y la intermediación del Estado se da en fórmulas cooperativas donde se hacen presentes nuevas formas de regulación que requieren negociación y coordinación. En la gobernabilidad se instaura la verticalidad estatal, aún en los procedimientos, ponderaciones y agendas de la consultas ciudadanas, mientras que en la gobernanza se procura la horizontalidad democrática a través de los consensos deliberativos que no están sujetos a estratos jerarquizados. En la gobernabilidad también se observa que el Estado asigna las condiciones que deberán poseer las redes ciudadanas (a través de los reglamentos que constituyen la estructura y función de los Consejos Ciudadanos), en contraste en la gobernanza las redes sociales poseen mayor simetría entre los ciudadanos y el Estado. También en la gobernabilidad el Estado tiene la prerrogativa exclusiva para tomar acciones y definir políticas públicas; en contraste, la gobernanza procura la cooperación y hasta la delegación de acciones estatales. La realización del bien común y de los intereses generales no se encuentra en el monopolio del Estado y se ubica en la interacción del poder público, la iniciativa privada y la participación ciudadana. Prats acota que:

"La Comisión Europea, en la preparación de su Libro Blanco sobre la Gobernanza de 2001, adoptó la visión de que el modelo de gobernanza por redes se adaptaba mejor que los modelos jerárquicos tradicionales al contexto socioeconómico actual, caracterizado por los cambios rápidos, la fragmentación y problemas de políticas interconectados y complejos" (2005: 162).

Y ello se debió a que las recientes versiones de la gestión pública resultaron insuficientes porque los departamentos ejecutivos o agencias del gobierno no pudieron abarcar monopólicamente el conocimiento de especialidad para enfrentar los problemas y porque los desafíos (sobre todo los de seguridad, cohesión social y calidad de vida) requieren soluciones transversales y las jurisdicciones departamentales de la gestión pública están limitadas sólo a realizar las acciones facultadas que jurídicamente les compete.

Así pues, la gobernanza nace de la necesidad de crear estructuras y procesos de interacción entre las instancias ciudadanas afectadas y el Estado. Busca adoptar responsabilidades comunes y diferenciadas al constituir una forma de decidir con pluralidad de actores en tendencias de mayor horizontalidad y equilibrio. Por tanto, la gobernanza debe ejercerse con los principios democráti- 
cos de transparencia, participación, subsidiariedad horizontal, complementariedad y proporcionalidad entre actores públicos y privados.

Tomando en cuenta lo anterior, puede compilarse un inventario de elementos de la gobernanza que apuntan a modelar los programas de prevención comunitaria. Dicho inventario requiere, en primer lugar, liberar a la gobernanza del yugo de una mera administración pública o nueva gestión estatal. Es decir, la participación de actores públicos y privados (empresas, organizaciones no gubernamentales, asociaciones no lucrativas, entidades que agrupan a profesionales, etcétera) no sólo proveerán servicios, sino también definirán las políticas públicas y los valores que pautan su evaluación. Entre esos valores se encuentran la acción en red, el sistema socio-cibernético (tomando este término en su sentido etimológico), la inter-organización cooperativa que provoca el reequilibrio de las asimetrías del poder y la actualización electrónica del gobierno ante las demandas de la sociedad digital que le exigen mayor eficacia y eficiencia.

Otro elemento de la gobernanza, más allá de la mera cooperación entre los sectores privado y público, es la prestación de algunos servicios públicos por instancias privadas. Desde un punto de vista crítico contra el liberalismo, esta característica implica el riesgo de desplazar al Estado democrático por las funcionalidades del libre mercado. Debe evitarse que los gobiernos queden reducidos a meras agencias de gestiones y se sometan al servicio de los actores con mayores recursos económicos. La gobernanza, -para evitar su declive y el de la soberanía de sus actores-, debe constituirse con elementos de diversidad, complejidad y dinamismos suficientes para incluir todos los intereses en su búsqueda del mayor bien común. Es decir, debe evitar que la antigua uni-direccionalidad gubernamental del Estado sea sencillamente sustituida por la uni-direccionalidad de grupos hegemónicos de capital.

Las fórmulas iniciales de gobernanza; autogobierno, cogobierno y gobierno jerárquico que Kooiman (2005) había propuesto e inspiraron a muchos teóricos, quedan rebasadas por la participación ciudadana. Significativamente esto acontece al elevar el nivel de vida por medio de la prevención del delito. Se busca la minimización de un gobierno formal y la maximización de los objetivos compartidos nacidos de la soberanía. La soberanía es el fundamento último, delegada en el Estado, para instrumentalizar la fuerza pública. Es decir, la prevención comunitaria del delito encarna la metáfora de Osborne y Gaebler (1992) más el dirigir que el remar, que distingue muy bien la gobernanza de la gobernabilidad (sobre todo del poder ejecutivo). Se ha de distinguir la participación de la ciudadanía de la mera obediencia ciega a la autoridad encargada de velar por el orden público y la paz social (llámese policía, ejército, 
marina o armada). En pocas palabras: la prevención comunitaria del delito, modalidad de la gobernanza local, descentraliza la autoridad en la medida que el poder es transmitido a los ciudadanos con el efecto de 'menos gobierno' (remo) y 'más gobernanza' (dirección).

La noción de gobernanza, no obstante, recibe una crítica que también interpela a la prevención comunitaria del delito. Ambas -gobernanza y prevención comunitaria- enfatizan los procedimientos y/o la deliberación y descuidan la eficacia de los resultados (Peters y Jon, 2005: 123 y ss). Además, se alega que:

"el desempeño mejora cuando las decisiones se focalizan en los productos y resultados más que en los insumos y procedimientos -y que además- la gobernanza no es un sustituto del gobierno, sino una modalidad de gobernación con el gobierno... que replantea sus roles, formas organizativas y procedimentales" (Prats, 2005: 152 y 171).

Y aún más severamente Aguilar critica:

"Las evidencias disponibles conducen más bien a sostener la hipótesis de que la gobernanza nueva tiene su factor causal crucial en el enlace entre el proceso gerencial y el proceso politico-civil que ha caracterizado a las reformas institucionales... El retorno a la gobernanza por el gobierno... es una opción tal vez imaginable pero no viable" (2007: 11).

Ante estas críticas la gobernanza requiere consolidarse de manera efectiva y eficaz. Y por obedecer también a los intereses básicos del bien común, se propone una versión específica: la modalidad de la prevención comunitaria del delito con base en la participación ciudadana.

Un primer acercamiento a la prevención del delito lo ofrece Van Dijk: “...todas las políticas, medidas y técnicas, fuera de los límites del sistema de justicia penal, dirigidas a la reducción de las diversas clases de daños producidos por actos definidos como delitos por el estado" (1990: 205). A partir de este concepto pueden precisarse diversas formas de prevención. En primer lugar, las políticas, medidas y técnicas referidas en la definición de Van Dijk derivan en tácticas situacionales, ambientales, sociales y comunitarias. Las dos primeras apuntan a la reducción de oportunidades para la realización de los actos que según los códigos penales tipificarían como delitos. Ambas tienen un doble enfoque: la atención puede dirigirse a evitar que haya agentes del delito y/o apuntar a quienes pudieran ser pacientes (víctimas) del delito. En el primer enfoque las acciones se dirigen hacia la disuasión encaminada a los potenciales victimizadores y la reinserción social para los victimarios. En el segundo enfoque se haya la prevención del delito en manos de la posible víctima, prevención que no logra rebasar la táctica situacional y/o ambiental. La preven- 
ción situacional se alcanza al implementar obstáculos mecánicos y/o electrónicos para disuadir al delincuente bajo las premisas de la teoría de la elección racional, es decir, bajo la fórmula costo/beneficio o riesgo/éxito implicadas en la labor de delinquir. La prevención ambiental se logra en la media en que las realidades arquitectónicas y urbanísticas reducen las oportunidades del delito en función al control de acceso, la vigilancia y el refuerzo territorial (Hernando, 2008).

La mayor dificultad está en los retos de la prevención social, pues considera que el crimen es causado por las desigualdades sociales. En consecuencia, las soluciones estriban en mejores salarios, menores tasas de desempleo, mayor educación y en general condiciones de satisfactoria calidad de vida. Quizá el primero en postular este tipo de prevención fue Alexandre Lacassagne (18431924) para quien, en palabras de Núñez: "el delito no era consecuencia de un atavismo en el hombre [como lo había propuesto Ferri, Garófalo y Lombroso] sino que atribuye al medio social un papel importante en la aparición de conductas criminales" (2011: 60). Ideas similares y ampliadas que según Núñez (2011: 66 y 67) también pueden encontrarse en las propuestas criminológicas de Robert K. Merton, Glueck y Edwin H Sutherland. El enfoque de la prevención social centra su atención en: fortalecer los lazos familiares de los infractores, haber tenido educación por unos buenos padres que ejercieron la vigilancia adecuada, haber asistido a una escuela con disciplina humanitaria y atenta a evitar la deserción; y sobremanera, contar con un medio social que ofrece oportunidades laborales decentes y opciones sanas para el goce del tiempo libre. Pero no todo en la vida es miel sobre hojuelas.

Por tanto, deben considerarse las tácticas comunitarias de la prevención delictiva. La prevención comunitaria se construye como híbrido de las versiones situacionales, ambientales y sociales. Sozzo la define como: "técnicas de intervención que están orientadas a la comunidad/vecindario en lugar de estar orientadas a las potenciales víctimas o a los potenciales ofensores" (2000: 37). Esta concepción presenta otro matiz también de doble enfoque, y ello debe aprovecharse con ilación desde la participación ciudadana y la gobernanza hasta mecanismos de participación que en pocas ocasiones se han implementado en función de la prevención. El doble enfoque, en el caso comunitario, se revela porque la misma comunidad es el objeto de las intervenciones y simultáneamente es el sujeto o agente de las mismas. La prevención se dirige a evitar, -como tarea de las autoridades de seguridad pública-, que se cometan delitos y al mismo tiempo a evitar, -como responsabilidad de los ciudadanos-, que las personas se expongan y sean víctimas de los delincuentes. Para obviar el dilema objetivismo-paciente de la táctica preventiva versus subjetivismo-agente 
de la intervención, Sozzo amplifica su teorización con una apreciación de Pavarini (1994), que puede expresarse con una paráfrasis: 'la prevención comunitaria busca reconstruir el control social del territorio por parte de quien lo habita'. Esta sería una definición de prevención comunitaria suficiente si explícitamente involucrara al Estado y a la ciudadanía en disposición de gobernanza para el primero y en condiciones de actividades de participación para la segunda. De cualquier manera, en la 'reconstrucción del control social del territorio por quien lo habita', Sozzo y Pavarini vislumbraron una idea clásica rescatada recientemente: el vínculo vital entre hábitats-hábitos y habitantes.

Permítase una digresión cultural de tres párrafos para ilustrar el vínculo vital entre el hábitat de una comunidad y su importancia para los hábitos de los habitantes de la misma. En los orígenes más arcaicos de la lengua griega, la palabra ethos (Liddell \& Scott, 1996, entrada: ethos) no hacía referencia a la ética, sino a la madriguera; la morada donde habita un animal. Cuando esta idea se extendió al humano, entonces la ética significó la morada del hombre. Con el tiempo, el sustantivo ethos también se uso como verbo y ambos, sustantivo y verbo, se instauraron en el latín con los vocablos hábitat y habitar, respectivamente.

Por razones de adaptación el hábitat incide en las maneras de habitarlo y transformarlo, y cuando ello se convierte en algo regular se producen los hábitos. Los cuales, al constituirse en costumbres, configuran el ethos del comportamiento. De esta manera hábitat y hábitos marcan la conducta, es decir, causan el carácter de los habitantes y, a su vez, los hábitos también inciden en los hábitats.

De lo anterior se sigue que los hábitos y comportamientos sociales o éticos no existen en situaciones aisladas de sus ambientes (hábitats), ni de los demás habitantes; y la suma de ambientes y habitantes es la comunidad en vista a la cual se aboca la gobernanza para lograr la prevención delictual. De ello también se extraen las siguientes consecuencias: habitar en una comunidad implica un hábito o costumbre con cualidades sociales y éticas significativas ante la idea del delito que poseen los demás habitantes; los hábitats pueden transformar los hábitos y en consecuencia, las comunidades (hábitat, hábitos y habitantes) pueden transformar la incidencia delictual.

Para reconstruir el control social del hábitat por los propios habitantes existen varias acciones recomendables. Y lo mejor sería adquirirlas como hábitos. Desde el punto de vista de la gobernanza deben alinearse los intereses individuales, colectivos y del Estado. Tanto la gobernanza como la prevención comunitaria del delito requieren de las redes de gestión inter-organizacional y autoreguladas. Si bien es cierto que los ciudadanos comunes no están reconocidos 
legalmente para hacer uso público de sus fuerzas, los pactos de gobernanza les otorgan legitimidad para dirigirlas por vías deliberadas y consensuadas. "Menos remo y más dirección" provoca que el ciudadano privatista abandone las políticas públicas de arriba hacia abajo y se convierta en el ciudadano público (denominaciones que pertenecen a Ackerman, (1999)) que procura dirigir la política desde abajo hacia el resto de comunidad.

Cuando las estrategias se deliberan y consensuan en el conjunto de agentes privados (individuales y colectivos) y públicos, entonces se puede contar efectivamente con los recursos ciudadanos realmente disponibles. De la deliberación y el consenso -propios de la gobernanza-, se sigue la organización de actividades preventivas. En América Latina ello ha causado programas ejemplares: en Diadema, Brasil; Bogotá, Colombia; La Legua, Chile; Tlalpan, México. Seguramente estas campañas no son tan famosas como aquellas generadas en los Estados Unidos de Norteamérica cuyos slogans pasaron a la historia como leyendas imposibles de falsear: Broken Windows y Zero Tolerance. La diferencia entre éstas y aquéllas es crucial, pues mientras en las actividades preventivas el Estado y la comunidad están involucrados en intereses comunes; en las campañas norteamericanas el único interés es la seguridad pública sin atención a las dimensiones privadas. En las campañas norteamericanas el Estado es el único actor involucrado ya que los ciudadanos sólo son la fuente de financiamiento de las fuerzas públicas. En las actividades preventivas comunitarias la seguridad pública alcanza a la seguridad ciudadana porque incide en la vida privada al evitar consumos riesgosos de droga, abusos sexuales o violencia intrafamiliar y además promueve el desarrollo comunitario y humano. Las actividades ciudadanas son preventivas, mientras que las campañas norteamericanas, -si bien pretenden mostrarse preventivas-, en realidad sólo son actitudes punitivas de reacción por parte de la fuerza pública que desea la baja delictiva en zonas predeterminadas y no considera el riesgo de desplazar el delito a los hábitats vecinos.

Broken Windows nació de las ideas que James Q. Wilson y George L. Kelling publicaron en 1982 en un artículo del mismo título (Wilson y Kelling, 1982) y que fueron secundadas por el mismo Kelling y Catherine Coles en 1998 en el texto Fixing Broken Windows: Restoring Order and Reducing Crime in Our Communities (Kelling y Coles, 1998). La tesis central cae en la falacia de la cuesta resbalosa, pues consideran que al dejar impune conductas antisociales mínimas en un vecindario (por ejemplo, la presencia de graffiti o de basura en la vía pública), en la misma zona se presentará un aumento alarmante de las mismas conductas y un incremento de acciones indeseables (mendicidad, prostitución) hasta llegar a delitos mayores (secuestros, terro- 
rismo, etcétera). Así, suponen que la reacción firme y dura de parte de las instituciones de seguridad pública en lo leve prevendrá el acontecimiento de lo grave.

Mientras que Zero Tolerance (expresión popularizada a partir de 1994 siguiendo la idea Broken Windows, pero que se tomó del reporte de New Jersey publicado en 1973 bajo el título: ), obedece a una idea mayormente punitiva: proceder con la máxima severidad e inmediatez, -sin ningún tipo de atenuantes-, a castigar las más mínimas infracciones. Suponiendo que con ello se detendrán las marejadas del crimen.

Las diferencias entre actitudes punitivas criminalizadoras y las acciones comunitariamente productivas explican por qué los ciudadanos prefieren la actuación preventiva, dado que se perfila hacia las causas integrales del delito (situacionales, ambientales y sociales) y no sólo a mitigar o amedrentar sus antecedentes.

La prevención comunitaria, como especie de la gobernanza, no sólo genera programas y actividades contra el delito, sino que apunta a los aspectos del desarrollo humano que también lo previenen. Y en ese sentido genera una empatía que redunda en verdadera cooperación, la cual se complementa con la asignación de quienes serán los encargados y responsables de cada acción. Así, sin erogaciones para el Estado para efectos de estructuración organizacional (no así para la operación de programas), se crean instituciones mediadoras entre la ciudadanía y las instancias de gobierno. No obstante, los financiamientos para los programas y actividades también podrían darse en el contexto de una gobernanza local. Tal es el caso del contemporáneo mecanismo de participación ciudadana denominado "Presupuesto participativo" que se ha aplicado en algunos municipios de Brasil, algunas zonas de Bogotá y delegaciones de Ciudad de México.

\section{DIADEMA, BRASIL}

Diadema estaba en la cúspide de homicidios y de delitos de bajo impacto entre las municipalidades de Sao Paulo en el año 2000. Para revertir la situación las autoridades implementaron un programa de prevención comunitaria complementado con estrategias de salud pública, control policial, cultura de la legalidad y modificaciones en el control policial. Coadyuvante a estas acciones se aplicó el Presupuesto participativo.

En lo que corresponde a la prevención comunitaria de Diadema, caben destacar las siguientes acciones (Oficina de Naciones Unidas contra la droga y el delito, 2011: 84): la creación de un Departamento municipal de políticas sociales y seguridad pública. Departamento que surgió con elementos implícitos 
de gobernanza en la medida que recibía información ciudadana para el levantamiento georreferenciado de las actividades delictivas y estableció el seguimiento de las mismas de manera conjunta con autoridades y ciudadanos. Otra acción fue el establecimiento del Consejo Municipal para la Seguridad y la Prevención del Delito, que proponía las políticas más inmediatas para los programas de prevención, mostrando con ello una característica esencial de la gobernanza aunando la definición de políticas sociales y ambientales dirigidas a proyectos escolares. Entre otras experiencias exitosas cabe enumerar las campañas de entrega de armas de fuego, la recolección reflexiva de armas de juguete efectuada por los niños y la sensibilización sobre drogas y alcohol dirigida a adolescentes y jóvenes.

Aunque no existen estudios que muestren la correlación directa entre el Presupuesto participativo y la baja en la tasa delictiva en el caso de Diadema para los períodos 2000 a 2004, puede conjeturarse la vinculación. Muchos de los procedimientos de la prevención comunitaria coinciden con etapas y acciones del Presupuesto participativo. Y no sólo los procedimientos de planeación y ejecución, sino que también las características políticas y sociales. El Presupuesto participativo y la prevención comunitaria son acciones auto-reguladas, participativas sobre la línea generativa del capital social, aplicadas bajo el modelo de gobernanza y con impactos inmediatos en la mejora de la calidad de vida atendiendo a ésta por asuntos temáticos y puntuales. Sin embargo, el reconocimiento explícito entre el Presupuesto participativo y la prevención comunitaria apenas se ha insinuado, pues los Presupuestos participativos son mencionados en el reporte sobre Seguridad Pública: Medidas de Transformación (Diadema, Brasil) presentado en el Concurso "Ciudades para un futuro más sostenible" en el cual sumariamente se apunta: "los presupuestos participativos han abierto un diálogo constante entre gobierno y comunidades y ayudan a intensificar y expandir las aportaciones de la población a las discusiones sobre las arcas municipales" (Prefeitura de Diadema, 2006).

Es deseable contar con más datos correlativos entre los Presupuestos participativos y la disminución delictiva. A pesar de ello, al considerar que la Organización de Naciones Unidas indicó que el municipio de Diadema descendió 18 puestos en la estadística delincuencial, el hecho mismo es suficientemente estimulante para destacar esta hipótesis, dada las coincidencias estructurales, funcionales y ejecutivas de ambos procesos.

Si pudiera establecerse un primera equivalencia entre el proceso del Presupuesto participativo y la prevención comunitaria del delito, habría que decir que en el Presupuesto participativo se inicia con un acercamiento de las autoridades hacia la ciudadanía desde el momento en que se informa de la próxima 
implementación de dicho mecanismo de participación y se efectúa la correspondiente convocatoria para presentar proyectos. Ese acercamiento es equivalente al contacto y convocatoria de reuniones que tienen las autoridades de seguridad pública con y en las comunidades donde se generarán los programas de intervención en prevención del delito.

En segundo lugar la preparación y presentación de proyectos en ambos procesos se realiza bajo la fórmula de gobernanza como se ha descrito: se establecen redes de comunicación, negociación, inter-organización e inter-institucionalización para diseñar los proyectos que complementan recíprocamente las actividades del gobierno y las de los ciudadanos. En ambos casos los proyectos se enfocan a la solución de problemas y en esa medida cumplen con "la reconstrucción del control social del territorio por quienes lo habitan". Así por ejemplo, en el Manual sobre la aplicación eficaz de las Directrices para la prevención del delito de la Oficina de Naciones Unidas contra la droga y el delito (2011) puede hallarse que el control policial orientado a la comunidad ciudadana, aún en diversas versiones, tiene como elementos esenciales la implicación de la comunidad, la orientación a la solución de problemas y la descentralización (Oficina de Naciones Unidas..., 2011: 100), esos mismos elementos esenciales se encuentran en el Presupuesto participativo, dado que éste puede definirse como:

“... el mecanismo reconocido jurídicamente por el cual los ciudadanos ejercer el derecho de voz (para hacer propuestas de inversión pública con montos y programas), de voto (para decidir libre y deliberativamente entre sus planes y programas) de justicia social (para redistribuir proporcionalmente los bienes y servicios a cargo del gobierno) y de monitorización (de los recursos públicos a través de la transparencia y la rendición de cuentas), para definir las políticas públicas..." (Aguirre, 2014: 256).

En pocas palabras, las acciones a proponer, deliberar, votar y ejecutar por el financiamiento de un Presupuesto participativo pueden contener las acciones propuestas en los programas de prevención comunitaria.

En tercer lugar, las movilizaciones en ambos procesos presentan coincidencias individualizadas: desde la identificación y registro de los participantes, pasando por su capacitación, el desarrollo de talleres de trabajo, la evaluación y certificación de la viabilidad técnica, legal y económica de las actividades, la formalización de acuerdos y compromisos, hasta el seguimiento y registro de las acciones mismas.

En el caso de Diadema, las acciones coincidentes entre los Presupuestos participativos y la prevención comunitaria del delito fueron: la renovación o restitución de espacios urbanos; las actividades para jóvenes aprendices y la instalación de cámaras de vigilancia. También podrían coincidir, de haberse 
incluido en el Presupuesto participativo, las agencias y agentes de trabajo para dar seguimiento a los jóvenes en libertad condicional. Estas últimas actividades son altamente significativas en los programas de prevención, aunque obedecen al nivel terciario.

Las reconocidas criminólogas Joan Petersilia y Francis Cullen (2015) han insistido en que los presupuestos destinados a la construcción y manutención de prisiones se re-direccionen hacia las actividades comunitarias. En especial aquellas de reinserción social a través de los agentes encargados de dar seguimiento a la libertad condicional en las comunidades controladas (recuérdese, precisamente que en los Estados Unidos de Norteamérica la noción de prisión corresponde al nivel estatal, mientras que la de cárcel alude a la esfera del condado y que para el caso Latinoamericano equivaldría a las municipalidades comunitarias). Sin duda ello constituye un retorno al poder local no sólo en el plano presupuestal, sino también en el control policial y el servicio judicial.

El mejor desempeño policial también se da en los programas de prevención comunitaria al disponer del personal de seguridad pública como agentes comunitarios en vez de policías tradicionales. Así lo muestran los datos del cuadro comparativo de Kahn en relación a la experiencia brasileña en Sao Paulo que a continuación se reproduce.

Tabla I: Comparación entre la policía comunitaria y la policía tradicional

\begin{tabular}{l|c|c}
\hline $\begin{array}{c}\text { CUALIDAD EVALUADA } \\
\text { EN LA POLICÍA }\end{array}$ & $\begin{array}{c}\text { POLICÍA } \\
\text { COMUNITARIA }\end{array}$ & $\begin{array}{c}\text { POLICÍA } \\
\text { TRADICIONAL }\end{array}$ \\
\hline Más satisfactoria & $46.7 \% 34.6 \%$ & $39.6 \%$ \\
\hline Más solícita con la población & $50.6 \%$ & $42.9 \%$ \\
\hline Más educada & $53 \%$ & $17.9 \%$ \\
\hline $\begin{array}{l}\text { Más eficiente contra } \\
\text { el crimen }\end{array}$ & $21.4 \%$ & $29 \%$ \\
\hline Más riesgosa para el policía & $26.5 \%$ & $23.6 \%$ \\
\hline Más "dura" en su trabajo & $28.8 \%$ & $31.7 \%$ \\
\hline $\begin{array}{l}\text { Más satisfactoria para la } \\
\text { carrera policial }\end{array}$ & $39.1 \%$ & $10.3 \%$ \\
\hline Más sujeta a corrupción & $8.9 \%$ & $16.3 \%$ \\
\hline Más sujeta a violencia & $19.7 \%$ & Pá \\
\hline
\end{tabular}

Fuente: Kahn, Tulio (2004) Policía comunitaria: evaluando la experiencia de Sao Paulo. Chile: CED. 
El único elemento desfavorable para la policía comunitaria fue la mayor vulnerabilidad ante la violencia (último recuadro). Aunque en referencia a la prevención delictiva, -en opinión de los propios policías (el 20\% del personal policial y el $21.4 \%$ del personal policial comunitario)-, arrojó la opinión de que el patrullaje comunitario es más eficiente contra el delito. Es decir, hay una oposición entre la percepción ciudadana y la percepción de los propios policías entorno a la eficiencia de patrullaje contra el crimen. Ello es lógico porque la policía de prevención comunitaria no está adiestrada contra los delitos de narcotráfico, homicidio doloso, terrorismo, acciones paramilitares y los que comete el crimen organizado.

\section{LA LEGUA DE EMERGENCIA, SANTIAGO DE CHILE}

En La Legua de Emergencia, una comuna de San Joaquín al sur de la capital de la República de Chile, se realizaron, entre el año 2001 y 2003, actividades correspondientes a la prevención comunitaria del delito. Por su naturaleza participativa también podrían ser incluidas en la figura de la gobernanza y de los programas de un Presupuesto participativo.

En ese lugar del Cono Sur, las acciones de intervención se denominaron "líneas". Así por ejemplo, la primera línea se abocó a "generar un entorno más agradable para la convivencia entre vecinos" (Candina, 2006: 34). Línea que se tradujo en la reconstrucción de una zona multideportiva con $260 \mathrm{~m}^{2}$ de prados y $1,182 \mathrm{~m}^{2}$ de áreas verdes naturales. En otras áreas urbanas se dotó de luminarias peatonales y se agilizó la circulación al asfaltar tres pasajes y eliminar tres retenes físicos clandestinos.

Otra de las "líneas" abrió espacios para la participación y difusión de derechos. Se capacitó a veinte personas para tal efecto. Así mismo la línea de "expandir las oportunidades de recreación y expresión" implementó programas para alumnos y docentes en las que se realizaron actividades de pintura, literatura, convivencias familiares y apoyo al aprendizaje escolar. Se creó una "Casa de la Cultura para niños". Algunas otras líneas notables fueron "acercar la salud", que además de atender necesidades básicas de primeros auxilios capacitó a una docena de personas como agentes comunitarios en la prevención de la drogadicción. Otra línea fue "capacitación, empleo y desarrollo productivo", que generó más de una centena de empleos emergentes y capacitó a jefas de familia en telares, confección y lavado industrial, así como a la ciudadanía en general para la gestión de microcréditos. No se requieren muchas conjeturas para medir la enorme distancia entre estas acciones y los programas Broken Windows y Zero Tolerance. 
Las actividades realizadas en La Legua de Emergencia bien podrían clasificarse en acciones para la prevención social del delito. Al ser focalizadas a través de deliberaciones y consensos con los habitantes del territorio, caben dentro de la definición de la prevención comunitaria en el marco de la reconstrucción del control social del territorio por los habitantes del mismo. Aunadas a ellas se establecieron acciones típicas de control como la vigilancia y el patrullaje, ejercidos por juntas vecinales.

Lo anterior, en palabras de Candina (2006: 38) es un "regreso de las instituciones a los vecindarios marginalizados", es decir, el retorno del poder a las localidades de donde originalmente emana la soberanía ciudadana. Y aunque varias evaluaciones son disímiles entre la opinión de las autoridades y la comunidad respecto a la satisfacción de los programas (pues la ciudadanía desea que los policías tuvieran mayor incidencia en la limpieza e iluminación de la vía pública, la conservación de inmuebles abandonados en los vecindarios y, sobre todo, una concepción de la tarea policial como un trabajo para mejorar la calidad de vida); algunos puntos coincidentes son muy importantes para mostrar la gobernanza local. Uno de esos aspectos está referido a la propia actuación policial y del control ciudadano: "el patrullaje comunitario... parece tener un papel cierto en la reducción de la violencia policial e incentivar la participación comunitaria en las tareas de seguridad... la policía comunitaria ha mostrado un potencial para disminuir la violación de derechos ciudadanos por parte de la policía" (Candina, 2006: 56).

Destaca entonces la prevención comunitaria del delito porque transforma a la policía tradicional en una policía de mayor proximidad. Con lo cual incrementa el respeto a los derechos humanos de los ciudadanos y adopta la actitud de protección en vez de la beligerancia punitiva. La prevención, en lugar de la reacción ante el delito; y la promoción de la participación ciudadana, en lugar de la mera disuasión local de la infracción como pretenden las administraciones de Broken Windows y Zero Tolerance, son elementos comunes en la práctica exitosa de Chile y Brasil. Esos aspectos positivos marcan características del poder policial comunitario que muestran "el gobierno del pueblo, por el pueblo y para el pueblo", según el famoso discurso de Lincoln emitido en Gettysburg.

\section{BOGOTÁ, COLOMBIA}

Según el Manual sobre la aplicación eficaz de las Directrices para la prevención del delito, en el año 2007 la ciudad de Bogotá publicó su Libro blanco en el que "expuso sus objetivos a largo plazo para mejorar la seguridad y la calidad de vida de sus ciudadanos. Estableció además mecanismos de financiación conti- 
nua invitando a los distritos locales a solicitar fondos para emprender iniciativas de prevención" (Oficina de Naciones Unidas..., 2011: 43). Aunque la primera versión del Libro blanco es de enero de 2008 (UN-Habitat, 2008), no hay duda de que el exhorto a "establecer rubros específicos en los presupuestos locales y distritales para la prevención de la delincuencia" (2008: 54) es una versión aplicada e individualizada del Presupuesto participativo para la dimensión de la prevención comunitaria del delito en el marco de la gobernanza local. Versión que, como en muchos casos del Presupuesto participativo, no recibe dicha denominación.

La coincidencia de gobernanza entre las actividades del Presupuesto participativo y la prevención comunitaria vuelven a establecer la correlación teórica entre ambas formas de participación ciudadana aunque no se posean datos correlacionados en función de la baja en las tasas delictivas. De hecho, los programas de prevención generalmente se enfrentan al problema de cómo evaluarlos, es decir, ¿cómo evaluar lo que no sucede? En todo caso, habrá de enfatizarse las actividades coincidentes. A continuación se enumeran tanto las que siguieron a lo largo de los programas de 1993 a 2002, como las fueron vigentes hasta 2007:

a) "Plan desarme"; no sólo se reprimió la circulación de armas de fuego, sino que alrededor de 6,500 armas fueron entregadas a la policía voluntariamente.

b) Rehabilitación de espacios urbanos: tanto los aspectos inmobiliarios como de transporte fueron renovados en áreas específicas con mayor violencia (Avenida Caracas y zona de Cartucho).

c) "Frentes de Seguridad" fue un programa de comités de seguimiento de la delincuencia de barrio en el cual se fomentó la colaboración entre los policías de proximidad y los residentes. Se hizo a través de reuniones locales en las que se ventilaron los problemas de cada territorio.

d) Se crearon las Comisarías de familia como un medio para reducir la violencia doméstica, sobre todo la que afectaba a las mujeres toda vez que resultaban insuficientes las actividades de conciliación y mediación.

e) La profesionalización policial para la vigilancia preventiva (no sólo reacción).

f) Pactos de seguridad entre los actores institucionales y sociales

Después de las experiencias en Bogotá entre 1993 y 2008, para el año 2010 ya se había implementado en toda la República el Plan Nacional de Vigilancia Comunitaria por Cuadrantes, dependiente de la Policía Nacional de Colombia (2010). En dicho plan destaca la Tabla de Acciones Mínimas Requeridas 
(TAMIR) que involucra actividades de policía comunitaria y de acciones ciudadanas. De las actividades más exitosas cabe resaltar la continuidad de los Frentes de Seguridad Ciudadana que se ampliaron hacia nuevas redes entre la ciudadanía y la policía. Entre ambos impartían asesorías y visitas semanales a las escuelas en temas de resistencia, abusos y drogas. También fue notoria la implementación de "Escuelas de Seguridad Ciudadana" donde la colaboración entre los líderes de organizaciones vecinales y barriales con la policía resultó útil para ilustrar sobre la seguridad ciudadana pública. De igual manera se establecieron "Redes de apoyo y solidaridad" y "Redes de apoyo y comunicaciones" por las cuales la ciudadanía ejerce aspectos de gobernanza junto con las autoridades. Dentro de las actividades que pudieran llamar más la atención se encuentran los acercamientos a pandillas juveniles, a los adultos mayores en condiciones de población vulnerable y la "Policía Cívica Juvenil" que trabajó con niñas y niños los sábados por la mañana con objeto de enseñarles los rolles policíacos básicos y que, seguramente, en el futuro cercano serán los elementos comunicativos de información delictual más valiosos y factores multiplicadores de las acciones comunitarias.

Cabe destacar que gracias a las estrategias de planeación previas contempladas en la tabla TAMIR, una vez que fue terminada en su diseño y operación, el caso de Colombia es de los pocos que reporta instrumentación de indicadores para evaluar los efectos de impacto y no sólo indicadores de proceso de las acciones emprendidas en la prevención del delito. Por otra parte, la tabla TAMIR, como en Brasil y Chile, también muestra un desplazamiento de la policía tradicional hacia las policías de proximidad.

\section{TLALPAN, MÉXICO}

En México existen varias experiencias que por la naturaleza propia de la prevención comunitaria incluyen las perspectivas situacional, ambiental y social.

El Gobierno Municipal de la ciudad de Puebla, en su oportunidad, abordó el enfoque de prevención dirigido a evitar que los ciudadanos sean víctimas de delitos. Entre otras acciones y resultados elaboró el Manual ciudadano para la prevención del delito (Puebla, 2012) que consigna 13 delitos a prevenir, de los cuales la prevención en el trabajo, en el transporte público, en la calle o automóvil y en manejo de dinero, son de índole de prevención comunitaria.

El Estado de Aguascalientes, por su parte, también en el año 2012, desarrolló un "Plan de Prevención de las Violencias y la Delincuencia para el Estado de Aguascalientes" con un enfoque de prevención social que vinculó la participación ciudadana y las funciones policiales preventivas. Se destacó la participación ciudadana en los diagnósticos, las redes de información y colabo- 
ración para establecer sus tres ejes principales: creación o fortalecimiento de una red institucional, mejorar la vinculación para la generación de proyectos, aumento en la organización y participación ciudadana para la regeneración del tejido social.

Las líneas de acción propiamente comunitarias del segundo eje fueron: la campaña de difusión sobre temáticas de prevención (no conducir en estado de ebriedad, evitar la violencia familiar), que además proporcionaron información sobre derechos y obligaciones (salud sexual y reproductiva, derechos de la mujer), y la generación de un espacio de carácter no gubernamental para los integrantes de la red interinstitucional de prevención y la sociedad.

Las líneas de acción para el tercer eje fueron: fortalecer eventos y generar redes culturales a nivel estatal en grupos vulnerables; generar becas de educación artística profesional para los ganadores de los concursos artísticos; fortalecer los eventos deportivos, generando o fortaleciendo las redes sociales de grupos vulnerables; creación de un observatorio ciudadano a través de informantes clave en diversos sectores del estado, y la feria de la seguridad donde se difundieron los programas en materia de seguridad pública así como los productos y servicios para la prevención (Hernández y Zepeda, 2015).

Como puede conjeturarse, sólo las dos últimas acciones no podrían corresponder en estricto sentido a un programa de Presupuesto participativo, a menos que así lo decidiera la comunidad correspondiente y los financiaran. No obstante, todas las demás acciones enumeradas corresponden a la prevención comunitaria y son habitualmente -con mínimas variantes- programadas en las experiencias del Presupuesto participativo.

Aunados a estos y otros casos imposibles de enumerar por razones de espacio, el caso de la delegación Tlalpan, en la Ciudad de México, es significativo porque la Ley de Participación Ciudadana, promulgada en 2010, estableció en el artículo 83 la figura del Presupuesto participativo (Asamblea Legislativas del Distrito Federal, V Legislatura, 2010, artículo 83: 19) y en él consideró a la prevención del delito como uno de los tres rubros generales. En la reforma a dicha ley del 26 de agosto de 2011 los rubros generales se elevaron a cuatro y en la reforma del 13 de mayo de 2013, publicada en la Gaceta Oficial del Distrito Federal, la Asamblea Legislativa elevó a cinco los rubros de mayor importancia. En cada reforma la prevención del delito se conservó como un rubro general de vital importancia (Instituto Electoral del Distrito Federal, 2013: 16-18). Puede deducirse de lo anterior que el tópico de seguridad y prevención del delito es transversal, pues dentro de los proyectos específicos de la prevención se consideraron las luminarias y las alarmas, pero dentro de los otros rubros también destacan las luminarias, la recuperación de espacios públicos 
abiertos, espacios deportivos y culturales, gimnasios al aire libre, obras por colaboración (como una expresión práctica de la gobernanza) para mejorar la imagen urbana, las escuelas, las bibliotecas, los aspectos de higiene y salud pública, etcétera.

Lo anterior demuestra una correlación programática entre el Presupuesto participativo, la participación ciudadana, la gobernanza y la prevención comunitaria del delito. A pesar de ello, el enfoque de la prevención delictiva dentro del Presupuesto y la ciudadanía participativa no ha sido la perspectiva de abordaje, pues no se enfatiza el control social de un territorio por quienes lo habitan. Falta esa perspectiva específica para garantizar la transversalidad de la prevención.

\section{RESULTADOS DE LAS EXPERIENCIAS LATINOAMERICANAS: OBTENIENDO EL COMÚN DENOMINADOR DE LA PREVENCIÓN COMUNITARIA}

Si se desea tomar o recuperar el control para hacer efectiva la prevención comunitaria, las experiencias descritas coinciden en acciones dirigidas a evitar que se cometan delitos y también a que los ciudadanos no se ubiquen como sujetos vulnerables a la victimización. Es decir, presentan un común denominador al dirigirse a los niveles primarios (dirigida a la población en general) y secundarios (dirigida a potenciales victimizadores) de la intervención y no atienden el nivel terciario, según la conocida clasificación que Dammert (2005) aplicó para Latinoamérica.

Dentro del primer nivel puede considerarse una prevención disuasiva de nivel suave a través de campañas educativas, de gestión comunitaria, fuentes humanas de información sobre delitos y puntos de vulnerabilidad (inmuebles deshabitados, pasajes en abandono, atentados ecológicos) o contactos con ciudadanos cooperativos, informes sobre redes viales, alumbrado público, teléfonos o medios de comunicación públicos y de fácil acceso para el auxilio oportuno, instalación de rejas y alarmas, instauración de talleres culturales, artísticos, deportivos junto con comités de seguridad.

Dentro del segundo nivel, la prevención dirigida a que los ciudadanos no se hallen como sujetos vulnerables al delito, puede considerarse la prevención disuasiva de un nivel duro al establecer comités de rehabilitación para adictos con el objeto de evitar la reincidencia (Dammert y Lunecke, 2004: 47), brigadas de inspección a vehículos privados y públicos, cuerpos de control en el espacio público, retenes para revisión de personas, informes de inteligencia, reuniones con líderes que comandan frentes de seguridad que dan seguimiento a las 
denuncias. En un nivel muy superior de dureza, exclusivo de las fuerzas de seguridad pública, está la implementación operativa de patrullajes ciudadanos, guardias y grupos de vigilancia civiles o llanamente ciudadanos voluntarios ejerciendo las siente funciones policiales indicadas por el Consejo Nacional de Seguridad Pública de México. Las siete funciones policiales exclusivas para las fuerzas de seguridad pública son: armamento y tiro; capacidad física; defensa personal; detención y conducción de probables responsables; manejo de bastón policial; conducción de vehículos policiales; y operación de equipos de radio comunicación (Secretaría de Seguridad Pública, 2003).

Si se adoptan las tres teorías contemporáneas en la prevención del delito, pueden especificarse los elementos comunes de estas experiencias latinoamericanas. Ello se muestra en la Tabla II: Tabla de denominadores comunes en la prevención comunitaria.

Tabla II: Tabla de denominadores comunes en la prevención comunitaria

\begin{tabular}{|c|c|c|c|c|c|}
\hline $\begin{array}{l}\text { Prevención } \\
\text { Comunitaria } \\
\text { axial }\end{array}$ & $\begin{array}{l}\text { Diadema, } \\
\text { Brasil }\end{array}$ & $\begin{array}{l}\text { La Legua, } \\
\text { Chile }\end{array}$ & $\begin{array}{l}\text { Bogotá, } \\
\text { Colombia }\end{array}$ & $\begin{array}{l}\text { Tlalpan, } \\
\text { México }\end{array}$ & $\begin{array}{l}\text { Denominador } \\
\text { en común }\end{array}$ \\
\hline P. Social & $\begin{array}{l}\text { Salud pública. } \\
\text { Cultura de } \\
\text { legalidad. } \\
\text { Departamento } \\
\text { y Consejo } \\
\text { Municipal. } \\
\text { Presupuesto } \\
\text { participativo. }\end{array}$ & $\begin{array}{l}\text { Casa de la } \\
\text { Cultura. } \\
\text { Programa de } \\
\text { salud. } \\
\text { Capacitación } \\
\text { para empleo } \\
\text { y empresa. } \\
\text { Juntas } \\
\text { vecinales. }\end{array}$ & \begin{tabular}{|l|} 
Comités de \\
Barrio. \\
Comisarías de \\
Familia. \\
Pactos de \\
Seguridad. \\
Escuela de \\
Seguridad. \\
Policía juvenil. \\
Profesionaliza- \\
ción policial. \\
Presupuesto \\
participativo.
\end{tabular} & $\begin{array}{l}\text { Presupuesto } \\
\text { participativo. }\end{array}$ & $\begin{array}{l}\text { Presupuesto } \\
\text { participativo } \\
\text { enfocado a: } \\
\text { salud, cultura } \\
\text { y educación } \\
\text { cívica } \\
\text { institucionali- } \\
\text { zada en } \\
\text { seguridad. }\end{array}$ \\
\hline P. Ambiental & $\begin{array}{l}\text { Rehabilitación } \\
\text { de espacios } \\
\text { públicos }\end{array}$ & $\begin{array}{l}\text { Rehabilitación } \\
\text { de espacios } \\
\text { públicos }\end{array}$ & $\begin{array}{l}\text { Rehabilitación } \\
\text { de espacios } \\
\text { públicos y de } \\
\text { transporte } \\
\text { Redes y } \\
\text { acercamientos } \\
\text { a pandillas }\end{array}$ & $\begin{array}{l}\text { Rehabilitación } \\
\text { de espacios } \\
\text { públicos }\end{array}$ & $\begin{array}{l}\text { Rehabilitación } \\
\text { espacios } \\
\text { públicos }\end{array}$ \\
\hline
\end{tabular}




\begin{tabular}{l|l|l|l|l|l}
\hline $\begin{array}{l}\text { Prevención } \\
\text { Comunitaria } \\
\text { axial }\end{array}$ & $\begin{array}{l}\text { Diadema, } \\
\text { Brasil }\end{array}$ & $\begin{array}{l}\text { La Legua, } \\
\text { Chile }\end{array}$ & $\begin{array}{l}\text { Bogotá, } \\
\text { Colombia }\end{array}$ & $\begin{array}{l}\text { Tlalpan, } \\
\text { México }\end{array}$ & $\begin{array}{l}\text { Denominador } \\
\text { en común }\end{array}$ \\
\hline P. Situacional & $\begin{array}{l}\text { Cámaras de } \\
\text { vigilancia. } \\
\text { Recolección } \\
\text { de armas de } \\
\text { fuego. } \\
\text { Campañas } \\
\text { contra droga } \\
\text { yalcohol. }\end{array}$ & $\begin{array}{l}\text { Campañas } \\
\text { contra } \\
\text { drogadicción. } \\
\text { Patrullaje. }\end{array}$ & $\begin{array}{l}\text { Patrullaje } \\
\text { patrullaje en } \\
\text { transporte } \\
\text { público. }\end{array}$ & $\begin{array}{l}\text { Uso de } \\
\text { alarmas }\end{array}$ & $\begin{array}{l}\text { Campañas } \\
\text { antidrogas y } \\
\text { patrullaje } \\
\text { presencial o } \\
\text { mecanizado. } \\
\text { Policía de } \\
\text { proximidad. }\end{array}$ \\
\hline
\end{tabular}

Fuente: elaboración propia

Como puede observarse, en el común denominador de la prevención social domina el instrumento de participación ciudadana del Presupuesto participativo, los tópicos de salud y, sobre todo, la institucionalización de la participación ciudadana por la creación de instancias locales en departamentos, consejos, comisarías, escuelas y pactos o contratos sociales en torno a la convivencia y la seguridad. En cuanto a la prevención ambiental, la rehabilitación de espacios públicos es una constante ineludible, muy por encima de los diseños arquitectónicos de resguardo o vigilancia. Respecto a la prevención situacional, destacan las campañas contra los riesgos de la salud y la sociabilidad y en menor medida las tácticas de vigilancia, pero en todos los casos está presente la policía de proximidad.

\section{DISCUSIONES}

La participación ciudadana sería un sinsentido si no fuera útil para elevar la calidad de la seguridad ciudadana y pública al reducir la tasa delictiva. En esta afirmación hay tres variables que pueden y deben ser monitoreadas: los niveles de la participación ciudadana, la calidad de la seguridad y la tasa delictiva. Y a su vez, establecer las correlaciones entre unas y otras.

Para la prevención comunitaria del delito este ha sido el reto teórico y práctico más difícil de conseguir. En general, la literatura al respecto poco o prácticamente nada muestra de estas correlaciones. Las fuentes de información concernientes al caso de Bogotá son las más ilustrativas por contar con las mediciones temporales y comparativas sobre la baja en la tasa delictiva; de Diadema sólo existen reportes generales sin correlaciones precisas; Chile y México, siguiendo criterios internacionales, proponen un indicador general bajo la fórmula de 
contabilizar la medición de delitos por cada 100,000 habitantes. Esta última medida es relativa, pues no es proporcional ni realmente ilustrativa. En una misma ciudad, la medición de delitos resultará distinta al referirse a una comunidad residencial de clase socio-económica alta demarcada en 100,000 habitantes que en una comuna, favela o "barrio bravo" (según una popular expresión mexicana) limitada estadísticamente a igual número de habitantes. Los hábitats son distintos y los hábitos delictivos también, pues en las zonas residenciales podrían darse menos robos a transeúntes y más hurtos a residencias, mientras en las barriadas se contabilizarán menos secuestros y más delitos asociados a los pequeños beneficios inmediatos que buscan los infractores.

Para no tomar la prevención comunitaria del delito como un divertimento político o un esparcimiento de la ciudadanía privada en el escenario público de la gobernanza, debe imponérsele una responsabilidad social evaluable o monitorizada con indicadores. Las ciencias sociales, como las Ciencias de la Seguridad, la Criminología o la Victimología exigirían por lo menos dos tipos de indicadores: los que corresponden a las actividades en el proceso de la prevención y los correspondientes a los impactos.

Los indicadores de proceso pueden contabilizar, por ejemplo, el número y asistencia a las reuniones de planificación de los diversos programas que arriba se denominaron de nivel suave. La accesibilidad para establecer entrevistas de parte de los funcionarios gubernamentales con los ciudadanos participativos. El número de campañas de todo tipo, de informantes e informes, de acciones para recuperar y/o rehabilitar espacios urbanos, de actividades para proteger en la prevención ambiental o situacional a las personas y sus bienes a través de alarmas, rejas, luminarias, etcétera.

Los indicadores de impacto pueden ser, a su vez, subjetivos u objetivos. Dentro de los primeros cabe destacar las encuestas de satisfacción ciudadana o de percepción de la seguridad. En los segundos se encuentran los índices de criminalidad. Los índices de criminalidad, a su vez, pueden ser proporcionales o desproporcionales a los programas de prevención comunitaria. Así por ejemplo, los índices de criminalidad proporcionales han de medir los conflictos vecinales o entre pandillas, los conflictos de la población con la policía, los casos de robo con violencia a ciudadanos o con fuerza a inmuebles industriales, la violencia intrafamiliar o de género, la incautación de armas de fuego, drogas, autos o mercancías robadas, las lesiones por riñas, los accidentes de tránsito como infracciones administrativas, los delitos de abuso sexual, el asalto a bancos o comercios, el abigeato, el hurto a residencias y el tráfico de drogas al menudeo. Dentro de los índices no adecuados para evaluar la prevención comunitaria del delito se encuentra el homicidio doloso, el narcotráfico en altos 
volúmenes de trasiego, la trata de personas, el secuestro y las acciones del crimen organizado que pueden variar desde la producción de piratería masiva, pasando por el secuestro y la extorsión, hasta los delitos informáticos o el tráfico ilegal de especies animales o vegetales protegidas, la explotación forestal clandestina y la contaminación ecológica por el desecho o transporte inadecuado de residuos tóxicos. Obviamente en este rubro un sinnúmero de delitos también quedan excluidos del alcance de la prevención comunitaria, como son los fraudes mercantiles, los desfalcos financieros, las falsificaciones de documentos o papel moneda, las violaciones a contratos de trabajo, etcétera.

El reto ante los indicadores de impacto es doble. No sólo implica la obtención comparativa de datos antes y después de los programas de prevención, sino las evidencias de la correlación, la transparencia y rendición de cuentas gubernamentales. Datos que han de considerar la "cifra negra", es decir, los delitos que no se denuncian o no se registran. En general, el asunto no hace referencia a la eficacia de las autoridades de seguridad pública para consignar dichos índices, sino a su honradez en darlos a conocer o no hacer mal uso de los mismos. Así por ejemplo, respecto a la "Tamir" colombiana, la información llega a ser tan amplia que de esos datos Angarita afirma:

"se infiere igualmente una importante concentración de poder, situación que puede verse agravada en aquellos casos en los que, quienes controlan esa información, son funcionarios con prácticas corruptas y con vínculos a organizaciones criminales; por ello, esa concentración de información -y por tanto, de poder- puede constituir un alto riesgo para la propia seguridad de los habitantes del sector" (Angarita, 2014: 9).

Junto a este problema emerge otro igualmente alarmante: el uso excesivo de la fuerza por parte de la ciudadanía. Los patrullajes ciudadanos organizados en grupos de vigilancia civiles o los ciudadanos voluntarios con el ánimo de ejecutar funciones policiales, se han salido de control en más de alguna ocasión creando grupos paramilitares o las denominadas en México: "autodefensas". No se debe exhortar a la ciudadanía a rebasar los límites de la gobernanza, a participar en funciones exclusivas y reservadas para las instituciones de seguridad pública -por muy grande que sea el déficit gubernamental al respecto-. Una policía comunitaria conformada por ciudadanos sin la debida formación en dogmática policial, en el adoctrinamiento conforme al uso racional de la fuerza y en el eficaz adiestramiento para la persecución, detención, inmovilización y traslado de posibles delincuentes o sospechosos, o simplemente de infractores no penales sino administrativos, vulnera el Estado de Derecho tanto como la acción delincuencial misma. Ante este riesgo, debe limitarse la interactividad de la gobernanza y las facultades de la participación ciudadana con un 
delicado equilibrio en la desconcentración. El poder de la participación ciudadana debe ser potente, pero siempre legítimo y legal.

Cabe hacer notar que en las constantes y los comunes denominadores de la prevención comunitaria del delito ejercida por la gobernanza local, tanto en su planeación, ejecución y evaluación, se encuentran más presentes los indicadores de proceso que los de impacto. Que la mayoría de los indicadores de proceso son coincidentes con las acciones de participación ciudadana realizadas a través del Presupuesto participativo aunque no haya estudios explícitos de la respectiva correlación entre este mecanismo participativo y la tasa delictiva como indicador de impacto. Y que al menos existen menciones mínimas o implícitas del Presupuesto participativo en la prevención comunitaria.

Algunos aspectos negativos de la prevención comunitaria, sin embargo, se encuentran en ciertos efectos sociales. La reconstrucción o recuperación del control de un territorio acarrea la estigmatización socio-territorial, es decir, se genera una nueva categoría social o cultural, la de un "extraño", "foráneo" u "otro" que por su sola alteridad o diferencia es considerado peligroso. Todo aquel que vive fuera de las murallas divisorias de un barrio o zona residencial, que no está registrado por los sistemas de acceso o protección o no participa en la red de alarmas comunitarias corre el riesgo de ser criminalizado por mera exclusión.

Un efecto social de alto costo político consiste en que los miembros de la comunidad no dimensionen los alcances de la prevención y tengan expectativas sobre delitos que le corresponden de manera exclusiva a otras escalas del Estado. Por ejemplo, el tráfico de drogas a gran escala, el terrorismo, el contrabando de armas, las redes de trata, etcétera. En consecuencia, en los habitantes de las comunidades se generaría una frustración que los llevaría a la apatía ciudadana o, en el peor de los casos, a tomar acciones fuera de la legalidad; como por ejemplo, las ya mencionadas "autodefensas" mexicanas o los linchamientos.

La falta de indicadores de impacto sobre la tasa delictiva asociada a la prevención comunitaria ha sido una dificultad permanente, no sólo en América Latina, sino también en Estados Unidos. Destacados criminólogos como Crawford $(1997,1998)$ y Sherman (2002) reportaban estas carencias desde hace más de una década y se mostraban pesimistas ante la prevención comunitaria del delito. A pesar de lo anterior, los factores de éxito se identifican en la focalización de las intervenciones: tomar un asunto con especial concentración; ya sea la violencia intrafamiliar, la deserción escolar, la entrega de armas de fuego. También se deben focalizar los recursos humanos y el liderazgo personal e institucional de las autoridades con el deseo de establecer los programas con visión de continuidad. En contraste con las apreciaciones pesimistas, auto- 
res como Giller, Haggel, y Rutter (2000) por una parte, Krauskopf (1999) y Shaw (2001) por otra, coinciden en hacer notar experiencias exitosas cuando los aspectos de focalización han sido puntuales, especialmente el caso de trabajo comunitario con jóvenes. Quizá ello se deba a la adecuación de la intervención primaria y secundaria, pues en el caso de los jóvenes es más fácil el paso de ser victimarios o victimizados a convertirse en agentes de la prevención.

Un aspecto más a revalorar en la gobernanza de la prevención comunitaria es el rol de mando delegado en ciudadanos y el rol de género dentro del mando interno de los cuerpos policiales. Esta dimensión abre una futura línea de investigación porque los datos recabados en algunas experiencias muestran como factor importante de éxito el liderazgo civil y el femenino. Torres ha testimoniado que cuando las Coordinaciones de Seguridad Comunitaria han sido lideradas por civiles "con el fin de alejarlos del círculo de la corrupción de los mandos policiales... [y el mando táctico en la policía ha sido ejercido por una mujer] ....algo inusual en seguridad pública" (2005: 241), la confianza ciudadana se ha incrementado provocando mejores rendimientos del capital social.

\section{CONCLUSIONES}

En lo referente a la formación del capital social, la prevención comunitaria no presenta oposición desde el aspecto del control. Si, efectivamente, la prevención es 'la reconstrucción del control social del territorio por parte de quien lo habita', los habitantes de dicho hábitat son quienes constituyen el capital social. Capital que a largo plazo hace más efectiva y más barata -en relación a la fórmula costos/beneficios- la prevención que la reacción policial ante la presencia delictiva.

Más allá de la reconstrucción o recuperación del control de un hábitat por parte de sus mismos habitantes, la prevención comunitaria del delito aporta la solidaridad social. Aporta también mayores y mejores prácticas democráticas por la recomposición del tejido social y la efectiva y eficaz consolidación de la gobernanza. Con facilidad alcanza los niveles primarios (dirigida a la población en general) y secundarios (dirigida a potenciales victimizadores) de intervención preventiva y con una mayor estrategia podría alcanzar los niveles terciarios (enfocada a los victimarios para evitar las reincidencias).

Los diseños de prevención comunitaria muestran que los programas focalizados tienen más éxitos que los programas integrados (Dammert, 2005: 134). Por tanto, las relaciones entre la ciudadanía y las instituciones de seguridad pública deben planearse, organizarse e implementarse bajo el marco de la gobernanza y con el liderazgo coordinador de las autoridades. Además, los vínculos 
son altamente preferibles con las autoridades de escalas locales en vez de vincularse con funcionarios de otros rangos, pues las experiencias en contrario que se establecieron con autoridades de mayores esferas han mostrado impactos contraproducentes. Al respecto, debe notarse la excepción de Colombia, pues en ese país la Policía Nacional existe con un fuerte legado de la Policía Metropolitana y ello explica tanto el éxito en los indicadores de impacto como la facilidad para implementar en la formación policial y sus quehaceres diarios los programas de policía comunitaria.

Un desafío para la prevención comunitaria, así como para el Presupuesto participativo, son las fuentes de financiamiento para la operación de los programas. Los programas de Comuna Segura de Chile son ilustrativos; desde el año 2000 los criterios de priorización para el financiamiento se establecieron sobre líneas preferentes a la promoción de la participación comunitaria, el fomento de las organizaciones y formación de redes, la prevención de conductas delictivas o de riesgo social específicos, la gestión en grupos específicos, la organización de los proyectos con apoyo de asociaciones de distinta índole (escuelas, clubs, comunidades religiosas) y los proyectos elaborados por organizaciones juveniles y de adultos mayores. Éstos últimos son indicadores constantes de los procesos más deseables.

En términos concluyentes los factores generales para establecer programas exitosos, en la prevención comunitaria del delito a través de la gobernanza local, radican en siete denominadores que confirman la exigencia de institucionalizar la participación ciudadana. Esos comunes denominadores son: 1) la innovación, que recoge las iniciativas ciudadanas poco o nulamente imaginadas por las autoridades; 2) la precisión del impacto, es decir, la focalización a problemas concretos; 3) la asociación, entre ciudadanos individuales y grupos con la autoridad; 4) la gestión, que busca el ejercicio y defensa de derechos sociales y el seguimiento a las denuncias; 5) la sustentabilidad, a través de la viabilidad técnica, financiera y legal de los proyectos a aprobarse por los Presupuestos participativos; 6) el liderazgo ciudadano o de funcionarios comprometidos; y finalmente 7) la amplitud de inclusión y empoderamiento de cualquier miembro de la comunidad (niños e inmigrantes), no solo de los ciudadanos.

Como corolario final se deduce que cuando la participación ciudadana auxilia al Estado a proveer seguridad, entonces ambos logran hacer coexistir un máximo de libertad con un mínimo del ejercicio punitivo de parte de las instituciones de control. De manera que la seguridad pública se armoniza con la seguridad jurídica de cada ciudadano, un ideal largamente deseado por Baratta (2004) para evitar la transgresión de los derechos ciudadanos por las 
fuerzas de seguridad del Estado. Y sin duda alguna, la contemporánea prevención comunitaria del delito a través de la gobernanza local y sus vanguardistas instrumentos de participación ciudadana confirman la sabia tesis de Beccaria (1993:158): "Es mejor evitar los delitos que castigarlos".

\section{BIBLIOGRAFÍA}

Ackerman, B. (1999). “¿Un Neofederalismo?”. En J. Elster y R. Slagstad, Constitucionalismo y Democracia. Estudio introductorio de Alejandro Herrera, México: F.C.E., $205-207$.

Aguilar, L. (2007). "El aporte de la Política Pública y de la Nueva Gestión Pública a la gobernanza". Revista del CLAD Reforma y Democracia, No. 39, Caracas.

Aguirre, J. (2014). "Una contribución de Internet contra el déficit democrático: prerrogativas, riesgos, límites y alcances del Presupuesto participativo electrónico". Revista Internacional de Pensamiento Político, I Época, Vol. 9, 249- 265.

Angarita, P. (2014). "Políticas para enfrentar la violencia y la inseguridad en Colombia". Cuestiones de Sociología, No. 10, 1-13. Consultado el 11 de septiembre de 2015 de: http://www.cuestionessociologia.fahce.unlp.edu.ar/

Asamblea Legislativa del Distrito Federal, V Legislatura, (2010). Ley de participación ciudadana del Distrito Federal. México, D.F.

Baratta, A. (2004). Criminología crítica y crítica del derecho penal: introducción a la sociología jurídico penal. Argentina: Siglo XXI

Barnes, S. and Kaase M., (eds). (1979). Political Action. Mass Participation in Five Western Countries. Beverly Hills, CA: Sage.

Beccaria, C. (1993). Tratado de los delitos y las penas. Argentina: Editorial Heliasta S.R.L.

Cerrillo, A. (2005). La gobernanza hoy: 10 textos de referencia, Madrid: Instituto Nacional de Administración Pública.

Candina, A. (2006). Comunidad y prevención: una guía para el trabajo a nivel local. Chile: Centro de Estudios en Seguridad Ciudadana, Instituto de Asuntos Públicos, Universidad de Chile.

Crawford, A. (1997). The Local Governance of Crime: Appeals to Community and Partnerships. Oxford: Clarendon Press.

Crawford, A. (1998). Crime Prevention and Community Safety: Politics, Policies and Practices, Londres: Longman.

Dammert, L. y Lunecke, A. (2004). La prevención del delito en Chile. Una visión desde la comunidad. Chile: Centro de Estudios en Seguridad Ciudadana.

Dammert, L. (2005). "Prevención comunitaria del delito en América Latina: desafíos y oportunidades". Desafíos No. 13, 124-156. Bogotá, Colombia.

Ganuza, E. y Francés, F. (2015) "Citizen participation in Europe: a comparative analysis from the sociopolitical contexts". OBETS. Revista de Ciencias Sociales, vol. 10, No. 1, 235-260.

Glaser, B., y Strauss, A. (1967). The Discovery of grounded theory: strategies for qualitative research. Chicago: Aldine. 
Giller, H., Haggel, I., y Rutter, M., (2000). La conducta antisocial de los jóvenes, Cambridge: University Press

Hernando, F. (2008). "La seguridad en las ciudades: el nuevo enfoque de la geoprevención”. Scripta Nova. Revista Electrónica de Geografía y Ciencias Sociales. Barcelona: Universidad de Barcelona, 1 de agosto de 2008, vol. XII, núm. 270 (14). Consultado el 13 de agosto de 2015 de:

Hernández, F. y Zepeda, D. (2015). "El plan estatal de prevención social de la violencia y la delincuencia para el Estado de Aguascalientes: la participación ciudadana, la función policial preventiva y la confianza institucional". Archivos de Criminología, Seguridad Privada y Criminalística. Año 3, vol. V agosto-diciembre 2015. Consultado el 21 de agosto de 2015 de: www.somecrimnl.es.tl

Hernández-Sampieri, R., Fernández-Collado, C., Baptista, P. (2006) Metodología de la investigación. México: McGraw Hill.

Instituto Electoral del Distrito Federal (2013). Presupuesto participativo y planeación de proyectos. México: IEDF. Consultado el 20 de agosto de 2015 de:

Kahn, T. (2004). Policía comunitaria: evaluando la experiencia de Sao Paulo. Chile: CED.

Kelling, G. and Coles, C. (1998). Fixing Broken Windows: Restoring Order and Reducing Crime in Our Communities, USA: Touchstone Press.

Krauskopf, D. (1999) "Dimensiones críticas en la participación social de las juventudes", revisión del documento Participación y Desarrollo Social en la Adolescencia, Costa Rica.

Kooiman, J. (2005). "Gobernar en gobernanza”. En A. Cerrillo (comp.), La gobernanza hoy: 10 textos de referencia, Madrid: Instituto Nacional de Administración Pública.

Liddell, G. \& Scott, R. (1996). A Greek-English Lexicon, 9th ed., New York: Oxford Press.

Martí I Puig, S., Ortega, R., y Somuano, M. F. (eds.) (2011). La democracia en México. Un análisis a 10 años de la alternancia. Barcelona: Ediciones Bellaterra/El Colegio de México.

Núñez, L. (2011). "La prevención del delito a través de los paradigmas criminológicos”. En D. Ordaz y E. Cunjama (coord.). Criminología Reflexiva, Discusiones acerca de la criminalidad. México: Editorial Ubijus.

Organization for Economic Co-operation and Development (OECD). (2001). Citizens as partners. Information, consultation and public participation in policy-making. Paris: OCDE.

Oficina de Naciones Unidas contra la droga y el delito (2011). Manual sobre la aplicación eficaz de las Directrices para la prevención del delito. Serie de manuales sobre justicia penal. Nueva York: Naciones Unidas.

Osborne, D. and Gaebler, T. (1992). Reinventing Government. Massachutes: AddisonWesley.

Real Academia Española (1992). Diccionario de la Real Academia de la Lengua, 21ª. Edición. Madrid: RAE

Paniagua, A., Borunda, J., y Camargo, I. (2012). "Transparencia, participación ciudadana y gobierno electrónico: el caso del Gobierno Local de Ciudad Juárez, México". Sociedade e Cultura, 15: 1, Brasil, Universidad Federal de Goiás, 99-107. 
Pavarini, M. (1994). "Bisogni di Sicurezza e Questione Criminale". Rassegna Italiana de Criminología, Anno V - N. 4, Ottobre, Milano: Giuffrè Editore, 435-462.

Peters, G. y Jon P. (2005). "Gobernanza sin gobierno? Replanteándose la administración pública”. En A. Cerrillo (comp.). La gobernanza hoy: 10 textos de referencia, Madrid: Instituto Nacional de Administración Pública

Petersilia, J. \& Cullen, F. (2015) "Liberal but not stupid: meeting th promise of downsizing prisions". En Stanford Journal of Criminal Law and Policy, Winter 20142015. [Versión castellana en Criminología y Sociedad, Vol. 3, Núm. 4, 2014-2015, 11-116).

Policía Nacional de Colombia, Dirección General -Oficina de Planeación 2010 (2010). Estrategia institucional para la seguridad ciudadana: plan nacional de vigilancia comunitaria por cuadrantes (PNVCC). Aprobada el 5 de noviembre. Colombia: Gobierno Nacional.

Prats, J. (2005). "Modos de gobernación de las sociedades globales". En A. Cerrillo (comp.). La gobernanza hoy: 10 textos de referencia, Madrid: Instituto Nacional de Administración Pública.

Prefeitura de Diadema (2006). Seguridad Pública: Medidas de Transformación (Diadema, Brasil). Consultado el 20 de agosto 2015 de: recuperado 20 de agosto 2015

Puebla, Gobierno Municipal, Consejo Ciudadano de Seguridad Pública, Secretaría de Seguridad Pública y Tránsito Municipal (2012). Manual ciudadano para la prevención del delito. México: IMPLAN.

Secretaría de Seguridad Pública, Estados Unidos Mexicanos (2003) Manual de conocimientos básicos de la función policial. México: Sistema Nacional de Seguridad Pública.

Shaw, M. (2001). Invirtiendo en los jóvenes 12-18 años: enfoques internacionales para prevenir el crimen y la victimización, Montreal: Centro Internacional para la Prevención del Crimen (CIPC).

Sherman, L. (2002). "Trust and confidence in criminal justice". National Institute of Justice Journal. No. 248, 22-31

Sozzo, M. (2000) "Seguridad urbana y tácticas de prevención del delito". Cuadernos de Doctrina y Jurisprudencia Penal, Año VI, No. 10-B. Argentina; Ed. Ad-Hoc, 17-82.

Strauss, A., y Corbin J. (1990). Basics of qualitative research: grounded theory procedures and techniques. California: Sage.

Torres, B. (2005) "Barrios trabajando: una experiencia participativa de seguridad comunitaria y desarrollo social”. En E. López Estrada y R. Ferreira (Coord.). Pobreza, empleo y participación ciudadana: aportes para la política social. México: Universidad Autónoma de Tamaulipas, Universidad Autónoma de Nuevo León, 228-246.

UN-Habitat Programa Ciudades Más Seguras (2008). Libro Blanco de la Seguridad Ciudadana y la Convivencia de Bogotá Colombia: Alcaldía Mayor de Bogotá D.C.

Van Dijk, J. (1990). "Crime Prevention Policy: Current State and Prospects”. En G. Kaiser y H. J. Albrecht: Crime and criminal policy in Europe, Criminological research report, Vol. 43, Max Planck Institute, Freiburg, 1990, 205-220. 
Vallès, J. M. (2000). Ciencia política. Una introducción. Barcelona: Ariel.

Wilson, J. and Kelling, G. (1982). "Broken Windows". En The Atlantic Monthly, march.

JORGE FRANCISCO AGUIRRE SALA es mexicano, doctorado en Filosofía e investigador en el Instituto de Investigaciones Sociales de la Universidad Autónoma de Nuevo León, México. Autor de más de cien artículos y libros, sus aportaciones recientes versan sobre la democracia líquida, la participación ciudadana y la gobernanza, aplicadas a la construcción de políticas públicas en aspectos de justicia social, ecología y seguridad. Autor de la propuesta Ciudadanía Mediática, Perspectivas de la Comunicación, 2011. Entre sus publicaciones destacan: "La Democracia Líquida", UOC, 2016; "Los límites de la representatividad política y las alternativas de la democracia líquida", en Revista Internacional de Pensamiento Político, 2015; "Necesidad y condiciones de la democracia líquida: los primeros pasos en México", en Revista Culturales, 2016. Su vida y trabajo académico están consignados en 2000 Outstanding Intellectuals of 21st Century del International Biographical Centre, Cambridge, Inglaterra.

Recibido: 12/09/2015

Aceptado: 05/09/2016 


\title{
COOPERATIVAS INDEPENDIENTES ENTRE LA EXHIBICIÓN CINEMATOGRÁFICA Y LA GESTIÓN CULTURAL: EL CINE CIUDADANO EN LA PERIFERIA DE LA INDUSTRIA* \\ INDEPENDENT COOPERATIVES BETWEEN FILM EXHIBITION AND CULTURAL MANAGEMENT: CITIZEN CINEMA AT THE INDUSTRY'S PERIPHERY
}

\author{
Robert Arnau Roselló \\ Universitat Jaume I, España \\ rarnau@uji.es
}

\begin{abstract}
Cómo citar / Citation
Arnau Roselló, Robert (2016). "Cooperativas independientes entre la exhibición cinematográfica y la gestión cultural: el cine ciudadano en la periferia de la industria". OBETS. Revista de Ciencias Sociales, 11(2): 419-439.

doi:10.14198/OBETS2016.11.2.02

\section{Resumen}

A partir de la organización de cierto número de personas en cooperativas culturales, los llamados cines ciudadanos implementan una estrategia similar a la de la guerrilla de la cultura, reabriendo locales cinematográficos en quiebra o reflotando proyectos de salas de cine que habían quedado estancados. El motor esencial de estas experiencias se alimenta de la posibilidad de abrir un espacio en la periferia de la industria cinematográfica, gestionado directamente por los socios, capaz de rescatar películas que no podrían tener distribución comercial y quedarían sin proyectar en el cajón de alguna distribuidora residual. Por ello, estos espacios dinamizados por los movimientos sociales se configuran como una alternativa real a las censuras que promueve por naturaleza el sistema de distribución comercial cinematográfica.
\end{abstract}

\footnotetext{
*El presente estudio ha sido financiado con la ayuda del Proyecto de Investigación de la convocatoria Universitat Jaume I-Bancaja, con el título "La crisis de lo real: la representación documental e informativa en el entorno de la crisis financiera global", código 111301.01/1, para el periodo 2014-17, bajo la dirección del Dr. Javier Marzal Felici.
} 
Palabras Clave: Exhibición cinematográfica; Cooperativas culturales; Movimientos sociales; Cine ciudadano; Independiente; Distribución alternativa.

\begin{abstract}
From the organization of a number of people in cultural cooperatives, called citizens cinemas implemented a similar strategy of guerrilla's culture, reopening bankrupt film locals or cinema projects that had been stalled. The key driver of these experiences is fed by the possibility of opening a space in the periphery of the film industry, directly managed by the partners, able to rescue films that might not have commercial distribution and would not projecting in the drawer of a residual distribution. Therefore, these spaces energized by social movements are configured as a real alternative in front of censures promoting by the film commercial distribution system.
\end{abstract}

Keywords: Film exhibition; Cultural cooperatives; Social movements; Citizen Cinema; Independent; Alternative distribution.

\title{
Extended Abstract
}

In recent years is perceptible an increase in certain types of initiatives in the field of film exhibition that retrieve and update strategies from past experiences in time such as film clubs or arthouse rooms. The tradition of a certain associative film goes far back in time, almost to the origins of film exhibition, but in the seventies when the film clubs organized around social political movements whose main objective is to organization of film screenings in all types of screens, lives its moment of greatest splendor.

The circulation of films by these alternative distribution channels, fueled mostly by films banned by the censorship in Spain or films made by film militant groups in the period, it is a window to the outside (and inside) for many viewers who can not access these contents otherwise. The distribution system has its cracks and their own censorship, so that the subversion of the dominant models highlights the need for renewal of some imposed methods that eliminate the decision-making capacity of the viewer. Schedules (ideologies) imposed by the multinationals of the distribution (the American majors) that propose social, cultural, political models and eliminate any possibility of interference from other narratives cornered look through the screen quota.On the other hand, in the eighties the rise of the arthouse rooms had allowed to find a certain kind of film that had no place in commercial cinemas. The precipitous rise and fall of these screens takes place in just two decades, but the spirit that encourages those who initiated these wanderings survives in some current organizational models, as here try, so-called Citizens Cinemas.

Today, from the organization of a number of people in networks and cultural cooperatives, citizens cinema implements a similar strategy of guerrilla's culture, reopening bankrupt film locals or cinema projects that had been stalled. The key driver of these experiences is fed by the possibility of opening a space in the periphery of the film industry, directly managed by the partners, able to rescue films that might not have commercial distribution and would not projecting in the drawer of a residual distribution.

It is, in short, a grassroots movement with a clear horizontally inspiration derived from the experiences of recent movements Occupy Wall Street or the 
15-M. Reorganized spaces by these groups are set up as a real alternative (now working normally in some Spanish cities) to the censorship that naturally promotes commercial film distribution and serve as an engine of socio-cultural initiatives in a citizens recovered area. Through the analysis of the genesis of some pioneering projects in Spain, as CineCiutat, Cines Zoco Majadahonda or Numax, we will try to outline the horizon on which the movement seems to develop at present updating the role of the film clubs.

\section{INTRODUCCIÓN: CINES CIUDADANOS Y ACTIVISMO POLÍTICO- SOCIAL. NUEVAS ESTRUCTURAS ORGANIZATIVAS EN LA DISTRIBUCIÓN CINEMATOGRÁFICA DIGITAL}

En estos últimos años es perceptible el incremento de cierto tipo de iniciativas en el campo de la exhibición cinematográfica cuya inspiración nuclear proviene principalmente de dos ámbitos complementarios, pero diferenciados: por un lado recuperan y actualizan estrategias derivadas de experiencias anteriores en el campo de la exhibición cinematográfica tales como los cineclubes o las salas de arte y ensayo; por otro, desplazan a la gestión cultural los esquemas organizativos y estructurales que alentaron los recientes movimientos sociales globales, tales como Occupy Wall Street o el 15-M en España.

Estos dos focos principales de inspiración, en cuyo seno conviven la gestión cultural independiente y la horizontalidad heredada de las organizaciones sociales asamblearias protagonistas del 15-M, han precipitado el ensanchamiento de una grieta en el actual sistema de distribución cinematográfica que, aún en proceso de mutación por la irrupción de la tecnología digital, suscita innumerables incógnitas y presenta enormes desafíos de adaptación dada su naturaleza esencialmente conservadora. Lo curioso en este caso, por infrecuente, es que dichos desafíos procedan del exterior de la institución cinematográfica, del ámbito de lo civil, para el cual hasta ahora no había espacio fílmico específico construido por -y para- sí mismo.

Es paradójico que el cine, tradicionalmente punta de lanza ideológica de las Industrias Culturales, esté siendo uno de los últimos sectores en adaptar su sistema de exhibición a la realidad digital y lo haga de un modo tan lento, a pesar de que la evolución del parque de salas, el número de espectadores y la recaudación de taquilla sea efectiva (Izquierdo, 2010, p. 21). Una de las razones que explica esta aparente contradicción, y también la génesis de los cines ciudadanos, es que la industria cinematográfica representa un caso paradigmático en cuanto a la concentración de medios se refiere. La posición de dominio de las Majors estadounidenses en el sector no proviene, como suelen argumentar desde las propias compañías, de una mayor identificación del público con el cine norteamericano o una ventaja competitiva en términos de calidad técnica y grado de espectacularización, sino de una restricción efectiva de la capacidad 
de elección de los espectadores a través del control del mercado de la distribución, la cartelera y las cuotas de pantalla.

Además, la estructura oligopólica de dichas empresas, sobre todo en EEUU, concentra en manos de unas pocas compañías (y sus filiales más o menos explícitas) más del 90\% del mercado norteamericano. Sin embargo, en Europa, aunque el dominio es significativo, la atomización del mercado causado por la fragmentación de las audiencias impide tal situación. Las compañías locales no pueden hacer frente a los gigantes de las Majors, de modo que hasta el 60\% del mercado autóctono europeo se ve copado por producciones de Hollywood y su arquetípico blockbuster. Y es que, como sostiene Bagdikian (2004), los productos audiovisuales poseen costes estructurales que benefician la creación y consolidación de mercados oligopólicos, de tal forma que para las estructuras de cierta envergadura, una vez el producto audiovisual ha generado ingresos por el valor de su coste producción, cada ingreso adicional es beneficio bruto. Así, para combatir la incertidumbre de un mercado de base creativa, estas empresas optan por producir un número anual de películas (pongamos, por ejemplo, 10) que garantice, por simple probabilidad, el éxito en taquilla de un par de ellas, y permita cubrir las pérdidas de las ocho restantes (Pardo y Sánchez-Tabernero, 2012, p. 42).

De ese modo, las compañías hegemónicas con mayor presencia en las pantallas, implementan estrategias abusivas sustentadas por su posición ventajosa en el mercado y su poder en el sector. No es de extrañar, pues, que la propia OCDE, desde finales del siglo pasado, advierta de que las salas que no están integradas en una estructura vertical o no forman parte de una gran multinacional pueden sufrir desventajas competitivas importantes, de muy diversa índole.

Una situación de agravio que viene condicionada por numerosos factores dispersos como la preferencia de los productores por reservar los estrenos más populares para las salas con mayores ingresos (normalmente aquellas propiedad de grandes complejos), las exigencias de los periodos de programación amplios, el otorgamiento de derechos exclusivos de distribución que aseguran la audiencia a costa de las salas menores cercanas (zoning), la adquisición obligatoria de filmes mediocres que se venden conjuntamente con las grandes producciones (block booking), o incluso la adquisición a ciegas del film por parte del exhibidor (blind bidding), lo cual acrecienta las desventajas de los pequeños y medianos exhibidores (OCDE, 1996, p. 9) que ven amenazado su modelo de negocio por el insaciable show business.

Ciertamente, esta presión que ejercen las Majors sobre las industrias cinematográficas de otros países, no sólo tiene un carácter económico, sino también, y sobre todo, socio-cultural (Sánchez Ruiz, 2007). Se trata de un cine que com- 
bina la voluntad de recepción masiva, cuyo objetivo final es ser entendible por todo el mundo, con la necesidad de exportación de modelos políticos, económicos y culturales a través de estrategias de distribución basadas en las más agresivas técnicas de mercadotecnia (Wasko, 2003). De hecho, su modelo de implantación hace que sea la propia distribución la que configure la industria del cine como tal, ya que a medida que aumenta la demanda de películas, aumenta la producción, relación que no funciona en sentido contrario. La saturación de las pantallas con películas de temática y planteamiento narrativo homogéneo y las dificultades para la entrada en los circuitos de producciones alternativas, hacen que sea necesaria una alta dosis de creatividad para distribuir (y rentabilizar mínimamente) algunas películas (Izquierdo, 2010, p. 51).

Es en este contexto complejo, precisamente, donde hay que encuadrar las iniciativas de los cines ciudadanos (Community Supported Theatres, en EEUU), en el tiempo de las secuelas provocadas por la tremenda crisis económica de 2008 , de las redes sociales y la participación ciudadana a través de la herramientas propias de la web 2.0, de los movimientos sociales Occupy, de la sociedad-red. Sin embargo, pese a su reciente génesis, estas iniciativas ciudadanas hunden sus raíces en las huellas dejadas por intentos de organización y distribución alternativos a los circuitos comerciales muy anteriores en el tiempo.

La tradición de un cierto cine asociativo se remonta muy atrás en España. Ya durante la etapa republicana se experimentó un profundo auge del movimiento cineclubista en las principales provincias españolas que, sin embargo, se vio truncado por la Guerra Civil y el posterior régimen dictatorial franquista (Ruiz Muñoz, 2012).

Pero en la década de los setenta el cineclubismo, organizado en torno a movimientos sociales de carácter político cuyo objetivo fundamental consiste en la organización de proyecciones cinematográficas en todo tipo de locales como excusa para actos clandestinos de los militantes antifranquistas, vive su momento de mayor esplendor. La circulación de películas por estos circuitos alternativos de distribución, alimentados en su mayoría por películas prohibidas por la censura en España o filmes militantes realizados por colectivos cinematográficos del periodo, supone una ventana al exterior (y al interior) para muchos espectadores que no pueden acceder a estos contenidos de otro modo.

Así, se convierten catalizadores de este "otro" cine entre un público heterogéneo que accede a una destacable variedad de espacios de exhibición marginales. En 1974 la Central del Curt (CDC) se funda como la primera plataforma alternativa de distribución cinematográfica de las prácticas independientes y/o militantes en el estado español (aunque en el terreno del cine independiente cabe señalar la importancia del llamado Volti, la red de locales del sin- 
dicato $\mathrm{CCOO}$ en las que se proyectaba material clandestino o prohibido por el régimen). Como distribuidoras autogestionadas por sus miembros, contribuyen de manera significativa a la configuración de una red cinematográfica de información y debate ideológico-político en una sociedad civil que presenta una absoluta necesidad de este tipo de productos culturales dado el contexto institucional de desgaste del régimen y de evolución política profunda que se vive en esa década. En sus propuestas programáticas se entiende el trabajo de un modo integral, en el que se combinan la distribución con la búsqueda ininterrumpida de puntos de exhibición a través de la inmersión en las problemáticas de los barrios, sindicatos y otras agrupaciones sociales. En definitiva, se trata de la materialización de un grupo de gente que desde el ámbito cinematográfico pretende incidir en el contexto político del momento (Arnau, 2006, p. 232).

Sus miembros, por tanto, se sienten ideológicamente identificados con los diversos conflictos y demandas sociales, tienen en sus manos material cinematográfico y siempre existe un nexo común con las demás redes de movilización, de forma que es posible difundir ciertas imágenes negadas desde la televisión estatal o el principal aparato de propaganda del régimen, el noticiario No-Do. Durante casi ocho años, la CDC posibilita la difusión de unos 120 films que no circulan por los canales de exhibición comercial del Aparato Cinematográfico Industrial y producidos al margen de él, además de una media de unas 600 contrataciones de films por año de existencia, una cifra nada despreciable, asimilable a una distribuidora comercial del sector nacional en ese momento. El sistema comercial de distribución tiene sus grietas y sus propias censuras, de modo que la subversión de los modelos dominantes pone en evidencia la necesidad de renovación de algunos métodos impuestos que eliminan la capacidad decisoria del espectador. De este vacío, emergen las prácticas colectivas ciudadanas.

Por otro lado, a partir de 1967 el auge de las salas de Arte y Ensayo (los repository cinemas -arthouse cinemas- en EEUU), al tiempo que anuncia la crisis del cineclubismo (que se desencadena entonces, pero acaba prácticamente con la componente crítica del movimiento unas décadas después) permite encontrar en las pantallas un cierto tipo de cine que no había tenido cabida hasta ese momento en las salas comerciales. Su papel precursor, aunque en menor grado que el movimiento cineclubista, resulta del hecho de alzarse contra el imperio de las distribuidoras en busca de films de muy distinto carácter al de aquel comercializado y consumido por el gran público. Proyecciones de películas clásicas o de culto, documentales o films independientes que tratan de mantener viva la idea del cine como arte y artefacto cultural de transformación social, al servicio de las inquietudes de la sociedad civil frente al avasallamiento (y el vaciado de sentido) de la industria mainstream. El ascenso y caída estrepitosa 
de estas salas tiene lugar en apenas dos décadas, tanto su auge como su declive son instantáneos, pero el espíritu que alienta a los que iniciaron estas andaduras pervive en algunos modelos organizativos actuales como los que a continuación trataremos, de los llamados Cines Ciudadanos.

\section{METODOLOGÍA E HIPÓTESIS DE TRABAJO}

El planteamiento metodológico de este estudio se ha estructurado en torno a varios tipos de fuentes, de diverso carácter y procedencia. La revisión bibliográfica se centra, por una parte, en el repaso de estudios destacados sobre la distribución cinematográfica y la concentración de medios (Gomery, Izquierdo, Pardo y Sánchez-Tabernero, Bagdikian, Augros), así como informes realizados por organismos públicos para ubicar la investigación en el terreno concreto de la exhibición fílmica (OCDE, ICAAV). Por otra, en aquellos estudios que analizan los recientes movimientos sociales, y las redes tanto sus especificidades como sus estrategias políticas o comunicativas (Giménez, Piñeiro-Otero, Christakis, Castells).

El debate (y la discusión científica) acerca del papel desempeñado por estos focos de distribución en la industria (secundarios, si tenemos en cuenta las dimensiones del sector), se ubica precisamente, en el terreno de confluencia entre la distribución cinematográfica y el papel de estas organizaciones colectivas frente a la estructura oligopolística del negocio fílmico a través del intento de superación el tradicional contexto de concentración de medios. Nuestra aportación pretende incidir en este aspecto particular sin olvidar, desde luego, algunas otras cuestiones relevantes (como las trazas de estas iniciativas, etc.). Las referencias al sector de la distribución son, pues, seminales para apuntalar este estudio, ya que fuera de este ámbito no se producen tales sinergias. Resultará esencial, por tanto, tal como propone Ruíz, enmarcar las actividades que aquí se describen en el contexto de una lectura indefectiblemente ligada a la función social e ideológica que desempeñan en paralelo a la evolución social (Ruíz Muñoz, 2012).

Como decíamos más arriba, la génesis de los cines cooperativos puede ser abordada desde diversas perspectivas y desde el análisis de muy diversos factores, pero para profundizar en el funcionamiento de estos grupos es necesario en primer lugar realizar un trabajo de campo que permita contrastar las escasas fuentes bibliográficas sobre el particular y complementarlas, en su caso. Esta tarea no puede ser obviada en un trabajo de estas características puesto que lo que nos interesa es estudiar las innovaciones que estos grupos aportan al ámbito de la autogestión y la producción cultural, y no hay otra manera de hacerlo que no sea a través del contacto directo con la gestión cotidiana de dichas asociaciones. 
Por ello, para el trabajo de campo se ha accedido a fuentes documentales de un modo directo al contactar con las cooperativas que forman parte de la muestra (asociaciones abiertas y documentos públicos) y entrar en los mailings de las listas de información de los socios. Dossieres de prensa, actas de las asambleas, estatutos de las asociaciones y demás documentos internos han sido la fuente principal en este ámbito específico. Aún así, cabe señalar que la propia esencia horizontal, pública y transparente de dichas cooperativas garantiza un acceso a las fuentes sin ninguna restricción ya que las asambleas son públicas, transcritas y enviadas a los socios, así como las cuentas. De otra parte, el escrutinio de la actividad de estos movimientos asociativos se ha realizado a través de entrevistas electrónicas a determinados socios y miembros de las juntas directivas, lo que a efectos metodológicos supone un contraste con las herramientas analíticas precedentes, no obstante, el acceso al trabajo interno de estos grupos no es posible, ni deseable, de otro modo. Además, los distintos acercamientos hacen aflorar en el texto cuestiones diversas, complementarias, cuya consideración individual resultaría incompleta, ligeramente descontextualizada.

Precisamente, a la hora de determinar nuestras hipótesis de trabajo hemos tratado de acotar el objeto de estudio desde dos planteamientos y enunciados básicos: en primer lugar, los Cines ciudadanos no pueden ser entendidos sin comprender la trayectoria y alcance del movimiento cineclubístico en España, porque son, entre otras cosas, la actualización del papel que aquellos desempeñaron anteriormente; en segundo lugar, la gestación de las experiencias actuales a partir de los modelos organizativos promovidos desde los movimientos sociales Occupy o el 15-M ha abierto espacios a un tipo de manifestación cultural que se encontraba al margen de las pantallas, recuperando el papel protagonista y proactivo de la sociedad civil.

\section{RESULTADOS Y DISCUSIÓN: PLATAFORMAS COLABORATIVAS Y REDES DE CINES ASOCIATIVOS EN ESPAÑA}

Una aproximación a las experiencias de los cines ciudadanos no debe pasar por alto la enorme diversidad de planteamientos que lo impulsan, y la variedad de modelos con los que toma forma, para lo que debe tener muy presente que se trata de un fenómeno multiforme, cambiante, en permanente desarrollo (como un Work in Progress) que a pesar de iniciar muy recientemente su andadura en nuestro país, parece tener un largo recorrido por delante. Esta diversidad se manifiesta en diferentes maneras de hacer, modos de organización alternativos, composiciones y dimensiones distintas de los grupos, hasta en la propia naturaleza de las asociaciones que lo promueven y de las iniciativas que implementan. 
Así, para establecer un marco que escape a las particularidades de cada experiencia (que más adelante trataremos específicamente), podemos identificar determinados factores que han condicionado de un modo global la existencia de tales experiencias, que han servido de estímulo o allanado el terreno para la emergencia de un movimiento de tales características.

Como primer punto de atención cabe señalar el resultado devastador de la crisis económica de 2008 y sus efectos "colaterales" en el sector audiovisual, particularmente en España. Las consecuencias de la caída en 2007 de Lehmann Brothers, la banca de inversión más importante -y más endeudada- del mundo, desencadenan una crisis financiera internacional cuyas dimensiones no tienen precedente en la historia. Las repercusiones se extienden por todo el planeta vertiginosamente, hasta el punto de generar el colapso de varias economías nacionales (algunas de la zona euro: Islandia, Irlanda, Grecia) en pocas semanas. En nuestras fronteras el impacto es también inmediato, pero sobre todo, radical. De los fastos del sector de la construcción y los créditos fáciles, a las más pura ruina a través de un rescate financiero para un sector bancario endeudado y esquilmado por sus responsables. Reforma laboral, servicios sociales suspendidos, sanidad y educación decapitadas, hundimiento del consumo, empresas cerradas, todo ello casi de la noche a la mañana. En un país inundado de servicios, apenas quedaron comercios abiertos.

Por supuesto, el sector cinematográfico no es ajeno a este proceso de desintegración económica y vive, por añadidura, sus propios desafíos internos para adaptar su modelo de negocio a la demanda digital. Como se desprende de los datos del informe del ICAAV, en el año 2014 todavía se identifica un parque del 20\% de las salas de cine que están pendientes de adaptar sus equipos a la proyección digital, con el gasto que esa operación supone, mientras el descenso de los espectadores es manifiesto (el aumento del IVA al 21\% impuesto por el gobierno del PP es la puntilla definitiva) y se intenta paliar ese descenso de recaudación y afluencia con actividades como la "Fiesta del cine" (con pases entre semana a precios reducidos). Los exhibidores ven mermar sus ingresos rápidamente al tiempo que deben afrontar los gastos de la digitalización de sus salas, situación que desemboca en innumerables casos en una estrepitosa quiebra de las empresa y un cierre inmediato de las salas. De las doscientas salas que llega a ofrecer la cadena Renoir en toda España, apenas resisten cuatro en las zonas urbanas de mayor población. Esas cifras se disparan en el caso de los cines de tamaños reducido, el cierre de salas se precipita en cadena, sin que los propietarios puedan emprender acciones para evitarlo (ICAAV, 2014). El sector sufre un impacto arrollador, desprotegido, se va disgregando hasta prácticamente desaparecer (un ejemplo extremo lo encontraríamos en el caso de ciudades 
medianas como Pontevedra, Tarragona o Jaén - de más de cien mil habitantesque se quedan en apenas unos años sin puntos de exhibición cinematográfica).

Tampoco la sociedad civil es ajena a tamaña convulsión económica, de hecho es la clase trabajadora la que más sufre los efectos perniciosos de la crisis, por cuanto repercute despiadadamente en aquellos sectores de población más expuestos a las desigualdades. La situación que arrastra el país se torna insostenible para una parte de la población que, harta de conformarse con el statu quo, se organiza independiente y colectivamente para reclamar abiertamente una sociedad más justa, menos corrupta, cuyas prioridades se encuentren al servicio de los ciudadanos. A raíz de la publicación en mayo de 2010 del ensayo ¡Indignaos!, de Stephan Hessel, se va fraguando una corriente de opinión política -sobre todo en Europa, pero también en EEUU- en torno al concepto de Ciudadanos Indignados que canaliza gran parte del malestar de la sociedad civil por la situación económico-política. El 15 de Marzo de 2011, lo que empieza siendo una acampada espontánea de medio centenar de personas en la Plaza del Sol de la ciudad de Madrid, se va extendiendo por el país hasta convertirse en un movimiento social de dimensión internacional conocido como Movimiento de los Indignados. El aliento de la convocatoria, promovida desde la plataforma ¡Democracia Real YA! ${ }^{1}$ y simultánea a las revueltas sociales agrupadas bajo la etiqueta de Primavera árabe (2010-2013), cruza el atlántico y contagia la emergencia de movimientos similares de trascendencia global como Occupy Wall Street (a raíz de la ocupación del Zukotti Park en la ciudad de Nueva York, EEUU). No parece haber dudas acerca de las líneas programáticas que son comunes a estas protestas (Giménez, 2011, p. 12)., pero en el caso del 15-M en España el orden de las exigencias revela el grado de hartazgo de la sociedad española, zarandeada por una crisis catastrófica amplificada por unos gestores incapaces e indecentes Reivindicaciones como la supresión de los privilegios de la clase política, la reforma de las leyes electorales, las medidas reales contra la corrupción, la educación pública, la mejora de las condiciones laborales, la regulación de la banca y el sistema financiero o la instauración de sistemas de democracia directa condensan el espíritu de estos grupos y ponen de manifiesto el potencial de una sociedad civil organizada para liderar un cambio político que la tenga en consideración.

El papel que desempeñan las redes sociales en el impacto de estas mutaciones es, sin duda, el primer desencadenante de las transformaciones sociales

${ }^{1}$ La información generada por el propio grupo sobre la génesis y el rol de esta plataforma en la configuración inicial del movimiento 15-M puede ampliarse en: http://www.demo craciarealya.es/ 
que acarrean. El concepto de red social como conjunto organizado de ciudadanos en el que se integran las personas y las conexiones entre ellas (Christakis, 2010, p. 27), ha vivido un desarrollo exponencial paralelo al de las TIC que ha transformado, ampliándolo, su espectro de aplicación. Como sostiene Piñero-Otero (2012), estas redes, dinamizadas por relaciones no mediadas tecnológicamente entre sujetos proactivos (generalmente procedentes de espacios de reivindicación tradicionales), se han convertido en el principal espacio de discusión de los movimientos sociales, culturales, vecinales, o políticos que han empleado la web 2.0 como herramienta de suma relevancia para la movilización social, llegando a constituir el principal medio de los actores sociales para actuar, informar, organizar o dominar (Castells, 2001, p. 66).

De alguna manera, todos estos factores combinados generan un contexto específico muy concreto, por esa razón, limitamos nuestro estudio al caso español, en el que se conjugan por un lado, los vacíos del ámbito de la exhibición cinematográfica, con la creciente movilización social alentada por una cada vez más nutrida red de ciudadanos organizados colectivamente. La exhibición fílmica se ha convertido en estos últimos años en uno de los puntales de la industria que más necesita actualizar su modelo para evitar ser desplazado por los nuevos patrones de consumo nacientes, atomizados, deslocalizados, bajo demanda, móviles, ubicuos. Lo que la industria consideraba su principal amenaza, el negocio de la piratería, ha resultado una anécdota en comparación con el desafío que supone la adaptación a estos nuevos consumos. El reto es, hoy, adaptarse a las tendencias de un sector que ya no dirige sus esfuerzos a la captación de nuevos espectadores, sino que trata de facilitar el retorno y fidelización de los ya existentes a través de la diversificación de la oferta, ya no importa tanto qué consumimos, sino las dinámicas que pautan nuestro consumo audiovisual.

El cierre de las salas y la paralización de la exhibición en muchas ciudades parecía presagiar un panorama repleto de salas multiplex en grandes centros comerciales y poco más, pero poco a poco los antiguos espectadores se agrupan y comienzan a organizarse para abrir cines en diferentes ciudades españolas. Las iniciativas son colectivas, pero también individuales, cooperativas y empresariales (de pequeñas dimensiones), de este modo, la cinefilia y la militancia socio-política se ligan para iniciar un camino nuevo, es el momento de cristalización de los diferentes proyectos de cines ciudadanos. Aunque trataremos los casos más relevantes individualmente, cabe señalar, como pionero en la puesta en marcha de una iniciativa ciudadana paradigmática, la trascendencia del proyecto CineCiutat en la definición y posterior desarrollo del modelo asociativo al hacerse cargo a través de una asociación de vecinos de la gestión de los cines Renoir en Palma de Mallorca. 
A esta experiencia autogestionaria inicial se sumarán otras casi inmediatamente, como la propia creación de la asociación Xarxa Cinema para la administración de los Renoir de Palma, los Cines Zoco de Majadahonda en Madrid (también antiguos Renoir), el cine Groucho de Santander, la cooperativa Númax en Santiago de Compostela, la cooperativa Aragó Cinemas en Valencia, el Cine Aranda en Burgos y otros proyectos complementarios de salas independientes arthouse, como Zumzeig en Barcelona, Pathé en Sevilla. Su unión, a través CineArte, la Red de Cines Independientes para la cultura y el arte, se configura como un elemento esencial en el desarrollo, puesta en marcha y federación de las iniciativas, así como en la cristalización definitiva de un movimiento aglutinado en torno a ella que se va consolidando poco a poco en algunos puntos del país.

Todas ellas comparten determinados elementos comunes. Para luchar contra los gigantes de la exhibición buscan ofrecer un producto diferente (Versión Original, Cine de autor, independiente, programaciones de festivales, películas no estrenadas en cicuitos comerciales, etc.) y que la sala desborde su actual concepción, limitada al entretenimiento de masas, para convertirse en un espacio cultural abierto a otro tipo de actividades relacionadas más o menos directamente con el cine: talleres, encuentros con autores, profesionales, presentaciones literarias, en definitiva, como un espacio común en que la sociedad civil establezca la programación sin restricciones. Además, pretenden crear un espacio colectivo más estable donde las agrupaciones puedan desarrollar su vocación pedagógica y dinamizadora a partir de la organización de actividades complementarias que contribuyan a un cierto grado de alfabetización audiovisual del público asistente.

La financiación es su principal escollo, por lo que las estrategias para dotar de fondos a los proyectos utilizan herramientas diversas como el crowfunding, las participaciones de empresas locales y aportaciones voluntarias de socios que permiten hacer viables las iniciativas. En este aspecto, cabe destacar la importancia vertebradora de Coop 57, la cooperativa de servicios financieros creada por los extrabajores de la editorial Bruguera tras la suspensión de pagos de la empresa, cuyos servicios de asesoría y concesión de préstamos han permitido a las asociaciones evitar la dependencia de los bancos. La organización, que no se presenta como una cooperativa de crédito ya que distingue entre personas físicas y jurídicas a la hora de conceder sus servicios, se concibe como una herramienta al servicio de proyectos enmarcados en la economía social, estructurada en torno a una red de aproximadamente 300 entidades de apoyo al emprendedurismo ético y solidario. Tras una evaluación de la viabilidad de los distintos proyectos en función de una serie de consideraciones como el 
interés social, la vinculación con el territorio, los mecanismos de gestión democrática, la solvencia económica y la naturaleza no lucrativa de las asociaciones, Coop57 admite las solicitudes para financiar parcialmente sus iniciativas. La existencia de esta cooperativa, a la que pertenecen una gran parte de los cines ciudadanos, ha consolidado los mecanismos de supervivencia y viabilidad económica de sus respectivos espacios, asumiendo como propios los planteamientos culturales de esta transformada sociedad civil.

La iniciativa pionera en España, como hemos señalado más arriba, es la de CineCiutat ${ }^{2}$, en Palma de Mallorca, que arranca en solitario en el año 2012 en un panorama absolutamente desalentador y se convierte poco a poco en el referente de los demás proyectos, inspirados por el alcance y potencial de esta experiencia inicial. Su configuración, estructura, financiación, programación y modelo organizativo son el paradigma esencial para casi todos los proyectos que se inician después. La idea surge entre un muy reducido grupo de cinéfilos cuando en mayo de ese año la sala Renoir de Palma se ve abocada al cierre por la suspensión de pagos de la empresa que gestiona esos cines en toda España. La decisión inicial de mantener el cine abierto de forma que las salas de versión original no desaparecieran de las islas baleares, se lleva a cabo a través de la campaña Salvem els Renoir y la posterior creación de la asociación Xarxa $\mathrm{Cinema}^{3}$, que asume las diferentes gestiones para mantener el cine en funcionamiento y garantiza la continuidad de un proyecto incierto en sus primeros pasos.

El proyecto se hace posible gracias a la acción de los ciudadanos, pero también cuenta con la complicidad de los propietarios de los locales (que rebajan el alquiler un 30\%) y la antigua propietaria del complejo, Alta Films, que acabará donando el material técnico de proyección a la asociación, con lo que el impulso financiero inicial se hace mucho más liviano, manejable para las exiguos ingresos del grupo. Es la primera vez que un equipo de personas amantes del cine consiguen poner en marcha un proyecto común para salvaguardar una oferta cultural en vías de extinción y la culminación de esta fase inicial se celebra con la apertura efectiva de los cines, el 13 de Julio de 2012, con el apoyo de profesionales del cine como Rossy de Palma, Agustí Villaronga o Toni Bestard.

Se trata, obviamente, de una organización sin ánimo de lucro, cuyos ingresos provienen exclusivamente de las cuotas de los socios -casi 3000 actual-

\footnotetext{
${ }^{2}$ La documentación original sobre la génesis y el desarrollo posterior del proyecto se puede encontrar en: http://cineciutat.org/es/

${ }^{3}$ Los estatutos de la asociación describen otros aspectos de la organización y dinámicas internas de la red de cines que se pueden consultar en: http://cineciutat.org/es/xarxacinemal
} 


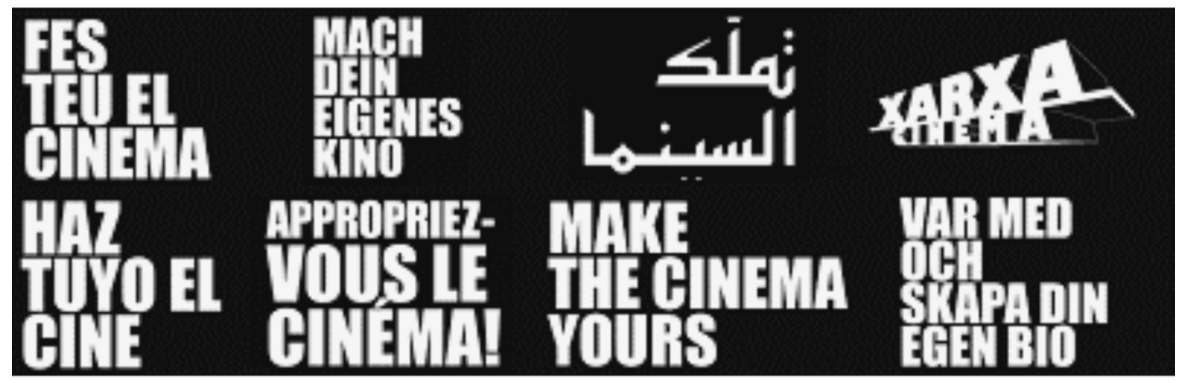

Figura 1: cartel de la campaña Fes teu el cinema (Xarxa Cinema)

mente- y abonados que, mediante el pago de una mensualidad, adquieren una serie de derechos y se convierten en copropietarios de un cine independiente, alejado de intereses comerciales o institucionales. El sistema de funcionamiento y organización -sustentado por las tecnologías digitales 2.0- se basa en la horizontalidad y la participación democrática, con una total implicación de los socios en la gestión cotidiana de los cines, con figuras como el abonado o el voluntario que recuperan la implicación de la base como modelo organizativo colectivo por medio de campañas de concienciación social como por ejemplo Fes teu el cinema (ver figura 1).

La asamblea general y la autogestión son los pilares básicos de su concepción de la participación y la acción social, pero su estructura tiene capacidad para albergar un equipo de 5 personas cuyo trabajo para la asociación está debidamente retribuido por considerarse de dedicación exclusiva y necesario para un correcto funcionamiento: gerente, proyeccionista, taquillera, acomodador y encargado del palomitón. La existencia de una junta directiva, jerárquica en sus decisiones respecto al socio, no implica verticalidad ya que está compuesta por 10 miembros elegidos por la Asamblea y representantes de las Comisiones de trabajo (compuestas por socios y voluntarios). El resto de la gestión se realiza mediante estas comisiones de trabajo conformadas por voluntarios (Programación, Filmoteca, Actividades Educativas, Comunicación, Traducción, Nuevas Tecnologías, Sostenibilidad Económica, Difusión, Eventos, CinèFilms, Laboratorio de Ideas, etc.), cuya labor constituye la actividad troncal de la asociación y el núcleo del trabajo creativo que desarrollan.

Por su parte, la Asamblea general, convocada cada tres meses, es el órgano al que se someten todas las decisiones importantes del proyecto y tiene capacidad para enmendar, ratificar o desestimar las distintas iniciativas, garantizando así que el control efectivo de la asociación recaiga, en última instancia, sobre los propios socios. No obstante, los entresijos de la administración de un sala de 
cine son mucho más complejos y han requerido de una enorme dosis de imaginación a la hora de acometer algunos de los desafíos principales a los que se enfrentan como colectivo dedicado a la gestión cultural cinematográfica. Como parte del sector, aunque situado en la periferia de un negocio basado en las grandes producciones, CineCiutat se ve inmerso de lleno en la problemática de la digitalización que sufren los cines de tamaño reducido. Para abordar tal proceso, precipitado por la falta de circulación en el mercado de la distribución de copias para proyección en $35 \mathrm{~mm}$., un grupo minoritario de 12 socios decide aportar capital para la inversión necesaria y por medio de la creación de la sociedad limitada "Digital i Tal", con aportaciones de entre 500 y 2500 euros, se procede a la compra de dos proyectores digitales con el objetivo de renovar el equipamiento de dos salas pequeñas.

De otro lado, a pesar de la situación de monopolio territorial que ejercen las distribuidoras en España -que se ven obligadas a excluir a operadores atípicos de sus carteras de clientes para evitar la pérdida de su cuota con los grandes exhibidores- el proyecto ha contado con el apoyo de aquellas que gestionan el tipo de cine que programan en sus salas. A medida que las carteleras han reflejado la presencia de estos nuevos espacios, las distribuidoras han comenzado a abrir su catálogos y a distribuir sus films de manera regular en estas pantallas, sumando clientes por pequeños que fueran.

La programación de la sala oscila entre repertorios de cine en versión original subtitulada, con un interés especial por el cine europeo, las cinematografías emergentes en las que se engloba tanto el cine español contemporáneo, como cine catalán en la lengua propia de las islas baleares, películas autoproducidas o autofinanaciadas, etc. Estas películas sirven, precisamente, de punto de conexión entre las distintas actividades, como debates o presentaciones de autores cinematográficos, expertos, etc. de tal modo que la sala acaba convertida en un espacio cultural abierto, vivo, en el que la efervescencia creativa se retroalimenta para dinamizar la vida cultural de la ciudad (tal como ocurría en la década de los 70 con los cineclubs). Y este es un aspecto fundamental de este proyecto, su capacidad para establecer conexiones con todo tipo de entidades y organizaciones (Filmoteca, Universidad, Ayuntamiento y otras) que sustenten la red que, a su vez, multiplica las posibilidades de éxito de las diferentes iniciativas.

Entre estas actividades y convenios cabe destacar aquel que alimenta la sección "CinèFilms", cuya programación consiste en proyecciones de films importantes de la historia del cine presentados en directo por algún experto para generar un debate posterior entre los asistentes. También los ciclos organiza- 
dos por el "Arxiu del So i la Imatge" que incluyen cine internacional rodado en Mallorca, cine experimental o producciones singulares en colaboración con el área de cultura del ayuntamiento de Palma. O, por último, la presentación y asistencia de directores consagrados que los socios tienen oportunidad de conocer de cerca a partir de las sesiones exclusivas que se programan en estos espacios con la participación de Jaime Rosales, David Trueba, Ventura Pons, Kike Maíllo, Javier Rebollo o Patricio Guzmán, entre otros.

El carácter que la asociación Xarxa Cinema ha impreso a su proyecto CineCiutat ha condicionado el posterior desarrollo de iniciativas similares en otros puntos de nuestra geografía, respondiendo a la crisis con un modelo de gestión que no depende del estado ni del mercado, sino de la voluntad de los ciudadanos organizados por preservar espacios culturales como las salas de cine. Su influencia en la gestación de este movimiento es fundamental, pero su papel asesor y su función como punto de encuentro de iniciativas similares todavía lo es más, dado que a partir de sus consejos y experiencias otras muchas asociaciones han logrado convertirse en realidad. CineCiutat es, en definitiva, la semilla de la que germinan los cines ciudadanos en España.

Sin embargo, existen otros proyectos como los cines Zoco de Majadahonda que, a pesar de estar profundamente influenciados por el modelo de CineCiutat, tiene sus propias particularidades. Es el caso de los cines Zoco, emblemáticas salas de exhibición madrileñas fundadas en 1979 que programan cuidadosamente películas en versión original y cine independiente hasta que se precipita su cierre en 2012 por quiebra de la empresa propietaria Renoir, asediada por los problemas que hemos descrito anteriormente y que, por otra parte, afectan a la totalidad del sector de la exhibición. Ante la falta de cines en la localidad un grupo de vecinos crea una asociación para gestionarlos y se establece el contacto con CineCiutat, que impulsa considerablemente la iniciativa. En líneas generales, como en el caso anterior, sus propuestas básicas se condensan en la creación de una asociación sin ánimo de lucro, "Cines Zoco Majadahonda", dedicada a promover el cine en el panorama cultural de la zona noroeste de Madrid a partir de la puesta en marcha de una sala de los ciudadanos para los ciudadanos, financiada por las aportaciones de los socios (algunos de ellos ilustres, como David Trueba, Juan Diego o Carlos Iglesias) libre de intereses comerciales y que permita mantener en su puesto laboral a los siete empleados del cine. Desde estas premisas iniciales, compartidas con su antecesor, se pretende hacer del espectador un elemento activo del acto cinematográfico, reforzando las herramientas de empoderamiento de la sociedad civil a través de una cultura autogestionaria y participativa. 
Su política de programación es sensiblemente distinta de la de CineCiutat, pese a que la estructura organizativa se asemeja bastante, lo cual le provee de un carácter singular, específico, con una visión particular de la programación que, aunque coincidente en los aspectos generales con las de la experiencia mallorquina, despliega su propia personalidad. Las cuatro salas de las que disponen los cines Zoco distribuyen su programación en torno a una oferta organizada en varios ámbitos diferentes, pero complementarios. En la sala 1, de casi 200 butacas, se proyectan películas de estreno, tanto de cine independiente como de cine comercial, como de cine español, que incluyen films de muy diverso carácter, desde el más familiar, hasta el más innovador, en V.O y versión doblada. En la sala 2, de casi 170 butacas, estrenos recientes -como los tradicionales cines de reestreno- con películas de menor impacto. Éste es un aspecto destacable de la oferta de los Zoco, por cuanto demuestra el grado de adaptación de la propuesta a su contexto específico, programando un cine que pudiera atraer público externo a la asociación y de ese modo reforzar la financiación de la organización a través del aumento de la recaudación en taquilla. Como estrategia supone un intento de convergencia de públicos diferentes que busca extender el radio de acción de la iniciativa aunando proyecciones minoritarias con otras capaces de convocar a un mayor de espectadores, de gusto diverso. En las salas 3 y 4, ambas de 55 plazas, se programa el "Cineclub" con películas clásicas, documentales, ciclos temáticos, retrospectivas de directores y sesiones con presencia de invitados para fomentar el encuentro y debate con los espectadores.

También cabe destacar la vocación pedagógica de la iniciativa que oferta un abanico de cursos, talleres, seminarios, debates y conferencias organizadas para el intercambio de conocimiento, el aprendizaje y la reflexión sobre muy distintos aspectos del hecho fílmico en su conjunto, con lo que se sitúa como un agente cultural destacado de la ciudad. Zoco Majadahonda, como proyecto continuador de la labor iniciada por cineCiutat en Mallorca, se abre hueco en la oferta cultural de una capital como Madrid construyendo con su propia idiosincrasia un espacio alternativo de consumo crítico.

El proceso de gestación ha sido prácticamente similar en otras iniciativas ubicadas en diferentes lugares de España: la Asociación Amigos de Groucho en Santander, la cooperativa Aragó Cinemas en Valencia, CineBaix en Sant Feliu de Llobregat, cada una de ellas con sus vicisitudes, sus propias problemáticas y modelos particulares. No podemos, por limitaciones de objeto y espacio, analizar cada iniciativa por separado, pero es necesario hacer referencia por último a la cooperativa Númax en Santiago de Compostela, por su relevancia, su marcado carácter experimental y su vocación innovadora. 
Tal como la propia cooperativa argumenta ${ }^{4}$, Númax nace como un proyecto de autoempleo de sus socios fundadores para crear un espacio que pretende favorecer la confrontación de ideas, el encuentro y el debate mediante la prestación de servicios y productos culturales, artísticos y educativos. La base del proyecto se configura entorno a una sala independiente con proyecciones diarias en V.O., la única en Galicia, en el difícil contexto de desaparición de los espacios de exhibición, pero además su propuesta se desdobla en un proyecto de librería y un laboratorio de ideas que completan el marco de la iniciativa. En esta línea específica, enlaza la tradición de los cines de Arte y Ensayo con los nuevos cines de investigación y vanguardia (Recherche et découverte), como ocurre actualmente en aquellos modelos de sala que tratan de combinar la innovación activa en las prácticas cinematográficas con la experimentación en las prácticas culturales (entre sus principales referentes se encuentran proyectos como el Anthology Film Archives de Nueva York, el Cine Tonalá de Mexico D.F., o la sala Zumzeig de Barcelona).

$\mathrm{Su}$ original propuesta, a medio camino entre la gestión cultural y la intervención social, viene acompañada de un proyecto sólido, de amplio alcance, que define con claridad sus objetivos en un marco de escasa competitividad (lo que le diferencia del caso de Zoco Majadahonda). Ese hecho, considerado aisladamente, no sería relevante si no tuviéramos en cuenta una cierta dimensión investigadora que caracteriza la iniciativa de Númax, pero si nos atenemos a las dimensiones de uno y otro proyecto, comprendemos inmediatamente que, precisamente, ese desierto de la exhibición que es Santiago es el que genera un modelo de cooperativa ajustado a su medida y expectativas. Por ello, el cine Númax se presenta como un lugar de encuentro y un espacio de referencia en el que una nueva generación de creadores y espectadores críticos puedan compartir sus trabajos, generando vectores de confluencia, de reflexión y acción cultural independiente en un contexto desolador.

Su dimensión pedagógica, pues, se concreta sobre todo en la organización de talleres formativos impartidos por realizadores profesionales sobre diferentes aspectos de su trabajo, con seminarios y presentaciones orientadas al publico joven, considerado como uno de los pilares del éxito y continuidad del proyecto. Pero también desempeña un papel fundamental en este aspecto la librería de la cooperativa, especializada en Literatura, Arte y Pensamiento, con un fondo inicial de más de 3000 volúmenes que contiene novedades y libros clásicos entre los que se establece un diálogo o una relación nueva. Se organizan

\footnotetext{
${ }^{4}$ Los inicios, características y programación del proyecto están disponibles en una muy atractiva e intuitiva web: https://numax.org/
} 
recorridos literarios que acompañan las proyecciones programadas de modo que se refuerza el vínculo entre disciplinas, al tiempo que se incide en el rol de mediador cultural de la asociación. La tercera pieza del proyecto es el Laboratorio de ideas, un estudio de diseño gráfico, comunicación y producción audiovisual que distingue esta iniciativa en el panorama de los cines ciudadanos, al sumergirse de pleno en la producción de contenidos audiovisuales, la edición y la formación especializada en el campo de la imagen. Su proyecto particular integra elementos diversos bajo un concepto innovador de la actividad cultural autogestionada, respaldado por los socios y con un elevado grado de implicación del tejido social y la comunidad, pero al mismo tiempo la confluencia de voluntades en torno al fenómeno genera las sinergias necesarias para que se concrete una iniciativa de autoempleo, cooperativa, en contacto permanente con la sociedad en la que se desarrolla e implementa.

\section{CONCLUSIONES: HACIA UN NUEVO ESPACIO DE INTERVENCIÓN CULTURAL CIUDADANA}

A pesar de que este estudio no agota la investigación sobre las prácticas de cine asociativo o ciudadano, puesto que se concibe como una aproximación introductoria centrada en la contextualización y la génesis de dicho movimiento, hemos podido establecer una serie de conclusiones generales susceptibles de ampliación en futuras aproximaciones a este objeto específico. A raíz de lo que hemos podido verificar realizando el análisis de los distintos aspectos del fenómeno y el planteamiento de nuestras hipótesis, nos encontramos en situación de afirmar que en la actualidad, a partir de la organización de cierto número de personas en redes y cooperativas culturales, el cine ciudadano cobra forma a través de estrategias inspiradas en la acción política ciudadana, inspiradas en las de la guerrilla de la cultura, recuperando salas de exhibición cinematográfica en quiebra o reflotando aquellas que han quedado estancadas tras la devastadora crisis económica. Su radio de acción se circunscribe al ámbito urbano mayoritariamente, espacio en el que, lógicamente, las redes de ciudadanos pueden ser más amplias y la singular oferta de sus salas tiene más potenciales espectadores interesados en este tipo minoritario de cine.

Estos particulares focos de resistencia cultural han generado ciertos espacios en la periferia de la industria cinematográfica, gestionados directamente por los socios, capaces de aunar la voluntad rescatar películas que no podrían tener distribución comercial y quedarían sin proyectar en el cajón de alguna distribuidora residual, con la movilización social, el pensamiento crítico y la acción cooperativa en pos de una cultura más libre de ataduras económicas, participativa, producida, gestionada y consumida al margen del dictat de las 
Industrias Culturales. Se trata, en definitiva, de un movimiento de base cultural con una clara inspiración horizontal derivada de las experiencias políticas de los recientes movimientos sociales como el 15-M, que ha canalizado su actividad a través del ámbito específico de la exhibición cinematográfica cooperativa. Como tal, concentra sus energías en componer y apuntalar un movimiento asociativo cuya función primordial es promover el agrupamiento de las salas de exhibición ciudadanas y arthouse, impulsando modos emergentes de gestión asociativa civil que contribuyan, desde dentro, a la reconstrucción del tejido productivo del cine en España.

Por naturaleza, los espacios reorganizados por estos colectivos se configuran como una alternativa real (hoy ya funcionan con normalidad en numerosas ciudades españolas) a las censuras que impone la distribución comercial cinematográfica y sirven como motor de iniciativas socio-culturales en un ámbito recuperado por los ciudadanos, que se construye con su propio esfuerzo e ideario, poniendo el foco precisamente sobre aquellas cuestiones que les afectan y por las que se sienten motivados a movilizarse.

De ello podemos deducir que la crisis de las salas comerciales de exhibición no es causa directa de la falta de espectadores, sino que proviene más bien del agotamiento de un modelo de negocio que se resiste al cambio retrasando su adaptación a los nuevos escenarios de consumo audiovisual. La evolución en la gestión de la demanda está generando espectadores más conscientes de lo que quieren ver y de su papel generador de actividad cultural en un mundo global, en el que dada la falta de disponibilidad de espacio en las carteleras para cinematografías que se alejen de las propuestas mainstream, las salas especializadas como las que se proponen desde los cines ciudadanos tienen un papel muy importante que desempeñar, así como un enorme vacío que cubrir.

\section{REFERENCIAS BIBLIOGRÁFICAS}

Augros, J. (2000) El dinero de Hollywood. Financiación, producción, distribución y nuevos mercados. Barcelona: Paidós Ibérica

Arnau, R. (2006) La Guerrilla del celuloide: resistencia estética y militancia politica en el cine español (1967-1981). Tesis doctoral. Castellón: TDX

Bagdikian, B.H. (2004) The New Media Monopoly. Boston: Bacon press.

Castells, M. (2001) La galaxia Internet. Reflexiones sobre Internet, empresa y sociedad. Madrid: Areté.

Christakis, N. A., Fowler, J. H. (2010) Conectados. Madrid: Taurus.

Giménez, I., Taibo, C., Antentas, J.M., Vivas, E., Mateo, J.P., Domènech, A. y Monedero, J.C. (2011). La rebelión de los indignados. Madrid: Editorial Popular. Gomery, D. (1991) Hollywood: el sistema de estudios. Madrid: Verdoux. 
Izquierdo, J. (2010) El cine digital. La distribución y exhibición españolas ante el reto tecnológico. Madrid: Ediciones de las Ciencias Sociales.

ICAAV (2014) El cine y el video en datos y cifras. Madrid: MECD [disponible en línea en: http://www.mecd.gob.es/cultura-mecd/areas-cultura/cine/mc/cdc/ano-2014.html]

OCDE (1996) Competition Policy and Film distribution. Paris: Organisation for Economic Co-operation and Developement.

Pardo, A. y Sánchez-Tabernero, A. (2012) "Concentración de la distribución cinematográfica en España". Anàlisi, 47, 37-56.

Piñeiro-Otero, T., Costa, C. (2012) «Ciberactivismo y redes sociales. El uso de Facebook por uno de los colectivos impulsores de la 'spanish revolution', Democracia Real Ya (DRY)». Observatorio (OBS*), 6 (3), 89-104.

Ruiz Muñoz, M. J. (2012) "El cine alternativo como instrumento de cambio durante la transición española. Función política, social y cultural de los cineclubs y los festivales", Razón y Palabra, vol.17, nº 80.

Sánchez Ruiz, A. (2007) "Industrias culturales, diversidad y pluralismo", Global Media Journal, 7, 25-47.

Wasco, J. (2003) How Hollywood Works. London: SAGE.

ROBERTO ARNAU ROSELLÓ es licenciado en Comunicación Audiovisual por la Universidad de Valencia (1997) y Doctor por la Universidad Jaume I de Castellón (2006). Ha impartido clases en el Instituto Universitario de Tecnología de la Universidad de Franche Comté (Besançon, Francia) donde ha llevado a cabo proyectos tecnológicos, tareas docentes y de investigación. Actualmente es profesor de la Universitat Jaume I en los grados de Comunicación Audiovisual y Periodismo, así como en el Master Universitario en Nuevas Tendencias y Procesos de Innovación en Comunicación. Director del Laboratorio de Ciencias de la comunicación (LABCOM) de 2008 a 2016, su actividad se ha desarrollado tanto en el terreno de la investigación, como en de la gestión, como en el del ejercicio profesional en el sector audiovisual (como guionista, realizador, productor, director de fotografía o ayudante de dirección). Investigador en el grupo de investigación ITACA-UJI (Investigación en tecnologías aplicadas a la comunicación audiovisual). Entre sus publicaciones se cuentan numerosos capítulos de libro y comunicaciones en congresos internacionales, así como artículos en revistas científicas como Estudios sobre el mensaje periodístico, Fotocinema, Historia y Comunicación social, ICONO 14, o Comunicación y Medios.

Recibido: 30/01/2016

Aceptado: 29/11/2016 



\title{
¿LA DEMOCRACIA ES UN SISTEMA DEPENDIENTE DE VALORES COMO EL CONFORMISMO Y LA OBEDIENCIA? UN ESTUDIO COMPARADO SOBRE LAS VALORACIONES QUE JÓVENES Y ADULTOS ESPAÑOLES HACEN DE LA DEMOCRACIA \\ IS DEMOCRACY A DEPENDENT VALUE SUCH AS CONFORMITY AND OBEDIENCE? A COMPARATIVE STUDY ON THE ASSESTMENTS THAT YOUNG AND ADULT SPANISH DO OF DEMOCRACY
}

\author{
Liberto Carratalá Puertas \\ Universidad de Alicante, España \\ liberto.carratala@ua.es
}

\section{Cómo citar / Citation}

Carratalá Puertas, Liberto (2016). “ ¿La democracia es un sistema dependiente de valores como el conformismo y la obediencia? Un estudio comparado sobre las valoraciones que jóvenes y adultos españoles hacen de la democracia”. OBETS. Revista de Ciencias Sociales, 11(2): 441-460.

doi:10.14198/OBETS2016.11.2.03

\section{Resumen}

Las investigaciones sobre la calidad de la democracia y la valoración que la ciudadanía realiza de ella han girado en torno a la influencia que el sistema económico o el político ejerce sobre las dimensiones que la componen. Los resultados han tenido un alcance explicativo limitado. Para superar este déficit se propone llevar a cabo un análisis de la cuestión desde una perspectiva que articule el nivel macro, la estructura política y económica, y micro, la subjetividad de la ciudadanía. Este trabajo abre una línea de investigación alternativa y complementaria a las ya existentes, con el objetivo de comprender cómo los valores humanos influyen en la valoración de la experiencia democrática de los jóvenes y adultos españoles. Los resultados, derivados del análisis de los datos con la técnica de los modelos de ecuaciones estructurales (SEM), ponen de relieve la diferencia existente entre jóvenes y adultos en sus 
respectivas valoraciones de la democracia, aunque coinciden en que es insatisfactoria.

Palabras clave: Valores humanos, modelos estructurales, democracia, juventud, política, actitudes, dimensiones de la democracia, ciudadanía, gobierno, cambio social.

Abstract

The researches on democracy's quality and the assessment citizens make of it have usually turned around the influence of economic or political systems applied on its dimensions. The results have had a limited explanatory range. In order to get over this shortfall, the proposal is the analysis from a perspective that will articulate macro and micro levels. This work will open an alternative and complementary research line to existing ones with the aim to understand how human values have influence on the assessment of the democratic experience from young and adult Spanish people. The results derived from data analysed with Structural Equation Models (SEM) underline the difference between young's and adult's values of democracy even though they agree it is unsatisfying.

Keywords: Human values, structural modelling, politics, attitudes, democracy's dimensions, government.

\section{Extended abstract}

The researches on democracy's quality and the assessment citizens make of it have usually turned around the influence of economic or political systems applied on its dimensions. The results have had a limited explanatory range. In order to get over this shortfall, the proposal is the analysis from a perspective that will articulate macro and micro levels. This work will open an alternative and complementary research line to existing ones with the aim to understand how human values have influence on the assessment of the democratic experience from young and adult Spanish people. The results derived from data analysed with Structural Equation Models (SEM) underline the difference between young's and adult's values of democracy even though they agree it is unsatisfying.

The main purpose of this research is knowing how human values have influence in the assessment that Spanish citizens make of democracy just as it is. Will also be analysed the way these affect each dimension, factor or element in which the research of this type of political order may decompose. To this end, a comparative study between young and adult population will be carried out. In order to elaborate the research's theoretical framework, Shalom Schwartz's proposals will be used to place the research on human values; to address the micro perspective of society will use Leonardo Morlino's; and Ronald Inglehart's and Christian Welzel's will be used to analyse the macro perspective, centred on democracy, its dimensions and the articulation with the micro view.

Schwartz's structure of values allows us to delve into relationships between micro and macro levels of society's analysis. It therefore means an ideal tool to know which ones are closer to a type of political regime and which are far from it. In the same way, Ronald Inglehart (2006) contributes with an interes- 
ting and complementary view on the influence of values on democratization processes of societies.

Leonardo Morlino's theory (2009) offers an excellent logical framework for the research on democracy's quality. To him, a good democracy or a democracy of quality would be that of a stable institutional order that will, by means of a correctly working body and mechanism, realize and guarantee freedom and equality of citizens. For this author democracy is composed of three dimensions: Procedural, Substantive and Instrumental.

In our empirical approach, we have used a multivariant analysis method known as structural equations model (SEM). To build the structural models on the influence of human values on the assessment of democracy by young and adult Spaniards (figures 1 and 2) we have used data from European Social Survey Round 6 (ESS, 2012).

From the comparative of both models we fathom that youth considers the Substantive dimension democracy's most important, the one that defines, from a normative perspective, this political system that has in values Freedom and Equality its main elements. Nonetheless, adults consider that the most important in democracy is its procedural character, reflected in the vote and in an electoral system in which several political parties concur and compete. An aspect to keep in mind, taking as reference human values, is that the keenest among young and adult on Materialist values -in the sense given by Inglehart and Welzel (2006)- are the ones defining the hierarchy of the dimensional structure of democracy. Values Achievement and Conformity associate positively with democracy's Freedom and Equality for the young and with Procedural dimension for the adults. According to the set out hypothesis, the second relationship was anticipated but not the first one.

Another issue worth highlighting is the preponderance that Materialist values Achievement and Conformity have over Postmaterialist values conveyed by Self-direction, Stimulation and Universalism in the proposed models. Spain is a country with a significant level of social and economic development where, according to Inglehart's theory, Postmaterialist values should surpass as reflected in the study by Carratalá (2016). Therefore, models in which their weight is lesser attract the attention even in cases in which the difference between both value sets is not great.

In the light of the results, if the great objective of this govern system, as put by Leonardo Morlino (2009), is making Freedom and Equality for the citizens, it is not achieved in Spain. It is significant that in adult population's model Materialist values Conformity and Achievement are linked with the dimension of democracy with the greatest weight and hierarchy within the structure. Just the same as with youth's model, even though the predominant factors are different.

\section{INTRODUCCIÓN}

La tarea de estudiar la democracia es compleja, como casi todas las que ocupan a los científicos sociales cuando se proponen abordar cualquier tema desde una perspectiva empírica. Los indicadores para medir el apoyo y la satisfacción 
con la democracia que se han utilizado habitualmente-democracia como mejor sistema político y satisfacción con la forma en que funciona- se han comportado como herramientas que han dado un resultado parcial o indirecto sin saber bien qué aspectos de ésta tienen el apoyo o la valoración -positiva o negativade la ciudadanía (Levine y Molina, 2009; Gómez et al., 2010; Morlino, 2009a; Torcal et al. 2006).

Easton (1976) sentó las bases conceptuales para el estudio empírico de la democracia y ha sido el autor referente en la producción investigadora en este ámbito. A pesar de todo, los resultados obtenidos en las investigaciones basadas en sus criterios han sido limitados y orientados a las actuaciones de los políticos y los resultados conseguidos.

Otras investigaciones que han supuesto un referente en este ámbito de investigación, han sido las llevadas a cabo por Ringen (2007), abriendo una línea de trabajo basada en la cuestión «qué democracia es buena para». Este enfoque también arrojó resultados limitados porque concentraba las valoraciones de la ciudadanía en una sola dimensión, siendo insuficiente para analizar la calidad de un sistema democrático.

Sí se han realizado preguntas adecuadas en estudios empíricos sobre actitudes hacia la democracia en sociedades específicas. Podemos poner por caso las investigaciones en los países de América Latina (ver Ai Camp, 1998; Baviskar y Malone, 2004 o Lagos, 2005), en África (Bratton, Mattes y Gyimah-Boadi, 2005) y los realizados con la ex-URSS como sociedad de estudio (Reisinger, Miller y Hesli, 1995; Whitefield y Evans 1996).

Estos países tienen en común el hecho de cuentan con democracias con un bajo nivel de democratización o que se encuentran en periodo de transición. Sin embargo y, a pesar de sus virtudes, adolecen de capacidad comparativa.

Este trabajo pretende explorar nuevas líneas de investigación, en concreto, aquellas que ponen el acento en la articulación de los niveles de análisis macro y microsociológico. Dicho de otra forma, el principal objetivo de este estudio consiste en conocer cómo los valores humanos influyen en la evaluación que la ciudadanía de España hace de la democracia tal y como la conocen. También se analizará cómo éstos afectan a cada dimensión, factores o elementos en los que se puede descomponer el estudio de este tipo de organización política. Con tal fin se realizará un estudio comparado entre las poblaciones juvenil y adulta.

Una vez señalados los fines de esta investigación, se expondrá el marco teórico que la orientará. Para ello se utilizarán las propuestas de Shalom Schwartz, para situar la investigación sobre los valores humanos y para tratar la perspectiva micro de la sociedad, las de Leonardo Morlino, y las de Ronald Inglehart 
y Christian Welzel para analizar la perspectiva macro, centrada en la democracia, sus dimensiones y la articulación con la visión micro.

Los valores son motivaciones abstractas profundamente enraizadas que sirven de guía al individuo además de justificar o explicar actitudes, normas, opiniones o acciones, tal y como defienden Halman y de Moor (1994), Rokeach (1973), Schwartz (1992) o Williams (1968). Los valores pueden ser reflejo de cambios sociales importantes en comunidades y países.

Hemos elegido la teoría de los valores humanos de Shalom Schwartz (1992, 2001, 2003 y 2007) porque se basa en referencias empíricas sólidas, que facilitan el análisis de las relaciones causales entre los valores y las dimensiones que componen la democracia. Los valores actúan como una variable intermedia entre el desarrollo económico y el proceso de democratización. Como demostraron Inglehart y Welzel (2006), la mejora de las condiciones económicas en la población produce cambios en el sistema de valores de la sociedad que, a su vez, influyen en la esfera institucional. A diferencia de los hallazgos de Inglehart (2000) sobre la influencia de los valores en la esfera institucional, la estructura de los valores de Schwartz nos permite profundizar en las relaciones entre el nivel micro y macro del análisis de la sociedad. Supone, por tanto, una herramienta idónea para conocer cuáles se encuentran próximos a un tipo de régimen político como el democrático y cuáles están más alejados.

El trabajo de Shalom Schwartz supone un notable y relevante esfuerzo por conseguir una teoría universal de los valores. Este autor establece diez valores esenciales para dar respuestas a los problemas de la condición humana. Dimensiones culturales que reflejan aspectos básicos que las sociedades deben hacer frente para regular la actividad humana. Según esta teoría, los valores tipo pueden agruparse en cuatro dominios de valor superior (Tabla 1), orientaciones más amplias y universales, en función de la afinidad de los contenidos motivacionales. Así, tenemos las siguientes categorías o dominios: Abierto al cambio, Autotrascendencia, Conservación y Autopromoción. Cada categoría contiene valores tipo que se oponen a otros dado que su activación de manera simultánea es incompatible. No obstante, es necesario hacer constar que Schwartz sitúa el valor Hedonismo en los dominios Abierto al Cambio y Autopromoción, como se puede observar en la tabla 1 .

La teoría de Schwartz contempla, además, una estructura en las relaciones que tienen consecuencias sociales, psicológicas y políticas en forma de lógicas y conflictos lo que será especialmente importante para el estudio de la democracia.

También proporciona una visión interesante y complementaria a esta teo ría, las aportaciones de Ronald Inglehart (2006) sobre la influencia de los valo- 
Tabla 1. Los cuatro dominios de valor y los diez valores tipo

\begin{tabular}{l|c|c}
\hline Dominio de valor & Valor tipo & Oposición \\
\hline Abierto al cambio & $\begin{array}{c}\text { Autonomía } \\
\text { Estimulación } \\
\text { Hedonismo }\end{array}$ & \\
\hline Autotrascendencia & Universalismo & Autopromoción \\
& Benevolencia & \\
\hline Conservación & Conformidad & Abierto al cambio \\
& Tradición & \\
\hline Autopromoción & Seguridad & \\
& Poder & Autotrascendencia \\
& Logro & \\
\hline
\end{tabular}

Fuente: elaboración propia

res en los procesos de democratización de las sociedades. De esta forma, los valores de autoexpresión -aquellos que representan la libertad de pensamiento y de acción- serían característicos de las sociedades modernas en contraposición a los valores orientados a la defensa y conservación de la supervivencia. En un estudio comparado en cinco países de la Unión Europea sobre la influencia de los valores humanos sobre las dimensiones de la democracia en los jóvenes (Carratalá, 2016) se establece una correspondencia empírica entre los valores Postmaterialistas de Inglehart y los dominios de valor de Schwartz Abierto al cambio y Autotrascendencia; y de los Materialistas con los de Conservación y Autopromoción.

Por otra parte, la teoría de Leonardo Morlino (2009) ofrece un excelente marco lógico para el estudio de la calidad de la democracia. Para este, una buena democracia o una democracia de calidad sería aquel ordenamiento institucional estable que mediante instituciones y mecanismos que funcionan correctamente realiza y garantiza la libertad y la igualdad de la ciudadanía.

Morlino introduce en el análisis de la democracia tres perspectivas a partir de las cuales podemos evaluarla: según sus procedimientos normativos, el contenido o parte sustantiva de la democracia; según el resultado del procedimiento anteriormente mencionado; y según el grado de satisfacción alcanzado por la ciudadanía derivado del cumplimiento de sus expectativas.

La primera dimensión tiene como protagonista a la democracia como cumplimiento de los procedimientos establecidos, tanto los de carácter legal como 
otros tipos de acuerdos normativos. En esta perspectiva se considera el grado de respeto a las reglas de juego limpio como, por ejemplo, el sistema de selección de los representantes de la ciudadanía.

En el segundo eje, la parte sustantiva de la democracia, encontramos el grado de cumplimiento y el respeto efectivo a los derechos de los ciudadanos y ciudadanas. Estos últimos están formados por los derechos civiles, derechos sociales y derechos políticos. Los civiles son aquellos referidos al derecho a la vida, a la libertad, a la propiedad, la familia, etc. Los políticos son los que hacen referencia al derecho al voto activo y pasivo, de asociación, de manifestación (o de expresión) e información. Finalmente, los sociales son aquellos que hacen referencia al derecho a la salud, a la educación, a los servicios de protección social y a la seguridad social.

Por último, la tercera dimensión está representada por la satisfacción de la ciudadanía en el grado de cumplimiento de las expectativas puestas en la democracia. En este sentido, Morlino se refiere al hecho de que los contenidos y los procedimientos deben derivar en unos resultados satisfactorios para la sociedad.

De acuerdo con la propuesta teórica que hemos expuesto anteriormente, se plantean las siguientes hipótesis. El dominio de valor Apertura al cambio debe mostrar una asociación positiva con la Dimensión Valorativa. Según la teoría de Morlino, los aspectos fundamentales que recoge esta dimensión son los valores que orientan la práctica democrática, la Libertad y la Igualdad que luego se traducen en derechos civiles, sociales y políticos.

Con Autotrascendencia se espera una asociación positiva con el componente pragmático y el inclusivo de la democracia. En concreto, para el valor Universalismo se espera una fuerte relación con Dimensión Instrumental, ya que considera que los gobiernos tienen como una de sus funciones la reducción de las desigualdades.

Para el dominio de valor Autopromoción se espera que muestre una relación positiva con la Dimensión Procedimental. Finalmente, para Conservación se espera una relación positiva con la Dimensión Procedimental ya que proporciona al sistema estabilidad y previene cualquier tipo de cambio sustancial.

\section{METODOLOGÍA}

Cuando desde la perspectiva empírica se habla de la variable edad, se hace aconsejable situar la idea de juventud en el contexto analítico preciso. Los límites conceptuales existentes entre la juventud y la edad adulta, como una categoría política, han dado lugar en las últimas décadas a una variedad de situaciones que caracterizan a la condición juvenil: aspectos culturales compartidos, la 
inserción en el sistema productivo, la emancipación, la fecundidad y la experiencia en el sistema político, hacen necesario considerar el hecho social y biológico de la juventud de manera vinculada. No podemos hablar de este concepto como una categoría homogénea, sino como un agregado de población con un conjunto de características comunes y otras que los diferencian internamente (Alaminos, 2008).

Reconociendo estas dificultades, para realizar una aproximación adecuada a la realidad, se seguirán las indicaciones de Francés y Santacreu (2014) por ser aplicables a esta investigación. Así, la elección de la edad de 30 años como un umbral diferencial entre la juventud y la edad adulta, se justifica fundamentalmente por el hecho de que la acción política de las administraciones públicas españolas diseñada para los jóvenes están dirigidas a individuos que tienen como máximo esa edad. Por otro lado, el umbral inferior se ha fijado en 18 años, porque es a partir de dicha edad cuando las instituciones españolas conceden plenos derechos políticos a los individuos con estatus de ciudadano. De esta forma, en este trabajo entenderemos que la población joven hace referencia a los individuos que tienen entre 18 y 30 años. Esto permitirá proponer un análisis de tipo comparativo con el resto de la población, que será considerada como "adultos" para los fines de este estudio.

En nuestro enfoque empírico de la evaluación de la democracia y sus relaciones con los valores humanos individuales de los jóvenes y adultos hemos utilizado un método de análisis multivariante conocido como modelo de ecuaciones estructurales (SEM). Para construir los modelos sobre la influencia que los valores humanos tienen en la evaluación de la democracia según los jóvenes y los adultos españoles (figuras 1 y 2), hemos utilizado los datos de la $6^{a}$ ola de la Encuesta Social Europea (ESS, 2012). El uso de esta base de datos se justifica por el hecho de que es la más actualizada que existe en la actualidad y que contiene las variables necesarias para el análisis propuesto. Los tamaños de las muestras utilizadas en el análisis corresponden a aquellos casos válidos para el conjunto de variables que integran los diferentes modelos estructurales desarrollados, tal y como se puede apreciar en las tablas 2 y 3 . De acuerdo con el modelo que utiliza datos de la ESS, el tamaño de la muestra válida de los casos entre 18 y 30 años es $n=261$ y para el modelo que utiliza datos del ESS, para los casos de más de 30 años, el tamaño de la muestra válida es $\mathrm{n}=1267$.

La técnica SEM permite el análisis de múltiples relaciones entre subconjuntos de variables, así como la posibilidad de incorporar conceptos teóricos o variables latentes en el proceso. De esta forma, podemos proponer una estructura relacional empírica en el contexto de nuestra propuesta teórico explicativa. Para el análisis se ha empleado el programa LISREL, exactamente la ver- 
sión de este software número 8.80. Para la evaluación de los resultados de los modelos estructurales se han utilizado dos métodos. Siguiendo las indicaciones de Alaminos (2005), en primer lugar se evaluó la bondad de ajuste de los modelos de ecuaciones estructurales a través del examen de las pruebas de bondad de ajuste: Root Mean Square Error of Aproximation (RMSEA) (valores $\leq 0,08$ son aceptables); del Goodness of Fit Index (GFI) (valores superiores a 0,90 indican un buen ajuste); del Adjusted Goodness of Fit Index (AGFI) (valores superiores a 0,90 indican un buen ajuste); Normed Fit Index (NFI) (valores superiores a 0,90 son deseables); Non-Normed Fit Index (NNFI) (valores superiores a 0,95 indican un buen ajuste), o el Standarized Root Mean Square Residual (SRMR) (valores cercanos a 0 se consideran favorables). En segundo lugar, los caminos o path en los diagramas de los modelos de ecuaciones estructurales han servido para determinar la significación estadística de cada relación. En los diagramas causales, todas las cargas de dependencia se presentan en su solución de valores estandarizados que representan a valores-T mayores de 1,96 .

\section{RESULTADOS Y DISCUSIÓN}

Los resultados sobre la valoración de la experiencia democrática de los jóvenes españoles derivan del análisis de los elementos instrumental, normativo y procedimental y de sus relaciones de dependencia con los valores humanos. Una primera aproximación de tipo descriptivo a este estudio podría centrarse en contestar a esta pregunta: ¿están los jóvenes españoles satisfechos con el funcionamiento de la democracia? La respuesta podría ser afirmativa pero necesita ser matizada. En Carratalá (2016) y Carratalá y Francés (2016) se pone de manifiesto que los jóvenes de la Unión Europea que están satisfechos con sus gobiernos también lo están con el funcionamiento de la democracia. Se trata de una asociación condicionada a su opinión sobre los gobernantes. En el caso de España, como los jóvenes están poco satisfechos con ellos, el grado de satisfacción con la democracia se encuentra en un nivel bajo.

Otra cuestión que necesita de una respuesta nítida es saber si la visión de los jóvenes españoles es característica de su grupo de edad. Es decir, ies sustancialmente distinta la valoración que éstos hacen de la democracia de la de sus conciudadanos mayores de 31 años? Los resultados ofrecen una respuesta afirmativa. Se expondrán a continuación los datos derivados de contraponer dos modelos de ecuaciones estructurales que dan cuenta de las asociaciones existentes entre los valores humanos y las dimensiones que componen la democracia.

Comenzaremos el análisis haciendo referencia a los datos descriptivos, con las puntuaciones promedio en cada una de las variables medidas, sobre la eva- 
luación que los entrevistados realizan de su experiencia democrática. El primer dato importante que encontramos es que tanto jóvenes (en una escala de 4,55 sobre 10$)$ como adultos $(4,88)$ le dan un suspenso a la democracia. Aunque sea por poco, no supera la prueba. En los jóvenes la variable que mejor puntuación recibe $(6,82)$ es la capacidad que la oposición tiene de criticar con libertad la acción de gobierno. Sólo una variable más supera los cinco puntos y mide la percepción que tiene este grupo de encuestados sobre la capacidad deliberativa de los electores $(5,94)$. Sin embargo, los jóvenes encuestados suspenden con claridad a la democracia en su papel como redistribuidor de la riqueza $(2,98)$ siendo este el valor más bajo de todos los indicadores medidos.

En el análisis por dimensiones, según la valoración de los jóvenes, solo aprueba en el factor procedimental (5,92 puntos promedio), suspendiendo en el sustantivo $(4,20)$ y en el instrumental $(3,01)$, este último el peor de los tres.

En cuanto a las valoraciones de la población adulta, las puntuaciones promedio son ligeramente más altas en todas las variables que las obtenidas de los jóvenes. Como en el caso anterior, el valor promedio más alto lo encontramos en la variable libertad de los partidos de la oposición para criticar la acción del gobierno $(7,45)$. También superan el valor 5 promedio el indicador referido a la capacidad deliberativa de la población $(6,13)$ y la fiabilidad de los medios de comunicación para ofrecer información con la que juzgar la acción gubernamental $(5,69)$. En el apartado negativo, el papel de redistribuidor del estado es el aspecto más deficiente de la democracia española según la percepción de la población adulta $(3,03)$.

Por dimensiones, al igual que en el caso de la población joven, la procedimental es la única que supera el valor 5 promedio $(6,27)$. Por debajo queda la sustantiva o normativa $(4,47)$ y la instrumental $(3,10)$, nuevamente la peor valorada.

Como hemos visto anteriormente, los valores son constructos abstractos que orientan, junto a otros elementos cognitivos, las acciones de los individuos. Según los datos que ofrece el análisis descriptivo, la población adulta y joven tienen afinidad por valores diferentes. Si bien son los valores del dominio Autotrascendencia con los que se identifican principalmente -de manera más intensa en el caso de los adultos entrevistados, 7,12 puntos promedio sobre 10 por 6,83 puntos-, el peso del dominio de valor Conservación es destacadamente más notorio $(6,47$ puntos) que en los jóvenes $(5,50)$. La población entre 18 y 30 años, por el contrario, muestra una mayor identificación con los valores del dominio Abierto al cambio $(6,12)$ que los adultos $(5,22)$. Ambas poblaciones se manifiestan alejadas del dominio de valor Autopromoción, con 4,87 puntos promedio para los jóvenes y 4,08 para los adultos. 
Tabla 2. Valores promedio de los ítems que valoran la democracia en España

\begin{tabular}{|c|c|c|c|}
\hline & & & Medias* \\
\hline Dimensión & Indicadores & Jóvenes & Adultos \\
\hline \multirow[t]{3}{*}{ Procedimental } & $\begin{array}{l}\text { En España los votantes discuten } \\
\text { sobre política con personas que } \\
\text { conocen antes de decidir su voto }\end{array}$ & 5,94 & 6,13 \\
\hline & $\begin{array}{l}\text { En España los diferentes partidos } \\
\text { ofrecen alternativas claramente } \\
\text { diferenciadas entre sí }\end{array}$ & 4,99 & 5,24 \\
\hline & $\begin{array}{l}\text { En España los partidos de la } \\
\text { oposición tienen libertad para } \\
\text { criticar al gobierno }\end{array}$ & 6,82 & 7,45 \\
\hline \multirow[t]{2}{*}{ Valorativa } & $\begin{array}{l}\text { En España los medios de } \\
\text { comunicación proporcionan } \\
\text { información fiable para juzgar } \\
\text { al gobierno }\end{array}$ & 4,96 & 5,69 \\
\hline & $\begin{array}{l}\text { En España los derechos de las } \\
\text { minorías están protegidos }\end{array}$ & 4,54 & 4,63 \\
\hline \multirow[t]{6}{*}{ Instrumental } & $\begin{array}{l}\text { En España el gobierno protege a } \\
\text { toda la ciudadanía contra la } \\
\text { pobreza }\end{array}$ & 3,04 & 3,16 \\
\hline & $\begin{array}{l}\text { En España el gobierno toma } \\
\text { medidas para reducir las } \\
\text { diferencias en el nivel de ingresos }\end{array}$ & 2,98 & 3,03 \\
\hline & MEDIA FINAL & 4,55 & 4,80 \\
\hline & Dimensión procedimental & 5,92 & 6,27 \\
\hline & Dimensión valorativa & 4,20 & 4,47 \\
\hline & Dimensión instrumental & 3,01 & 3,10 \\
\hline
\end{tabular}

Fuente: Elaboración propia

*Los promedios se expresan en puntos en una escala de 1 a 10 
Tabla 3. Valores promedio de los ítems sobre los valores humanos en España

\begin{tabular}{|c|c|c|c|}
\hline & & & Medias* \\
\hline Dominio de valor & Indicadores & Jóvenes & Adultos \\
\hline \multirow[t]{2}{*}{ Autotrascendencia } & $\begin{array}{l}\text { Es importante que las } \\
\text { personas sean tratadas con } \\
\text { equidad y disfruten de } \\
\text { igualdad de oportunidades }\end{array}$ & 7,18 & 7,28 \\
\hline & $\begin{array}{l}\text { Es importante cuidar la } \\
\text { naturaleza y el medioambiente }\end{array}$ & 6,48 & 6,95 \\
\hline \multirow[t]{3}{*}{ Abierto al cambio } & $\begin{array}{l}\text { Es importante tener nuevas } \\
\text { ideas y ser creativo }\end{array}$ & 6,27 & 6,00 \\
\hline & $\begin{array}{l}\text { Es importante intentar nuevas } \\
\text { y diferentes cosas en la vida }\end{array}$ & 6,12 & 4,92 \\
\hline & $\begin{array}{l}\text { Es importante buscar la } \\
\text { diversión y cosas que den } \\
\text { placer }\end{array}$ & 5,97 & 4,73 \\
\hline Conservación & $\begin{array}{l}\text { Es importante comportarse } \\
\text { siempre correctamente para } \\
\text { evitar que puedan decir que } \\
\text { ha hecho algo mal }\end{array}$ & 5,50 & 6,47 \\
\hline \multirow[t]{5}{*}{ Autopromoción } & $\begin{array}{l}\text { Es importante tener éxito y que } \\
\text { que la gente reconozca los } \\
\text { logros }\end{array}$ & 4,87 & 4,08 \\
\hline & Autotrascendencia & 6,83 & 7,12 \\
\hline & Abierto al cambio & 6,12 & 5,22 \\
\hline & Conservación & 5,50 & 6,47 \\
\hline & Autopromoción & 4,87 & 4,08 \\
\hline
\end{tabular}

Fuente: Elaboración propia

${ }^{*}$ Los promedios se expresan en puntos en una escala de 1 a 10 
Tabla 4. Valores promedio* de los valores Materialistas y Postmaterialistas

\begin{tabular}{l|c|c}
\hline & Jóvenes & Adultos \\
\hline Postmaterialistas & 6,12 & 6,17 \\
\hline Materialistas & 5,19 & 5,28 \\
\hline
\end{tabular}

Fuente: Elaboración propia

${ }^{*}$ Los promedios se expresan en puntos en una escala de 1 a 10

Atendiendo a la tipología de Inglehart, en la que se establece la división entre valores Postmaterialistas -que se corresponden empíricamente con los valores del dominio Autotrascendencia y Abierto al cambio (Carratalá, 2016)- y Materialistas -compuestos por los dominios Conservación y Autopromoción-, adultos y jóvenes muestran promedios similares, teniendo mayor peso los Postmaterialistas (6,12 para los jóvenes y 6,17 para los adultos) que los Materialistas (5,19 para los jóvenes por 5,28 para los adultos).

Dentro del análisis de los modelos estructurales, los parámetros de bondad de ajuste son adecuados, así como los índices referidos a las relaciones entre factores. De esta forma, se puede asegurar que los modelos cumplen con todos los requisitos de significación estadística, tal y como se puede comprobar en la tabla 5 .

El modelo de los jóvenes (figura 1) representa al de una democracia liberal basada en valores materialistas. Los valores sustantivos de la democracia, los que son propios de una democracia liberal, tienen la cualidad de articular a las dimensiones Instrumental y Procedimental. La carga de este factor sobre el procedimental es fuerte $(0,66)$, como también lo es con respecto a la dimensión instrumental $(0,79)$. La Valorativa está representada por la fiabilidad de la información que difunden los medios de comunicación y la preservación de los derechos de las minorías.

En cuanto a las cargas de dependencia que se observan en el modelo al poner en relación las variables exógenas (los valores humanos) con las endógenas (las dimensiones de la democracia) los resultados son bastante expresivos. Por un lado, siguiendo la propuesta taxonómica de Inglehart y Welzel (2006) que divide los valores humanos en Postmaterialistas y Materialistas, son estos últimos los que apuntan a la dimensión que mayor peso tiene en el modelo. Nos referimos a los valores que pertenecen a los dominios Conservación y Autopromoción, a su vez, compuesto por los valores universales Conformismo y Logro respectivamente. La relación de ambos ( 0,23 en el caso de Conservación; 0,16 en el de Autopromoción) con la Dimensión Valorativa de la democracia es positiva de tal forma que cuanto más se identifica un joven con los valo- 
res referidos, mayor es la constatación de que en España los indicadores se ven cumplidos.

Los valores Postmaterialistas, compuestos por los dominios de valor Abierto al cambio y Autotrascendencia, apuntan a las otras dos dimensiones. Dentro de los primeros encontramos al valor Universalismo, de contenidos igualitaristas y ambientalistas, que carga $(0,10)$ sobre la Dimensión Procedimental. Además, la relación es de tipo positivo, es decir, cuanto más se identifica el entrevistado con este valor humano, mayor es la constatación de que en España existe una oferta de partidos diversa y nítida, que existe una oposición libre de criticar la acción del gobierno y que los ciudadanos discuten con otros sobre asuntos de política antes de votar en unas elecciones.

El otro dominio de valor Postmaterialista, Abierto al cambio, apunta a la Dimensión Instrumental de la democracia. Éste está compuesto por los valores Autonomía, Estimulación y Hedonismo y mantienen una asociación negativa con este factor $(-0,14)$. Por tanto, cuanto mayor es la identificación de la población de referencia, menor es la constatación de que en España el gobierno no cumple con su misión de reducir las desigualdades y proteger a los ciudadanos de la pobreza.

\section{Figura 1. Modelo estructural evaluación de la democracia de los jóvenes españoles}

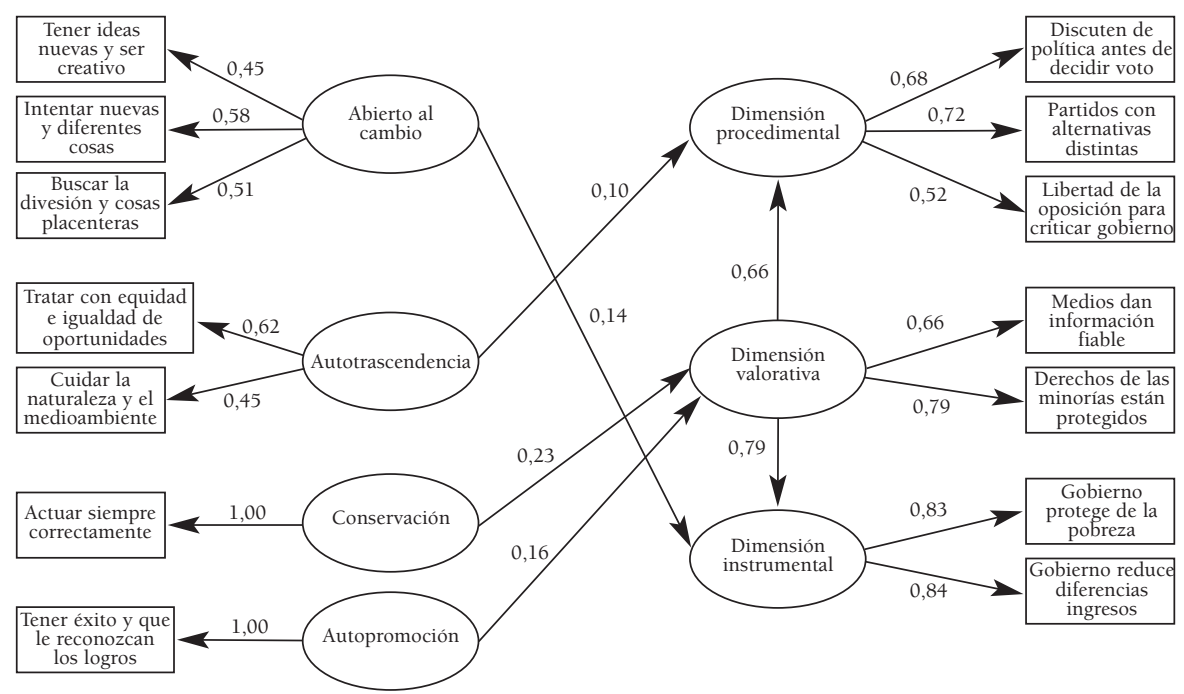

Fuente: Elaboración propia 
Figura 2. Modelo estructural evaluación de la democracia de los adultos españoles

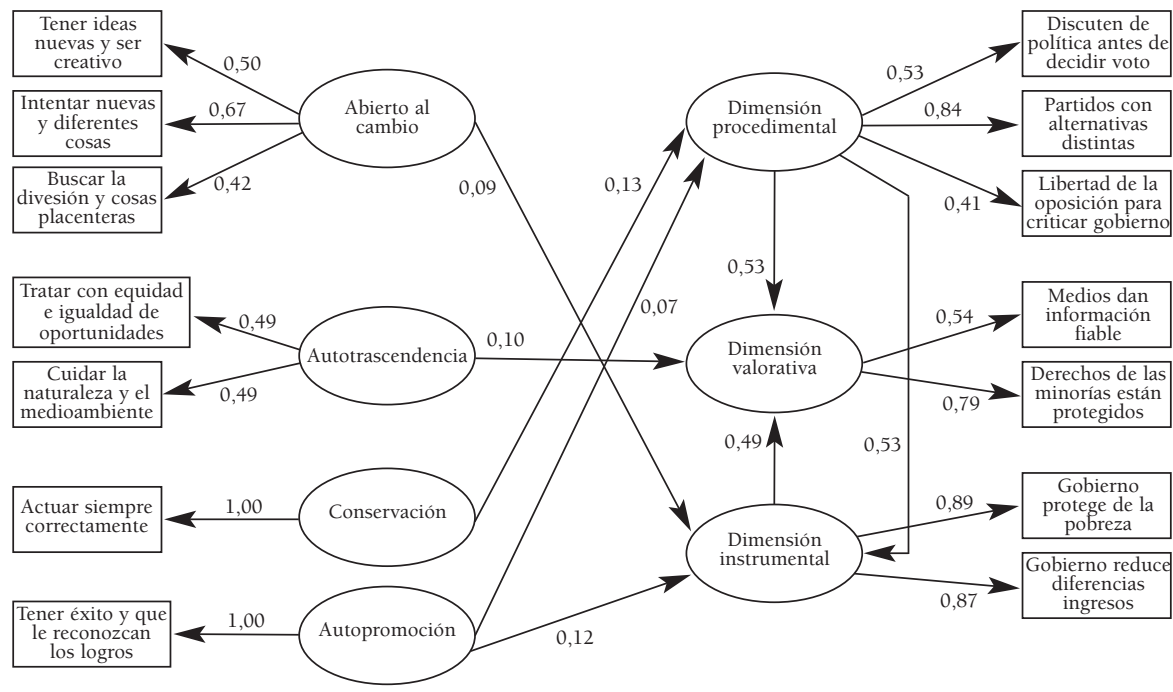

Fuente: Elaboración propia

Tabla 5. Índices de bondad de ajuste global

\begin{tabular}{l|c|c|c|c}
\hline & & & \multicolumn{2}{|c}{ Modelos } \\
\hline Estadísticos & Variación & Valores recomendados & Jóvenes & Adultos \\
\hline RMSEA & & $<0,08$ & 0,037 & 0,048 \\
\hline GFI & $0-1$ & $>0,90$ & 0,95 & 0,97 \\
\hline AGFI & $0-1$ & $>0,90$ & 0,93 & 0,96 \\
\hline NFI & $0-1$ & $>0,90$ & 0,93 & 0,95 \\
\hline NNFI & $0-1$ & $>0,95$ & 0,97 & 0,95 \\
\hline SRMR & & Cercanos a 0 & 0,048 & 0,038 \\
\hline
\end{tabular}

Fuente: Elaboración propia

El modelo de los adultos (figura 2) se puede resumir diciendo que está sustentado en el valor de la seguridad que proporcionan los procedimientos. Si en el modelo de los jóvenes menores de 30 años el factor que ordenaba al resto era el normativo o sustantivo, en el de los mayores de 31 es la Dimensión Procedimental. La carga de ésta tiene más fuerza sobre la Valorativa y la Instrumental, sien- 
do 0,53 en ambos casos. Cabe destacar que la Dimensión Instrumental también apunta a la normativa con bastante fuerza $(0,49)$.

Como en el caso de los menores de 30 años, los valores Materialistas apuntan ambos a la dimensión que articula la estructura del modelo que estamos describiendo. Los dos dominios de valor, Conservación y Autopromoción, mantienen una asociación de tipo positivo con el factor procedimental de la democracia. La fuerza del valor Conformismo es moderada $(0,13)$ y la de Logro también $(0,07)$. El domino de valor Autopromoción también mantiene una relación de tipo positivo con la Dimensión Instrumental $(0,12)$. También carga sobre ella el dominio de valor Abierto al cambio (Postmaterialista), que lo hace con signo negativo $(-0,09)$. El otro valor Postmaterialista, Autotrascendencia, apunta a la dimensión sustantiva de la democracia, aunque de forma modera$\mathrm{da}(-0,10)$, a la que se asocia con signo negativo.

Especialmente interesante es el hecho que en este modelo estructural los valores Materialistas mantienen relaciones de tipo positivo con las dimensiones de la democracia, mientras que en los Postmaterialistas lo son de tipo inverso. Otro aspecto que llama la atención es el hecho de que las dimensiones con mayor jerarquía dentro del modelo concentran el mayor número de cargas de dependencia lo que demuestra que el carácter procedimental de la democracia en España es relevante para dicha población.

En resumen, y haciendo balance del cumplimiento o no de las hipótesis planteadas, los resultados dicen que en el modelo de los jóvenes no se confirma ninguna de las relaciones esperadas, mientras que en el de los adultos sí que ha respondido a las expectativas las relaciones entre los valores Conservación y Autopromoción con la Dimensión Procedimental de la democracia, siendo rechazadas el resto de las hipótesis planteadas.

\section{CONCLUSIONES}

Las investigaciones sobre la calidad de la democracia y la valoración que la ciudadanía realiza de ella han girado en torno a la influencia que el sistema económico o el político ejerce sobre las dimensiones que la componen. Sus resultados a menudo han tenido una capacidad explicativa limitada y se ha echado en falta someter el análisis desde una perspectiva que articule el nivel macro y micro (Gómez et al., 2010). Este trabajo ha pretendido modestamente dar continuidad a una línea de estudios sobre la democracia iniciados recientemente bajo esta premisa, poniendo a prueba el alcance explicativo de los valores humanos y la influencia que tienen en las personas su percepción de la democracia. Prueba de ello son los estudios de Carratalá (2016) sobre la percepción de los jóvenes de la Unión Europea sobre la calidad de la democracia y de 
Carratalá y Francés (2016) donde se pone en liza esta perspectiva macro-micro para conocer cómo los jóvenes y adultos en España definen la democracia.

Este estudio se ha marcado como objetivo conocer cómo jóvenes y adultos españoles, desde una perspectiva comparada, valoran la democracia y la influencia que los valores humanos tienen sobre ésta. Y los resultados no han podido ser más concluyentes. Si bien los datos procedentes del análisis descriptivo muestran que existen bastantes semejanzas en la valoración que hacen jóvenes y adultos de la democracia -ambos grupos poblacionales son críticos y la consideran deficiente- la perspectiva estructural arroja un panorama bien distinto que presenta dos valoraciones de la democracia sensiblemente diferentes.

De la comparativa de ambos modelos se deduce que los jóvenes consideran que la dimensión más importante de la democracia es la sustantiva, la que define, desde un punto de vista normativo, este sistema político que tiene en los valores de Libertad e Igualdad sus elementos principales. Sin embargo, los adultos consideran que lo más importante de la democracia es su característica procedimental, la cual se ve reflejada en el voto y en un sistema electoral en el que concurren en competencia diversos partidos políticos.

Un aspecto a tener en cuenta, entrando ya en el terreno de los valores humanos, es que los jóvenes y adultos más afines a los valores Materialistas -en el sentido que le otorgan Inglehart y Welzel (2006)- son los que definen la jerarquía de la estructura dimensional de la democracia. Los valores Logro y Conformismo se asocian positivamente con los valores de la democracia, Libertad e Igualdad, para los jóvenes, y con la dimensión procedimental para los adultos. Según las hipótesis planteadas, la segunda relación era esperada pero no en el primer caso.

Otra cuestión destacable es la preponderancia que tienen en los modelos propuestos los valores Materialistas, Logro y Conformismo, sobre los Postmaterialistas representados por Autonomía, Estimulación y Universalismo. España es un país con un nivel de desarrollo social y económico apreciable donde, según la teoría de Inglehart, deberían predominar los valores Postmaterialistas, tal y como queda reflejado en el estudio de Carratalá (2016). Por lo tanto, llama la atención que en los modelos su peso sea menor, aunque las diferencias entre ambos no sean grandes.

A la luz de los resultados, si el gran objetivo de este sistema de gobierno, como dice Leonardo Morlino (2009), es hacer la Libertad y la Igualdad de los ciudadanos, en España no se consigue. Es significativo que en el modelo de la población adulta los valores Materialistas Conformismo y Logro sean los que se vinculan con la dimensión de la democracia que mayor peso y jerarquía 
tiene en la estructura. Justamente lo mismo que ocurre en el modelo de los jóvenes, aunque se trate de factores predominantes diferentes.

Los interrogantes que sugieren los datos expuestos son los siguientes: cómo es posible que los valores Postmaterialistas tengan un peso tan secundario en ambos modelos y qué consecuencias puede tener. Algunos autores indican que esta situación podría explicar la permisividad de la ciudadanía ante hechos intolerables en una democracia como la corrupción (Gómez et al., 2010), argumento que justificaría la existencia de una sociedad civil pasiva, desmotivada con la política y que se siente incapaz de influir en los escenarios de decisión política.

Ambas cuestiones apuntan a una posible explicación: como el propio Inglehart y Welzel (2006) argumentan, en una situación de retroceso en las condiciones económicas de la población es posible que los valores Materialistas recuperen el peso que perdieron en la fase de desarrollo económico y social con respecto a los Postmaterialistas que propiciaron las distintas oleadas democratizadoras. En la misma línea de pensamiento, Palacios (2016) señala a la crisis económica como factor decisivo en la valoración que la ciudadanía realiza de la democracia como deficiente.

También es interesante la reflexión de Palacios cuando hace referencia a una España de "dos velocidades" donde, por un lado, los sectores sociales que habitan en zonas donde disfrutan de menos recursos (PIB per cápita) en forma de bienes y servicios públicos son más condescendientes con el funcionamiento de la democracia; y, por el otro, aquellos habitantes de zonas más prósperas que son más críticos con la democracia. Esto nos puede llevar a concluir que, según los modelos propuestos, las personas que se identifican con los valores Materialistas -debido a su actitud permisiva, obediente y conformista- han conseguido imponer su visión acerca del funcionamiento de la democracia sobre la de aquellos con un sentido más crítico, igualitarista y autónomo. En consecuencia, estos últimos habrían adoptado una postura indolente y hastiada debido al propio funcionamiento del sistema.

Un aspecto, este último, que no es baladí, puesto que estamos hablando de una dinámica que tiene como principal derivación la continua reproducción del actual modelo de funcionamiento de la democracia y la degradación de su calidad en España, si es posible considerar que ésta tuvo momentos mejores. Confirmar este último apunte debería ser materia de estudio en próximas investigaciones. 


\section{BIBLIOGRAFÍA}

Ai Camp, R. (1998). "Province Versus the Center: Democratizing Mexico's Political Culture" in Kelly, P. (ed.) Assessing Democracy in Latin America. Boulder, Westview Press.

Alaminos, A. (2005). El análisis de la realidad social. Modelos estructurales de covarianzas. Alicante: Obets. Universidad de Alicante.

Alaminos, A. (2008). "La juventud y sus límites operativos". Revista Obets, 2, p. 5-23.

Baviskar, S. y Malone, M.F. (2004). "What Democracy Means to Citizens and Why It Matters". European Review of Latin American and Caribbean Studies, 76, p. 3-24.

Bratton, M., Mattes, R. y Gyimah-Boadi, E. (2005). Public opinion, democracy, and market reform in Africa. Cambridge. Cambridge University Press.

Carratalá, L. (2016). La estructura de valores en la Unión Europea: cómo definen y valoran los jóvenes europeos la democracia a través de su sistema de valores. Tesis Doctoral, Universidad de Alicante.

Carratalá, L. y Francés, J.F. (2016). "Youth and Expectations on Democracy in Spain: the Role of Individual Human Values Structure of Young People in Dimensions of Democracy”. Partecipazione \& Conflitto, no 9 (3). En prensa.

Easton, D. (1976). Esquema para el análisis político. Buenos Aires: Amorrortu.

Francés, J.F. y Santacreu, O. (2014) «Crisis política y juventud en España: el declive del bipartidismo electoral». Societá Mutamento Politica, vol. 5. nº10, p. 107-128.

Gómez, B., Palacios, I., Pérez, M., Vargas, R. (2010). Calidad de la democracia en España. Una auditoria ciudadana. Barcelona: Ariel.

Halman, L. y de Moor, R. (1994). "Religion, churches and moral values". En Ester P, Halman L, de Moor. The Individualizing Society. Tilburg: Tilburg University Press.

Inglehart, R. (2000). "Culture and Democracy" en Culture Matters. Huntington, S. y Harrison, L. Nueva York: Basic Books.

Inglehart, R. y Welzel, C. (2006). Modernización, cambio cultural y democracia: la secuencia del desarrollo humano. Madrid: Centro de Investigaciones Sociológicas (CIS).

Lagos, M. (2005). Latinobarómetro 2004, América Latina y Unión Europea. Latinobarómetro.

Morlino, L. (2009a). Democracia y democratizaciones. Madrid: Centro de Investigaciones Sociológicas (CIS).

Morlino, L. (2009b). Qualities of Democracy. How to Analyse them? Florencia: Istituto Italiano di Scienze Umane.

Palacios, I. (2016). Los españoles y la calidad de la democracia. Madrid: Centro de Investigaciones Sociológicas (CIS).

Reisinger, W.M., Miller, A.H. y Hesli, V.L. (1995). "Public Behavior and Political Change in Post-Soviet States". Journal of Politics, 57(4), p. 941-970.

Ringen, S. (2007). What Democracy is For. On Freedom and Moral Government. Princeton, Princeton University Press.

Rokeach, M. (1973). The Nature of Human Values. New York: Free Press. 
Schwartz, S.H. (1992). "Universals in the Content and Structure of Values: Theory and Empirical Tests in 20 Countries". Advances in Experimental Social Psychology, Vol. 25, ed. Mark P. Zanna, 1-65. New York: Academic Press.

Schwartz, S.H. (2001). "¿Existen aspectos universales en la estructura de los valores humanos?". En Ros, M \& Gouveia, V. (Coords.). Psicología Social de los Valores Humanos. Desarrollos teóricos, metodológicos y aplicados. Madrid: Biblioteca Nueva.

Schwartz, S.H. (2003). A Proposal for Measuring Value Orientations across Nations. Chapter 7 in the Questionnaire Development Package of the European Social Survey.

Schwartz, S.H. (2007). "Value Orientations: Measurement, Antecedents and Consequences across Nations". En Jowell, R., Roberts, C., Fitzgerald, R. y Gillian Eva, G. (eds) Measuring attitudes cross-nationally: Lessons from the European Social Survey, 161-193. London: Sage.

Schwartz, S.H. y Bilsky, W. (1990). "Toward a theory of the universal content and structure of values: Extensions and cross-cultural replications". Journal of Personality and Social Psychology, 58, p. 878-891.

Torcal, M.; Montero, J.R. y Teorell, J. (2006). "La participación política en España: modos y niveles en perspectiva comparada.". En Montero, J.R.; Font, J. y Torcal, M. (eds). Ciudadanos, asociaciones y participación en España, pp. 47-75. Madrid: Centro de Investigaciones Sociológicas (CIS).

Whitefield, S. y Evans, G. (1996). "Support for Democracy and Political Opposition in Russia, 1993 and 1995". Post-Soviet Affairs, 12, p. 218-242.

Williams, R. M., Jr. (1968). "Values". En Sills, E. (Ed.), International Encyclopedia of the Social Sciences. New York: Macmillan.

LIBERTO CARRATALÁ PUERTAS. Doctor en Sociología, actualmente trabaja como profesor en el Departamento de Sociología I de la Universidad de Alicante. Sus campos de investigación son la sociología política, los procesos de participación ciudadana, comunicación política, jóvenes y valores humanos. Ha tomado parte en numerosas investigaciones para instituciones públicas donde ha trabajado como investigador principal y colaborador. Además, es autor de artículos, informes y libros sobre procesos de acción comunitaria.

Recibido: 11/09/2016

Aceptado: 13/12/2016 


\title{
PERCEPCIÓN DE LOS DIRIGENTES ESTUDIANTILES UNIVERSITARIOS SOBRE LA RESPONSABILIDAD SOCIAL UNIVERSITARIA ${ }^{1}$ \\ PERCEPTION OF COLLEGE STUDENT LEADERS ABOUT UNIVERSITY SOCIAL RESPONSABILITY
}

\author{
Ricardo Gaete Quezada \\ Universidad de Antofagasta, Chile \\ ricardo.gaete@uantof.cl
}

\begin{abstract}
Cómo citar / Citation
Gaete Quezada, Ricardo (2016). "Percepción de los dirigentes estudiantiles universitarios sobre la responsabilidad social universitaria". OBETS. Revista de Ciencias Sociales, 11(2): 461-485. doi:10.14198/OBETS2016.11.2.04

\section{Resumen}

El artículo analiza el significado otorgado por estudiantes universitarios al concepto de responsabilidad social universitaria, mediante una investigación con enfoque cualitativo a través de un estudio de caso único e instrumental, considerando la entrevista semi-estructurada y el focus group como técnicas de recolección de la información.

Se concluye que la responsabilidad social de la universidad plantea el desafío de reenfocar la misión institucional, hacia un proceso de formación vinculado a la realidad social circundante, así como mediante un rol social más activo de la universidad frente a las necesidades y problemáticas sociales del territorio en donde las universidades están instaladas.
\end{abstract}

Palabras clave: dirigentes estudiantiles, responsabilidad social universitaria, educación superior, universidades chilenas, investigación cualitativa.

\section{Abstract}

The article analyzes the meaning given by university students to the concept of university social responsibility, through research with a qualitative approach

\footnotetext{
${ }^{1}$ El artículo es parte del proyecto Fondecyt de Iniciación a la Investigación №11121144 denominado "Una mirada a la responsabilidad social universitaria en la ciudad de Antofagasta".
} 
through a single and instrumental case study, considering the semi-structured interview and the focus group as information gathering techniques.

It is concluded that the social responsibility of the university raises the challenge of refocusing the institutional mission, towards a formation process linked to the surrounding social reality, as well as through a more active social role of the university in face of the social needs and problems of the territory where the universities are installed.

Key words: university leaders, university social responsibility, higher education, chilean universities, qualitative research.

\section{Extended Abstract}

The review of the literature related to the concept of University Social Responsibility, suggests that this model attaches great importance to the social impacts of university life, therefore, it examines how universities can contribute more effectively to balanced, inclusive and sustainable development the society. On the other hand, much research on this subject delve into the opinion and knowledge of students on social responsibility, as well as on the skills that are related to the formation of socially responsible professionals.

In this context, since 1998 UNESCO makes a call for universities to assume their social responsibility, embedded in the so-called knowledge society, forcing the universities to reflect on the effectiveness and impact of its mission to that scenario, creating useful knowledge to solve major social problems. Thus, the first part of this article provides an overview of the main existing theoretical guidelines in the literature on the concept of university social responsibility, with special emphasis on studies examining the student perspective on socially responsible behavior universities.

In the second part, the results of the research indicate that university leaders interviewed link the concept of social responsibility with a more active and close social role of the university, with respect to the issues that directly affect the community's territory or presented region is inserted each university. Also, they relate the concept of university social responsibility a training process that is capable of confronting students and their professional knowledge with the needs and requirements of the community.

From a methodological perspective, the objective of this study is to describe the perceptions of university student leaders on socially responsible behavior of the universities in the city of Antofagasta in Chile, for which a qualitative research design type is used.

Furthermore, the technique of gathering information is the semi-structured interview carried a total of fourteen interviews during 2014, in a single format, in one meeting and focused on a single theme. The interviewer will provide the same stimulus or initial approach to each respondent on the problems studied, using a pattern of collating the relevant topics for research, and only in those cases where the respective respondent does not encompass within their any intervention of the issues, only then will proceed to formulate the respective question on this topic.

As for the subjects to interview, a purposive sample of theoretical type that prioritizes substantive representation over that of statistical type is used, since what 
is intended is to include stakeholders of interest regarding the speech reproducing trying to saturate places of enunciation, ie when data arising from repeated interviews start and do not add new elements to the discussion under investigation.

Under the above, the purposive sample of the study includes university student leaders who were elected democratically to join Federations of Students or centers Students from the following universities: University of Antofagasta, Catholic University of the North. University Pedro de Valdivia, based Antofagasta.

For the analysis and interpretation of data procedures established by Grounded Theory data supported by the Atlas Ti software, using the following procedure shall be followed: identification of incidents to assign codes (microanalysis); comparison of substantive codes, concepts and categories (Codification); and the integration of these elements into a theory that is drawn from the data to construct theoretical hypotheses.

For triangulation of data, focus group technique developed with seven Presidents of centers of undergraduate students at the University of Antofagasta and Northern Catholic University used.

Finally, the main conclusions of this work, it is possible to note that most of the studies on the university social responsibility where students are the main focus point out that this concept is related to various forms of expression associated with values, volunteerism, sustainable development or as a personal commitment applied to both student level, and in the future professional practice.

The process of social construction of the concept of university social responsibility analyzed in this work from the experiences and views of university student leaders of the city of Antofagasta, clearly raises the need to manage a profound change in the way in which a university develops its traditional functions of teaching and research, and must strengthen what is now known in Chile as the role of connectedness, traditionally known as a university extension.

Thus, an important channel the socially responsible behavior of universities aspect is the training process of students, which according to the results of this study is related to the implementation of strategies of learning more active on the role of students take advantage of the environment to facilitate more effective and clear contribution of students to the search for solutions to the needs of the community from their own process of university education.

The constructivist view expressed by university leaders about the training process is consistent with use of more contemporary proposals of university teaching, in which the central axis of the educational model is the student and not the university professor, transforming our view an important indicator of socially responsible behavior of a university.

However, the rigidity of the curriculum and the rule of format more traditional kinds of expository used by teachers, has raised students from universities in the city of Antofagasta the need to seek instances to channel their concerns greater interaction with the community, for which they have developed inte- 
resting projects university volunteer as a way to connect their learning process with the implementation of measures of social intervention.

The other major axis of the concept of university social responsibility identified in the study, relates to what UNESCO designated in 1998 as the "relevance of higher education", that is, the fit between what society expects educational institutions superior and what they actually do, which results in no less challenge for universities whose institutional performance is often related to interests rather internal. But also, keep in mind that some universities also receive a strong external influence depending on the religious or secular orientation having, if state or private, or national or regional presence to name a few aspects that can facilitate or affect greater or lesser orientation towards society, in terms of relevance of his work as a fundamental pillar of socially responsible behavior.

According to the university leaders interviewed in our study, the relevance referred to by UNESCO expresses among other issues the commitment that each university shows the development of the area or region where it is inserted, the answers offered to the needs of regional or local community through the generation of useful knowledge to solve these problems, as well as the way in which the relationship between the university and the different social actors in each territory is strengthened.

This second axis of the concept of university social responsibility described in our study is oriented towards the external environment of universities, by posing a major challenge to break with the traditional view of tower of ivory which are described many times, moving towards closer links with the community and the environment that welcomes them.

\section{INTRODUCCIÓN}

El artículo presenta parte de los resultados obtenidos en el proyecto Fondecyt de Iniciación a la Investigación N¹1121144 denominado "Una mirada a la responsabilidad social universitaria en la ciudad de Antofagasta".

El propósito principal de este trabajo es describir las miradas que asignan al concepto de responsabilidad social universitaria (RSU) los dirigentes estudiantiles de las universidades de la ciudad de Antofagasta en Chile, mediante un enfoque de investigación cualitativo a través de entrevistas semi-estructuradas.

La literatura relacionada con la RSU atribuye una gran importancia a los impactos sociales del quehacer universitario y cómo la universidad puede contribuir efectivamente al desarrollo más equilibrado de la sociedad. Por otro lado, muchas investigaciones indagan en la opinión y conocimiento de los estudiantes sobre la responsabilidad social, así como respecto de las competencias que están relacionadas con la formación de profesionales socialmente responsable. 
En ese contexto, desde 1998 la UNESCO viene desarrollando un importante llamado a las universidades para que asuman su responsabilidad social insertas en la denominada sociedad del conocimiento, lo que obliga a las instituciones universitarias a reflexionar sobre la efectividad e impacto de su misión en dicho escenario.

Así, el artículo en su primera parte ofrece un resumen de los principales lineamientos teóricos existentes en la literatura sobre el concepto de RSU, con especial énfasis en los estudios que analizan la mirada estudiantil sobre el comportamiento socialmente responsable de las universidades.

En la segunda parte, se presente los resultados de la investigación que señalan que los dirigentes universitarios entrevistados vinculan el concepto de responsabilidad social con un rol social más activo y cercano de la universidad, respecto de las problemáticas que afectan directamente a la comunidad del territorio o región donde está inserta cada institución universitaria. Asimismo, relacionan el concepto de RSU con un proceso de formación profesional que sea capaz de confrontar a los estudiantes y sus conocimientos profesionales con las necesidades y requerimientos de la comunidad.

\section{REVISIÓN DE LA LITERATURA}

En 1984, Derek Bok ex Presidente de la Universidad de Harvard publicaba un libro en el que reflexionaba sobre la responsabilidad social de la universidad moderna en torno al concepto de "multiversity", a través del cual intentaba describir los nuevos roles que le correspondían a las universidades norteamericanas de aquella época frente a los nuevos y crecientes requerimientos de la sociedad.

Posteriormente, en 1998 durante la Conferencia Mundial de Educación Superior realizada en Paris, la UNESCO formuló un llamado a las universidades para que asumieran una mayor responsabilidad social en el contexto de su rol en la sociedad del conocimiento, por lo que desde entonces el concepto de RSU ha adquirido un importante desarrollo a nivel mundial (De la Calle et al, 2007; Gaete, 2011).

En dicho escenario, el filósofo francés François Vallaeys (2008:209) se ha transformado en uno de los principales consultores internacionales sobre esta temática, definiendo a la RSU como:

Una política de mejora continua de la universidad hacia el cumplimiento efectivo de su misión social mediante 4 procesos: gestión ética y ambiental de la institución; formación de ciudadanos responsables y solidarios; producción y difusión de conocimientos socialmente pertinentes; participación social en promoción de un desarrollo más humano y sostenible. 
Asimismo, Vallaeys et al (2009) señalan que la RSU se define en función de los impactos generados en virtud del quehacer universitario, identificando 4 posibles tipos de impactos:

- Impactos organizacionales: relativos a los aspectos laborales y ambientales, etc.

- Impactos educativos: relacionados con la formación académica y ciudadana.

- Impactos cognitivos: vinculados con la producción de conocimiento, investigación, etc.

- Impactos sociales: extensión universitaria, proyección social de la universidad, etc.

Otro de los aportes relevantes a la difusión e investigación sobre el concepto de RSU proviene de Chile, a partir la ejecución del proyecto "Universidad Construye País" (UCP), iniciativa que estuvo vigente entre los años 2001 al 2008, que define este concepto como "la capacidad que tiene la universidad como institución, de difundir y poner en práctica un conjunto de principios y valores generales y específicos por medio de los procesos clave de gestión, docencia, investigación y extensión, respondiendo socialmente así ante la comunidad universitaria y el país en que está inserta" (Jiménez, 2002:11).

La definición de RSU del proyecto UCP en Chile se sustentaba en la existencia de un conjunto 11 de valores y principios distintivos de la universidad socialmente responsable: dignidad de la persona humana, libertad, ciudadanía democracia y participación, sociabilidad y solidaridad para la convivencia, bien común y equidad social, desarrollo sustentable y medio ambiente, aceptación y aprecio a la diversidad, compromiso con la verdad, integridad, excelencia, interdependencia e interdisciplinariedad.

También desde el ámbito Latinoamericano, la Asociación de Universidades confiadas a la Compañía de Jesús en América Latina (AUSJAL) ha desarrollado contribuciones importantes para la instalación de la RSU en las universidades de América Latina, definiendo el comportamiento socialmente responsable de las universidades como:

La habilidad y efectividad de la universidad para responder a las necesidades de transformación de la sociedad donde está inmersa, mediante el ejercicio de sus funciones sustantivas: docencia, investigación, extensión y gestión interna. Estas funciones deben estar animadas por la búsqueda de la promoción de la justicia, la solidaridad y la equidad social, mediante la construcción de respuestas exitosas para atender los retos que implica promover el desarrollo humano sustentable. (AUSJAL, 2009:9). 
Actualmente, algunos investigadores han analizado a la RSU desde diferentes perspectivas, confirmando el carácter "caleidoscópico" que se le asigna en la literatura, existiendo diferentes significados y enfoques conceptuales de la RSU (Martínez, 2008; Martí et al, 2011). Así por ejemplo, De la Cruz y Sasia (2008) identifican tres significados de la RSU:

- Consecuencialista: La universidad debe devolver a la sociedad lo que ésta le ha dado, en términos de una deuda con la sociedad con un sentido asistencial y reactivo.

- Contractual: Respuestas universitarias a las demandas de la sociedad, expresadas en un compromiso social de la universidad.

- Prospectivo: Contribución universitaria para regenerar a la sociedad, más allá de su misión institucional, actuando como un agente social en colaboración con otros agentes.

En cambio, Gaete (2011) identifica tres enfoques o perspectivas de la RSU:

- Gerencial: Analizan el impacto del quehacer universitario en la sociedad, especialmente mediante la rendición de cuentas hacia sus stakeholders.

- Transformadora: Fortalecen el rol de la universidad en el debate y reflexión sobre una sociedad más justa y sustentable.

- Normativo: Consagración del comportamiento ético y moral de las personas en la sociedad y en la propia universidad, mediante valores y principios.

De acuerdo con Larrán y López (2010), la investigación relacionada con el concepto de RSU ha estado mayormente relacionada con la evaluación de las percepciones de los estudiantes sobre el concepto, la oferta formativa sobre la responsabilidad social corporativa en las universidades y los estudios de caso relacionados con las universidades que han adoptado este modelo.

Sin embargo, cuando el foco de atención de los estudios e investigaciones sobre la responsabilidad social se concentra en la percepción o significado que tiene la RSU para los estudiantes, surgen otras perspectivas interesantes que orientan la forma de comprender este concepto, especialmente en lo relativo a la formación universitaria como el medio para proporcionar a los futuros profesionales universitarios los conocimientos y capacidades necesarias para empatizar con los demás, valorar las consecuencias de su ejercicio profesional en la sociedad, o contribuir a la comunidad con una mayor vocación de servicio (De la Calle, 2007; Martínez, 2008; Martí-Vilar et al, 2011).

En ese contexto, una de las estrategias de formación que fortalecen o desarrollan a la RSU en los estudiantes universitarios es el aprendizaje servicio (Martínez, 2010), el cual busca combinar en el proceso formativo universitario una intencionalidad pedagógica y una solidaria (Cecchi, 2006), las que no necesa- 
riamente se desarrollan de forma coordinada, por el contrario, muchas veces las expresiones solidarias de los estudiantes se canalizan a través del denominado voluntariado universitario, el cual obedece a iniciativas desarrolladas por los propios estudiantes, y no de manera institucionalizada.

Según De la Calle \& Jiménez (2011), la RSU no implica únicamente a la acción social, ya que no se trata de llevar a cabo acciones puntuales de tipo altruista o con carácter humanitario, por lo que las acciones que incluyen únicamente al voluntariado o la acción social de los universitarios no son suficiente expresión de la RSU.

En el cuadro 1, se presentan algunos ejemplos de investigaciones sobre la RSU que consideran a la perspectiva estudiantil como eje o perspectiva importante para analizar dicho concepto.

Cuadro 1. Investigaciones sobre la RSU basadas en la perspectiva estudiantil

\begin{tabular}{l|l|l}
\hline Autores & Objetivo del estudio & Principales hallazgos o resultados \\
\hline Nustamante \& & $\begin{array}{l}\text { Auto-atribución de } \\
\text { comportamientos } \\
\text { socialmente } \\
\text { responsables en } \\
\text { estudiantes chilenos. }\end{array}$ & $\begin{array}{l}\text { Mejores resultados se obtienen respecto } \\
\text { de los comportamientos respeto por los } \\
\text { espacios compartidos, auto-cuidado, } \\
\text { convivencia social y responsabilidad } \\
\text { académica. }\end{array}$ \\
\hline $\begin{array}{l}\text { Domínguez \& } \\
\text { López (2009) }\end{array}$ & $\begin{array}{l}\text { Desarrolla un } \\
\text { cuestionario abierto } \\
\text { para estudiantes de } \\
\text { Trabajo Social, para } \\
\text { observar la medida } \\
\text { en que el tema de la } \\
\text { RSU forma parte de } \\
\text { sus intereses. }\end{array}$ & $\begin{array}{l}\text { Los estudiantes afirman el rol clásico de } \\
\text { la universidad es la formación con matices } \\
\text { no solo profesionales sino también } \\
\text { humana y responsable, en diálogo abierto } \\
\text { con la sociedad, sensible a sus problemas, } \\
\text { respetuoso del medio ambiente, entre } \\
\text { otros. }\end{array}$ \\
\hline Jara \& & $\begin{array}{l}\text { Analiza el efecto del } \\
\text { voluntariado } \\
\text { Uidal (2010) } \\
\text { RSU en estudiantes } \\
\text { universitarios chilenos. }\end{array}$ & $\begin{array}{l}\text { Los jóvenes que comienzan a desarrollar } \\
\text { voluntariado tienen una muy alta/alta } \\
\text { responsabilidad social. No obstante, el } \\
\text { voluntariado tiene un efecto bajo en la } \\
\text { responsabilidad social. }\end{array}$ \\
\hline López \& & $\begin{array}{l}\text { Examinar actitudes y } \\
\text { valores sobre la ética } \\
\text { la responsabilidad } \\
\text { social corporativa de } \\
\text { los estudiantes de } \\
\text { Admon. de empresas, } \\
\text { Universitat Jaume I. }\end{array}$ & $\begin{array}{l}\text { Los estudiantes encuestados se muestran } \\
\text { más próximos al enfoque de los } \\
\text { interesados (stakeholders), que al modelo } \\
\text { de los intereses de los accionistas } \\
\text { (2011) }\end{array}$ \\
\hline
\end{tabular}




\begin{tabular}{|c|c|c|}
\hline Autores & Objetivo del estudio & Principales hallazgos o resultados \\
\hline $\begin{array}{l}\text { De la Calle \& } \\
\text { Jiménez (2011) }\end{array}$ & \begin{tabular}{|l|} 
Analiza el constructo \\
responsabilidad social \\
del universitario en \\
alumnos de la \\
asignatura de \\
responsabilidad social \\
Universidad Francisco \\
de Vitoria España.
\end{tabular} & $\begin{array}{l}\text { Escala de medida de la RS del universitario, } \\
\text { entendiéndola como el compromiso } \\
\text { personal con los demás y con el entorno } \\
\text { que asume cada universitario hoy, para el } \\
\text { día de mañana ejercer su profesión como } \\
\text { un servicio a la sociedad en la búsqueda } \\
\text { del bien común. }\end{array}$ \\
\hline $\begin{array}{l}\text { Díaz \& Facal } \\
\text { (2011) }\end{array}$ & \begin{tabular}{|l|} 
Conocer la percepción \\
de estudiantes de \\
carreras de la \\
Universidad de la \\
Empresa respecto de la \\
responsabilidad social \\
de la universidad.
\end{tabular} & $\begin{array}{l}\text { La mayoría de los encuestados conocen los } \\
\text { términos relacionados al desarrollo } \\
\text { sostenible, los que no han sido obtenidos } \\
\text { en la formalidad curricular sino que han } \\
\text { sido adquiridas en la educación extra } \\
\text { universitaria (no formal). }\end{array}$ \\
\hline $\begin{array}{l}\text { Martí-Vilar et } \\
\text { al (2011) }\end{array}$ & $\begin{array}{l}\text { Analizar la influencia } \\
\text { de la formación } \\
\text { académica en generar } \\
\text { un sentido de } \\
\text { responsabilidad social } \\
\text { en alumnado de } \\
\text { universidades } \\
\text { iberoamericanas. }\end{array}$ & $\begin{array}{l}\text { Representa una primera aproximación al } \\
\text { estudio de la RSU desde la perspectiva de } \\
\text { la interacción de procesos educativos, } \\
\text { procesos de psicología básica, } \\
\text { neuropsicología, psicología social y } \\
\text { metodología. }\end{array}$ \\
\hline $\begin{array}{l}\text { Navarro et } \\
\text { al (2012) }\end{array}$ & $\begin{array}{l}\text { Identificar valores y } \\
\text { actitudes hacia la } \\
\text { responsabilidad social } \\
\text { en estudiantes } \\
\text { universitarios. }\end{array}$ & $\begin{array}{l}\text { Las dimensiones valóricas medidas se } \\
\text { relacionan positiva y significativamente } \\
\text { con el comportamiento socialmente } \\
\text { responsable. }\end{array}$ \\
\hline $\begin{array}{l}\text { Arango et } \\
\text { al (2014) }\end{array}$ & $\begin{array}{l}\text { Determinar la relación } \\
\text { entre formación } \\
\text { académica, empatía, } \\
\text { valores y } \\
\text { comportamientos } \\
\text { socialmente } \\
\text { responsables en } \\
\text { estudiantes de } \\
\text { pregrado. }\end{array}$ & $\begin{array}{l}\text { Existe una mayor atribución de } \\
\text { comportamientos socialmente } \\
\text { responsables relacionados con el } \\
\text { autocuidado, ecología / medioambiente y } \\
\text { respeto por los espacios compartidos. }\end{array}$ \\
\hline
\end{tabular}

Fuente: Elaboración propia 
Según lo planteado en el cuadro 1 , los principales ejes de las investigaciones basadas en las perspectivas de los estudiantes universitarios buscan por una parte conocer la percepción que tienen sobre el concepto de RSU (Domínguez y López, 2009; De la Calle y Jiménez, 2011; Díaz y Facal, 2011). Por otro lado, existen estudios que analizan las actitudes y los comportamientos socialmente responsable de los estudiantes (Davidovich et al, 2005; Bustamante y Navarro, 2007; López y Segarra, 2011; Navarro et al, 2012; Arango et al, 2014). Asimismo, Jara y Vidal (2010) analizan el efecto que tiene el voluntariado universitario en la RSU en estudiantes universitarios chilenos.

Además, respecto del cuadro 1 podemos observar un dominio importante del enfoque de investigación cuantitativo y el uso del cuestionario como instrumento para recolectar la información de los estudios sobre la RSU desde la perspectiva de los estudiantes, situación que en Chile fue desarrollada de manera pionera para esta temática por Davidovich et al (2005) desde la perspectiva psicológica, construyendo un cuestionario piloto para evaluar comportamientos socialmente responsables en estudiantes universitarios, con énfasis en la frecuencia del comportamiento y la intención subyacente en el mismo.

\section{METODOLOGÍA}

La investigación desarrollada desde la perspectiva del paradigma interpretativo-hermenéutico, tiene como objetivo principal comprender el concepto de RSU desde la mirada dialógica y simbólica del significado, experiencias y proyecciones que le atribuyen al mismo las partes interesadas en el quehacer universitario. Para ello, se utiliza un diseño de investigación de tipo cualitativo, considerando para el caso del presente artículo el análisis de la percepción que tienen los dirigentes estudiantiles universitarios sobre el comportamiento socialmente responsable de las universidades de la ciudad de Antofagasta en Chile.

La técnica de recolección de la información es la entrevista semi-estructurada realizándose un total de catorce entrevistas durante el año 2014, en un formato individual, en un solo encuentro y enfocadas en una sola temática. El entrevistador proporcionará el mismo estímulo o planteamiento inicial a cada entrevistado sobre la problemática estudiada, utilizándose una pauta de cotejo de los tópicos relevantes para la investigación, y solamente en aquellos casos en los que el respectivo entrevistado no abarcara dentro de su intervención alguno de dicho temas, solo entonces se procederá a formular la pregunta respectiva sobre dicha temática.

En cuanto a los sujetos a entrevistar, se utiliza una muestra intencional de tipo teórica que prioriza la representatividad sustantiva por sobre aquella de tipo estadística, dado que lo que se intenta es incluir a los actores sociales de inte- 
rés en cuanto al discurso que reproducen con el propósito de "recoger la información más relevante para el concepto o teoría buscada" (Ruiz Olabuénaga, 2007:64), intentando saturar los lugares de enunciación, es decir cuando los datos que surjan de las entrevistas comiencen a repetirse y no aporten nuevos elementos al análisis del tema investigado.

En virtud de lo anterior, la muestra intencional del estudio incluye a los dirigentes estudiantiles universitarios que fueron elegidos democráticamente para formar parte de las Federaciones de Estudiantes o Centros de Alumnos de las siguientes universidades: Universidad de Antofagasta, Universidad Católica del Norte, Universidad Pedro de Valdivia, sede Antofagasta.

Para el análisis e interpretación de los datos se seguirán los procedimientos establecidos por la teoría fundamentada de los datos (Grounded Theory) apoyados por el software Atlas Ti, mediante el siguiente procedimiento: identificación de los incidentes para asignarle códigos (microanálisis); comparación de los códigos sustantivos, conceptos y categorías (Codificación); y la integración de estos elementos en una teoría que se elabora a partir de los datos que permitan construir hipótesis teóricas.

Para la triangulación de los datos, se utiliza la técnica de focus group desarrollada con siete presidentes de centros de alumnos de carreras de pregrado de la Universidad de Antofagasta y Universidad Católica del Norte.

\section{RESULTADOS}

A partir de las transcripciones de las catorce entrevistas semi-estructuradas realizadas a dirigentes universitarios, se obtuvieron diferentes discursos sobre la RSU y sus principales características, por lo que dicho concepto según los entrevistados se estructura en torno a dos grandes categorías: Rol social de la universidad y formación profesional.

De acuerdo con el cuadro 2, algunos de los dirigentes universitarios entrevistados plantean claramente cuál debe ser el significado y la aplicación de la responsabilidad social al ámbito universitario:

"...la responsabilidad social universitaria, es lo que es el rol social, que las Instituciones en este caso educativas tienen sobre la comunidad, tienen sobre los procesos tanto reivindicativos, como de transformación de la comunidad, entonces la Universidad en sí tiene un rol social importantísimo que cumplir, porque son un aporte también al mejoramiento de la calidad de vida de los ciudadanos y de las ciudadanas..." (E4)

“...si es que la universidad habla de responsabilidad social o se enmarca bajo ese sello, lo primero que tendría que hacer es que las mismas mallas curricu- 
Cuadro 2. Categorías de análisis de los resultados

\begin{tabular}{|c|c|c|c|}
\hline Códigos & Conceptos & Categorías & Categoría central \\
\hline Mallas curriculares & \multirow{3}{*}{$\begin{array}{l}\text { Modelo } \\
\text { educativo }\end{array}$} & \multirow{5}{*}{$\begin{array}{c}\text { Proceso } \\
\text { formativo } \\
\text { relacionado } \\
\text { con el entorno }\end{array}$} & \multirow{11}{*}{$\begin{array}{c}\text { Concepto de } \\
\text { responsabilidad } \\
\text { social } \\
\text { universitaria }\end{array}$} \\
\hline Aprendizaje servicio & & & \\
\hline Rol de los profesores & & & \\
\hline Sensibilidad social & \multirow{2}{*}{$\begin{array}{l}\text { Voluntariado } \\
\text { universitario }\end{array}$} & & \\
\hline $\begin{array}{c}\text { Organizaciones sociales } \\
\text { estudiantiles }\end{array}$ & & & \\
\hline Necesidades sociales & Respuestas a los & \multirow{6}{*}{$\begin{array}{l}\text { Rol social } \\
\text { de la } \\
\text { universidad }\end{array}$} & \\
\hline $\begin{array}{l}\text { Investigación } \\
\text { universitaria }\end{array}$ & $\begin{array}{c}\text { problemas de la } \\
\text { comunidad }\end{array}$ & & \\
\hline Identidad regional & \multirow{2}{*}{$\begin{array}{c}\text { Compromiso } \\
\text { regional }\end{array}$} & & \\
\hline $\begin{array}{c}\text { Diagnóstico problemas } \\
\text { regionales }\end{array}$ & & & \\
\hline Enfoque sistémico & \multirow{2}{*}{$\begin{array}{c}\text { Relación univer- } \\
\text { sidad-sociedad }\end{array}$} & & \\
\hline Transformación social & & & \\
\hline
\end{tabular}

Fuente: Elaboración propia

lares, estén adecuadas a un punto de vista más social, ósea que los estudiantes tengan una visión de lo que pasa realmente en la comunidad, las deficiencias que ellos tienen, del compromiso que ellos tienen como profesionales para ayudar al desarrollo de esas problemáticas y que luego se puedan solucionas. En términos de la investigación que debe tener una universidad, si es que tiene responsabilidad social, tiene que estar ligada a aspectos más sociales de por qué se dan esas problemáticas y cuáles son las soluciones que necesita la sociedad..." (E13)

Lo planteado en el cuadro 2, también queda reflejado en el focus group con presidentes de centros de alumnos, como la estrategia de triangulación con las entrevistas individuales utilizado en nuestra investigación:

"...la responsabilidad social se puede decir como un pilar fundamental al rol que tiene la universidad de incorporar a la comunidad, para que junto a ella hacer universidad, yo creo que uno de los pilares fundamentales que debe tener una institución en cuánto a formar profesionales como también junto a estos, saber de las deficiencias que tienen a nivel social..." (P.2)

Así, formar profesionales plenamente conscientes del entorno y los problemas sociales del mismo parece ser un aspecto importante de la RSU en opinión de 
los estudiantes entrevistados durante nuestra investigación, lo que a su vez se encuentra conectado con un importante rol social del quehacer universitario.

\subsection{El rol social de la universidad}

Respecto de esta categoría del concepto de RSU, desde un punto de vista teórico diferentes autores coinciden en destacar que una parte importante de dicho concepto está relacionado con una mayor incidencia de la universidad en la sociedad, debiendo asumir un protagonismo o un rol más importante en la determinación del tipo de sociedad más idónea para el siglo XXI (UNESCO, 1998; De la Cruz \& Sasia, 2008; Gaete, 2011).

En el caso de los estudiantes entrevistados en la investigación desarrollada en la ciudad de Antofagasta, éstos identifican tres grandes aspectos que describen este rol: (1) respuestas a las problemáticas de la comunidad, (2) compromiso regional y (3) relación de la universidad con la sociedad.

Así, los dirigentes estudiantiles evidencian la importancia que tiene el fortalecimiento del rol social de la universidad más allá del habitual funcionamiento dentro de sus campus, pasando a orientar una parte importante de su quehacer institucional hacia la generación de contribuciones reales y concretas para solucionar las principales problemáticas regionales y para alcanzar un desarrollo más sostenible de la Segunda Región.

\subsubsection{Respuestas a las problemáticas de la comunidad}

En lo relativo a esta subcategoría, los dirigentes universitarios plantean en las entrevistas que el quehacer universitario socialmente responsable debe estar directamente conectado con la búsqueda de las causas y soluciones a las principales necesidades sociales como una cuestión prioritaria.

“....responsabilidad social universitaria debería enfocarse en las reales necesidades de la comunidad, responderle a esas necesidades..." (E10)

"...la investigación que debe tener una universidad, si es que tiene responsabilidad social, tiene que estar ligada a aspectos sociales de por qué se dan esas problemáticas y cuáles son las soluciones que necesita la sociedad..." (E13)

Así, existe una clara alusión a la función de investigación como un ámbito importante para que las universidades que deseen fortalecer su RSU desarrollen proyectos y líneas de investigación que intenten generar el conocimiento necesario para apoyar a la sociedad local en la solución de las problemáticas que la afectan con mayor urgencia. Lo anterior, es posible triangularlo con un discurso proveniente del focus group: 
“...había una interacción distinta, ya de la universidad con la comunidad, en el desarrollo de esa comunidad, en la capacitación de esa comunidad, incluso en actividades que no fueran ligadas a una ciencia específica, sino que a ver las problemáticas reales de la comunidad y ver nosotros con nuestras herramientas que nos entrega la Universidad como podríamos solucionarlas..." (P.7)

En este sentido, Domínguez y López (2009) concluyen que la universidad socialmente responsable a través de un diálogo abierto, debe ser capaz de prever y alertar a la sociedad sobre nuevas tendencias para evitar situaciones graves que la pongan en riesgo.

Así, la investigación universitaria socialmente responsable se transforma en un pilar fundamental para concretar un rol social más activo a través de la generación constante de nuevo conocimiento que ofrezca respuestas claras para las problemáticas locales más relevantes, impulsando investigaciones y estudios que sean más pertinentes en ese sentido.

\subsubsection{Compromiso regional}

Según los estudiantes entrevistados el rol social de la universidad como categoría del concepto de RSU, también se ve reflejado en un "Compromiso Regional" en cuanto a los impactos del quehacer universitario en la Región o el territorio donde la universidad está instalada.

"...somos una universidad regional y tenemos que mejorar nuestra región, por lo tanto, todo lo que es responsabilidad social, lo enfrasco hacia la comunidad..." (E1)

“...más allá del asunto que pueda pasar con los estudiantes, está el asunto de los mismos estudios que ellos hacen, que estén muy orientados a problemáticas de la región que se están desarrollando, los problemas que puede tener la comunidad..." (E13)

Desde una perspectiva teórica, los impactos de la universidad en la sociedad como parte del concepto de RSU fueron planteados en la literatura inicialmente por Vallaeys (2008) y reafirmados por propuestas posteriores (De la Calle y Sasia, 2008; Gaete, 2011). En las transcripciones del focus group realizado con presidentes de centros de alumnos, encontramos otro discurso que realza la importancia del compromiso regional de las universidades con la RSU:

“...la sustentabilidad universitaria es importante, cómo vamos hacer que la universidad siga circulando, vinculándose con la comunidad y la comunidad con la universidad, entonces sin una consciencia va a ser unidireccional, se van a venir personas a estudiar acá y se van a ir afuera, no se va potenciar la región, porque van a estar estudiando conceptos que no son de aquí..." (P.7) 
De esta forma, la universidad socialmente responsable debe asumir un compromiso importante con el territorio o región en donde la universidad está inserta, situación que por ejemplo es planteada por la UNESCO (1998) a través del concepto de pertinencia de la educación superior, que establece la necesidad de que el quehacer universitario se ajuste a los requerimientos de la sociedad, especialmente aquella más próxima a cada universidad.

Por ello, el compromiso regional como un aspecto del comportamiento socialmente responsable de una universidad debe ser asumido con un carácter estratégico de largo plazo, que pueda estar expresado explícitamente por ejemplo en su declaración de misión y visión institucional. Dentro de las acciones concretas que puedan reflejar este compromiso con lo regional y la comunidad más próxima, es posible mencionar por ejemplo una oferta formativa acorde a los requerimientos laborales propios de la región, o con la creación de instancias estratégicas que permitan a las universidades demostrar permanentemente este compromiso como los procesos de rendición de cuentas o el desarrollo de acciones que busquen beneficiar claramente a los habitantes de la región en el mediano y largo plazo, a través de centros u observatorios sobre aspectos ambientales o clínicas odontológicas o jurídicas.

\subsubsection{Relación universidad-sociedad}

En este elemento se establece la necesidad de fortalecer y profundizar una vinculación más estrecha y cercana entre ambas partes, especialmente desde la perspectiva de considerar a la universidad como integrante de la propia sociedad, no como un elemento aislado, diferente o desconectado de la misma:

“...cuando la universidad se olvidó que es parte de la comunidad pasa esto, pasa que estemos hablando de responsabilidad social universitaria..." (E10)

"...la responsabilidad social universitaria, es lo que es el rol social, que las instituciones en este caso educativas tienen sobre la comunidad, tienen sobre los procesos tanto reivindicativos, como de transformación de la comunidad..." (E4)

Los participantes del focus group también destacan la necesidad de que la RSU se traduzca en una fuerte integración con la comunidad:

“... definiría la responsabilidad social en cuanto al rol de incorporar a la comunidad hacia la universidad y junto a ella hacer universidad, porque hacer universidad no es solamente fumarse un pucho e irse pa la casa, hacer universidad es debatir, discutir, crear..." (P.2) 
Asimismo, en la literatura relativa al concepto de RSU, Gaete (2011) plantea el rol transformacional de la universidad socialmente responsable, para describir la estrecha relación que debe existir entre la sociedad y sus universidades, en cuanto a la contribución que estas últimas deben realizar al tejido social donde están insertas, asumiendo un mayor liderazgo social para apoyar a la sociedad en la obtención de un desarrollo más sostenible.

La función de vinculación con el medio que actualmente desarrollan muchas universidades, antiguamente denominada como "Extensión universitaria", puede transformarse en un espacio tremendamente interesante para desarrollar acciones que fortalezcan la relación de la universidad con su entorno, que le permitan asumir una mayor interacción y liderazgo de la sociedad local para guiarla hacia escenarios de desarrollo más favorables dentro del territorio.

\subsection{Formación profesional}

Una segunda categoría atribuida al concepto de RSU por parte de los dirigentes universitarios entrevistados durante la investigación, se relaciona con el tipo de formación profesional que debe proporcionar una universidad socialmente responsable a sus estudiantes, la cual según los dirigentes universitarios entrevistados estaría vinculada con cuatro grandes elementos que la describen: modelo educativo, aprendizaje servicio, rol del profesor y voluntariado estudiantil.

De esta manera, el concepto de RSU según los dirigentes universitarios entrevistados se basa en un proceso de formación profesional con características distintivas, que abarcan los aspectos más estratégicos del funcionamiento de una universidad como lo es su modelo educativo donde se definen las bases fundamentales de su proyecto institucional. Pero también, los estudiantes entrevistados identifican aspectos más operativos relativos a su formación profesional socialmente responsable, como las estrategias de enseñanza-aprendizaje o la injerencia de sus profesores en este proceso.

Finalmente, los dirigentes universitarios entrevistados asignan un papel muy importante a las actividades de voluntariado universitario, como una reacción de los estudiantes para intentar subsanar las carencias que identifican en su proceso formativo respecto de una mayor conexión con la realidad local, desarrollando acciones en terreno mediante la creación de una serie de organizaciones sociales con base estudiantil.

\subsubsection{Modelo educativo}

En lo que se refiere al "Modelo educativo", los dirigentes universitarios entrevistados lo señalan como una instancia importante para que la universidad 
socialmente responsable plasme una fuerte orientación hacia la comunidad y no hacia el mercado a la hora de formar a sus profesionales.

“...la universidad debería ser en base a la responsabilidad social con la comunidad, debería incentivarse y debería hacerse una proyección no ser un modelo educativo, como el que tiene ahora, que es un modelo en competencia..." (E10)

“...si quieren incorporar un poco más el asunto de la responsabilidad social o de una visión más comprometida con la sociedad, es necesario un cambio en las mallas curriculares, lo que le estás enseñando a los estudiantes..." (E13)

En la literatura, los análisis y propuestas teóricas de Vallaeys (2008) o Jiménez (2002) dan cuenta de la importancia de la formación socialmente responsable y a nivel empírico este aspecto es analizado reiteradamente (ver cuadro 1). Desde el focus group realizado en la investigación para triangular los resultados, también es posible confirmar dicha importancia:

“...tu pasaste tus ramos con un siete, pero no formaste la parte personal que es la más importante creo yo y que es con la cuál tu tení las herramientas necesarias para salir adelante, porque lo demás es puro libro..." (P.2)

Así, el modelo educativo que las universidades socialmente responsable desarrollen debe proporcionar lineamientos claros para la incorporación de conocimientos, habilidades y actitudes, que combinen equilibradamente dentro del proceso formativo los aspectos técnicos propios de cada perfil profesional, con el desarrollo de una mayor sensibilidad social y un liderazgo transformacional (Gaete, 2011b) respecto de las contribuciones de los estudiantes y futuros profesionales para alcanzar sociedades más justas, equitativas y sustentables.

Respecto de lo anterior, es importante mencionar la existencia en Chile del "Modelo educativo para educar la responsabilidad social" desarrollado por la Universidad de Concepción, Pontificia Universidad Católica de Valparaíso, Universidad de la Frontera y Universidad de Talca, para formar profesionales con valores, comportamientos y actitudes que los capaciten para ejercer una efectiva responsabilidad social dentro de la sociedad.

\subsubsection{Aprendizaje servicio}

Una segunda característica de la formación socialmente responsable identificada por los dirigentes universitarios en la investigación es el aprendizaje servicio, en términos de vincular simultáneamente en el proceso formativo tanto

2 http://www2.udec.cl/rsu/index.php?option=com_content\&view=article\&id=16\& Itemid $=17$ 
la intencionalidad pedagógica como la solidaria (Cecchi, 2006), algo que a juicio de los estudiantes lamentablemente no se configura en la actualidad en los modelos educativos de las universidades locales, lo que les ha llevado a desarrollar acciones de voluntariado universitario por iniciativa propia de los estudiantes.

“...la formación de profesional incluya el conocimiento de la comunidad, logre reconocer las realidades de su comunidad y no se quede simplemente en el aula, que es lo que suele pasar en estas universidades, que hay muchas carreras que son de salas, son básicamente que uno está en la sala..." (E1)

“...la responsabilidad que tiene uno frente a responder a la sociedad siendo un alumno universitario, siendo una persona de la universidad, formándose, que tiene varias ramas donde se puede ayudar a la sociedad, educando, promoviendo estilo de vida..." (E8)

Cabe mencionar que en países como Venezuela, por ejemplo, existe desde el año 2005 el denominado "Servicio Comunitario del Estudiante de Educación Superior" (SCEES), que mediante la estrategia de aprendizaje-servicio genera un espacio de desarrollo a la RSU muy relevante de analizar (Alonso, 2012).

Una percepción similar a la identificada en las entrevistas se observa en los resultados obtenidos en el focus group:

"...cada grupo tiene trabajar un tema referente a lo que es la localidad, es decir, problemas pedagógicos, problemas de cualquier tipo en el caso de nuestra área, tienen que ser de un impacto que tenga que ver directamente con la comunidad..." (P.3)

Así, diversas investigaciones vinculan a la formación socialmente responsable con un mayor compromiso con los demás y con el entorno, mayor conocimiento de la necesidad del otro y con un ejercicio profesional orientado hacia el bien común, entre otros atributos (De la Calle y Jiménez, 2011; Martí-Vilar et al, 2011; Arango et al, 2014).

De esta forma, dentro de las características de la formación universitaria que los estudiantes entrevistados valoran muy positivamente como parte del concepto de RSU, está el hecho de conocer de manera directa e in situ la realidad local de las personas y grupos que viven en la ciudad o territorio donde la universidad está instalada, ir a la comunidad y conocer cómo viven y qué problemáticas tienen. Asimismo, incorporar en su proceso formativo actividades docentes en donde sea posible contribuir activamente en la solución de problemáticas concretas de la sociedad, rompiendo de esta manera la habitual hegemonía de los aspectos teóricos sobre acciones más prácticas en las clases que reciben en la universidad. 


\subsubsection{Rol del profesor}

A consecuencia de lo planteado en el punto anterior, los dirigentes universitarios entrevistados también asignan un rol muy importante a los profesores para desarrollar un proceso formativo más socialmente responsable, especialmente respecto a la orientación que deben darle a sus clases hacia las problemáticas sociales propias de cada localidad o territorio en donde esté inserta la universidad:

“....ahora el profesor que está impartiendo este ramo, les puso como obligación que tenían que hacer un proyecto social..." (E2)

“...cuesta mucho motivar ahora al docente que vaya por voluntad propia al operativo o ayudarte en un trabajo, como que cuesta sacarlo del aula o de la oficina, quizás igual falta que la misma universidad le dé tiempo para poder participar de estas actividades..." (E3)

El rol de los docentes también está presente en los discursos sobre la RSU que se desarrollan los estudiantes que participaron en el focus group realizado para triangular los resultados de la investigación:

“... [Los profesores] igual están súper encuadrados de lo que la institución quiere entregar, la institución aunque en su misión y visión digan que quieren integrarse a la comunidad, los fines son otros, son fines más económicos..." (P.5)

Lamentablemente, existe una perspectiva negativa de los estudiantes sobre el rol del profesorado que los forma en cuanto a no vincular las clases con problemáticas y necesidades sociales reales relacionadas con su futuro ejercicio profesional, encasillando el proceso formativo en aspectos o estrategias de enseñanza de carácter más teórica que práctica lo que les impide conocer de manera más real y cercana lo que sucede en la comunidad en la cual deberán insertarse a ejercer su profesión.

Tal y como fuera señalado anteriormente, si bien existen pocas investigaciones con enfoque cualitativo sobre la percepción de los docentes sobre la RSU y su rol para incorporar dicho concepto al proceso formativo, en el estudio Ojeda (2013:22) por ejemplo se concluye que es necesario que los docentes "se capaciten, se involucren y promuevan la responsabilidad social desde sus respectivos ámbitos de influencia", confirmando con ello el importante rol que estos actores tienen respecto del concepto de RSU.

\subsubsection{Voluntariado universitario}

Finalmente, uno de los hallazgos distintivos de este estudio se relaciona con las iniciativas de voluntariado universitario que los estudiantes están desarro- 
llando por propia motivación, evidenciando un ejercicio de emprendimiento social importante, algo que está presente algunas entrevistas realizadas:

"...está trabajando 15 horas semanales en su trabajo comunitario, en su voluntariado, en lo que él considere que es correcto devolverle a la comunidad, bueno, que esas 15 horas se la reconozcan y sean tomadas como electivo..." (E10)

“...que el estudiante que no solamente se queda en el aula, sino que busque otras áreas más sociales, en las que se pueda desarrollar y aprender cuestiones súper nuevas, nosotros solamente trabajamos con estudiantes voluntarios, somos todos voluntarios..." (E12)

En el focus group la temática del voluntariado universitario también es un ámbito destacado:

"... desde que entre a la universidad he tenido la oportunidad de trabajar con un grupo de personas, en el cual hemos estado haciendo proyecto, para ayudar a una comunidad, a un campamento en este caso y he conocido mucha gente que trabaja con campamentos y ve sus problemáticas..." (P.4)

Según el estudio de Jara \& Vidal (2010) reseñado en el cuadro 1 de este trabajo, los estudiantes que realizan voluntariado poseen una alta responsabilidad social como un factor explicativo de este tipo de prácticas estudiantiles. Sin embargo, estas autoras consideran necesario que las universidades impulsen de manera institucional las acciones de voluntario universitario, por tratarse de una expresión importante de su comportamiento socialmente responsable.

No obstante, en el caso de lo planteado por los dirigentes universitarios entrevistados durante la investigación, las expresiones de voluntario universitario desarrollados surgen exclusivamente por iniciativa de los propios alumnos, se concentran preferentemente al alero de carreras del área de la salud tales como Odontología, Enfermería o Kinesiología y han avanzado hacia procesos de formalización de su funcionamiento que se traduce en la tramitación de personalidad jurídica o constitución formal ante notario, con el propósito de asociarse con otras entidades públicas o privadas para el desarrollo de sus actividades:

“...Salud en Terreno nace hace más menos ocho años, junto con la carrera de Medicina, nace con una iniciativa desde los mismos alumnos, un poco con el objetivo de retomar el rol social que debe tener el médico, nuestra carrera ha sido un poco víctima del sistema, que se ha vuelto muy comercial..." (E 2)

“...había un interés más del alumnado que desarrollara esa parte social, si igual es el interés de nosotros, o sea hay otras agrupaciones que tienen intereses de mantener en la población, pero también nuestro interés recae en generar este 
espíritu social dentro del alumnado, nosotras quizás somos un grupo, pero

la idea es que toda la carrera se empape de esto..." (E 7)

Los textos de las entrevistas realizadas citados anteriormente, ejemplifican algunas de las motivaciones que dieron origen a una serie de organizaciones sociales de carácter estudiantil en algunas universidades de la ciudad de Antofagasta, buscando espacios y experiencias reales para realizar iniciativas de carácter asistencial en terreno, pero que también abarquen contribuyan a los propios procesos formativos de los estudiantes que desarrollan los voluntariados universitarios identificados. Así, las universidades que pretendan fortalecer su comportamiento socialmente responsable debieran prestar un mayor apoyo a este tipo de iniciativas, para que se extiendan a toda la universidad y no dependan únicamente de los esfuerzos de los estudiantes o radicados en una unidad específica como la Pastoral Universitaria.

\section{CONCLUSIONES}

La mayoría de los estudios sobre la RSU donde los estudiantes son el foco principal señalan que dicho concepto se relaciona con diversas formas de expresión asociadas con valores, voluntariado, desarrollo sustentable o como un compromiso personal aplicado tanto a nivel estudiantil, como en el futuro ejercicio profesional.

El proceso de construcción social del concepto de RSU analizado en este trabajo, a partir de las experiencias y puntos de vista de dirigentes estudiantiles universitarios de la ciudad de Antofagasta, plantea claramente la necesidad de gestionar un cambio profundo en la forma en la cual una universidad desarrolla sus tradicionales funciones de docencia e investigación, debiendo además fortalecer lo que hoy se denomina en Chile como la función de vinculación con el medio, conocida tradicionalmente como extensión universitaria.

Así, un aspecto importante para canalizar el comportamiento socialmente responsable de las universidades es el proceso de formación profesional de sus estudiantes, lo que según los resultados de este estudio se encuentra relacionado con la implementación de estrategias de enseñanza aprendizaje más activa en cuanto al rol de los estudiantes, que aprovechen el entorno para facilitar una contribución más efectiva y clara de los estudiantes a la búsqueda de soluciones a las necesidades de la comunidad desde su propio proceso de formación universitaria.

La mirada más constructivista expresada por los dirigentes universitarios respecto de su proceso de formación está en consonancia con utilización de propuestas más contemporáneas de docencia universitaria, en las cuales el eje cen- 
tral del modelo educativo es el estudiante y no el profesor universitario, transformándose a nuestro juicio en un indicador importante del comportamiento socialmente responsable de una universidad.

Sin embargo, la rigidez de los planes de estudio y la preeminencia del formato de clases más tradicional de carácter expositivo utilizado por los profesores, ha planteado a los estudiantes de las universidades de la ciudad de Antofagasta la necesidad de buscar instancias para canalizar sus inquietudes de mayor interacción con la comunidad, para lo cual han desarrollado interesantes proyectos de voluntariado universitario como vía para conectar su proceso formativo con la realización de acciones de intervención social.

La buena acogida de los habitantes de la ciudad de Antofagasta, así como de otras ciudades de la Región, sumado al interés de algunas instituciones públicas y empresas privadas por colaborar con estas acciones de voluntariado, ha llevado a los estudiantes a transformar el voluntariado universitario en verdaderos emprendimientos sociales, realizando las gestiones pertinentes para obtener personalidad jurídica para darle una mayor sostenibilidad en el tiempo a los proyectos desarrollados por los estudiantes en la comunidad.

La situación descrita anteriormente, es un claro ejemplo de la relevancia que tiene el hecho de que los profesores universitarios utilicen metodologías y estrategias docentes que permitan conectar el proceso formativo de sus estudiantes con la realidad social que los rodea, para conocer de manera real y concreta las problemáticas de la comunidad local y vincular su futuro ejercicio profesional con las necesidades de la sociedad, como una clara expresión de la RSU especialmente a partir de la implementación de un modelo educativo institucional coherente con tales propósitos.

El otro gran eje de concepto de RSU identificado en el estudio se relaciona con lo que la UNESCO denominó en 1998 como la "pertinencia de la educación superior", es decir, la adecuación entre lo que la sociedad espera de las instituciones de educación superior y lo que éstas efectivamente hacen, lo que se traduce en un desafío no menor para las universidades cuyo funcionamiento institucional muchas veces está relacionado con intereses más bien de carácter interno. Pero además, hay que tener presente que algunas universidades también reciben una fuerte influencia externa dependiendo de la orientación más religiosa o laica que posean, si es de carácter estatal o privado, o su presencia nacional o regional por nombrar algunos aspectos que puedan facilitar o afectar su mayor o menor orientación hacia la sociedad, en términos de pertinencia de su quehacer como pilar fundamental del comportamiento socialmente responsable.

Según los dirigentes universitarios entrevistados en nuestro estudio, la pertinencia a la que alude la UNESCO se expresa entre otras cuestiones en el 
compromiso que cada universidad muestra con el desarrollo de la zona o región donde se encuentra inserta, las respuestas que ofrece a las necesidades de la comunidad regional o local a través de la generación de conocimiento útil para solucionar dichas problemáticas, así como por la forma en la cual se fortalece la relación de la universidad con los diferentes actores sociales en cada territorio.

Este segundo eje del concepto de RSU descrito en nuestro estudio se orienta hacia el ámbito externo de las universidades, planteándoles el importante desafío de romper con la tradicional perspectiva de torre de marfil con la cual son descritas muchas veces (Bok, 2008), avanzando hacia una mayor vinculación con la comunidad y el entorno que las acoge.

De esta manera, para el adecuado logro de ambos pilares del concepto de RSU identificados en nuestro estudio, resultará imprescindible el ejercicio de liderazgo institucional del Rector y su equipo directivo para gestionar eficientemente los cambios que son necesario implementar en torno a un modelo de RSU, mediante decisiones estratégicas que afectan la cultura y el funcionamiento organizacional más tradicional de las universidades, que permitan avanzar en la consolidación de un comportamiento socialmente responsable basado en procesos de formación desarrollados a través de estrategias de aprendizaje servicio, así como en una mayor pertinencia del quehacer universitario para alcanzar un rol social más activo de cada universidad.

\section{REFERENCIAS BIBLIOGRÁFICAS}

Arango, O.; Clavijo, S.; Puerta, I. y Sánchez, J. (2014). "Formación académica, valores, empatía y comportamientos socialmente responsables en estudiantes universitarios" Revista de la Educación Superior, 43, 169, 89-105.

AUSJAL (2009). Presentación sintetizada del sistema de autoevaluación y gestión de la responsabilidad social universitaria en AUSJAL. Disponible en: http://www. ausjal.org/tl_files/ausjal/images/contenido/Documentos/Publicaciones/Documen tos\%20Institucionales/RSU\%20AUSJAL\%20version\%20acotada.pdf (Consultado 15 de julio de 2014)

Bok, D. (2008). Más allá de la torre de marfil. La responsabilidad social de la universidad moderna. Buenos Aires: Universidad de Palermo.

Bustamante, M. \& Navarro, G. (2007). "Auto-atribución de comportamientos socialmente responsables de estudiantes de carreras del área de Ciencias Sociales”. Revista Perspectivas, 18, 45-63.

Cecchi, N. (2006). "Aprendizaje servicio en la educación superior. La experiencia latinoamericana”. Presentación en Seminario Internacional Responsabilidad social universitaria: aprendizaje servicio, Caracas. 
Davidovich, P.; Espina, Á.; Navarro, G. \& Salazar, L. (2005). "Construcción y estudio piloto de un cuestionario para evaluar comportamientos socialmente responsables en estudiantes universitarios". Revista de Psicología, 14, 1, 125-139.

De la Calle, C. \& Jiménez, P. (2011). "Aproximación al concepto de responsabilidad social del universitario". Revista Comunicación y Hombre, 7, 236-247.

De la Calle, C.; García, J. \& Jiménez, P. (2007). "La formación de la responsabilidad social en la universidad". Revista Complutense de Educación, 18, 2, 47-66.

De la Cruz, C. \& Sasia, P. (2008). "La responsabilidad de la universidad en el proyecto de construcción de una sociedad". Revista Educación Superior y Sociedad 13, 2, 17 52.

Díaz, M. \& Facal, S. (2011). "Percepciones de los estudiantes de la Facultad de Ciencias Empresariales sobre la responsabilidad social universitaria”. Revista Investigación y Desarrollo 19, 2, 340-365.

Domínguez, M. \& López, E. (2009). "Estudiantes universitarios opinan sobre la responsabilidad social universitaria”. Revista Humanismo y Trabajo Social, 8, 223-246.

Gaete, R. (2011a). "La responsabilidad social universitaria como desafío para la gestión estratégica de la Educación Superior: el caso de España”. Revista de Educación, 355, 109-133.

Jara, K. \& Vidal, D. (2010). "Voluntariado y responsabilidad social en jóvenes estudiantes de educación superior de la provincia de Concepción, Chile". Revista Trayectorias, 12, 31, 137-152.

Jiménez, M. (2002). La Universidad Construye País. Santiago de Chile: Corporación Participa. Disponible en: http://participa.cl/wp-content/uploads/2007/05/la-universidad-construye-pais.pdf (Consultado 03 de junio de 2013)

Larrán, M. y López, A. (2010). Análisis de contenido de los planes estratégicos de las universidades públicas andaluzas bajo la perspectiva de la responsabilidad social, pp.175-187. En De la Cuesta, M., De la Cruz, C. y Rodríguez, J. (Coords.) Responsabilidad Social Universitaria. La Coruña: Netbiblo.

López, M. \& Segarra, M. (2011). "Actitudes de los estudiantes de administración de empresas hacia la responsabilidad social corporativa y la ética empresarial”. Revista Complutense de Educación, 22, 2, 235-248.

Martí-Vilar, M.; Almerich, G.; Cifuentes, J.; Grimaldo, M.; Martí, J.; Merino, C. \& Puerta, I. (2011). "Responsabilidad social universitaria: Estudio iberoamericano sobre la influencia de la educación en la formación de profesionales responsables con la sociedad". Revista Técnica Administrativa, 10, 3. Disponible en: http://www. cyta.com.ar/ta1003/v10n3al.htm (Consultado 15 de enero de 2014)

Martínez, M. (Ed) (2010). Aprendizaje servicio y responsabilidad social de las universidades. Barcelona: Octaedro. 
Martínez, R. (2008). "Aplicaciones de la responsabilidad social universitaria en el contexto de formación en Colombia”. Revista Educación Superior y Sociedad, 13, 2, 163-174.

Navarro, G.; Boero, P.; Jiménez, G.; Tapia, L.; Hollander, R.; Escobar, A.; Baeza, M. \& Espina, Á. (2012). "Valores y actitudes socialmente responsables en estudiantes chilenos". Revista Calidad en la Educación, 36, 124-147.

Ojeda, J. (2013). Responsabilidad social, construcción de un concepto desde la percepción del docente universitario. Revista Teorías, enfoques y aplicaciones en las Ciencias Sociales (TEACs), 5, 12, 11-24.

Ruiz Olabuénaga, J. (2007). Metodología de investigación cualitativa, cuarta edición. Bilbao: Universidad de Deusto.

UNESCO (1998). Declaración Mundial sobre Educación Superior en el siglo XXI: Visión y Acción. Paris.

Vallaeys, F; de la Cruz, C. \& Sasia, P. (2009). Responsabilidad Social Universitaria. Manual primeros pasos. México D.F.: Mc Graw Hill.

Vallaeys, F. (2008). Responsabilidad Social Universitaria: una nueva filosofía de gestión ética e inteligente para las universidades. Revista Educación Superior y Sociedad, $13,2,191-220$.

RICARDO GAETE QUEZADA. Chileno, nacido en la ciudad de Antofagasta en 1974, Licenciado en Ciencias de la Administración por la Universidad de Antofagasta (1998), Magíster en Gestión Pública por la Universidad Complutense de Madrid (2002), Máster en Docencia para profesorado universitaria por la Universidad de Barcelona (2016) y Doctor en Procesos de Cambio Social (Sociología) por la Universidad de Valladolid (2011). Docente e investigador de la Universidad de Antofagasta en Chile, adscrito al Departamento de Ciencias Sociales de la Facultad de Ciencias Sociales, Artes y Humanidades.

Recibido: 06/07/2015

Aceptado: 22/07/2016 



\title{
DONDE LA CIUDAD SE ESCRIBE. PRENSA, URBANIZACIÓN Y CULTURA EN ROBERT E. PARK ${ }^{1}$ WHERE THE CITY IS WRITTEN. ROBERT E. PARK: ON PRESS, URBAN GROWTH AND CULTURE
}

\author{
Emilio M. Martínez Gutiérrez \\ Universidad Complutense de Madrid, España \\ emilmmar@ucm.es
}

\begin{abstract}
Cómo citar / Citation
Martínez Gutiérrez, Emilio M. (2016). "Donde la ciudad se escribe. Prensa, urbanización y cultura en Robert E. Park". OBETS. Revista de Ciencias Sociales, 11(2): 487-512. doi:10.14198/OBETS2016.11.2.05
\end{abstract}

\section{Resumen}

La recepción de la obra de Park se ha ceñido principalmente a sus trabajos de ecología urbana. Hoy día se advierte una lectura más amplia y plural que explora entre otros aspectos sus aportaciones teóricas y empíricas a otros campos de interés como la opinión pública y la prensa. El artículo aborda la vinculación existente entre prensa y ciudad, laboratorios de la modernidad y espacios de socialización, en el pensamiento de Park, partiendo de su experiencia como reporter y su vocación académica.

Palabras clave: Investigación sociológica/ Comunicación/ Prensa/ Ciudad/ Park/ Escuela de Chicago/ Cultura urbana.

\section{Abstract}

Perspectives on reception of R. Park's work have mainly revolved around urban ecology. At present we can perceive a broad and diverse reading that explores their theoretical and empirical contributions to other subjects such as public opinion and press and so on. This article deals with the link between press

\footnotetext{
${ }^{1}$ Este artículo fue escrito en el marco de una investigación de mayor alcance sufragada por el Ministerio de Educación dentro del Programa de movilidad de investigadores 2015 (PRX 14/00525).
} 
and city, laboratories of modernity and spaces of socialization, in the work and life of Park, reporter and sociologist.

Key words: Sociological Research/ Communication/ Press/ City/ Park/ Chicago School/ Urban Culture

\section{Extended Abstract}

Since the publication of "The city: Suggestion for the Investigation of Human Behaviour in the Urban Environment", first in 1915 (American Journal of Sociology) and then -with significant variations- in the collective volume The City, written with Ernst Burgess, Robert McKenzie and Louis Wirth, the reception of the Robert Ezra Park's work has essentially adhered to the urban dimension. In detail to that original scientific perspective known as urban ecology (one of the most important contributions of the Chicago School). In spite of the obvious merits, we can assure that this research line is only a bright stage of a long career related with the specific processes of the American urbanization. This partial reading, predominant until the 1990s, begins recently to be revised, either exploring the course of a comprehensive understanding of the overall work or examining other issues such as racial issues, immigration, public opinion and sociology of press. Of course, the issues and realities referred appear plentiful and crosswise in many writings of Park. Cause of these issues integrate the central problematic that gives full meaning to intellectual progression of R. Park: the study of social interactions, or the compositions of social order in changing times. Both in the one as in the other matter social communication plays a key role.

The aim of this paper is to uncover the multidimensional conception of social order and social change at Park's thought such as shown in the study of the city like ecological pattern and moral order in relation to the social communication and press. In this sense, we aspire to know the connexion between Park as author dedicated to journalism and that becomes sociologist and scholar of urban research and sociology of the press. What does the path of the journalist researcher in urban sociology? What influence does the world of news and communication in the constitution of metropolitan fabric and social structure? What are the consequences for press of heterogeneous population growth in cities? We seek to establish the profiles of this connections using as the most appropriate methodology the review of his work, following a kind of hermeneutic cycle based on the interpretation of texts in contexts. According to this methodology we can notice a plural and transversal interpretation of Robert Park's work, after considering inter alia the historical, social and intellectual context of their works and life (the reform discussion, the immigrant question in war times and so on). Struck by the dynamism that has regained its contribution to the consideration of public opinion, the social communication and the press (an absolutely modern interpretation). Such recovery rectifies certainly the canonical reading whereby the first incursion of sociological research in this sphere of studies corresponded to the work of Columbia University. But especially it involves the recognition of research consistency of the author. Indeed, without this reference to that plane of Park's 
path it would be very difficult to scope a full understanding of its sociological conception.

Until Park, Sociology generally had neglected the study of the press. This omission was certainly strange as press was a modern cultural product. Only in Max Weber's speech to the German Sociological Association (1910) we found a serious solicitation to exploring this social domain away from a moralistic approach. That is precisely the survey we find in Park, within a comprehensive program of work powered by two sources: (a) the experience as a reporter, editor and publicist; and (b) the intellectual reflection. The practice becomes an object of study. Then, if Park is not a pioneer, we can consider him a qualified analyst.

Park's prospect on press runs between intuitive knowledge and scientific knowledge, according to the distinction exposed in "News as a Form of Knowledge" (1940). There are several texts about this topic: "Foreign Language Press and Social Progress" (1920), "The Natural History of the Newspaper" (1923), "American Newspaper Literature" (1927), "News and the Human Interest Story" (1940), "News and the Power of Press" (1941), "Moral and the News (1941). We can observe that this course is more analytical than critical, taking the role of information in democracy and collective action (in the perspective of political sociology). This perspective derives in part from the Anglo-Saxon interpretation about the role of press as control device of citizenship (training / information / concerted action) and Government. It is a very interesting line of work that opens on the professional group: the role of the reporter and the course of their information. Another very original path is the one linked to the study of the urban phenomenon, which stems largely from his activity as city reporter and city editor. We find here how Park understands press and city as laboratories of modernity, and press becomes, like naturalistic romances, the privileged place to encrypt the urban daily life.

Sociologist imagined by Park seems a super-reporter. There is not an epistemological discontinuity between journalistic and sociological praxis at Park's thought, only a difference of degree. However, the journalistic experience of Park takes curious paths on the issues of sociological research and explains its obstinacy for direct data collection and the subjects themselves. Salerno (Sociology Noir. Studies at the University of Chicago in Loneliness, Marginality and Deviance 1915-1935, 2007) suggest the precipitation of a kind of sociology noir. Park's research explores the link between communication, press and city in several texts: "Natural History of Newspapers' (1923)," The immigrant community and immigrant press "(1925)," Urbanization as Measured by newspaper circulation "(1929) "Newspaper circulation and metropolitan regions" (1933). We are not talking about something cross, but the forthright study of the relation (1) between press and urban evolution; and (2) between press and urban culture. Indeed, "The City" (1915/1925) -text that opens the urban sociology research-is inconceivable without this reference to communicative processes. This connection is also expressed in many other "urban" texts on communication and media in the hardware configuration of the city or those where the author examines the role of the press on modern urban 
culture. Because urban growth is never seen as simple agglomeration of activities, social groups and individuals but as a cultural process. The modern press, a product of these urban conditions, contributes to the spread of urban values and also speeding up the assimilation process of city inhabitants of all conditions and origins. Hence, it is granted a key role in delineating a new social order, typical of complex environments; and moreover, a socializing role.

\section{INTRODUCCIÓN}

En 1915 vio la luz en el American Journal of Sociology el texto "La ciudad. Sugerencias para el análisis del comportamiento humano en el medio urbano", artículo firmado por Robert E. Park. Una segunda versión aparecería con algunos cambios diez años después en una obra colectiva (The City) donde bajo la dirección de Park participaban investigadores como Burgess, McKenzie y Wirth, esto es, el núcleo duro de lo que después sería conocido como la ecología urbana de Chicago.

Inmediatamente desde su edición hasta hoy la obra ha resultado un referente para la investigación sociológica sobre la ciudad. Pese a las controversias suscitadas respecto al valor inaugural que tendría para la sociología urbana y al alcance teórico que se le podría conceder, en el ámbito académico se admite que la recepción de la obra de Park se ha ceñido fundamentalmente a la dimensión urbana, en concreto a esa original perspectiva sobre la articulación de las comunidades en el territorio conocida como ecología de la ciudad.

Ciertamente el conjunto de sus escritos sobre el fenómeno urbano destaca por su lucidez y agilidad, con una orientación positiva hacia el hallazgo, paralela a una menor preocupación por la conceptualización. Pero con todo, y sin restarle sus enormes méritos, no deja de ser sino una fase brillante de una trayectoria dilatada, relativa, de un lado, a un periodo concreto de su producción y, de otro, a una etapa igualmente especifica del proceso de urbanización de la sociedad americana. Podríamos decir que resulta pues una lectura parcial. Predominante durante muchas décadas, esta interpretación comienza a ser rectificada de unos años a esta parte, bien explorando el cauce de una comprensión global del conjunto de su obra (Abbot, 1999; Guth, 2008), bien discurriendo por otros ámbitos característicos de su trabajo relativamente acotados, como los problemas raciales, la inmigración, la opinión pública y el mundo de la prensa. Relativamente acotados, insistimos, pues los temas y las realidades a que se refieren aparecen abundante y transversalmente en muchos de sus escritos cuando la cuestión central interpelada lo consiente. E integran esa problemática que da sentido a su progresión intelectual: el estudio de las interacciones 
sociales y el problema del orden social en situaciones de cambio acelerado. En lo uno y en lo otro la comunicación social desempeña un rol fundamental.

\section{OBJETIVOS Y METODOLOGÍA}

A partir del examen de los escritos y trayectoria de Park, siguiendo una hermenéutica que interprete la relación entre textos y contextos, el objetivo que proponemos en este trabajo es abordar la concepción poliédrica de lo social característica de su pensamiento, tal como se presenta en el estudio de la ciudad como modelo ecológico y orden moral en relación con la comunicación social y la prensa. En ese sentido, planteamos la correspondencia entre el Park dedicado al periodismo y el que deviene sociólogo y académico, estudioso de la ciudad y de la prensa. ¿Qué aporta la trayectoria del periodista al del investigador en sociología urbana? ¿Qué influencia tiene el mundo de las noticias y de la comunicación en la constitución del entramado físico y social metropolitano? ¿Qué evolución depara a la prensa la acumulación de población heterogénea en las ciudades? ¿No es la prensa el primer lugar donde la ciudad se cuenta, como sostiene Muhlmann (2008)?

Estas cuestiones sólo pueden enfrentarse sobre la base de aceptar que Park no se deja encerrar "en lecturas simplificadoras ni entre imperativos binarios" (Plenel 2008: 8). Con él siempre deambulamos por ámbitos in fieri, hibridados, acordes al itinerario de quien nunca dejó de ser "a Minnesota boy", como lo describió Raushenbush (1979) en uno de los estudios más completos dedicados al autor. Un tipo de la frontera intermedia, lo que deja impronta en su andadura y disposición -de un sitio a otro, de una ciudad a otra, de un oficio a otro-. Guth (2012) también se refiere a él en términos muy parecidos, cuando describe sus pasos por Berlín, Estrasburgo y Heidelberg: un Wandervogel [ave de paso] cuya existencia nómada se acomoda a su más que notable vagabundeo intelectual. Esa disposición explica en parte su talento para franquear territorios al margen, lugares intersticiales, sujetos y vidas en trance, atento a la hibridación cultural como la que representa la ciudad pero igualmente la prensa, a la vez instrumento de control e integración social, mercancía y producto cultural, espacio de encuentro y de socialización.

\section{LA RECEPCIÓN CONTEMPORÁNEA: LECTURAS PLURALES}

En la reciente sociología francesa se manifiesta la voluntad de superar la estricta acotación de la obra parkiana al ámbito urbano. Dicha lectura procedía del "descubrimiento" de la escuela de Chicago por Chombart de Lauwe (1950) has- 
ta su reactualización por parte de Grafmeyer \& Joseph (1979) ${ }^{2}$. Los trabajos de J. M. Chapoulie (2001), P. Lannoy (2004), D. Cerfaï (2008), D. Le Breton (2008), y muy en especial de Suzie Guth (2004, 2008), entre otros, aconsejan una interpretación más amplia, plural y transversal de su obra, atendiendo entre otros aspectos al contexto histórico, social e intelectual de su trabajo (el debate reformista, su inserción en el pragmatismo, la prolongación en el interaccionismo simbólico, las derivaciones por la sociología política hasta su recepción por disciplinas concurrentes en el estudio de la sociedad). Llama la atención el dinamismo con que se ha recobrado su aportación al estudio de la opinión pública, la comunicación social y la prensa (una interpretación absolutamente moderna). Tal recuperación rectifica sin duda la lectura canónica según la cual la primera incursión de la investigación sociológica en este campo de estudios correspondía a los trabajos de Columbia. Pero especialmente supone el reconocimiento de la coherencia investigadora del autor. En efecto, sin la referencia a esa faceta de la trayectoria parkiana sería harto difícil alcanzar una comprensión cabal del pensamiento y orientación de sus exploraciones sociológicas.

Una primera aproximación en esta dirección lo encontramos en el estudio de Bourmeau (1988), que tienen continuidad en los trabajos de Muhlmann en Du journalisme en démocratie (2004). En esta obra se dedica todo un capítulo a la sociología de la prensa en Park. Por su parte, Suzie Guth (2008) retoma los planteamientos sobre la muchedumbre y la opinión pública expuestos en la tesis doctoral de Park, Masse und Publikum (texto traducido al francés en el 2008). Y en Le journaliste et le sociologue (2008) Muhlmann y Plenel reúnen algunos textos de Park consagrados al estudio de las noticias, la circula-

${ }^{2}$ En realidad la primera referencia en el ámbito académico francés a la escuela de Chicago la encontramos en el texto "Chicago, expérience ethnique" (1932) de Maurice Halbwachs. Éste realizó una estancia en la Universidad de Chicago durante el otoño de 1930, por invitación de E. Faris. En el citado texto se da cuenta de los trabajos, los planteamientos y el contexto de esa "escuela particular de sociología" como la denominó el durkheimiano. De la realidad social de Chicago, Halbwachs da testimonio también en la serie de ocho artículos publicados durante ese tiempo en el diario Le Progrès de Lyon, lo que no deja de tener su interés en el marco de las relaciones entre la sociología (científica) y la información periodística.

Merece la pena referir el primer contacto entre Park y Halbwachs en la Universidad de Chicago, no muy afortunado. En una de las cartas que dirige a su mujer Halbwachs le confiesa que: "Hoy, cuando me disponía a comer solo, un sociólogo llamado Park ha venido a sentarse a mi mesa. Este Park es un tipo que debe rondar los sesenta, de fisionomía adusta, pero al que no le falta estilo. Tiene el aire de un filósofo alemán. Pero es uno de los tipos a quien más me cuesta comprender. Se dedica a la sociología urbana. Cuando subí a mi habitación ya no podía más". Topalov ha reunido las cartas, textos y los escritos científicos asociados a la estancia americana de M. Halbwachs en Écrits d'Amerique (2012). 
ción de la prensa, la formación de la opinión pública y su relación con el poder. La aproximación cultural y política de la prensa también es tratada en la exposición de Lazar (2006).

En la sociología española la recepción de Park ha seguido un curso similar, privilegiando la referencia ecológica. Atendiendo a sus derivaciones sobre la desorganización de las comunidades locales, la antropología y el trabajo social han discurrido igualmente por ese ámbito casi estipulado. No obstante, otras lecturas han actualizado su reflexión sobre la comunicación y la prensa. La traducción de La masa y el público apareció en la Revista Española de Investigaciones Sociológicas en 1996, con la excelente presentación de Sánchez de la Yncera y López-Escobar. Poco después se editó la monografía de R. Berganza (2000), hasta hoy el texto más completo en español sobre esta dimensión del pensamiento de Park. En 2013 Cuadernos de Información y Comunicación publicó la traducción del texto de Park "Moral and the News" (1941). No deja de ser interesante que haya sido en el ámbito más hibridado de los estudios de Comunicación, quizás menos inclinado al prejuicio hacia lo que algunos plantean como investigaciones "profanas" sobre la realidad social, donde se ha impulsado una lectura más abierta de la obra de Park.

\section{COMUNICACIÓN Y SOCIOLOGÍA DE LA PRENSA}

Considerando que la prensa puede operar como agente de transformación y control social, y que es a la vez producto de la modernización, como la propia sociología, cabía esperar el interés de ésta por el escrutinio de la prensa. Cierto que contamos con observaciones de Tocqueville, Durkheim o Tarde, pero se trata de reflexiones muy generales, incorporadas o derivadas de sus teorías sobre la democracia, la solidaridad social, las representaciones colectivas, las leyes de la imitación social... en el advenimiento de una sociedad de masas, industrial y urbana. Ninguna aborda específicamente el papel de la prensa aunque si se preocupan ciertamente por la opinión pública. (No deja de sorprender que autores como Marx o Simmel, que tanto escribieron en los periódicos de su tiempo, apenas incorporasen la cuestión a sus reflexiones). El caso de Max Weber es otro. Es bien conocida su contribución a la caracterización de la prensa y del periodismo en el ámbito de las relaciones (y vocaciones) de poder, en El político y el científico. Pero además encontramos su firme invitación al estudio sociológico de la prensa en su alocución ante la Asociación Alemana de Sociología (Frankfurt, 1910). Weber estima necesario alejarse de posiciones críticas de corte moralizante para atender el quehacer de los profesionales de la prensa (periodistas, editores...), los requisitos y las influencias actitudinales, o su papel en la construcción del espacio público... Es precisa- 
mente este escrutinio lo que hallamos en los escritos de Park, donde la invitación se convierte en un firme programa de trabajo. En su caso, un programa alimentado por dos fuentes: (a) su experiencia como reportero, editor y agente de prensa; y (b) su reflexión intelectual. De Park se puede decir que "antes de escribir sobre la prensa, escribía en ella" (Bourmeau 1988: 51), práctica profesional que deviene objeto de estudio. Si Park no es un pionero, sí es un analista doblemente cualificado.

Su interés por el periodismo se manifestó pronto, animado por J. Dewey, de quien asume el valor social de la comunicación y el rol de la prensa como dispositivo de control social e instrumento de integración y preservación cultural. Dewey le animó a estudiar la naturaleza y función del periódico toda vez que Park había mostrado su inclinación actuando como editor de The Argonaut, periódico universitario de Ann Arbor. Tras graduarse (1887), receloso de la vida académica, desconectada a su juicio de la realidad y muy sedentaria, Park ejerce el oficio entre 1877 y 1898 en diarios de Detroit, Minneapolis, Denver, Nueva York y Chicago. En el Minneapolis Journal trabajó como cub reporter y pasa tres años viajando "y viendo la clase de cosas que ve un reportero" (Park 1950: v). En el Detroit Tribune y el Denver Times actúa como city editor. Alcanza La Meca del periodismo, Nueva York, en 1892 e intenta la crítica cultural en el Chicago Journal. Por otro lado, Dewey facilitó su encuentro con Franklin Ford y la aventura del Thought $\mathrm{News}^{3}$, un proyecto fallido de diario preocupado por el registro fiel de las fluctuaciones de la opinión pública, con una información rigurosa de los problemas sociales.

Dejando atrás esta práctica directa (aún actuaría como agente de prensa de la Congo Reform Assocation y del líder negro Booker T. Washington en el Tuskegee Institut) Park inicia el camino de la reflexión intelectual. Su interés por la prensa deriva hacia la reflexión sobre las noticias, la comunicación y la opinión pública. De Harvard pasa a Berlín y a Estrasburgo, donde estudia con Windelband (Escuela neokantiana de Baden), a quien seguirá a Heidelberg, donde defiende su tesis Masse und Publikum. Lo que se pretendía un estudio sobre el periodismo termina orientándose hacia un análisis conceptual, procurando discernir los significados atribuidos a las nociones de masa y de público en un diálogo entre la filosofía americana (Boston y Michigan) y los planteamientos europeos (las tesis de Windelband, Tarde, Le Bon, Durkheim o la escuela italiana de Lombroso).

La perspectiva de Park sobre la prensa discurre entre el conocimiento intuitivo de quien está en el oficio y el conocimiento científico que aspira a disec-

${ }^{3}$ El periódico fue pensado como un instrumento pedagógico destinado a la explicación de la realidad social. Pero también se pretendía una herramienta de cultura cívica (política) para el fortalecimiento de los valores democráticos. 
cionar su naturaleza, haciendo buena esa distinción entre un saber fundado en la familiaridad y un saber objetivo de la ciencia que expondría en "News as a Form of Knowledge" (1940). Son varios los textos consagrados al ámbito de la prensa y del periodismo: "Foreign Language Press and Social Progress" (1920), "The Natural History of the Newspaper" (1923), "American Newspaper Literature" (1927), "News and the Human Interest Story" (1940), "News and the Power of Press" (1941), "Moral and the News (1941). En este haz de trabajos se percibe una clara orientación analítica antes que crítica, realizada desde el interior, atendiendo al papel desempeñado por la información en la democracia y en la acción colectiva (situándose así en la óptica de la sociología política). Este recorte deriva en parte de la tradición anglosajona sobre el papel de la prensa como útil de control social de la ciudadanía (formación/información/acción concertada; paso de la masa al público) y del gobierno. Pero es de gran interés la línea de trabajo que abre sobre el grupo profesional, el rol del reportero así como el análisis del recorrido de su producto, la información. Otra vía muy original es la que se vincula con el estudio del hecho urbano, que proviene en gran medida de su actividad como city reporter y city editor.

Abordaremos aquí la forma como esta práctica y reflexión profesional se vierte en su pensamiento sobre la ciudad y las relaciones sociales en el ámbito urbano; el modo en que presenta a la prensa y a la ciudad como laboratorios de la modernidad; o cómo la prensa deviene, al igual que la novela naturalista, lugar privilegiado para cifrar la vida cotidiana de la ciudad.

\section{CONTRIBUCIÓN A LA INVESTIGACIÓN SOCIAL Y URBANA}

Como ya hemos mostrado en otro lugar (Martínez 2013) los primeros cursos de Park en Chicago atendieron básicamente a las cuestiones raciales, la opinión pública y la masa, el periódico y los social surveys. Precisamente la invitación que William I. Thomas le cursó para integrarse a la disciplina del Departamento de Chicago obedecía a la competencia que Park había mostrado sobre estos temas. El de la ciudad no le era ajeno, por supuesto, pero hasta entonces nada había escrito sobre ella desde una perspectiva estrictamente sociológica. La investigación de Lannoy (2004) muestra cómo en realidad el texto conocido como The City es el resultado del curso dado sobre The Survey, tras una adaptación a la temática del "comportamiento humano en el medio urbano" (como indica el título del artículo mismo).

La adaptación revelaba la orientación empírica ambicionada por la sociología de Chicago: documentación, observación directa e investigación aplicada frente a las tentaciones especulativas de la filosofía social o de la perspectiva sociohistórica. Park consideraba que las ciencias puramente intelectuales co- 
rrían el riesgo de perder el contacto con la realidad, hasta el punto de que los símbolos manejados podrían reducirse a simples juegos dialécticos, propios de la escolástica. Las propias opciones y tradiciones intelectuales (el ascendente del pragmatismo) habilitarían la senda inductiva frente a la sociología de gabinete. Pero la opción experimental respondía asimismo a otras exigencias, de contexto y de vocación. Una era enfrentar la compleja realidad de la ciudad de Chicago, prototipo del crecimiento metropolitano. Otra, atender la importancia de la cuestión social, como se refería entonces el conflicto y las desigualdades sociales inherentes al capitalismo, que Chicago experimenta brutalmente por entonces. Esta cuestión ceñía un ámbito prioritario de estudio e intervención, articulado en el espíritu de reforma que impregnó a la prensa y a la sociología estadounidense: el social survey movement. En esta combinatoria de cuestiones Park encuentra en la redacción de The City una oportunidad para impulsar un amplio proyecto de investigación en cuyo diseño y posterior desarrollo confluyen sus experiencias previas como reporter y city editor.

\subsection{Chicago Lab}

En 1904 Max Weber describía de este modo Chicago:

"Chicago es una de las ciudades más increíbles. Junto al lago hay algunos barrios residenciales, bellos y agradables, por lo general casas de piedra de estilo más duro y pesado; justo detrás, viejas casitas de madera, igual que en Helgoland. Luego están los tenement [casas de vecindad] de los obreros y una absurda suciedad vial; nada de adoquines, unas calles miserables fuera del barrio residencial; el estado de las calles de la city, entre los sky-scrapers [rascacielos] es horripilante (...) Delirante es la mezcla de pueblos: los griegos les limpian las botas a los yanquis por cinco centavos; los alemanes son sus camareros; los irlandeses se ocupan de la política; los italianos se encargan de los trabajos más sucios. Toda la enorme ciudad (más grande que Londres) se parece, a excepción de los barrios residenciales, a una persona a quien le hubieran quitado la piel y cuyas vísceras se vieran trabajar" (Weber 1995: 443-444)

"Delirante mezcla de pueblos." En términos muy parecidos lo expresó años después Halbwachs cuando se refería a Chicago como una "experiencia étnica".

"Ante sus ojos se despliegan (...) nuevas fases de una evolución urbana sin parangón. (...) Todo ello en una aglomeración enorme, con múltiples diferenciaciones según raza, nacionalidad, profesión y nivel social, también según los estilos de vida y las características morales, de tal modo que los medios sociales más diversos se yuxtaponen y se enfrentan a veces sin transición. (...) Grupos desintegrados, grupos en formación, vida colectiva dispersada, concentrada, suspendida y ralentizada, agitada y discordante, de tal modo que las características más anormales aparecen ahí con toda claridad (...) o bajo 
formas que no es posible encontrar en ninguna otra parte." (Halbwachs [1932] 2008: 207-208)

No se trataba sólo de su brutal explosión territorial y demográfica (anexionando terrenos conforme se iba colmando de población inmigrante en busca de las oportunidades que una economía en expansión ofrecía), sino también de su heterogénea composición social y cultural. Chicago seguía siendo una ciudad de frontera, con toda esa variedad de tipos y situaciones sociales que llamó la atención de políticos, reformadores, periodistas, académicos, sindicalistas, etc. Park de hecho toma la ciudad como lugar idóneo para el estudio de la vida social, al entender que "amplifica, despliega y exhibe las más variadas manifestaciones de la naturaleza humana" (Park, 1999:126). La mención a la ciudad como laboratorio social, más que un tropo afortunado, parece apuntar a un doble propósito en su caso:

(1) animar el espiritu de curiosidad sin el cual no es posible ahondar en el conocimiento de los hechos sociales;

(2) en símil clínico, asegurar un saber preciso y objetivo más allá de la mera familiaridad con el entorno.

Porque hay un mundo que también se da por supuesto que debe cuestionarse, de ahí la obediencia a la reclamación de Williams James (On a Certain Blindness in Human Beings) ante la opacidad relativa y la diversidad de la vida social, difícilmente aprehensible en el estricto marco de las categorías positivistas.

\subsection{Investigación periodística y sociología noire}

Como confiesa en sus notas autobiográficas, un primer ánimo fáustico lo había arrojado al mundo del periodismo. De ese modo Park pudo dejar atrás el universo de la especulación, descender al mundo sensible e inmediato donde radicaba el valor de la experiencia (Dewey). La ciudad, una especie de organismo social a su parecer, se perfilaba igualmente como un microcosmos donde indagar y registrar puntualmente los avatares de la vida urbana (la pobreza, el vicio, los disturbios raciales, las epidemias, los tugurios, los establecimientos y trayectorias de los inmigrantes...). De esa manera podía obtener "una concepción de la ciudad, de la comunidad y de la región que iba más allá del simple fenómeno meramente geográfico" (Park 1950, viii).

Primero, en calidad de periodista:

"me dediqué a todo tipo de temas y conocí íntimamente una enorme cantidad de aspectos de la vida de una ciudad. Estoy seguro que cubrí muchos más kilómetros por las ciudades de todos los rincones del mundo que cualquiera de mis contemporáneos" (Ibid.). 
Como cuando en el New York Journal el city editor le envió a buscar un fumadero de opio y una casa de juego que la policía no terminaba de localizar.

"Entré en el fumadero de opio con mucha suerte (...). El lugar estaba atestado de la canalla de la ciudad y hablaban sin tapujos de la casa de juegos a la que yo pretendía acceder. Uno de ellos, ignorando quién era yo, consintió en conducirme hasta ella. Entramos pero no llegamos muy lejos. Uno de los dueños del 'garito' era bien célebre en los tribunales y, naturalmente, conocía a todos los reporteros habituales. Enseguida me reconoció y me sacaron fuera. ¿Si estaba asustado? A buen seguro que sí, pero ya tenía mi escrito" (Park, en Bourmeau 1988:51).

La experiencia periodística de Park le lleva por derroteros curiosos respecto a los temas de investigación sociológica convencionales y explica tanto su obstinación por la recolección de datos directos como su proceder (Faris 1969: 109). En realidad muchas de sus posteriores observaciones, los temas de las pesquisas que dirigió -sobre el comportamiento colectivo, la estructura de la ciudad y los tipos sociales que la habitaban (el hobo, los gangs, las taxis-dancers, el Jack-Roller...)- responden a un universo atípico para el académico pero familiar para el periodista de investigación. Una vez incorporados al campo de interés científico ganan cuerpo cuando son tamizados por la concepción sociológica de los procesos de desorganización social en la ciudad. Esta temática ha llevado a Roger A. Salerno (2007) a sugerir la precipitación de una sociología noire, (término aplicado a las narrativas y representaciones oscuras de la vida urbana), al modo en que hubo una novela negra y un cine negro, todos ellos productos culturales de un tiempo social y de unas vivencias específicas en la gran ciudad. (¡Se trata del Chicago de los roaring twenties!).

El interés por la observación directa, el trabajo de campo, el uso de mapas y otros tipos de representaciones cartográficas, las entrevistas, los estudios de casos e historias de vida también responden en gran parte al desempeño de su actividad como reportero. Esa curiosidad y esas artes de inmersión en la realidad social es lo que deseaba transmitir a sus alumnos, trabajando con ellos al modo de una redacción e incitándolos a bajar al terreno, en un ejercicio que prefigura el método del depth reporting. Anderson recuerda los consejos de Park para su investigación sobre The Hobo: "Anota todo cuanto veas, oyes y sabes, como un reportero", no dudando -a decir de Plenel (2008: 10)_ en construir esa ciencia de la sociología a partir de los "aportes bastardos e inclasificables como los del periodismo."

La preocupación por sustentar la explicación de los fenómenos sociales en la experiencia directa le llevó a insistir reiteradamente en la realización del trabajo de campo. Howard Becker, otro sociólogo poco convencional, se hace eco de las solicitaciones parkianas al respecto: 


\begin{abstract}
"Se os ha dicho que hojeéis en las bibliotecas y acumuléis notas y una gruesa capa de polvo. Se os ha aconsejado que elijáis los problemas de estudio que cuenten con amplia y enmohecida documentación, que repose en formularios preparados por burócratas hastiados y cumplimentados a regañadientes por aspirantes a una ayuda, por almas caritativas o empleados indiferentes. Es lo que se llama 'mancharse las manos con la auténtica investigación' (...). Pero es necesario algo suplementario: la observación de primera mano. Id a los salones de los hoteles de lujo, penetrad en los asilos nocturnos, sentaos en los canapés de la Gold Coast o en los jergones de los bajos fondos (...) En suma, ensuciaos los bajos de los pantalones en la verdadera investigación." (Chapoulie 2001: 118).
\end{abstract}

El trabajo de campo, aun con cierto aire de bricolaje y diletantismo, era un requisito formal de las monografías chicagüenses, pero sobre todo era una exigencia incluida en la formación sociológica de los estudiantes de Chicago. De hecho no era insólito verlos por diferentes áreas de la ciudad prestos a observar, anotar y describir cuanto sucedía, muchas veces acompañados por los profesores, Park entre ellos. Como éste afirmaba no era necesario dirigirse a regiones exóticas para encontrar contenidos de interés:

“(...) el hombre civilizado constituye un objeto de investigación igualmente interesante, y además su vida resulta más accesible a la observación y al estudio. La vida y la cultura urbanas son más variadas, sutiles y complejas, pero los resortes fundamentales son semejantes en ambos casos. Los mismos métodos de observación paciente que antropólogos como Boas y Lowie han aplicado al estudio de la vida y costumbres de los indios norteamericanos pueden emplearse incluso de forma más fructífera al estudio de las costumbres, creencias, prácticas sociales y concepciones generales de la vida que prevalecen en Little Italy, en el bajo North Side de Chicago, o para registrar los más sofisticados hábitos de los residentes de Greenwich Village y de los alrededores de Washington Square, en Nueva York" (Park [1915/1925]1999: 50)

Ciertamente encontramos un impulso original a los procedimientos etnográficos pero se trata de una etnografía atípica, casi una aproximación naturalista a las significaciones y a la dimensión subjetiva de los hechos sociales (Coulon 1994). Esta aspiración y su abordaje descansaban en la experiencia adquirida como reportero de investigación (teñida asimismo por un indisimulado reconocimiento por la literatura naturalista de Zola y Sherwood Anderson); también en la influencia pragmatista (que tendría continuidad en el interaccionismo simbólico); y por supuesto en los planteamientos de W. I. Thomas sobre la "definición de la situación". Había que situarse en la perspectiva del otro y ubicar dicha opción en el ámbito de los procedimientos empíricos, pues "el sociólogo no está interesado principalmente por los sucesos en sí mismos, los 
considera más bien como establecidos; le interesa especialmente las actitudes de las personas implicadas, tal como se reflejan en los muy diferentes relatos que ofrecen del mismo suceso histórico. Le interesa todo lo que pueda esclarecer las actitudes y hacerlas inteligibles" (Park, citado en Chapouile 2001: 117).

\section{INFORMACIÓN E INVESTIGACIÓN SOCIOLÓGICA}

"Cuando era city editor y reportero es cuando comienzo mis estudios de sociología... Para el artículo que escribí sobre la ciudad [The City, AJS, 1915] me apoyé mucho en la información que había adquirido como reporter observando la ciudad. Más tarde, cuando me correspondió dirigir un número cada vez mayor de estudiantes encontré que mi experiencia como city editor, dirigiendo un equipo editorial, me había puesto en una buena posición. La sociología, después de todo, trata sobre cuestiones a propósito de las cuales los periodistas tienen una buena dosis de conocimiento directo. Y junto a eso, la sociología trata precisamente de aspectos de la vida social que encuentran habitualmente sus expresiones más evidentes en las informaciones y documentos históricos y humanos. Se puede decir que un sociólogo es simplemente un reporter más científico, más preciso, más responsable" (Park en Bulmer, 1984: 91).

El sociólogo imaginado por Park se antojaba un súper-reportero. No hay en su planteamiento una ruptura epistemológica entre las praxis periodística y sociológica, sino tan sólo una diferencia de grado. La idea de un continuum aparece asimismo en la caracterización que Park realiza acerca del conocimiento intuitivo o familiar y el conocimiento científico en "News as a Form of Nowledge" (1940). Es típica de su esquema intelectual, donde prospera su inconfundible ambivalencia, que consiente interpretaciones compatibles: periodismo y sociología como ámbitos complementarios pero bien específicos. De ahí que la dedicación constante de Park para distinguir la observación sociológica de otras formas de escrutinio sea "algo que no está claro para él, que tiene un pasado periodístico del que no desea renegar y un nuevo estatus como sociólogo (...). Construye así una epistemología subyacente a sus trabajos (...) que puede ser leída en gran parte como una racionalización-legitimación de su propia trayectoria" (Bourmeau 1988: 59).

Lo que comparten ambos, el Park periodista y el Park sociólogo, es una lucha tenaz contra los enfoques morales, como proponía el movimiento reformista. En el periodismo la referencia es el muckraker (aunque en sus escritos sobre la sociología de la prensa sus consideraciones podrían aplicarse a los artículos que anteponen opinión a información); en la sociología, el peligro viene del movimiento de encuestas sociales. 
A finales del siglo XIX y principios del XX, el contexto social urbano generado por el capitalismo resultó tan desgarrador, tan excesivas las desigualdades, y la corrupción política y moral tan extendida que surgió un tipo de periodismo que orientaba su labor a la denuncia social. El muckraker era el héroe de tales hazañas ${ }^{4}$ : una figura consagrada al periodismo de investigación, al compromiso social, que advertía mediante sus escritos de las terribles condiciones de vida de los más humildes. El propio Park confiesa haberlo practicado $^{5}$ y llega a reconocerlo como una fuente no desdeñable de apreciaciones originales sobre la ciudad y el arte de la investigación, una vez pulido su tono dramático. No obstante, la sociología parkiana lo aparta desde el momento en que el propósito es avanzar por un conocimiento objetivo basado en la información precisa. De ahí que con el tiempo más que un modelo de investigación este tipo de investigación periodística sea tematizada como objeto de estudio/investigación (The Survey).

Ciertamente esta práctica de investigación cobró forma en el marco de un movimiento reformista más amplio que alcanzó incluso a la sociología americana en sus primeros pasos. En efecto, la primera generación de los sociólogos chicagüenses contemplaba la ciencia social como una herramienta de conocimiento e intervención sobre los problemas sociales. Esta disposición encontraba eco en las numerosas asociaciones cívicas y caritativas (Hull House, The Working People's Social Science Club, etc.) que instruían "encuestas sociales" en la órbita de la sociología aplicada y la asistencia social, procediendo en los social settlements de inmigrantes y desfavorecidos de la metrópoli. Park asumía el tributo debido al movimiento reformista en lo que se refiere a la investigación primaria. Empleó de hecho los pormenorizados estudios de Booth en Life and Labour of the People of London; se apoyó en la experiencia de los Hull House Maps and Papers en el curso de sus exposiciones sobre la desorga-

${ }^{4}$ Destacaron por su difusión e impacto The Shame of our Cities de Lincon Steffens (1904) a quien Park admiraba; Tramping with tramps, Studies and Sketches of Vagabond Life (Josiah Flynt, 1901); My Mamie Rose (O. Kildare, 1903), The Jungle (Upston Sinclair, 1905), así como How the other half lives de Jacob Riis. Bajo distintos formatos, siempre bien documentados en la medida en que son protagonizados por sus autores, estos escritos operarían en varios frentes: el político (reforma social), el profesional (periodismo) y el metodológico (estudio de caso).

${ }^{5}$ Aunque renegaba después de esta orientación, Park asumió este rol en el seno de la Congo Reform Association cuando se inicia la batalla internacional contra la barbarie del dominio belga en la colonia africana. Park publicaría en el Everybody's Magazine "The blood money of the Congo", "Recents atrocities in the Congo State", "The terrible story of the Congo", siempre en la órbita del reformismo y la práctica del muckraking. Lyman (1992) enjuicia estos textos como góticos, de tintes dramáticos, al uso de la época, repletos de lugares comunes que los redactores toman prestados de los relatos de los misioneros. 
nización social en la ciudad; y otro tanto puede decirse del Pittsburg Survey de P. Kellog, referencia mayor de la encuesta social. Apreciaba su interés y los datos que suministraban, pero les concedía un estatuto menor: no eran un modelo metodológico, sólo fuente de documentación e incluso objeto de estudio (así resultaba en el curso sobre The Survey. De la misma forma que consideraba que la información (de los hechos) convierte al reportero en un reformador más eficaz que el editorialista, también deseaba desmarcar la sociología del ánimo intervencionista, de los do-gooders, de los programas dirigidos de acción política y del trabajo social. Por eso desconfiaba del despliegue de los social surveys por cuanto la definición del objeto de estudio (los problemas sociales) y los métodos analíticos propuestos podían contaminar eventualmente la naturaleza científica de la sociología.

"Gran parte de la información se ha recolectado simplemente con el fin de determinar qué hacer en un caso dado. Los hechos no se han seleccionado para contrastar teorías sociales. Los problemas sociales se han recogido en su mayoría para apoyar tal o cual doctrina, no para probarla. En muy pocos casos se han hecho investigaciones, desinteresadamente, para determinar la validez de una hipótesis." (Park \& Burgess, 1921: 44).

La construcción de un ámbito de jurisdicción propiamente científico exigía otra definición del objeto y método sociológicos, afirmada sobre la neutralidad axiológica. Debía diferenciarse pues entre la investigación social y la investigación sociológica, neutral y objetiva. Y en ese sentido, insistía en que

"lo primero que han de aprender los estudiantes de sociología es a observar y a registrar sus observaciones (...) más que a formular opiniones. Los hechos más importantes de que tienen que ocuparse los sociólogos son opiniones (actitudes y sentimientos); pero en tanto que (...) no aprendan a tratar las opiniones como los biólogos tratan los organismos -es decir, disecándolas, reduciéndolas a sus elementos primarios, describiéndolas (...) no cabrá a obtener un progreso señalado de la ciencia sociológica" (Park, en Hughes 1974: 616)

Park activaba una orientación clínica de los procedimientos pertinentes de observación del cambio social y la naturaleza del conocimiento científico. El análisis de la sociedad no podía ser científico y moral a la vez, dos planos sobre la realidad social difícilmente reconciliables: el descriptivo y el normativo. Esta postura intelectual resultaba perfectamente válida para el ejercicio del periodismo, como se desprende de sus escritos sobre la prensa y de la experiencia misma del Thougts News (sobre el papel de las noticias y el influjo en la opinión pública de la información imparcial). 


\section{COMUNIDAD Y COMUNICACIÓN EN EL MEDIO URBANO}

La formalización de la perspectiva ecológica vino en auxilio de una determinación más clara de la objetivación y los procedimientos clínicos, aspirando a la búsqueda de generalidades sobre el desarrollo de la sociedad desde las regularidades observadas en el metabolismo social y en los procesos implicados. Es el paso necesario para elevar hipótesis relativas al ámbito de la superestructura moral de la existencia colectiva. Así, la ecología humana parkiana estimaba (como antes la morfología social durkheimiana) que el incremento del volumen y densidad de la población acrecentaba la división del trabajo, la diferenciación social y los procesos de individualización, con sus implicaciones tanto en la estructura territorial de los grupos sociales como en el desarrollo mismo de las interacciones sociales y de un nuevo orden moral.

Remitiéndonos a la articulación entre los procesos ecológicos y culturales, el modelo metropolitano de concentración y diferenciación interna de las actividades económicas, grupos sociales y hábitats residenciales (basado en la competencia biótica, el dominio y la sucesión) resulta mediado por la comunicación en el plano material (vías, medios e instrumentos) y en el social (interacciones, representaciones colectivas, opinión pública). Sin los modernos medios de comunicación sería harto complicado comprender la transformación de la metrópoli. Los medios acentúan la concentración y la movilidad en un proceso de implosión-explosión general y de localización diferencial (distritos comerciales, suburbios residenciales, áreas naturales), ambas inscritas en una urbanización de los valores, hábitos y estilos de vida. La sociedad sólo existe en y es posible por la comunicación, que habilita la integración social de los elementos de un conjunto diversificado pero interdependiente como la metrópoli moderna. Concilia la posibilidad de la vida individual en el marco de una existencia colectiva. Puede aventurarse, pues, un orden moral instituido sobre una base ecológica; dicho de otro modo, sobre la infraestructura biótica (basada en la competencia) se constituye una superestructura moral (basada en el consenso, la tradición y la costumbre). Un orden moral en continuo ajuste, dinámico y precario no obstante, pues la metrópoli representa una sociedad en transición permanente hacia formas articuladas de solidaridad orgánica. Como realidad heterogenética y compleja por su tamaño, densidad, diversidad étnica y profesional, la gran ciudad define una nueva forma de existencia: nuevos patrones de interacción social, de comportamiento y de organización. Un ambiente caracterizado por una potente carga secularizadora y por un racionalismo imposible de hallar en las pequeñas comunidades, apegadas al ámbito local y a lo concreto, sometidas al ciclo repetitivo de ritmos e interacciones. 
Asociada a la idea de comunicación -por su capacidad para neutralizar las distancias físicas y sociales- es imposible eludir la importancia atribuida a la movilidad, especialmente sus efectos en el despliegue de disposiciones típicas del temperamento urbano: el pensamiento abstracto y el cosmopolitismo. Por lo demás, la movilidad aparece inscrita en los ciclos de organización-desorganización-reorganización que atraviesan grupos e individuos en diferentes momentos de su desarrollo. En "La comunidad urbana como modelo espacial y orden social" (1926) Park es categórico al respecto:

"El telégrafo, el teléfono, la prensa y la radio transforman el mundo en una gigantesca cámara de resonancia, anulando las distancias y quebrando el aislamiento que antes separaba a razas y pueblos. Nuevos medios de comunicación están permanentemente multiplicando y complicando las relaciones sociales. La historia de la comunicación es, en un sentido propio, la historia de la civilización. (...) Pero, hay que decirlo, los medios de comunicación no tendrían la significación que han adquirido hoy en día si su desarrollo no hubiera estado acompañado de un incremento de la división del trabajo. (...) Precisamente porque la comunicación desempeña un papel fundamental en la existencia de una sociedad puede decirse que la geografía y todos los demás factores que limitan o facilitan la comunicación forman parte de su estructura y de su organización. (...). Como concepto sociológico, la movilidad sólo es significativa en la medida en que asegura nuevos contactos sociales, y la distancia física sólo tiene valor para las relaciones sociales en tanto que es posible interpretarla en términos de distancia social. (Park [1926] 1999: 97-98).

Se trata de una movilidad territorial que supone necesariamente el cambio de perspectivas y de referencias en un nuevo entorno. Pero la movilidad no se limita al cambio de localización; también puede medirse "por el número y la diversidad de estímulos a los que uno y otra responden. La movilidad depende no sólo de los transportes sino también de la comunicación". (Park [1926] 1999: 97). Estamos ante una segunda modalidad de movilidad típicamente social -de posiciones sociales en la estructura ocupacional y cultural-. Y puede ser una movilidad con o sin desplazamiento físico. La ciudad es precisamente el ámbito privilegiado de posibles e incesantes interacciones entre grupos e individuos que la habitan, usan y construyen, lo que marca el acceso a diferentes sistemas de significados, a nuevos modos de obrar y pensar. Se trata de la experiencia de la alteridad y lo que conlleva: universos ajenos de discurso en situación de co-presencia, diferentes referencias sociales al margen de las constricciones del grupo primario (familia, vecindario, localidad).

Llevada a sus últimas consecuencias, la argumentación sobre la movilidad en "La ciudad" describe una realidad social bifronte: cuanto posee de estimulación intelectual lo tiene de inestabilidad y fragilidad. 
"Los transportes y las comunicaciones han provocado, entre otras modificaciones silenciosas pero profundas, lo que he denominado 'la movilización del individuo'. (...) han multiplicado para el individuo las oportunidades de contacto y de asociación con sus semejantes, pero han vuelto esos contactos y las relaciones más efímeras e inestables. Una gran parte de la población de las grandes ciudades, incluidos los que residen en apartamentos o en casas de vecindad, viven más bien como si de un hotel se tratase, encontrándose pero sin conocerse entre ellos. De ahí deriva que las relaciones formales y ocasionales sustituyan a las estrechas y permanentes relaciones de la pequeña comunidad" (Park [1915/1925], 1999: 79).

Las mutaciones en la estructura material y social de la gran ciudad conllevan, como proceso crítico, fases de desorganización social y de desintegración moral de los individuos. La ruptura de los vínculos primarios, de las ataduras locales, de sus inhibiciones, la pérdida de influencia por parte instituciones primarias, la movilidad extrema..., todo eso puede llegar a provocar la quiebra del control social tradicional y la aparición de formas de comportamiento desviado. Muchas de las investigaciones de Chicago siguen esa dirección: los procesos de aculturación y desintegración moral en la ciudad (esa sociología noire a la que antes se aludía). Sin embargo, los cambios habidos introducen un nuevo orden que contiene las pulsiones del hombre y los comportamientos livianos. Independientemente de que la ley sustituya a la costumbre, el control social adopta una forma indirecta pero no menos efectiva: la moda y la opinión pública (el rumor de la aldea es sustituido por la prensa). La comunicación, al permitir una acción concertada, se erige como instrumento de cohesión social y acomoda el desarrollo individual al colectivo.

\section{DONDE LA CIUDAD SE ESCRIBE: CONSIDERACIONES SOBRE LA PRENSA EN EL MEDIO URBANO}

El interés por el orden y el cambio social en la ciudad, auspiciados por la comunicación, resulta patente en la sociología de la prensa parkiana. ¿No es acaso la prensa un producto típicamente urbano, como observa la historia de las ideas y de la publicidad? Park indaga en esta vinculación en textos como "Natural History of Newspapers" (1923), "The immigrant community and immigrant press" (1925), "Urbanization as measured by newspaper circulation" (1929), "Newspaper circulation and metropolitan regions" (1933). Ya no es algo transversal, sino un estudio franco sobre el vínculo (1) entre prensa y urbanización, entendida ésta como proceso de extensión, articulación y concentración de actividades y población heterogénea en el espacio; y (2) entre prensa y urbanismo, entendido éste como un modo de vida, lo que discurre por una 
caracterización típicamente cultural de ambos fenómenos. El interés de esos artículos radica en el modo original como Park aborda la evolución de la prensa a partir de la perspectiva ecológica. Por supuesto hay otros ecos, entre ellos los simmelianos -sobre la historia natural de las instituciones- pero resulta notable la forma en que esos procesos sin sujeto típicos del darwinismo y la ecología de Haeckel (las leyes de la competencia biótica y sus derivados, la sucesión, la dominación, la adaptación) esclarecen la transformación de este producto cultural que es la prensa en el mundo contemporáneo. Un mundo que es sobre todo urbano, de ahí la analogía empleada en la apertura del artículo:

"La prensa, como la ciudad moderna, no es una creación totalmente racional. Nadie ha buscado hacer de ella exactamente lo que es. Pese a todos los esfuerzos de individuos y generaciones enteras por controlarla y moldearla su manera, ella continúa creciendo y evolucionando según sus propias vías imprevisibles" (Park 2008, 41).

Dos cuestiones destacan en el planteamiento:

1. Prensa y urbanización discurren unidas. La transformación y extensión de la estructura urbana se asocia a la transformación de los medios (contenidos, formatos, fines y actuaciones).

2. La declarada naturalidad del fenómeno establece de un lado un ámbito de jurisdicción y metodología científica propia (la prensa como objeto de estudio clínico, desapasionado); de otro, la inequívoca pretensión de desvincular la "naturaleza" y evolución propia de la prensa respecto de las lecturas moralistas, del tipo The Brass Check de Sinclair. Park elude esta caracterización para tomarla como un producto de las condiciones de la vida moderna, de lo que se desprende un recorrido en términos evolutivos.

"Natural History of Newspaper" (1923), artículo incorporado en The City (1925) es ejemplar en ese sentido: explora la evolución de la prensa al hilo de las mutaciones de la estructura física, sociodemográfica y cultural de la ciudad. Atendiendo a esta contextualización, Park distingue distintas tipos de prensa.

- La primera forma no es sino una mera continuación rústica de los newsletters. El Boston Newsletter, primer periódico americano, surge en la estafeta de correos, lugar de encuentro y debate de los sucesos nacionales y comunitarios. "Si algún periódico debía ver la luz ése era el lugar idóneo, en proximidad inmediata de las fuentes de información" (Park 2008, 45). Marca una tendencia en la prensa local: el interés por el mundo próximo, y la organización del cotilleo y el rumor característicos de la vida 
de las pequeñas comunidades. Instrumentos de control social y a la vez de cohesión, la prensa amplificará su alcance bajo formatos de crónica costumbrista aderezada con aires novelescos.

- El segundo tipo se vuelca en la opinión. Tenía un antecedente en el registro de los debates parlamentarios de las primeras democracias liberales. Su recorrido es amplio y pone de manifiesto las relaciones de la prensa con el poder así como el poder de la prensa, que como apunta el propio Park -antes de que esta teoría sea elaborada- termina imponiendo la agenda a los políticos ${ }^{6}$. Esta prensa de opinión, que deriva hacia prensa de partido, tiene su apogeo en los EE.UU. durante la campaña antiesclavista (New York Tribune).

- Sacudiéndose paulatinamente la presión y dependencia de los partidos, surge y crece en las grandes ciudades la prensa independiente (v.gr. New York Times), de base comercial, retomando la importancia de los hechos y la difusión de las noticias. Es en la información y no en las doctrinas donde radica la virtud de la prensa, proporcionando referencias.

- El tipo de periódico que se impone en el ámbito metropolitano masificado es el correspondiente a la prensa sensacionalista, mezcla de literatura e información, jugando con las emociones, amor y romance para las mujeres, y el deporte y política para los hombres. Receta aplicada con éxito por J. Pulitzer (New York World) y William R. Hearst (San Francisco Examiner).

La evolución de la prensa sigue los patrones ecológicos asociados a los procesos de sucesión y dominación derivados de la competencia por la difusión; y es tributaria del progreso de la ciudad, igualmente regida por dichos procesos ecológicos. Hay que tener presente el incremento de lectores en el medio urbano pues con el advenimiento de la sociedad de masas - una sociedad compleja con un alto grado de diferenciación social y de división del trabajo- se impone la prensa con mayor capacidad de penetración entre el público urbano, al que proporciona referencias prácticas bajo un producto adaptado, normalizado y de registro cómodo. "Donde todo sucede todos los días no es posible dar detalles de cada uno de los incidentes, de las cosas fuera de lo común o de la rutina, pero se pueden seleccionar ciertos incidentes particularmente sorprendentes o novelescos para tratarlos como símbolos, por su dimensión

${ }^{6}$ Weber (1910) recuerda como en el siglo XVIII la prensa debía arrodillarse y pedir perdón ante el Parlamento inglés por violar el privilegio de conocer las deliberaciones del Parlamento (breach of privilege). En 1910 es la prensa la que pone de rodillas al Parlamento con la sola amenaza de no publicar sus discursos. Ese poder irá más lejos, como señala Park, adelantando teóricamente la importancia de la agenda mediática. 
humanamente ejemplar más que por su importancia individual y singular. La información en la ciudad pierde su carácter personal para hacerse arte. Deja de ser el relato de las actuaciones de hombres y mujeres concretos para convertirse en la crónica impersonal de costumbres y de la vida" (Park 2008, 47).

Esto no es óbice para que en el medio local sean bien recibidas las noticias sobre su entorno. Los periódicos locales inciden en esta faceta, que procura conocimientos prácticos y sociales necesarios (como aún hacen los diarios gratuitos o secciones locales de la prensa nacional). Pero la dominación de las grandes ciudades, la influencia que ejerce sobre su entorno es un hecho que ya no puede dejarse de lado, y los periódicos de vocación metropolitana constituyen una herramienta de propagación de esta dominación urbana. He aquí una evaluación cultural de la prensa metropolitana en tanto que instrumento de socialización y homogeneización, extendiendo el universo de los valores urbanos.

La circulación de la prensa resulta incluso un buen indicador de la dominación de la cultura y economía urbanas. Park explora esta vinculación, primero en "Urbanization as measured by newspaper circulation" (1929) y después, en una escala ampliada, en "Newspaper circulation and metropolitan regions" (1933). Basándose en el concepto de área cultural de Galpin y haciendo uso de la cartografía, se observa que "la circulación de la prensa, cuando es punteada en un mapa, sirve para delimitar con excepcional certeza los límites del área comercial local, y para medir al mismo tiempo la extensión y grado de dependencia de los suburbios respecto a la metrópoli, y de la metrópoli respecto a la región más extensa que domina" (Park 1974, 378). La urbanización ha quebrado los límites de la ciudad concebida como una estructura material coherente y contenida. El tejido urbano adopta una forma dispersa, dando lugar a suburbios residenciales entremezclados con usos rurales, industriales y comerciales. La extensión material y cultural de la ciudad se puede estimar indirectamente mediante la circulación de la prensa, en un gradiente de círculos concéntricos, similar al de los valores del suelo: desciende regularmente desde el centro hacia la periferia.

El análisis de la circulación de la prensa pone de manifiesto que:

1. la definición administrativa de ciudad resulta superada por el dinamismo de su realidad económica, que impone una lectura de las interrelaciones funcionales con el entorno;

2. la proliferación de estilos de vida diferenciados, como en los suburbios. Sus habitantes mantienen una vinculación intensa con el centro de mercado, posiblemente más que con su entorno inmediato. (Se trata de la commuter zone, el hábitat de los trabajadores pendulares, de alta movilidad social y espacial). 
Si el hábito y tipo de lectura de prensa proporciona un indicador indirecto sobre la cultura suburbana, otro tanto puede decirse de las subculturas urbanas. La variedad ecológica y social de la gran ciudad no se muestra únicamente en sus bordes, pues su configuración espacial exhibe áreas internas más o menos segregadas donde habitan grupos sociales de distinto rango y origen étnico. Park prestó una atención especial a estas áreas de inmigración. Chicago, esa ciudad de frontera, contaba con sectores como el Ghetto, Little Sicily, Black Welt, etc. que ofrecían un mosaico colorido de sectores diferenciados por sus moradores, costumbres, valores, universos de discurso, normas de decencia y presentación. Pero sectores sometidos también a la descomposición de los vínculos sociales primarios en la vorágine de la metropolización. Fuera del control ecológico del grupo, el individuo posee la libertad de moverse por los diferentes ambientes y regiones morales, dejando atrás las constricciones del grupo primario. Es el reverso de la desestabilización social, la desorganización grupal asociada a la movilidad colectiva e individual: ruptura de las continuidades históricas o de la reproducción del grupo. Situación típica en las comunidades inmigrantes que sufren la tensión de una identidad de origen (primera generación) y otra de destino (segunda generación). Es la tensión de los dobles vínculos, que se recrudeció en la época en que América se disponía a entrar en la Gran Guerra, planteándose el problema de la naturalización o "americanización de las poblaciones" ("the strangers within our gates").

Retomando la digresión simmeliana sobre el extranjero, Park veía en el inmigrante no sólo al sujeto concreto sino el personaje conceptual capaz de expresar el juego dialéctico de la proximidad y la distancia (proximidad espacial, distancia anímica) típica de la modernidad metropolitana: los vínculos sociales se despliegan en un juego entre la proxemia y la diastemia, acentuado con la división del trabajo, la diferenciación social y el individualismo. Pero la prensa contribuyó en parte a la asimilación de estas comunidades. En Nueva York llegó a haber 270 publicaciones sostenidas mayoritariamente por la población local, impresas en 23 lenguas diferentes. Y en Chicago hubo 19 diarios publicados en 7 lenguas extranjeras con una tirada diaria de 368.000 ejemplares. Remitiéndose a The Polish Peasant de Thomas \& Znaniecki, Park rescata la declaración del jefe de redacción del periódico publicado en ruso, Ruskoye Slovo de Nueva York, según el cual, tras una encuesta entre sus lectores encontró que de 312 interrogados sólo 16 leían regularmente el diario en Rusia y 10 de vez en cuando, y sólo 12 abonados a un semanal en su tierra de origen; alguno leía la hoja de la administración (volast). Sin embargo, trasladados a Nueva York todos pasaron a lectores asiduos de periódicos y revistas. Si la lectura era "un lujo en el campo, se convierte en una necesidad en la ciudad. En el medio 
urbano saber leer es casi tan indispensable como saber hablar. Esa es una de las razones de la abundancia de diarios en lengua extranjera" (Park 2008, 42). La prensa local actuó como agente de socialización proporcionando referencias grupales mientras abría una ventana a un mundo próximo más amplio, acompañando las incursiones de estas poblaciones hacia el exterior de sus enclaves donde hábitos, lengua, normas y valores eran desconocidos. Les suministró en suma referencias generales de la vida en las grandes ciudades americanas, mostrando que la urbanización tenía a la vez un componente cultural.

\section{CONCLUSIONES}

Regresar a la obra y trayectoria de Robert Park contribuye sin duda a superar la célebre desconfianza, aún bien patente, entre la sociología y el periodismo. Park, que reivindicó su pasado como reportero, concebía al sociólogo como un super-reportero. El estudio de la ciudad, que ha marcado ampliamente su recepción, se alimenta de hecho de la experiencia adquirida en el periodismo de investigación. Así, todo cuanto había aprendido sobre la ciudad en el curso de sus reportajes urbanos, la comparación entre las ciudades que había conocido durante sus quehaceres, la importancia atribuida a la comunicación como urdimbre social, su consideración sobre la objetividad de las informaciones recolectadas y trasmitidas, o el riesgo de propagar opiniones y posiciones morales son afluentes imprescindibles para comprender la contribución parkiana al estudio de la ciudad, a la metodología de la investigación sociológica y a esa temática noire a la que aludíamos.

"La ciudad" (1915/1925), texto que inaugura de hecho su orientación hacia la sociología urbana, no es concebible sin dicha referencia: tanto en el texto como en la realidad descrita los procesos urbanos y comunicativos se manifiestan necesaria y estrechamente vinculados. Esta ligazón se expresa asimismo en otros muchos escritos "urbanos" donde aborda la influencia de la comunicación y de los medios en la configuración material de la ciudad o en aquellos otros donde examina el papel de la prensa en la orientación de la cultura urbana moderna. Porque la urbanización nunca es vista como mera aglomeración de actividades, grupos sociales e individuos sobre un punto sino como un proceso cultural, que da lugar a comportamientos novedosos, a patrones normativos innovadores y a estilos de vida o tipos sociales característicos. La prensa moderna, una creación de esas condiciones urbanas, contribuye a la difusión de estos valores urbanos, acelerando además el proceso de asimilación entre los urbanitas de toda condición y origen. De ahí que se le conceda un papel básico en la definición de un nuevo orden social, característico de entornos complejos donde las relaciones secundarias cobran importancia; y en esa misma medi- 
da, un papel socializador, especialmente para los inmigrantes. Estos siempre requieren instrumentos que faciliten el recuerdo en común, las referencias tradicionales, un grado de privatismo. Su organización familiar y los protocolos de interacción interna cumplen durante un tiempo tal cometido. Pero fuera del vecindario, el espacio público urbano es el área de contactos secundarios donde las relaciones son relativamente impersonales, ofreciendo un registro de socialización más amplio y plural, como el del espacio de la publicidad y la prensa.

\section{REFERENCIAS BIBLIOGRÁFICAS}

Abbot, A. (1999). Department and Discipline, Chicago School Sociology at One Hundred. Chicago: The University of Chicago Press.

Berganza Conde, R. (2000): Comunicación, opinión pública y prensa en la sociología de Robert E. Park, Madrid: CIS.

Bourmeau, S. (1988). "Robert Park, journaliste et sociologue", Politix, 1, no 3-4, 50-61.

Breton, D. Le (2008). "Park et l'interactionnisme symbolique", en GUTH (dir.) Modernité de Robert Park, 261-270.

Bleman, L. S. (1976). "Robert E. Park: An Intellectual Portrait of a Journalist and Communication Scholar". Journalism History, vol. 2, 4, 116-132.

Blumer, M. (1984): The Chicago School of Sociology: Institutionalization, Diversity and the Role of Sociological Research, Chicago: University of Chicago Press.

Chapoulie, J.M. (2001). La tradition sociologique de Chicago (1892-1961), Paris: Seuil.

Cefaï, D. (2008). "Vers une écologie des publics. Park, l'opinion publique et le comportement collectif", en GUTH, op. cit., 155-188.

Coulon, A. (1994). L'École de Chicago. París: PUF (2ª ed.), 1994.

Faris, R. E. (1967). Chicago Sociology 1920-1932, Chicago: University of Chicago Press. Grafmeyer, Y. \& Joseph, I. (1979). L'École de Chicago. Naissance de l'ecologie urbaine, París: Aubier.

Guth, S. (2008) (dir.) Modernité de Robert E. Park, Paris: L'Harmattan, 313 p.

- (2012). Robert E. Park. Itinéraire sociologique de Red Wing à Chicago. París: L'Harmattan. Halbwachs, M. (2008): "Chicago, experiencia étnica", en MARTINEZ, E. (ed. y trad.) Maurice Halbwachs: Estudios de morfología social de la ciudad, Madrid: CIS.

Lannoy, P. (2004). "Quand Robert Park écrit 'La Ville' (1915). Essai de scientométrie qualitative". Revue d'Histoire des Sciences Humaines, 11, 157-184.

Lazar J. (2006). "Quand les nouvelles étaient une forme de connaissance. Souvenir insolite d'Ezra Park". Géographie, Économie, Société, 8, 489-498

Lindner, R. (1996). The reportage of urban culture- Robert E. Park and the Chicago School, Cambridge, Cambridge University Press.

Lyman, Stanford. M. (1992). Militarism, Imperialism and Racial Accommodation. An Analysis and Interpretation of the Early Writings of Robert E. Park, Fayeteeville: University of Arkansas Press.

Martínez, E. M. (1999): "Introducción", en PARK, R.E., La ciudad y otros ensayos de ecología urbana, Barcelona: Serbal, 7-47. 
- (2013). "La investigación ecológica de las comunidades locales". Empiria. Revista de Metodología de Ciencias Sociales, 25, 173-194.

Park, Robert E. (1922). "The Immigrant Press and its control", Americanization studies, the acculturation of immigrant groups into American society, Harpers and Brothers, 1992, cap. 16 (vol. 7)

- (1950-1955). Collected Papers of R.E. Park, Everett C. HUGHES et al., Glencoe, Ill: Free Press.

- (1974): "La urbanización medida por la circulación de prensa", en THEODORSON, Estudios de Ecología Humana, Barcelona: Labor, 1974, 377-390.

- (1999), La ciudad y otros ensayos de ecología urbana, Barcelona: Serbal (trad. y ed. de E. Martínez)

- (2008). Le journaliste et le sociologue (ed. por G. Mulhmann y E. Plenel), París, Le Seuil Park, R. y Burgess, E. (1921). Introduction to the Science of Sociology, Chicago: The University of Chicago.

Plenel, E. (2008). "Actualité de Park", en Park, R. Le journaliste et le sociologue, 7-18. Raushenbush, W. (1979) Robert E. Park. Biography of a sociologist, Durham: Duke University Press.

Salerno, R. (2007). Sociology noir. Studies at the University of Chicago in loneliness, marginality and deviance, 1915-1935. Jefferson (N.C.) MacFarland and Co. Inc. Publisher.

Sánchez de la Yncera, I. y López-Escobar, E. (1996). "Los barruntos de Park. Antes de Chicago". Revista Española de Investigaciones Sociológicas, 74, 345-359. (Incluye la traducción de La masa y el público de R. Park, 361-423).

Weber, Max (1910). "Para una sociología de la prensa", REIS, 57, 1992, 251-259. Weber, Marianne (1995). Max Weber. Una biografía. Valencia: Alfons el Magnanim.

EMILIO M. MARTÍNEZ GUTIÉRREZ es profesor titular de Sociología en la Universidad Complutense de Madrid. Anteriormente fue profesor en la Universidad de Alicante e investigador del Instituto Multidisciplinar de Estudios del Medio Ramón Margalef (UA), profesor visitante en la Universidad de París V (René Descartes) y del Cente Max Weber (Lyon II). Su área de trabajo principal versa sobre temáticas urbanas, sobre las que ha publicado numerosos artículos y libros así como traducciones de autores clásicos (R.Park, Wirth, H. Lefebvre y Maurice Halbwachs).

Recibido: 19/02/2016

Aceptado: 29/06/2016 


\title{
LA INTEGRACIÓN REGIONAL LATINOAMERICANA A PARTIR DE LAS OPORTUNIDADES PARA EL PROGRESO ${ }^{1}$ \\ THE LATIN AMERICAN REGIONAL INTEGRATION BASED ON ITS OPPORTUNITIES FOR PROGRESS
}

\author{
Jhoner Perdomo \\ Universidad Central de Venezuela, Venezuela \\ jhonerperdomo@yahoo.com \\ Luis Daniel Álvarez \\ Universidad Central de Venezuela, Venezuela \\ luis.daniel.alvarez.v@gmail.com \\ Sary Levy-Carciente \\ Universidad Central de Venezuela, Venezuela \\ saryle@yahoo.com \\ Mauricio Phélan \\ Universidad Central de Venezuela, Venezuela \\ mauphelan@gmail.com
}

Cómo citar / Citation

Perdomo, Jhoner; Álvarez, Luis Daniel; Levy-Carciente, Sary y Phélan, Mauricio (2016). "La integración regional latinoamericana a partir de las oportunidades para el progreso". OBETS. Revista de Ciencias Sociales, 11(2): 513-545. doi:10.14198/OBETS2016.11.2.06

\section{Resumen}

El objetivo de un Estado debería ser la ampliación de oportunidades y capacidades para que la ciudadanía promueva resultados que permitan el desarrollo humano. En este sentido, los países se integran en bloques para fortalecer sus políticas, dar respuestas a las demandas sociales y mejorar la calidad de

\footnotetext{
${ }^{1}$ Artículo elaborado en el marco del Proyecto CDCH-UCV PG-05-8650-2013/2.
} 
vida de sus habitantes. Por ello, la conformación de alianzas presume que quienes las conforman poseen elementos y objetivos en común. Se realiza un ejercicio a países de la región latinoamericana, mediante un análisis discriminante utilizando indicadores multidimensionales, cuyo objetivo es determinar cuáles son las condiciones que permiten diferenciar los respectivos convenios en la región, para nuestro análisis: MERCOSUR, ALBA y Alianza del Pacifico.

Palabras Claves: Integración Regional; Análisis Discriminante; Indicadores; MERCOSUR; ALBA y Alianza del Pacifico.

\begin{abstract}
The goal of a state should be expanding opportunities and capabilities citizenship to promote results that enable human development. In this regard, countries integrate into blocks to strengthen their policies, to respond to social demands and improve the quality of life of its inhabitants. Therefore the formation of alliances presumes that those who make them possess elements and objectives in common. An exercise is performed to countries in the Latin American region, using the discriminant analysis using multidimensional indicators, which aims to determine what are the conditions that allow differentiating blocks in the region, for our analysis: MERCOSUR, ALBA and Pacific Alliance.
\end{abstract}

Keywords: Regional integration; discriminant analysis; indicators; MERCOSUR; ALBA and Pacific Alliance.

\title{
Extended abstract
}

In a global world, Latin American countries cannot act as independent agents from the rest of the world. From the multidimensional approach of development, conditions that encourage and expand opportunities and capabilities so that citizenship could promote results that enable human development, have to be created. To favor the achievement of these goals, regional integration agreements are valuable mechanisms. The alliances formed in Latin America look for unifying efforts with common purposes and, at first, their members seemto have very homogeneous features. While the conformation of alliances express different interests -that can be of economic or political orderthe intention of the study is to analyze if in the groupings and their countries the populations' capabilities and opportunities are similar among them.

With the aim of studying the performance of several integration agreements worldwide, a very useful method is the Discriminant Analysis. Using selected indicators, itseeks to define the features that significantly distinguisha group, it allows consideringmembers of a group and to analyze its homogeneous or heterogeneous behavior in them, as well as validate significant differences with other groups or agreements. The Step by Steptechnique uses only those indicators with more influence, seeking to represent a discriminant function with the least amount of possible variables and which is equally significant to distinguish groups. For this reason the selected variables are those that provide centroids further away among groups and more concentrated within groups. In this sense, the technique reflects the result of the innerbehavior of each 
grouping, agreement or alliance, reflecting if its members have more or less commonalities, fostering its integration or rather the possibility to split up. In addition, the statistical test of contrast and probability of membershipshows the statistical probability of belonging to the original group or to some other group, and thus validate the consistency of the existing groupings.

For 19 countries of Latin America that make up the selected case studies: Southern Common Market (MERCOSUR), Bolivarian Alliance for the Peoples of our America (ALBA)and Pacific Alliance (AP), the data selected included indexes associated with welfare, civil liberties, political, economic, and environmental aspects to depict a multidimensional profile of each of the countries and of the respective blocks or associations, with an alternative perspective of development.

There were identified 60 indices that measure, in one way or another, environmental, socio-economic, political, technological and institutional aspects. From the list of indices,in a first moment were selected those with complete information for all Latin American countries. In a second step, it was made a comparative analysis of their dimensions to reduce the multiplied presence of the same dimension and to avoid some type of covariance between the selected indicators. Finally 10 indices were considered: Institutional Quality, Property Rights, Cost of Living, Democracy, Complexity, Misery, Social Progress, Global Innovation, Globalization and Fragile State; all multidimensional and largely associated with the dimensions established for the UN's sustainable development goals by the year 2030 .

Two statistical tests were performed among groups, the first among ALBA, AP and the rest of the countries of Latin America; the second among MERCOSUR, AP and the rest of the countries of Latin America. In the case of the first and second test, of the 10 variables under analysis, 6 and 7 had discriminatory power, respectively. Of them Global Innovation Indexfor the first test -in more favorable terms to Pacific Alliance- and Global Innovation Index and Misery Index for the second test, are enough in both cases to differentiate the groups under analysis and to develop a discriminant model. The fact that not all variables had discriminatory power is indicative that groups are not homogeneousin certain dimensions. By the contrary those with discriminatory power, indicate that those groups should be analyzed starting from those variables, since being more homogeneous in that indicator they allow a better representation of their country members.

The observed results with thestatistical test of contrast and probability of membershipfor the groupings for the first test is 100\% of the ALBA countries are integrated, while in AP is $83.3 \%$ of countries, and the countries of the rest of Latin America could be divided by which of these two agreements of integration have statistically significant characteristics with more association. Same thing happens with groupings of the second statistical test, whose results show an AP 100\% integrated and MERCOSUR 40\%.

These results indicate that MERCOSUR has heterogeneous features among its members, which in the long run could generate difficulties for the implementation of common policies. Instead, AP and ALBA while representin 
ghighly different alternatives, they are more stable groups, given the homogeneity of their countries members. The difference between them is the kind ofprojectthat guides them more or less towards a progress stage. While the analyzed groupings do not show harmony in every dimension and that still among countries that make up a particular groupthere are differences in some indicators, the results guide to the areas where each group must emphasize in their policies

Although the Latin American regionis very heterogeneous, some indexes threw certain inner homogeneity, especially the Innovation GlobalIndex that appears as a strong screener in those three agreements analyzed. This multidimensional index combines the quality of the institutional and political environment, regulatory and business stability, freedoms of expression and action, investment in humantalent, research and development, innovationlinks, know ledge absorption, impact, creation and dissemination. This way is a measurement that reflects the opportunities for development of a country. Innovation also attractscapital investment, generating employment and increasing economicgrowth, which reduces the Misery.Also within the components of the Innovation Global Index are the regulatoryenvironment, law enforcement, third leveleducation and ecological sustainability. This combination is not far behind the Agenda 2030 goals established by the UN that statesthe importance to foster innovation, promote a sustainable industrialization in balance with nature and besides to have a flexible infrastructure, transparency, rule of law and law enforcement.

By this, innovation is not only a keyelement for the integration of countries, but a fundamentalfactor for its progress. The difference in innovation levels between AP and ALBA are very important, not so much for the case of AP and MERCOSUR, however by 2014 all AP members are in better position to do business compared to countries belonging to MERCOSUR, which are, in very unfavorable positions according to the World Bank Report Doing Business 2014. This means that much emphasis must be done not only in innovation per se, but also in all the component of the index to promote common policies in the integration agreement aligned with Latin American progress, in a way that the process of innovation will weave ties of cooperation among several entities to guarantee a greater success. Groups must make great efforts to consolidate development strategies, with transfer of technology and training human talent altogether.

Thus, scientific innovation appears as the variable that synthesizes the ability of countries to leverage their development. It is worth saying that this innovation is based on a free society in which the exchange of ideas is possible without limitations, and where social arrangements encourage and spread it. Innovation shows the largest differences in the region: those groups that consolidate best strategies aligned to innovation, strong institutions and freedoms will have greater opportunity for their countries to obtain more favorable results for their citizens. By the contrary, groups with minor advances in that field will result in poor opportunities for the citizenship. The integration of Latin America should be comprehensive and uncut, and to emerge as 
a region one of the stages that must be overcome is the technological dependence and taking innovation as the cornerstone for their progress.

\section{REFERENTES TEÓRICOS E HISTÓRICOS SOBRE INTEGRACIÓN REGIONAL}

Desde fines del siglo XX se manifiesta a nivel mundial la convivencia de tendencias globalizadoras con las de integración regional, y en las que la intervención de diversos actores, (Estado-Nación, organizaciones no gubernamentales, empresas privadas y públicas y consumidores) conjuga intereses que influyen de manera determinante en los comportamientos que terminan definiendo la estructura organizacional de nuestro mundo y su desempeño. Los noventa mostrando un incremento de los procesos de integración, concluyendo los estudiosos del enfoque regional que ha surgido una nueva estructura en la que aparecen novedosas formas de institucionalización, crecimiento geográfico, redimensión de los enfoques, haciendo que se deje de lado la figura estrictamente económica, pasando a incluirse los derechos de propiedad intelectual y el tema ambiental; todo bajo un marco de fomento y protección a los derechos humanos. Los nuevos mecanismos de integración incluso han dejado atrás la noción de diplomacia cerrada y han pasado a establecer modelos de transparencia en los que la sociedad civil ejerce una labor de contraloría (De Lombaerde, Kingah y Rettberg, 2014).

Entre las corrientes que explican los mecanismos de integración está el neofuncionalismo que centra sus argumentos en la ganancia o pérdida que se presenta al asociarse a otros Estados, presentándose entonces la necesidad de politizar las etapas del proceso, buscando que se analice a profundidad el acercamiento entre los actores. Aunque el deseo es disminuir la influencia del nacionalismo, en las primeras etapas resulta inevitable una marcada presencia del Estado. Frente a esta corriente está la concepción intergubernamentalista que plantea que la existencia de instituciones se genera por los beneficios que los Estados puedan tener de su desempeño. Hay un control del Estado de todas las etapas del proceso de integración, dependiendo entonces el resultado del cálculo que pueda hacer cada uno (Álvarez y Victoria, 2011).

Sin embargo, finalmente no importaría si se presenta un modelo de integración avalado por lo político o lo económico, pues se terminan constituyendo mecanismos que van a tener impacto en lo social, lo financiero, lo político e incluso lo educativo. Si el objetivo es una alianza económica o la estructuración de un mecanismo político, las variables se transformarán para generar una instancia que termine desarrollando objetivos más amplios a los trazados inicialmente. 
Cabe recordar que los fenómenos de integración no son recientes: los primeros asomos de una integración fuerte se establecen hacia 1828 con la unión aduanera entre Prusia y Hesse-Darmstadt. Posteriormente se concreta la unión aduanera de Bavaria-Württemberg, la Unión Comercial de Alemania Central (German Zollverein), la unión impositiva de Alemania del Norte, la Unión monetaria Alemania y finalmente el Reich Alemán. El auge integracionista alcanzará a lo que hoy día es Suiza, cuando en 1848 se crea el mercado integrado y la unión política Suiza. De igual manera ocurre en Italia con el movimiento del Resurgimiento (Risorgimento). Por su parte, Count Paul Leusse en Francia, insiste en el establecimiento de una unión aduanera agrícola entre Francia y Alemania con un comité de aranceles a establecerse en Frankfurt. En Austria el político y economista Alexander Peez planeó una Unión Europea Central (MiddleEuropeanZollverein) que incluía a Francia. Posteriormente, en 1952 se crea la Comisión Europea del Carbón y el Acero y en 1957 se suscribe el Tratado de Roma naciendo la Comunidad Europea (Levy-Carciente y García, 2007).

Al referirnos a América, Andrade (2011) ubica los primeros intentos de integración regional en tratados de inspiración en la CEPAL, con miras a incentivar los vínculos bajo la premisa de favorecer el crecimiento y la industrialización, como proposiciones iniciales para alcanzar un desarrollo total. Estos procesos que se generaron y lograron plasmar una visión que perduró hasta los años ochenta y noventa, se tradujeron en la creación de zonas de libre comercio subregionales, como ALALC y ALADI; MCCA y SICA²; Acuerdo de Cartagena y la Comunidad del Caribe (CARICOM). Incluso la creación en 1975 del Sistema Económico Latino Americano (SELA) es una muestra más del enfoque y de la propuesta de alcanzar un esquema de formulación que no contemplase a los Estados Unidos y Canadá.

Las razones que sustentan la tesis de enfocar la integración desde una visión sustancialmente económica responden a la necesidad de comprender la delicada situación financiera que atravesaba la región. Para el caso de Venezuela, Romero (2005:115) nos comenta:

"Es en este marco sistémico que se desarrollan las políticas exteriores de Herrera y Lusinchi y dentro de ellas las relativas a la defensa y promoción de la democracia venezolana y hemisférica.

Con mayor o menor eficacia y eficiencia, fueron políticas diseñadas e instrumentadas para un tiempo de crisis. Sin embargo, aunque constreñido económicamente y bajo climas políticos domésticos y regionales de tensión y de nuevas visiones

\footnotetext{
${ }^{2}$ Siglas de Asociación Latinoamericana de Libre Comercio, Asociación Latinoamericana de Integración, Mercado Común Centro Americano, Sistema de Integración Centroamericano, respectivamente.
} 
este - oeste, las agendas de defensa y promoción de la democracia de ambos gobiernos continuaron -como señalamos antes- enfatizando los postulados de pluralismo ideológico y la cooperación bilateral y multilateral regional".

La politización del Pacto Andino hacia 1979 permitió darle mayor dinamismo a su estructura al dotarlo de un Parlamento con funciones establecidas, tribunales y de un Consejo Presidencial que pudiese ejecutar algunas acciones y no se limitara a ser un ente protocolar. A esta iniciativa transformada y modificada siguió la creación del Grupo Contadora. Como se evidencia, lo que llevó a los países a unirse no fue enfrentar mancomunadamente el problema económico, sino que la prioridad pasaba por atender la compleja coyuntura de la violencia que agitaba a gran parte de América Central. En palabras del ex-Canciller de Venezuela, Simón Alberto Consalvi:

"El Mecanismo Permanente de Consulta y Concertación Política es la respuesta a los diversos desafíos que tiene planteados América Latina. Sin concertación no hay manera de resolver los problemas que nos son comunes y que requieren, por tanto, de una posición conjunta. No es posible que mientras los países debilitados a las democracias individuales, para usar la expresión del Dr. Kissinger, coordinen sus acciones y definan sus politicas, los países de América Latina sean un archipiélago de indefiniciones". (Consalvi, 1988: 30).

De igual manera, al revisar las palabras de los Presidentes de Latinoamérica asistentes a la Cumbre de Acapulco, México, en noviembre de 1987, queda claro que la integración se contempla como un mecanismo para unificar la voz de la región. De esta forma, Argentina, Brasil, Paraguay y Uruguay dieron forma al MERCOSUR, mientras que Venezuela, Colombia, Perú, Bolivia y Ecuador procuraron un paso más y cambiaron al Pacto Andino por la Comunidad Andina de Naciones (que mantenía la misma estructura del ente fundado en 1969) que asomaba que su aspiración natural era ingresar al Mercado Común del Sur cuando estuviesen dadas las condiciones. Chile por su parte quedó de forma independiente, México optó por acercamientos económicos con Estados Unidos y Canadá, mientras que el Caribe buscó constituir su mercado común y Centro América, junto a República Dominicana, un mecanismo novedoso en el que resalta en desarrollo y estabilidad Costa Rica.

Desde inicios del siglo XXI han proliferado nuevas formas de asociación de países en la región latinoamericana, algunas que responden a criterios ideológicos, mientras otras se asientan en debates y estrategias económico-financieras. Destacan entre ellas los espacios de: ALBA, UNASUR, CELAC ${ }^{3}$, Alianza Pacífico y Petrocaribe.

${ }^{3}$ Siglas de Alianza Bolivariana para los Pueblos de América, Unión de Naciones Suramericanas y Comunidad de Estados Latinoamericanos y Caribeños, respectivamente. 


\section{ESQUEMAS DE INTEGRACIÓN LATINOAMERICANA BAJO ESTUDIO}

En el presente trabajo se revisarán desempeños de los países integrantes de los acuerdos de integración del MERCOSUR, la Alianza del Pacífico y la ALBA, por lo que a continuación se realizará una breve descripción de dichos esquemas.

\subsection{Mercado Común del Sur ${ }^{4}$}

El Mercado Común del Sur, MERCOSUR, es una iniciativa que tuvo sus orígenes en una propuesta bilateral suscrita en Foz de Iguazú, Brasil, el 30 de noviembre de 1985, pero que adquirió la forma que hoy se conoce el 26 de marzo de 1991 con la firma del Tratado de Asunción. Su entrada en funcionamiento a plenitud se concretó el 15 de diciembre de 1995.

"El MERCOSUR es un proceso abierto y dinámico. Desde su creación tuvo como objetivo principal procurar un espacio común que generara oportunidades comerciales y de inversiones a través de la integración competitiva de las economías nacionales al mercado internacional. Como resultado ha establecido múltiples acuerdos con países o grupos de países, otorgándoles, en algunos casos, carácter de Estados Asociados -es la situación de los países sudamericanos-. Estos participan en actividades y reuniones del bloque y cuentan con preferencias comerciales con los Estados Partes. El MERCOSUR también ha firmado acuerdos de tipo comercial, político o de cooperación con una diversa cantidad de naciones y organismos en los cinco continentes".

Los miembros plenos son Argentina, Brasil, Paraguay Uruguay y Venezuela, éste último Estado se adhirió a la iniciativa en el 200955. Bolivia está tramitando su proceso de adhesión, lo cual llevaría al MERCOSUR a contar con más de 290 millones de habitantes, en una extensión territorial de cerca de 15 millones de $\mathrm{km}^{2}$.

En 1998 el MERCOSUR buscó institucionalizarse declarando todo el territorio "Zona de paz y libre de armas de destrucción en masa" y estableciendo el Compromiso Democrático o Protocolo de Ushuaia, que contempla cláusulas de protección a la democracia, la libertad de empresa y la libertad de expresión. En 2005 se estableció un Fondo para la Convergencia Estructural del MERCOSUR (FOCEM) que a través de un aporte anual de cien millones de dólares busca reducir las asimetrías entre los socios. También es de este año

\footnotetext{
${ }^{4}$ Véase www.MERCOSUR.int/

${ }^{5}$ Después de un controversial procedimiento que se aprovechó de la suspensión temporal de Paraguay que atravesaba una crisis interna y cuyo parlamento vetaba el ingreso de Venezuela.
} 
la creación del Parlamento del MERCOSUR, que debe agotar algunas etapas. La idea del MERCOSUR es que todos los parlamentarios sean electos en comicios directos (no designados en segundo grado) y que eventualmente se elijan el mismo día, en una jornada denominada Día del MERCOSUR Ciudadano.

El MERCOSUR es la quinta mayor economía del mundo y posee todas sus costas en el Océano Atlántico y aunque ha desarrollado algunos parámetros judiciales y parlamentarios, aún incipiente en su proceso de adecuación. Cabe acotar que posee un Instituto de Políticas Públicas en Derechos Humanos que trata de informar y fomentar los procesos de memoria, justicia y reparación a las víctimas de las violaciones y atropellos durante las dictaduras militares.

\subsection{Alianza Bolivariana para los pueblos de nuestra América - Tratado de Comercio de los Pueblos (ALBA-TEP) ${ }^{6}$}

A diferencia de otros enfoques de integración, el ALBA no nace como una propuesta propia, sino como reacción frente al Área de Libre Comercio de las Américas (ALCA). En la III Cumbre de las Américas, en Quebec, Canadá, en abril de 2001, Venezuela manifestó no suscribir el ALCA. En diciembre de 2001, en el marco de la III Cumbre de Jefes de Estado y de Gobierno de la Asociación de Estados del Caribe, desarrollada en la isla de Margarita, Venezuela, tanto Cuba como el país anfitrión proponen una organización que pueda aglutinar a los Estados de la región y formular una "integración integral, económica, social, política y cultural". Finalmente, el 14 de diciembre de 2004 Venezuela y Cuba suscriben en La Habana el acta fundacional y sus protocolos de inicio. El 29 de abril de 2006 Bolivia se adhiere, proponiendo que se incorporen "Tratados de Comercio de los Pueblos" para promover el "intercambio solidario y complementario" y frenar a los Tratados de Libre Comercio que a juicio del Presidente boliviano "persiguen incrementar el poder y el dominio de los transnacionales".

Nicaragua se suma al ALBA el 11 de enero de 2007. El 26 de enero de 2008 ingresa Dominica y el 25 de agosto del mismo año lo hace Honduras. El 24 de junio de 2009 Ecuador se adhiere, sumado con San Vicente y Las Granadinas y Antigua y Barbuda. El 30 de julio de 2013 se unía Santa Lucía y posteriormente el 14 de diciembre de 2014 lo consiguieron San Cristóbal y Nieves y Granada. Cabe acotar que Honduras abandonó la instancia durante el gobierno transitorio del presidente Roberto Micheletti.

El ALBA ha tenido trece Cumbres ordinarias, ocho extraordinarias y dos en conjunto con PETROCARIBE. Aunque se estructura en áreas, la dinámica

\footnotetext{
${ }^{6}$ Véase www.alba-tcp.org/
} 
es altamente centralizada y carece de estructuras parlamentarias y judiciales. La óptica por la que se trabaja es en proyectos "Grannacionales" que tiene como meta la construcción de iniciativas supranacionales y una vertiente económica de solidaridad. En lo ideológico el fundamento "...viene dado por la afinidad conceptual de quienes integramos el ALBA, en cuanto a la condición crítica acerca de la globalización neoliberal y la necesidad de romper el esquema del comercio basado en la ficción del libre mercado". En el esquema de trabajo propone empresas conjuntas y proyectos mancomunados, así como propuestas de bancos e integración financiera. Los países que lo integran poseen cerca de setenta millones de habitantes, de los cuales el 64\% es población urbana, y el $66 \%$ de sus exportaciones son combustibles minerales, lubricantes y materiales relacionados. A diferencia de lo que son el MERCOSUR y la Alianza del Pacífico, la unión creada en torno al ALBA es marcadamente política, sustentando su acercamiento, no en una perspectiva financiera y económica, pues su estructura interna no se parece, sino en incrementar vínculos ideológicos y de cercanía en el ejercicio del poder. La gran mayoría de gobernantes del mecanismo, provienen de partidos políticos que no son tradicionales en sus países (Partido Socialista Unido de Venezuela, Alianza País de Ecuador o Movimiento Al Socialismo en Bolivia) o son de organizaciones que tienen un marcado acento antiestadounidense.

\subsection{Alianza del Pacífico ${ }^{7}$}

Es un mecanismo constituido el 28 de abril de 2011 y creado jurídicamente en Paranal, Antofagasta, Chile, el 6 de junio del año siguiente, en el que Colombia, Chile, México y Perú buscaban desarrollar modelos innovadores que les permitieran erigirse como una opción competitiva desde diversos ámbitos. Además de los miembros fundadores, Costa Rica y Panamá manifestaron su intención de sumarse a la organización, adelantando diversos acuerdos que en el corto plazo deben llevarlos a pertenecer a la estructura formal.

La Declaración de Lima, suscrita el 28 de abril de 2011 por los presidentes de Chile, Colombia y México, además de un enviado especial de Panamá, parte de una serie de consideraciones en las que los asistentes manifiestan coincidir en los avances en materia de desarrollo que se tradujo en el crecimiento del empleo, el fortalecimiento de la democracia y la reducción de la pobreza.

Sumado a ello, el esquema indica que reconoce los acuerdos de libre comercio entre los Estados participantes y establece que la meta no es sólo el fortalecimiento del Arco del Pacífico Latinoamericano, sino (contrario a lo que

${ }^{7}$ Véase www.alianzapacifico.net/ 
normalmente se señala), una mayor proyección hacia el continente asiático. Es decir que se busca un espacio que trascienda la regionalización e incluso puedan superarse otras experiencias como la del Foro de Cooperación Económica Asia - Pacífico (del que forman parte todos los miembros de la Alianza del Pacífico, salvo Colombia) y que pese a funcionar desde 1989, no posee un tratado formal que le otorgue institucionalidad.

Sobre las prioridades iniciales que otorga la Declaración de Lima a la incipiente organización, se observa que el énfasis se hará en facilitar el flujo migratorio, cooperación en materia de seguridad y financiera, capacidad de inversión conjunta y fortalecimiento de equipos técnicos. El Acuerdo suscrito en su IV Cumbre en Paranal, el 6 de junio de 2012, establece que la organización es un "área de integración regional", cuyos miembros reivindican la democracia, respetan la separación de poderes y ejercen la defensa de los derechos humanos.

Aunque los exhortos democráticos inician el documento, es notable el marcado acento comercial y económico que tiene. Incluso, es pertinente señalar que se reconocen los deberes de Colombia y Perú como Estados miembro de la Comunidad Andina de Naciones. Al revisar los objetivos de la Alianza del Pacífico se observa que las metas se conseguirán al avanzar de forma paulatina hacia la libre circulación de bienes, servicios, capitales y personas, al impulsar un mayor crecimiento, desarrollo y competitividad de las economías de los Estados miembro, para disminuir la inequidad, superar la exclusión y vencer la pobreza, y buscar la promulgación de políticas el Pacífico asiático. El acuerdo establece que para alcanzar las metas se recurrirá a mecanismos de fomento a zonas de libre comercio, a incentivar la libre circulación de capitales, a simplificar los trámites aduaneros y a facilitar los trámites consulares.

Las instancias de organización recaen en un Consejo de Ministros (de comercio y relaciones exteriores) y en una Presidencia pro témpore en la que cada país durará un año en el ejercicio. Para que un Estado pueda sumarse a la estructura, debe haber aprobación unánime en el Consejo de Ministros y previamente, el país que ha manifestado su voluntad de ingresar, tiene que tener tratados de libre comercio con todos los miembros.

A la par de haber suscrito el Acuerdo Marco, en la IV Cumbre se formuló una declaración en la que se reconoce haber alcanzado grandes logros en lo relativo a la promoción de las inversiones, cambio climático y comercio electrónico, además de seguir intentando eliminar aranceles comunes, crear una certificación electrónica de origen y establecer un mecanismo de movilidad académica y estudiantil para cursantes de pregrado y postgrado.

Aprovechando la participación en la XXII Cumbre Iberoamericana de Jefes de Estado y de Gobierno celebrada en Cádiz, España, se congregaron el 17 de 
noviembre de 2012 los Presidentes de Perú, Chile, México y Colombia para ratificar la necesidad de proyectar los objetivos hacia el Pacífico y enumerar los logros que se habían alcanzado hasta el momento, fundamentalmente en lo referente a eliminación de aranceles, supresión de visados y movilidad de personas. Hubo dos hechos que merecen mención porque pueden indicar la idea de la Alianza del Pacífico por trascender. El primero, es la creación de un Consejo Empresarial para vincular la iniciativa privada y el segundo, el ingreso de España, Uruguay, Australia, Canadá y Nueva Zelanda como observadores. La idea de vincular al empresariado se concretó con una cumbre en Cali, Colombia, se habló inclusive de integrar representaciones diplomáticas, asumiendo experimentalmente una Embajada compartida en Ghana y un espacio que Perú y Colombia mantienen en Vietnam y otro que Colombia y Chile poseen en Argelia y Marruecos. Esto es importante porque pareciera ir migrándose de una visión estrictamente económica a una integración en otros ámbitos que implique mecanismos de lucha contra la corrupción, desarrollo científico e investigativo y la posibilidad de institucionalizar la "Visa Alianza Pacífico".

El 10 de febrero de 2014 la institucionalización de la Alianza del Pacífico se vio fortalecida con la firma en Cartagena de Indias, Colombia, del Protocolo Adicional al Acuerdo Marco en el que se formaliza e indica la sistematización a seguir para poder alcanzar los elementos de integración, partiendo de la especificación de los organismos responsables por cada país y de establecer un conjunto de definiciones que engloban y uniforman a los cuatro Estados fundadores. De hecho, en una declaración adicional, los mandatarios manifestaron que con el protocolo adicional se culminaba una etapa trascendental en la integración regional y que se fortalecerán los vínculos entre los países al concretarse el proceso de liberalización de bienes, servicios e inversiones. Hay también éxitos referentes a materia educativa, investigativa e incentivos a la innovación, culminando la declaración con un documento anexo que sienta las metas inmediatas que deben llevarse a cabo.

\section{ANÁLISIS ESTADÍSTICO DE INDICADORES ALTERNATIVOS DE DESARROLLO COMO EJES DE INTEGRACIÓN REGIONAL}

En un mundo globalizado, los países que hacen parte de América Latina no pueden actuar como agentes independientes del resto del mundo. Desde el enfoque multidimensional del desarrollo, deben crear condiciones que favorezcan, y amplíen oportunidades y capacidades para que la ciudadanía promueva resultados que permitan el desarrollo humano. Para el logro de estos objetivos, los esquemas de integración regional se muestran como mecanismo útiles para favorecerlos. 
Los países que integran América Latina han profundizado en los últimos años lazos de integración en la conformación de diversos grupos, pero ésta integración debe ser entendida como algo más que una agregación de entidades, por el contrario debe lograrse una fusión densa y profunda, una unificación de potencialidades y fortalezas para el desarrollo de sus ciudadanos (Díaz, 2012). En este sentido, los países de la región buscan favorecer sus políticas públicas integrándose para dar respuestas a las demandas sociales y mejorar la calidad de vida de sus habitantes. En virtud de lo anterior, el propósito del análisis es determinar si la gobernabilidad para desarrollos integrales en la región se puede estudiar a partir de la conformación de alianzas que tienen como objetivo integrase alrededor de fines políticos y/o económicos principalmente.

La sub-región de América Latina no es homogénea, a pesar de tener vínculos geográficos, históricos y culturales, cada país aplica sus propias políticas para enfrentar sus problemas; pero a pesar de ello, existen similitudes significativas en algunos países (Levy-Carciente, Phélan y Perdomo, 2014). Las alianzas conformadas en la sub-región buscan unificar esfuerzos con similares objetivos en común y en primera instancia pareciera que quienes lo conforman tienen elementos que los hacen muy homogéneos. A pesar de que la conformación de alianzas atiende de forma a expresa a intereses diferentes -como puede ser de orden económico y otros de orden más político- la intención del estudio es analizar si en las agrupaciones y los países que la conforman, manifiestan de forma similar las capacidades y oportunidades de sus poblaciones. En este sentido, se formula como hipótesis, que los integrantes de Mercado Común del Sur, la Alianza del Pacifico y la Alianza Bolivariana para los Pueblos de América, tengan condiciones y/o resultados en políticas públicas homogéneos internamente a los grupos.

Se realizará un análisis a diecinueve países de Latinoamérica, haciendo uso de grupos compuestos por los tres acuerdos de integración descritos anteriormente: MERCOSUR, AP y ALBA. El objetivo es determinar cuáles son las características que permiten diferenciar los acuerdos y detectar posibles adhesiones, por similitud de características a partir de indicadores alternativos al desarrollo.

El análisis del grado de homogeneidad e integración de la región, se puede realizar mediante la aplicación de dos procedimientos estadísticas: Análisis de Conglomerados y Análisis Discriminante. El primero tiene como objetivo determinar los países que estadísticamente conforman grupos homogéneos de acuerdo a ciertas características significativas que tienen en común, medidas a partir de algún indicador. En el segundo procedimiento, Análisis Discriminante, se conocen a priori los grupos de países, y lo que se busca es determinar las características que significativamente los diferencia como grupos. 
Justificado en lo descrito y asociado al objetivo de estudio, la técnica estadística más apropiada para éste estudio es el Análisis Discriminante, técnica que busca una función lineal de modo que maximice la variabilidad entre los grupos para discriminarlos y determinar si existen diferencias significativas entre un conjunto de variables de dos o más grupos, así como identificar que variables tienen mayor poder discriminatorio.

El Análisis Discriminante se realiza con una selección de índices de bienestar, de libertades civiles, aspectos políticos, económicos y ambientales que conforman un perfil multidimensional de cada uno de los países y de los respectivos bloques o asociaciones, con una perspectiva alternativa al desarrollo. La selección de los indicadores se basó en primer lugar en una alternativa a los indicadores tradicionales de relaciones comerciales para estudiar convenios político-económicos, tales como importaciones y exportaciones, preferencias arancelarias y cuotas, para ampliar a un compendio de indicadores más relacionados al desarrollo integral de los países que componen los bloques.

En este sentido, para la selección de los índices, como primer elemento de análisis, desde hace varios años, se ha realizado una copiosa recopilación documental y electrónica de índices alternativos sobre diversos temas asociados al desarrollo. Se tomaron índices del inventario de Romina Bandura (Bandura, 2008), índices sobre derechos civiles y políticos de la base de datos de Pipa Norris ${ }^{8}$, de informes y documentos internacionales como los Informe de Desarrollo Humano, y fundamentalmente a través de búsquedas propias mediante fuentes electrónicas. Resultado de este esfuerzo se han logrado identificar sesenta índices que miden, de una u otra forma, aspectos ambientales, socio-económicos, políticos, tecnológicos, institucionales. Del total de índices recolectados se seleccionaron en primera instancia aquellos que contaban con datos completos para todos los países latinoamericanos. En segunda instancia, para los índices seleccionados se realizó un análisis comparativo de las dimensiones que poseían, con el objetivo de reducir la presencia multiplicada de la misma dimensión y evitar algún tipo de covarianzas entre los indicadores seleccionados ${ }^{9}$. En virtud de lo anterior se seleccionaron 10 índices $\left(\right.$ Tabla \#1) ${ }^{10}$,

${ }^{8}$ Véase http://www.pippanorris.com

${ }^{9}$ Tal es el caso del Îndice de Libertad de Prensa que está incorporado en el Índice de Calidad Institucional, Índice de Progreso Social y el Índice de Estado Frágil.

${ }^{10}$ Véase: http://www.fundacionlibertad.org.pa/;

http://internationalpropertyrightsindex.org/;

http://www.eiu.com/public/topical_report.aspx?campaignid=Wcol2014; http://www.eiu.com/public/topical_report.aspx?campaignid=Democracy0814; http://atlas.media.mit.edu/en/; http://www.cato.org/blog/world-misery-index-108countries\#3yFpFC:Xnx; 
Tabla \#1. Índices. Países de América Latina

\begin{tabular}{l|c|c|c|c|c|c|c|c|c|c}
\hline Países/Índices & $\begin{array}{c}\text { Calidad } \\
\text { Institucional } \\
\mathbf{( 2 0 1 1 )}\end{array}$ & $\begin{array}{c}\text { Índice de } \\
\text { Derecho de } \\
\text { Propiedad } \\
\mathbf{( 2 0 1 4 )}\end{array}$ & $\begin{array}{c}\text { Índice de } \\
\text { Costo de } \\
\text { Vida (2014) }\end{array}$ & $\begin{array}{c}\text { Indice de } \\
\text { Democracia } \\
\mathbf{2 0 1 3}\end{array}$ & $\begin{array}{c}\text { Índice de } \\
\text { Complejidad } \\
\mathbf{( 2 0 1 2 )}\end{array}$ & $\begin{array}{c}\text { Índice de } \\
\text { Aflicción } \\
\mathbf{( 2 0 1 4 )}\end{array}$ & $\begin{array}{c}\text { Índice de } \\
\text { Progreso } \\
\text { Social (2015) }\end{array}$ & $\begin{array}{c}\text { Índice de } \\
\text { Innovación } \\
\text { Global (2014) }\end{array}$ & $\begin{array}{c}\text { Índice de } \\
\text { Globalización } \\
\text { (2013) }\end{array}$ & $\begin{array}{c}\text { Índice de } \\
\text { Estado Frágil } \\
\text { (2014) }\end{array}$ \\
\hline Argentina & 0,372 & 4,40 & 67,12 & 6,84 & 0,304 & 68,00 & 73,08 & 35,13 & 58,30 & 47,30 \\
\hline Bolivia & 0,298 & 4,50 & 40,02 & 5,79 & $-0,335$ & 18,38 & 63,36 & 27,76 & 53,08 & 78,90 \\
\hline Brasil & 0,482 & 5,50 & 55,33 & 7,12 & 0,316 & 42,79 & 70,89 & 36,39 & 59,21 & 61,40 \\
\hline Chile & 0,833 & 6,80 & 53,21 & 7,8 & $-0,029$ & 14,42 & 78,29 & 40,64 & 72,91 & 42,00 \\
\hline Colombia & 0,502 & 5,00 & 38,92 & 6,55 & 0,412 & 19,61 & 68,85 & 35,5 & 52,40 & 83,10 \\
\hline Costa Rica & 0,688 & 6,00 & 62,53 & 8,03 & 0,362 & 26,87 & 77,88 & 37,3 & 61,64 & 48,50 \\
\hline Cuba & 0,134 &.. &.. & 3,52 &.. &.. & 60,83 &.. & 48,88 & 70,80 \\
\hline Ecuador & 0,282 & 5,00 & 45,57 & 5,87 & $-0,420$ & 13,72 & 68,25 & 27,5 & 54,01 & 77,30 \\
\hline El Salvador & 0,559 & 4,90 & 50,64 & 6,53 & 0,186 & 12,56 & 64,31 & 29,08 & 62,59 & 72,00 \\
\hline Guatemala & 0,427 & 4,80 & 50,42 & 5,81 & $-0,154$ & 21,21 & 62,19 & 30,75 & 59,67 & 80,30 \\
\hline Honduras & 0,372 & 4,50 & 53,06 & 5,84 & $-0,300$ & 28,07 & 61,44 & 26,73 & 60,93 & 77,90 \\
\hline México & 0,534 & 5,20 & 41,26 & 6,91 & 0,989 & 10,05 & 67,50 & 36,02 & 59,25 & 71,10 \\
\hline Nicaragua & 0,365 & 4,60 & 47,85 & 5,46 & $-0,790$ & 25,06 & 62,20 & 25,47 & 54,42 & 78,40 \\
\hline Panamá & 0,626 & 5,60 & 55,16 & 7,08 & 0,449 & 9,39 & 71,79 & 38,3 & 67,43 & 55,70 \\
\hline Paraguay & 0,328 & 4,10 &.. & 6,26 & $-0,329$ & 27,01 & 67,10 & 31,59 & 57,57 & 71,60 \\
\hline Perú & 0,589 & 5,00 & 49,43 & 6,54 & $-0,182$ & 20,09 & 67,23 & 34,73 & 64,30 & 72,90 \\
\hline R. Dominicana & 0,434 & 4,90 & 55,95 & 6,74 & $-0,021$ & 27,98 & 62,47 & 32,29 & 60,22 & 73,40 \\
\hline Uruguay & 0,677 & 6,10 & 68,55 & 8,17 & 0,332 & 28,37 & 79,21 & 34,76 & 65,28 & 37,90 \\
\hline Venezuela & 0,099 & 3,20 & 111,01 & 5,07 & $-0,692$ & 106,30 & 63,45 & 25,66 & 49,44 & 76,50 \\
\hline
\end{tabular}

Fuente: Páginas oficiales de los distintos indicadores señalados

Calidad Institucional, Derecho de Propiedad, Costo de Vida, Democracia, Complejidad, Aflicción, Progreso Social, Innovación Global, Globalización y Estado Frágil; todos ellos multidimensionales.

Una vez escogidos los 10 índices, se cotejaron con las dimensiones trabajadas en documentos previos y que conforman el enfoque adoptado para medir el bienestar (Levy-Carciente, Phélan y Perdomo, 2015). En buena medida también asociados con las dimensiones establecidas para las metas de desarrollo sostenible de la ONU (2015) para el año 2030, relacionados a los aspectos económicos, sociales, ambientales, de violencia, cohesión social, innovación, institucionalidad, transparencia y la integración; dimensiones rescatados y recomendados por el Panel de Alto Nivel de la ONU (2013) como factores primordiales y que ahora serán monitoreadas para las metas de los próximos 15 años en los objetivos de cada país de las Naciones Unidas y en sus integraciones regionales.

En el presente ejercicio se presentan y analizan los 10 índices seleccionados en dos grandes dimensiones que explican, en cierta medida, la multidimensionalidad del concepto de desarrollo y sus relaciones con el bienestar y la calidad

http://www.socialprogressimperative.org/es; http://www.globalinnovationindex.org/; http://www.kof.ethz.ch/;

http://library.fundforpeace.org/library/cfsir1423-fragilestatesindex2014-06d.pdf 
Figura \#1. Potencialidades y Eficiencia Sinérgica

\begin{tabular}{|c|c|c|c|c|c|c|c|c|c|c|c|c|c|}
\hline \multirow[b]{3}{*}{ Indices/Dimensiones } & \multicolumn{9}{|c|}{ Potencialidades } & \multirow{2}{*}{\multicolumn{4}{|c|}{ Efficiencia Sinérgica }} \\
\hline & \multicolumn{2}{|c|}{ Capacidades Humanas } & \multirow{2}{*}{$\begin{array}{c}\begin{array}{c}\text { Capacidades } \\
\text { Naturales }\end{array} \\
\text { Ambiente }\end{array}$} & \multicolumn{6}{|c|}{ Oportunidades } & & & & \\
\hline & $\begin{array}{c}\text { Saludd, } \\
\text { Edacuación, } \\
\text { Ingreso }\end{array}$ & $\begin{array}{c}\text { Equidad } \\
\text { Disstributiva }\end{array}$ & & Politicas & $\begin{array}{c}\text { Agencia } \\
\text { (Expresion de } \\
\text { Ideas) }\end{array}$ & $\begin{array}{c}\text { Satisffacción } \\
\text { Material }\end{array}$ & \begin{tabular}{|l} 
Respeto a la \\
Diferencia
\end{tabular} & Justicia & Derechos & Sociedad & Tecnología & Ecológica & Relacional \\
\hline Calidad Institucional & & & & & $x$ & $\mathrm{x}$ & & $x$ & & & & & \\
\hline $\begin{array}{l}\text { İdice de Derecho de } \\
\text { Propiedad }\end{array}$ & & & & & & & & $x$ & $x$ & $\mathrm{x}$ & & & \\
\hline Índice de Costo de Vida & & & & & & $x$ & & & & & & & \\
\hline Indice de Democracia & & & & $x$ & & & $x$ & & & & & & \\
\hline Índice de Complejidad & & & & & & & & & & & $x$ & & \\
\hline Índice de Aflicción & $x$ & & & & & & & & & & & & \\
\hline Índice de Progreso Social & $x$ & & $x$ & & $x$ & & $\mathrm{x}$ & $x$ & $x$ & & & $x$ & \\
\hline $\begin{array}{l}\text { İndice de Innovación } \\
\text { Global }\end{array}$ & $x$ & & $x$ & $\mathrm{x}$ & & & $\mathrm{x}$ & & & & $x$ & $x$ & \\
\hline Índice de Globalización & $x$ & & & & & & & & & & & & $\mathrm{x}$ \\
\hline
\end{tabular}

de vida de las poblaciones (ver Figura \#1). De las dos dimensiones que se consideran, la primera se refiere a las Potencialidades (condiciones básicas necesarias); mientras la segunda se refiere a las derivaciones de estas potencialidades en Eficiencia Sinérgica, relacionados con la calidad de vida que disfrutan las personas en todos los países. Las potencialidades se dividen a su vez en dos categorías: aquellas mediciones que recogen las capacidades -humanas y naturales- con las que cuenta una población y aquéllas que recogen las oportunidades que el ordenamiento institucional ofrece a dicha sociedad. De otro lado, la eficiencia y sostenibilidad de apropiadas condiciones de vida para la sociedad, dependerá de la capacidad de alcanzar una combinación sinérgica de las potencialidades. Esto es lo que hemos definido como eficiencia sinérgica (Levy et al, 2015).

Las capacidades fueron evaluadas a partir de derechos y aspectos relacionados con la salud, educación, los ingresos, la desigualdad y el ambiente. Las oportunidades fueron evaluadas a partir de las condiciones institucionales: las reglas de juego imperantes (que incluye leyes, normas, reglas de conducta, ordenamientos organizativos, y otros) y para ello se consideraron: la libertad de acción política, la libertad de expresión de ideas, la libertad para satisfacer las necesidades materiales, el respeto a la diferencia, a la alteridad y el respeto a las reglas y normas establecidas. Por su parte la eficiencia sinérgica fue evaluada a partir de aspectos como satisfacción colectiva, avances tecnológicos, sostenibilidad ambiental y relacionamiento mundial.

Con la selección de indicadores de la Tabla \#1, los países que conforman la sub-región y la técnica de Análisis Discriminante, se aplica una serie de pruebas estadísticas para determinar el comportamiento de los grupos de América 
Latina. Es importante resaltar que estos grupos conformados no son el resultado de un proceso aleatorio o natural, son en nuestro caso agrupaciones existentes, conformadas por voluntad política.

Dado que el análisis discriminante exige que las agrupaciones conformen grupos disjuntos entre sí, se realizaron dos pruebas estadísticas:

- Prueba I: considera los grupos ALBA (Venezuela, Cuba, Nicaragua, Ecuador y Bolivia), AP (Colombia, México, Perú, Chile, Costa Rica y Panamá, los dos últimos en proceso de anexión), y un tercero con el resto de países bajo estudio no asociados a estos esquemas de integración (Brasil, República Dominicana, Uruguay, Paraguay, Argentina, Honduras, Guatemala, El Salvador);

- Prueba II: analiza MERCOSUR (Argentina, Brasil, Paraguay, Uruguay y Venezuela), AP (Colombia, México, Perú, Chile, Costa Rica y Panamá, los dos últimos en proceso de anexión) y un tercero con el resto de países bajo estudio no asociados a estos esquemas de integración (Bolivia, Cuba, Ecuador, El Salvador, Guatemala, Honduras, Nicaragua y República Dominicana).

La conformación de un tercer grupo para el resto de países de Latinoamérica asociados a los esquemas de integración revisados en cada prueba atiende a la necesidad de analizar toda la región en su conjunto y considerar la cercanía que estos países pudieran tener con las agrupaciones existentes. La consideración de un país en un grupo dependerá de ejercicio que se esté analizando, en la Tabla \#2 se puede observar los países que conforman los grupos en cada prueba estadística.

Es importante resaltar que otros países del Caribe que forman parte de la región y/o pertenecen algún grupo, como el caso del resto de los países miembros del ALBA, no se integraron al análisis. Solo se incluirá República Dominicana y Cuba como islas de habla hispana, el resto de las islas tienen dependencia de otros países que pueden distorsionar el análisis, tal es el caso de Puerto Rico como país dependiente de los Estados Unidos y otras islas de Caribe dependientes de Inglaterra, Holanda y Francia, donde adicionalmente presentan un acercamiento cultural y lingüístico muchos más asociados a ellos. Además, en algunos casos, estos países presentan ausencia de datos para diversos indicadores que podrían comprometer la consistencia del estudio, como es el caso de algunos países miembros del ALBA.

En el caso particular de Cuba, a pesar de tener valores ausentes, se consideró incluir en el estudio dado su particularidad e importancia para los análisis de la sub-región, éste país tiene ausencia de datos para cinco de los índices 
Tabla \#2. Conformación de Grupos según prueba estadística

\begin{tabular}{|c|c|c|}
\hline Países/Pruebas & $\begin{array}{c}\text { Prueba Estadística I: } \\
\text { Grupo ALBA =1, } \\
\text { Grupo AP =2 y } \\
\text { Otros }=\mathbf{3}\end{array}$ & $\begin{array}{c}\text { Prueba Estadística II: } \\
\text { Grupo MERCOSUR =1, } \\
\text { Grupo AP }=\mathbf{2} \text { y } \\
\text { Otros }=\mathbf{3}\end{array}$ \\
\hline Argentina & 3 & 1 \\
\hline Bolivia & 1 & 3 \\
\hline Brasil & 3 & 1 \\
\hline Chile & 2 & 2 \\
\hline Colombia & 2 & 2 \\
\hline Costa Rica & 2 & 2 \\
\hline Cuba & 1 & 3 \\
\hline Ecuador & 1 & 3 \\
\hline El Salvador & 3 & 3 \\
\hline Guatemala & 3 & 3 \\
\hline Honduras & 3 & 3 \\
\hline México & 2 & 2 \\
\hline Nicaragua & 1 & 3 \\
\hline Panamá & 2 & 2 \\
\hline Paraguay & 3 & 1 \\
\hline Perú & 2 & 2 \\
\hline R. Dominicana & 3 & 3 \\
\hline Uruguay & 3 & 1 \\
\hline Venezuela & 1 & 1 \\
\hline
\end{tabular}

seleccionados, por lo que se imputaron dichos valores para poder incluirlo en el análisis. La técnica de imputación de los datos aplicada, dado la particularidad de los indicadores con presencia de valores extremos, se realizó por medio de la variable más correlacionada donde existe el valor ausente y con dicha variable se tomó el valor adyacente del vecino más próximo por encima y por debajo de Cuba para interpolar dos valores que promediados resultan el valor final imputado, como método más óptimo en este caso. Esta misma técnica se aplicó para imputar el valor ausente que presentaba Paraguay en un indicador (ver Tabla \#3 y detalles en Anexo A).

Para las pruebas se consideraron, en los 10 indicadores seleccionados, los valores más actualizados para los 19 países de la región Latinoamericana (ver 
Tabla \#3. Índices: Los valores ajustados. Países de América Latina

\begin{tabular}{|c|c|c|c|c|c|c|c|c|c|c|c|}
\hline & Índices & \begin{tabular}{|c|} 
Calidad \\
Institucional \\
(2011)
\end{tabular} & $\begin{array}{c}\text { Índice de } \\
\text { Derecho de } \\
\text { Propiedad } \\
\text { (2014) }\end{array}$ & $\begin{array}{c}\text { Índice de } \\
\text { Costo de } \\
\text { Vida (2014) }\end{array}$ & \begin{tabular}{|c|} 
Indice de \\
Democracia \\
2013
\end{tabular} & $\begin{array}{c}\text { Índice de } \\
\text { Complejidad } \\
\text { (2012) }\end{array}$ & $\begin{array}{c}\text { Índice de } \\
\text { Aflicción } \\
\text { (2014) }\end{array}$ & $\begin{array}{c}\text { Índice de } \\
\text { Progreso } \\
\text { Social } \\
(2015)\end{array}$ & $\begin{array}{c}\text { Índice de } \\
\text { Innovación } \\
\text { Global } \\
\text { (2014) }\end{array}$ & $\begin{array}{c}\text { Índice de } \\
\text { Globalización } \\
\text { (2013) }\end{array}$ & $\begin{array}{c}\text { Índice de } \\
\text { Estado } \\
\text { Frágil } \\
\text { (2014) }\end{array}$ \\
\hline Países & Etiqueta & CALIDADIT & IPRI & CLI & IDEMOC & COMPLEJ & MISERY & SPI & ING & GLOBALIZ & FRAGIL \\
\hline Argentina & Ar & 0,372 & 4,40 & 32,88 & 6,84 & 0,304 & 32,0 & 73,08 & 35,13 & 58,30 & 52,70 \\
\hline Bolivia & Bo & 0,298 & 4,50 & 59,98 & 5,79 & $-0,335$ & 81,6 & 63,36 & 27,76 & 53,08 & 21,10 \\
\hline Brasil & $\mathrm{Br}$ & 0,482 & 5,50 & 44,67 & 7,12 & 0,316 & 57,2 & 70,89 & 36,39 & 59,21 & 38,60 \\
\hline Chile & Ch & 0,833 & 6,80 & 46,79 & 7,8 & $-0,029$ & 85,6 & 78,29 & 40,64 & 72,91 & 58,00 \\
\hline Colombia & Co & 0,502 & 5,00 & 61,08 & 6,55 & 0,412 & 80,4 & 68,85 & 35,5 & 52,40 & 16,90 \\
\hline Costa Rica & $\mathrm{Cr}$ & 0,688 & 6,00 & 37,47 & 8,03 & 0,362 & 73,1 & 77,88 & 37,3 & 61,64 & 51,50 \\
\hline Cuba & $\mathrm{Cu}$ & 0,134 & 3,34 & 55,78 & 3,52 & $-0,566$ & 16,0 & 60,83 & 23,82 & 48,88 & 29,20 \\
\hline Ecuador & Ec & 0,282 & 5,00 & 54,43 & 5,87 & $-0,420$ & 86,3 & 68,25 & 27,5 & 54,01 & 22,70 \\
\hline El Salvador & $\mathbf{S r}$ & 0,559 & 4,90 & 49,36 & 6,53 & 0,186 & 87,4 & 64,31 & 29,08 & 62,59 & 28,00 \\
\hline Guatemala & Gu & 0,427 & 4,80 & 49,58 & 5,81 & $-0,154$ & 78,8 & 62,19 & 30,75 & 59,67 & 19,70 \\
\hline Honduras & Ho & 0,372 & 4,50 & 46,94 & 5,84 & $-0,300$ & 71,9 & 61,44 & 26,73 & 60,93 & 22,10 \\
\hline México & $\mathbf{M x}$ & 0,534 & 5,20 & 58,74 & 6,91 & 0,989 & 90,0 & 67,50 & 36,02 & 59,25 & 28,90 \\
\hline Nicaragua & $\mathrm{Ni}$ & 0,365 & 4,60 & 52,15 & 5,46 & $-0,790$ & 74,9 & 62,20 & 25,47 & 54,42 & 21,60 \\
\hline Panamá & Pn & 0,626 & 5,60 & 44,84 & 7,08 & 0,449 & 90,6 & 71,79 & 38,3 & 67,43 & 44,30 \\
\hline Paraguay & $\mathrm{Pr}$ & 0,328 & 4,10 & 59,98 & 6,26 & $-0,329$ & 73,0 & 67,10 & 31,59 & 57,57 & 28,40 \\
\hline Perú & $\mathrm{Pe}$ & 0,589 & 5,00 & 50,57 & 6,54 & $-0,182$ & 79,9 & 67,23 & 34,73 & 64,30 & 27,10 \\
\hline R. Dominicana & Do & 0,434 & 4,90 & 44,05 & 6,74 & $-0,021$ & 72,0 & 62,47 & 32,29 & 60,22 & 26,60 \\
\hline Uruguay & Ur & 0,677 & 6,10 & 31,45 & 8,17 & 0,332 & 71,6 & 79,21 & 34,76 & 65,28 & 62,10 \\
\hline Venezuela & $\mathbf{V z}$ & 0,099 & 3,20 & $-11,01$ & 5,07 & $-0,692$ & $-6,3$ & 63,45 & 25,66 & 49,44 & 23,50 \\
\hline
\end{tabular}

Tabla \#3). Es importante señalar que las ediciones de los indicadores varían entre 2011 y 2014, sin embargo estas diferencias, se consideraron poco relevantes, tomando en cuenta que las variaciones en un mismo indicador en el corto plazo son bajas. En cuanto a las diversas escalas presentes en las variables, no fue necesario su ajuste para el Análisis Discriminante, sin embargo, si lo fue el ajustar las direcciones de cada indicador para que queden todos orientados en el mismo sentido. Por esta razón se ajustaron la dirección en forma creciente de los indicadores Índice de Aflicción, Índice de Costo de Vida e Índice de Estado Frágil (Misery Index, Cost of Living Index, Fragile States Index). Esto para garantizar que en el análisis todos los indicadores estén en un sentido positivo de resultados hacia un mayor desarrollo humano (ver Tabla \#3).

\subsection{Resultados}

Para el análisis discriminante en ambas pruebas se aplicó la técnica denominada Paso a Paso ${ }^{11}$. Si bien varios indicadores pueden tener significativamente poder discriminatorio, la idea en un principio es conocer cuál de los indicado-

${ }^{11}$ Esta técnica permite simplificar al máximo posible la función discriminante en las características significativas que son suficientes para discriminar los grupos, de esta forma no hay que incluir todas las características (variables) que tengan poder discriminatorio para construir una función discriminante. 
res son más influyentes a la hora de discriminar a un individuo en un grupo $\mathrm{u}$ otro, de modo que la técnica Paso a Paso utiliza solo aquellos indicadores más influyentes, buscando representar una función discriminante con la menor cantidad de variables posibles y que sea igualmente significativa para diferenciar los grupos. Las variables resultantes permiten maximizar las diferencias de los grupos, digamos en un espacio gráfico, alejándose entre ellos lo máximo posible; por el contrario si se agrega otra variable, la función podrá seguir discriminando a los grupos, pero acercándolos más entre ellos (ver Figura \#2). Por esta razón se seleccionan las variables que proporcionen los centros de los grupos más alejados entre sí y más concentrados dentro de sí.

En la Prueba I (ALBA, AP, Otros), de los 10 indicadores considerados, existen 6 cuyas pruebas reflejan significativamente poder discriminatorio para diferenciar los grupos, estos son: Innovación Global, Calidad Institucional, Compleji-

Figura \#2. Distancia de los grupos de acuerdo al indicador

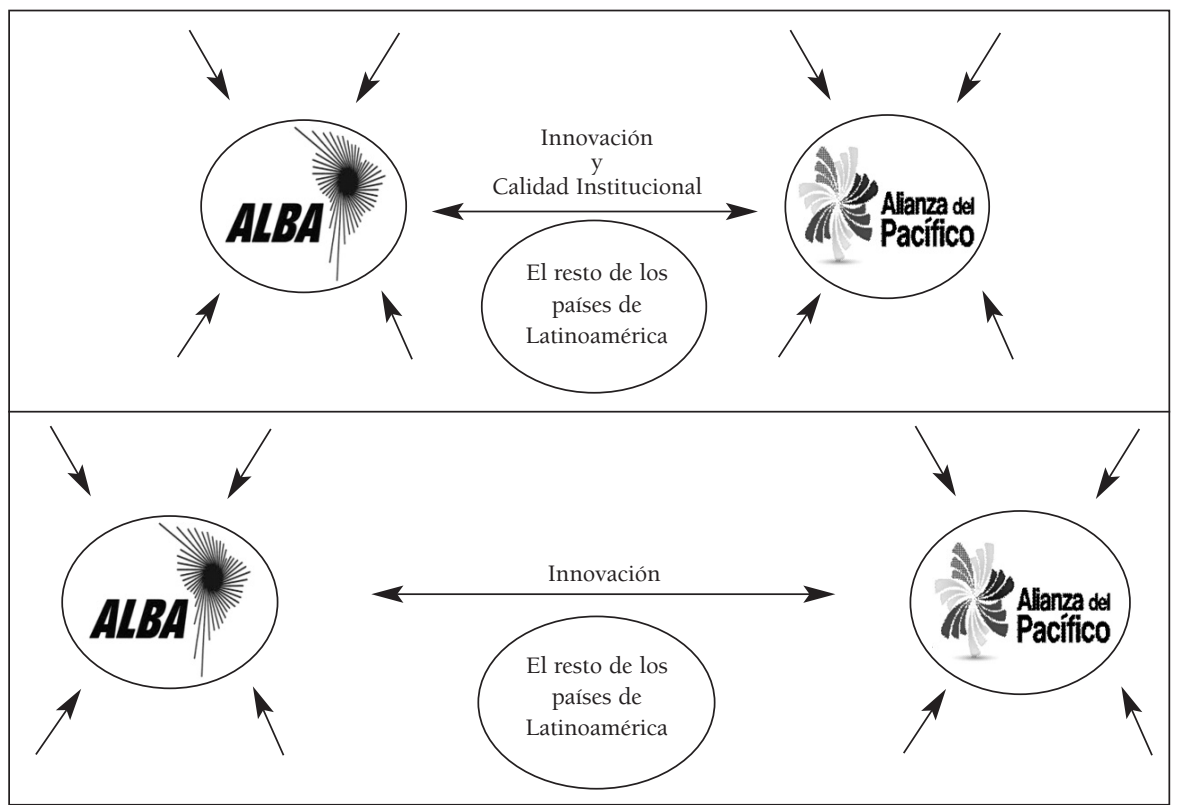

${ }^{12}$ Recoge la pertenencia de los sujetos a los grupos mediante un coeficiente que oscila entre 0 y 1 . Interesa que presente un valor lo más próximo a 1.

${ }^{13}$ Representa la diferencia entre grupos. Los valores próximos a 1 indican similitudes entre grupos, si su valor es cercano a 0 deberá interpretarse que los grupos son diferentes y por lo tanto, la función discriminante puede pronosticar adecuadamente a los sujetos. 
dad Económica, Relacionamiento Global, Democracia y Derecho de Propiedad. Sin embargo, aplicando la técnica Paso a Paso, el resultado es que el indicador de Innovación Global es suficiente para elaborar un modelo discriminante (ver Anexo C), la función explica el $100 \%$ de la variabilidad del modelo, con una correlación canónica ${ }^{12}$ de 0.868 y un valor de Wilks $^{13}$ en 0.246 , indicativos que los grupos son diferentes y que podrán discriminarse adecuadamente con esa variable en una sola función discriminante (ver Anexo D).

En la Figura \#2 se ilustra el caso de la primera prueba estadística, en el que los índices Innovación Global y Calidad Institucional discriminan muy bien a los grupos, pero donde la combinación de ambos hace que se acerquen más entre ellos, mientras que Innovación Global logra por si solo maximizar la distancia entre los grupos y discriminar mucho mejor.

En la Prueba II (MERCOSUR, AP, Otros), de los 10 indicadores considerados, existen 7 cuyas pruebas reflejan significativamente poder discriminatorio para diferenciar los grupos, estos son: Innovación Global, Progreso Social, Calidad Institucional, Complejidad Económica, Democracia, Aflicción y Estado Frágil (ver Anexo B). Una vez aplicada la técnica Paso a Paso, el resultado es que dos funciones discriminantes, la primera con Innovación Global y la segunda con Aflicción, son suficientes para diferenciar los grupos que conforman el análisis y elaborar un modelo discriminante (ver Anexo C), así mismo, las condiciones del modelo resultan adecuadas para discriminar o separar bien a los respectivos grupos en análisis (ver Anexo D).

El hecho de que no todas las variables tengan poder discriminatorio es indicativo de que los grupos en algunas dimensiones no son homogéneos, son países que conforman un grupo con resultados completamente distintos en ese indicador. Por el contrario cuando tienen poder discriminatorio, indica que los grupos deben ser analizados a partir de esas variables, ya que por ser más homogéneos en ese indicador, permiten representar mejor a los países integrados.

Una mejor ilustración de los resultados se obtiene con los valores de los centroides; éstos indican que los grupos son diferentes en la medida que sus distancias medias sean mayores, lo cual permite diferenciar a cada grupo y obtener una medida de su representación espacial (ver Anexo E). En la primera prueba estadística, la representación espacial entre los grupo ALBA, AP y Otros se obtiene con los valores $-2.316 ; 1.922$ y 0.006 respectivamente, sus diferencias son bien marcadas, hacia los extremos, con una distancia entre ALBA y AP que coloca en el centro al resto de los países de Latinoamérica y que además demuestra qué tan diferentes son ambos grupos entre sí. Además, permite observar las posiciones de los países con relación a su grupo de conformación y con relación a los otros grupos (ver Figura\#3). 
Figura \#3. Centroides de los grupos. Prueba I

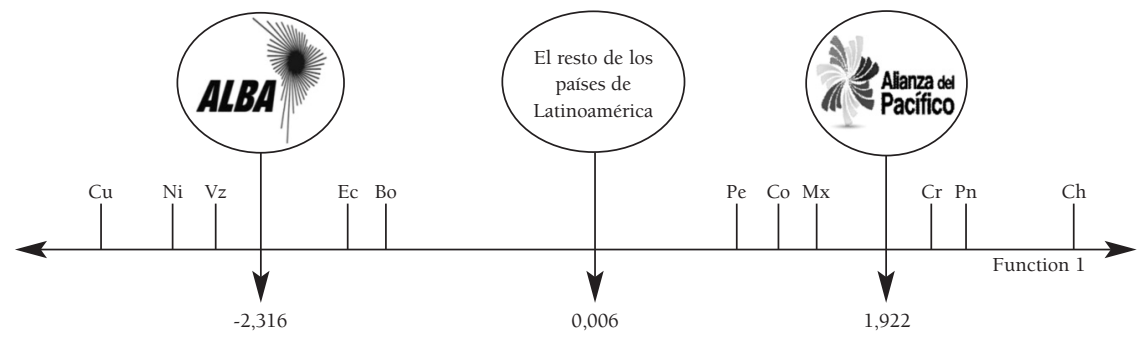

Por su parte en la segunda prueba, también son marcadas las diferencias entre los grupos, especialmente con la segunda función discriminante entre MERCOSUR y AP, aunque con presencia de algunos países muy aislados de sus centroides de grupo y más asociados a otros centroides de otros grupos, lo cual puede significar una asociación mayor hacia otro grupo por compartir características más similares (ver Figura\#4).

Figura \#4. Centroides de los grupos. Prueba II

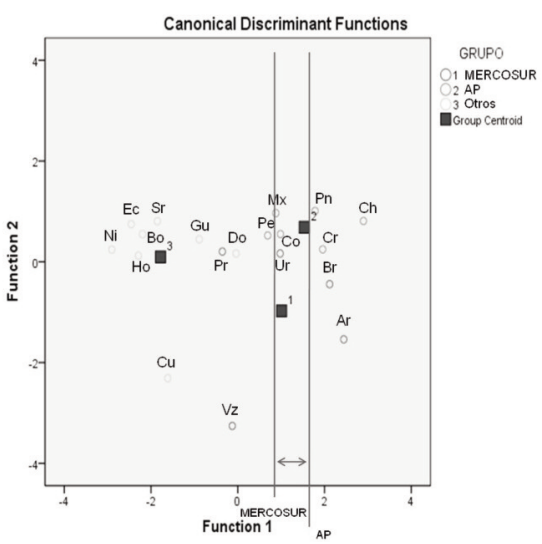

Función 1: Índice de Innovación Global. Se observa que los centroides para MERCOSUR y AP son muy cercanos para esta función, así como bien distantes ambos con el resto de Latinoamérica. Es de notar como particularmente Cuba y Venezuela son los países más alejados de sus respectivos centroides y más cercanos entre sí.

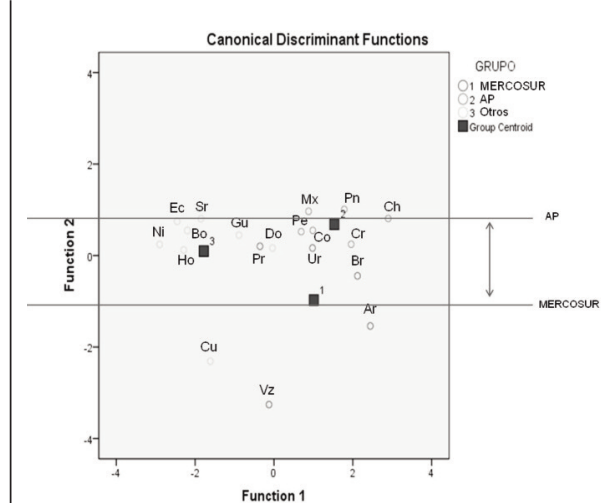

Función 2: Índice de Aflicción. Con esta función se distingue mayores diferencias entre los centroides de los tres grupos, principalmente MERCOSUR y AP. 
Ahora, por ser la Innovación Global un índice con poder discriminatorio para la región en ambas pruebas realizadas y por tratarse de un índice multidimensional, es de interés conocer cuál de sus componentes es el que presenta mayor poder discriminatorio, es decir, aplicar un análisis discriminante en los componentes de éste indicador.

El índice de Innovación Global está compuesto por las dimensiones: Institucionalidad, Capital Humano y de Investigación, Infraestructura, sofisticación del mercado, sofisticación del negocio, salidas de conocimiento y tecnología, y salidas creativas. El resultado obtenido muestra que de las diversas dimensiones que componen este indicador; para países que conforman los grupos de la primera prueba estadística, resulta la Institucionalidad como el factor con mayor poder discriminatorio, y a lo interno de ella se determinó que el ambiente regulatorio y cumplimiento de la ley como las más significativas. Para los países que conforman los grupos de la segunda prueba estadística, el Capital Humano y de Investigación y la Infraestructura son los factores con mayor poder discriminatorio, y a los interno de ellos se determinó que la educación terciaria y sostenibilidad ecológica son las más significativas.

Adicionalmente, es importarte observar la consistencia de los grupos conformados por las alianzas ALBA, MERCOSUR y AP en las dos pruebas realizadas, para esto se aplicó un test estadístico de contraste y probabilidad de pertenencia ${ }^{14}$, cuyo resultado permite obtener la probabilidad estadística de pertenecer al grupo de origen o a otro grupo diferente, dado el perfil del individuo en el indicador de la función discriminante. Para ello se obtiene una Matriz de Confusiones donde se expresan los individuos según su grupo de origen y por el grupo pronosticado al cual tienen un perfil más asociado (ver Tabla \#5 y Anexo F).

De lo anterior se extrae que en la Prueba I, el 100\% de los países del ALBA conservan su pertenencia al grupo, y de los países del grupo 3 (Otros), se observa un país, Honduras, con cercanía al ALBA. Esto quiere decir que Honduras tiene un perfil más asociado a ALBA que a Otros. Por su parte, en el grupo AP, el 83,3\% de los individuos se mantienen como grupo, pero Perú tiene características que lo asocian más hacia el resto de Latinoamérica (Otros) por sus resultados en la función discriminante. Mientras, Brasil y Argentina (ubicados en Otros), tienen un perfil más asociado hacia AP y el resto de los países (Guatemala, El Salvador, Uruguay, Paraguay y República Dominicana) quedan

${ }^{14}$ El cálculo de probabilidad de pertenecer a un grupo, se realiza con la condición de conocer a priori la pertenencia de un individuo a un grupo específico, en nuestro caso ALBA, AP, MERCOSUR, OTROS, para clasificarlo posteriormente al grupo con mayor probabilidad a posteriori. 
Tabla \#5. Resultado de la Clasificación

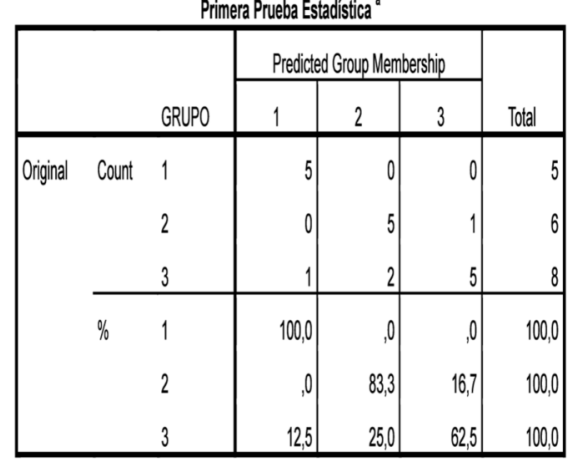

a. $78,9 \%$ of original grouped cases correctly classified.

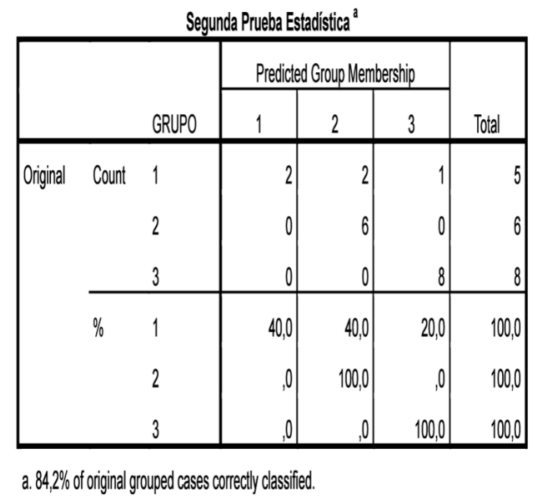

sin cambios de grupo, ya que presentan probabilidades estadísticas no significativas ${ }^{15}$. Sin embargo, los datos permiten observar hacia qué grupo (ALBA o AP) se encuentra más asociado los países ubicados en Otros, así, Guatemala y El Salvador, tiene perfiles más cercanos a los países del ALBA, mientras que Uruguay, Paraguay y República Dominicana se asemejan a los de AP (ver Anexo F).

Para la Prueba II, el 100\% de los países del grupo AP y del grupo de países de Latinoamérica (Otros) conservan su conformación de grupo, mientras que de MERCOSUR tanto Brasil como Uruguay presentan características más similares a la AP, y Paraguay a Otros. Asimismo, se puede observar que del grupo 3 (Otros), Bolivia, Cuba, Ecuador, Honduras y Nicaragua poseen perfiles similares a MERCOSUR, mientras que República Dominicana, Guatemala y El Salvador se muestran más asociados a AP.

Estos resultados indican que MERCOSUR presenta características heterogéneas entre los países que la integran, lo que a largo plazo podría generarle dificultades para la aplicación de políticas comunes. Lo anterior dialoga con planteamientos de Caetano (2009), quien indica que el MERCOSUR requiere un sinceramiento y que ello implica rediscutir su modelo de integración. En cambio, AP y ALBA si bien representan alternativas bien diferenciadas, son grupos más estables por las homogeneidades de los países que la integran, la diferencia entre ellas son las características que las proyectan más o menos hacia el progreso. A pesar de que las diversas agrupaciones analizadas no presentan armonía en todas las dimensiones y que aún entre países que conforman un

${ }^{15}$ Para que la probabilidad sea significativa debe ser mayor a 0,5. 
grupo particular existen diferencias en algunos indicadores, los resultados aconsejan cuales son las áreas donde cada grupo de integración debe hacer más énfasis en sus políticas de integración.

\section{REFLEXIONES FINALES}

La región Latinoamericana es muy heterogénea en cuanto a sus indicadores o mediciones y sucede lo mismo internamente para los diversos grupos de integración conformados. Sin embargo, algunos índices permiten encontrar cierta homogeneidad interna, especialmente el de Innovación Global que aparece como un fuerte discriminador de la integración para América Latina. Este índice es el resultado de la calidad en un entorno institucional político, regulatorio y empresarial estable, de libertades de expresión y acción, con inversión en talento humano, investigación y desarrollo, vínculos de innovación, absorción e impacto del conocimiento, su creación y difusión. De este modo es una medición que refleja las grandes oportunidades para el desarrollo de sus países. La innovación además permite tener una inversión de capital en los países donde se potencia, generando empleo y aumentado el crecimiento económico, que se traducirá en una disminución de la Aflicción, siempre y cuando se mantenga la institucionalidad.

Pero además dentro de los componentes del índice de Innovación Global también se resaltan como determinantes: el ambiente regulatorio, cumplimiento de la ley, la educación terciaria y la sustentabilidad ecológica. Estos resultados no distan de las metas establecidas por la ONU (2015) para el año 2030, donde se debe fomentar la innovación, promover una industrialización sostenible en total equilibrio con la naturaleza y además de tener una infraestructura flexible, transparencia y un estado de derecho para el cumplimiento de las leyes.

El entorno para la innovación es un factor fundamental, tal y como indica Oppenheimer (2014), un mal clima para los negocios, las burocracias, la intolerancia y la corrupción ahuyentaría fácilmente las innovaciones. Además, expresa que en la actualidad el progreso de los países depende cada día menos de los recursos naturales y mucho más de los sistemas educativos, científicos y sus innovaciones, donde los avances científicos determinarán quienes progresan más y quienes se quedarán cada vez más atrás.

Uno de los grandes problemas que ha tenido el Sur de América, es su "baja capacidad para producir bienes con valor agregado y exportar" como consecuencia de un pasado mercantilista y por precariedad en la ciencia y tecnología (Mata, 2011; 125). Por ello, la innovación no es solo determinante para la integración de los países, sino un factor fundamental para su progreso. Las diferencias en los niveles de innovación entre AP y ALBA son bien marcados, no 
tanto en el caso de AP, MERCOSUR, sin embargo en el año 2014, todos los países que integran la AP están en mejores posiciones para hacer negocios que los países que integran el MERCOSUR, los cuales están, en posiciones muy desfavorables según el informe Doing Business 2014 del Banco Mundial (Turzi, 2014).

En este sentido, se debe hacer énfasis en los diversos componentes que integran este índice y no solo a la innovación per se, para adelantar políticas en común desde los diversos grupos de integración alineados al progreso de América Latina; impulsando además lo que Oppenheimer (2014) denomina la globalización de la innovación, donde el proceso para innovar exige de lazos de cooperación entre diversos entes para garantizar un mayor éxito. Los grupos deben hacer grandes esfuerzos para consolidar estrategias de desarrollo, con transferencia de tecnología y formación de talento humano; si la creatividad es un proceso social que genera innovación, entonces los acuerdos de integración tienen su razón de ser en el fomento e intercambio del conocimiento.

La productividad científica correlaciona significativamente con el desarrollo económico y social de una nación, además de darle apertura a una sociedad y formar individuos prósperos (Jaffe et al, 2013). De este modo, las integraciones deben viajar por una vía más allá de acuerdos comerciales y políticos, deben fundamentarse en la cooperación tecnológica y científica para superar las asimetrías existentes, con mecanismos que incrementen el intercambio de conocimiento entre instituciones científicas y tecnológicas (Vessuri y Mercado, 2013).

Así, la innovación científica se nos muestra como la variable que permite sintetizar la capacidad que los países tienen para apalancar su desarrollo. Vale decir que esta innovación tiene como fundamento una sociedad libre en la que el intercambio de ideas sea posible sin cortapisas, y donde los arreglos sociales la fomenten y difundan.

En todos estos resultados se demuestra que la AP es la agrupación mejor posicionada frente a las recomendaciones de la ONU post-2015 para erradicar la pobreza extrema en la tierra para el 2030 y estar alineadas al tercer gran cambio necesario: transformar la economía para empleos y crecimiento inclusivo, aprovechando la innovación y las tecnologías para desatar el dinamismo económico, empleos e inversión (ONU, 2013). Pero tanto la AP como ALBA están sustentados en la perspectiva de quienes las dirigen, solo el tiempo dirá si existirán cambios en las alianzas o será el mismo éxito de las agrupaciones las que permitirá mantenerlas o no en el tiempo (Turzi, 2014), por los momentos, ambos deben dirigir sus políticas alineadas en este sentido para poder encaminarse a la prosperidad. 
Será en la innovación donde se muestren las grandes diferencias de la región: grupos que consoliden mejores estrategias alineadas a la innovación, la institucionalidad y las libertades, tendrán mayor oportunidad para que sus países obtengan resultados más favorables para sus ciudadanos. Por el contrario, grupos con menores avances en esa materia redundará en pobres oportunidades para la ciudadanía. En general la integración de América Latina debe ser amplia e integral y para surgir como región unas de las etapas que debe superar es la dependencia tecnológica y asumir la innovación como eje fundamental para su progreso.

\section{REFERENCIAS}

Álvarez, M; Victoria, M (2011). "Origen y evolución de los parlamentos en los procesos de integración regional: Los casos del Parlamento Europeo y el Parlamento del Mercosur", Colombia Internacional, Vol. 74, pp. 207-229. Retrieved May 14, 2015, from http://www.scielo.org.co/scielo.php?script=sci_arttext\&pid=S0121$56122011000200009 \& \ln g=e n \& t \operatorname{lng}=$ es .

Andrade, M (2011). "El aislamiento de Venezuela de los procesos de integración latinoamericanos", Mundo Nuevo, Año III, Vol. 2 (2011), No 7. Universidad Simón Bolívar. Venezuela.

Bandura, Romina (2008). A Survey of Composite Indices Measuring Country Performance, New York, United State, UNDP/ODS Working Paper, Office of Development Studies, United Nations Development Programme.

Caetano, G (2009) "Integración regional y estrategias de reinserción internacional en América del Sur" Nueva Sociedad, Vol 219 (enero-febrero 2009), ISSN: 0251-3552, www.nuso.org

Consalvi, S.A. (1988). Un Momento Histórico de América Latina, Caracas, Venezuela, Ed. Pomaire.

De Lombaerde, P; Kingah, S; Rettberg, A (2014) "Presentación: Procesos de integración política, social y económica", colomb.int. [online], n.81 (2014), ISSN 0121-5612. [cited 2015-05-14], pp. 19-24. Available from: http://www.scielo.org.co/scielo. php?script=sci_arttext\&pid=S0121-56122014000200003\&lng=en\&nrm=iso.

Díaz, L. (2012). La Integración Latinoamericana [desde 1750 hasta la actualidad], Caracas, Venezuela, G.E. Amerik, Cátedra Latinoamericana.

Jaffe, K; Caicedo, M; Manzanares, M; Gil, M; Rios, A; Florez, A, et al (2013). "Productivity in Physical and Chemical Science Predicts the Future Economic Growth of Developing Countries Better than Other Popular Indices". PLoS ONE 8(6), 2013: e66239. doi:10.1371/journal.pone.0066239.

Levy-Carciente, S; García, A (2007). "La Integración financiera latinoamericana a la luz de la experiencia europea", Revista del BCV, Vol. XXI(1):109-143, 2007, Banco Central de Venezuela. 
Levy-Carciente, Sary; Phélan, Mauricio; Perdomo, Jhoner (2014). "From Progress to Happiness: Measurements for Latin America" Social Change Review, Vol. 12(1) (summer 2014): 73-112. DOI: 10.2478/scr-2014-0004.

Levy-Carciente, Sary; Phélan, Mauricio; Perdomo, Jhoner (2015). "Potencialidades y Sinergias en América Latina", mimeo.

Mata M., L. (2011). Suramérica: Los retos del siglo XXI, Caracas, Venezuela, Ed. Academia Nacional de Ciencias, Fundación Alberto Adriani.

ONU. (2013). Una nueva alianza mundial: erradicar la pobreza y transformar las economías a través del desarrollo sostenible, Nueva York, Estados Unidos, Informe del Grupo de Alto Nivel de Personas Eminentes sobre la Agenda de Desarrollo Post-2015.

ONU. (2015). Indicators and a Monitoring framework for the sustainable development goals. New York, Unites States, A report to the Secretary General of the United Nations by the Leadership Council of the Sustainable Development Solutions Network.

Oppenheimer, A. (2014). ¡Crear o Morir! La esperanza de América Latina y las cinco claves de la innovación. Penguin Randim House, Grupo Editorial. Colombia.

Romero, M. (2005). Venezuela en defensa de la democracial 1958-1998, Caracas, Venezuela, Ed. Fundación para la Cultura Urbana.

Turzi, M (2014). "Asia y la i(des)integración latinoamericana?" Nueva Sociedad, Vol. 250 (marzo-abril 2014), ISSN: 0251-3552, www.nuso.org

Vessuri, H; Mercado, A (2013). "Desarrollo cientifico y tecnológico, políticas tecnológicas e industriales y recursos naturales". Conferencia de la UNASUR sobre recursos naturales y desarrollo integral de la región, (2013), pp. 1-9, UNASUR, Caracas.

\section{ANEXOS}

\section{Anexo A. Imputación de datos}

Para Cuba se imputaron los datos de los indicadores: Índice de Complejidad, Índice de Aflicción, Índice de Costo de Vida, Índice de Derecho de Propiedad, Índice de Innovación Global. Para Paraguay se imputó el dato correspondiente al Índice de Costo de Vida.

A continuación, se ilustra la imputación del dato Índice de Innovación Global para Cuba: La Innovación Global esta correlacionada con la Calidad Institucional. Ambos indicadores dada su relación son útiles para imputar valores ausentes en algún individuo. En nuestro caso Cuba tiene valor ausente en el indicador de Innovación Global, por lo tanto de la información que existe en el indicador de Calidad Institucional se imputara el valor ausente de Cuba en Innovación Global. Cuba se encuentre adyacente entre Venezuela y Ecuador en el indicador de Calidad Institucional, con estos países se obtienen dos valores interpolados para Cuba en la Innovación Global, con los cuales se promedia para obtener un valor final imputado: 


$$
\begin{aligned}
& A=0.134 * \frac{25.66}{0.0994}=34.59 \quad B=0.134 * \frac{27.5}{0.2822}=13.05 \\
& C=A+\frac{B}{2}=23.82
\end{aligned}
$$

\begin{tabular}{l|c|c}
\hline Países/Índices & $\begin{array}{c}\text { Calidad } \\
\text { Institucional } \\
\mathbf{( 2 0 1 1 )}\end{array}$ & $\begin{array}{c}\text { Índice de } \\
\text { Innovación } \\
\text { Global (2014) }\end{array}$ \\
\hline Venezuela & 0,099 & 25,66 \\
\hline Cuba & 0,134 & $\mathrm{C}$ \\
\hline Ecuador & 0,282 & 27,5 \\
\hline Bolivia & 0,298 & 27,76 \\
\hline Paraguay & 0,328 & 31,59 \\
\hline Nicaragua & 0,365 & 25,47 \\
\hline Argentina & 0,372 & 35,13 \\
\hline Honduras & 0,372 & 26,73 \\
\hline Guatemala & 0,427 & 30,75 \\
\hline R. Dominicana & 0,434 & 32,29 \\
\hline Brasil & 0,482 & 36,39 \\
\hline Colombia & 0,502 & 35,5 \\
\hline México & 0,534 & 36,02 \\
\hline El Salvador & 0,559 & 29,08 \\
\hline Perú & 0,589 & 34,73 \\
\hline Panamá & 0,626 & 38,3 \\
\hline Uruguay & 0,677 & 34,76 \\
\hline Costa Rica & 0,688 & 37,3 \\
\hline Chile & 0,833 & 40,64 \\
\hline & & \\
\hline
\end{tabular}

En nuestro estudio se decidió utilizar un promedio para representar el valor final imputado, para evitar el juicio de seleccionar el vecino más próximo por debajo o por encima del individuo a imputar, dado especialmente porque el dato ausente no es el resultado de un proceso aleatorio. Es importante resaltar además que se probaron diversas técnicas de imputación, pero ninguna tenía consistencia al realizar el análisis sin el dato imputado, por lo que esta técnica per- 
mitió que los datos imputados no alteraran el resultado del análisis, es decir el análisis discriminante no se altera por incluir los valores imputados.

\section{Anexo B. Variables con poder discriminatorio}

\section{Tests of Equality of Group Means}

\begin{tabular}{|l|r|r|r|r|r|}
\hline & Wilk' Lambda & \multicolumn{1}{|c|}{ F } & \multicolumn{1}{|c|}{ di1 } & \multicolumn{1}{c|}{ df2 } & \multicolumn{1}{c|}{ Sig. } \\
\hline CALIDADIT &, 338 & 15,644 & 2 & 16 &, 000 \\
COMPLEJ &, 406 & 11,693 & 2 & 16 &, 001 \\
MISERY &, 764 & 2,476 & 2 & 16 &, 116 \\
CLI &, 964 &, 299 & 2 & 16 &, 745 \\
IPRI &, 573 & 5,956 & 2 & 16 &, 012 \\
SPI &, 698 & 3,458 & 2 & 16 &, 056 \\
IDEMOC &, 452 & 9,695 & 2 & 16 &, 002 \\
ING &, 246 & 24,491 & 2 & 16 &, 000 \\
GLOBALL &, 469 & 9,049 & 2 & 16 &, 002 \\
FRAGIL &, 830 & 1,640 & 2 & 16 &, 225 \\
\hline
\end{tabular}

\begin{tabular}{|l|r|r|r|r|r|}
\hline & Wilk' Lambda & \multicolumn{1}{|c|}{$F$} & \multicolumn{1}{c|}{ df1 } & \multicolumn{1}{c|}{ d'2 } & \multicolumn{1}{c|}{ Sig. } \\
\hline CALLDADIT &, 569 & 6,070 & 2 & 16 &, 011 \\
COMPLEJ &, 635 & 4,594 & 2 & 16 &, 027 \\
MISERY &, 677 & 3,822 & 2 & 16 &, 044 \\
CLI &, 710 & 3,260 & 2 & 16 &, 065 \\
IPRI &, 704 & 3,369 & 2 & 16 &, 060 \\
SPI &, 491 & 8,281 & 2 & 16 &, 003 \\
IDEMOC &, 640 & 4,499 & 2 & 16 &, 028 \\
ING &, 342 & 15,394 & 2 & 16 &, 000 \\
GLOBALL &, 790 & 2,122 & 2 & 16 &, 152 \\
FRAGIL &, 681 & 3,744 & 2 & 16 &, 046 \\
\hline
\end{tabular}

Anexo C. Variables con suficiente capacidad explicativa para diferenciar los grupos

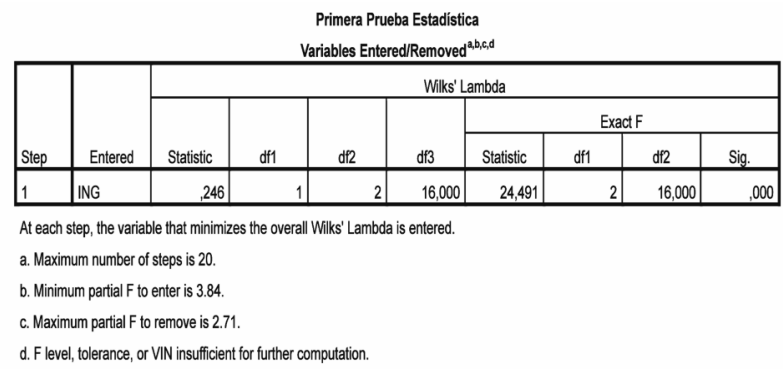

Segunda Prueba Estadistica Variables Entered/Removed ${ }^{\text {a,b,c,d }}$

\begin{tabular}{|c|c|c|c|c|c|c|c|c|c|}
\hline \multirow[b]{3}{*}{ Step } & \multirow[b]{3}{*}{ Entered } & \multicolumn{8}{|c|}{ Wilks' Lambda } \\
\hline & & \multirow[b]{2}{*}{ Statistic } & \multirow[b]{2}{*}{ df1 } & \multirow[b]{2}{*}{$d f_{2}$} & \multirow[b]{2}{*}{$\mathrm{df3}$} & \multicolumn{4}{|c|}{ Exact $F$} \\
\hline & & & & & & Statistic & df1 & $\mathrm{d} f 2$ & Sig. \\
\hline 1 & ING & 342 & 1 & 2 & 16,000 & 15,394 & 2 & 16,000 &, 000 \\
\hline 2 & MISERY & ,179 & 2 & 2 & 16,000 & 10,231 & 4 & 30,000 &, 000 \\
\hline
\end{tabular}

At each step, the variable that minimizes the overall Wilks' Lambda is entered.

a. Maximum number of steps is 20 .

b. Minimum partial $\mathrm{F}$ to enter is 3.84 .

c. Maximum partial $\mathrm{F}$ to remove is 2.71 .

d. F level, tolerance, or VIN insufficient for further computation 
Anexo D. Condiciones para las funciones discriminantes

Segunda Prueba Estadistica

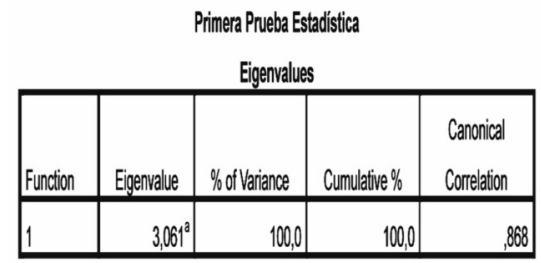

a. First 1 canorical disciminant tunctions were used in the analysis.

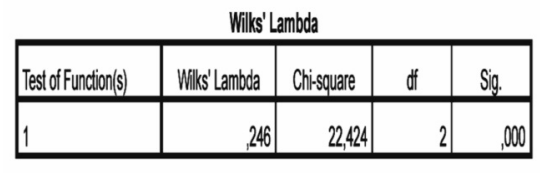

Eigenvalues

\begin{tabular}{|l|r|r|r|r|}
\hline Function & Eigenvalue & \% of Variance & Cumulative \% & \multicolumn{1}{c|}{$\begin{array}{c}\text { Canonical } \\
\text { Correlation }\end{array}$} \\
\hline 1 & $2,784^{\mathrm{a}}$ & 85,4 & 85,4 &, 858 \\
2 &, $477^{\mathrm{a}}$ & 14,6 & 100,0 &, 568 \\
\hline
\end{tabular}

a. First 2 canonical discriminant functions were used in the analysis.

Wilks' Lambda

\begin{tabular}{|l|r|r|r|r|}
\hline Test ofFunction(s) & Wilks' Lambda & Chisquare & \multicolumn{1}{c|}{ df } & \multicolumn{1}{c|}{ Sig. } \\
\hline 1 through2 &, 179 & 26,672 & 4 &, 000 \\
2 & 677 & 6,046 & 1 &, 014 \\
\hline
\end{tabular}

Anexo E. Coeficientes de la función y centroides

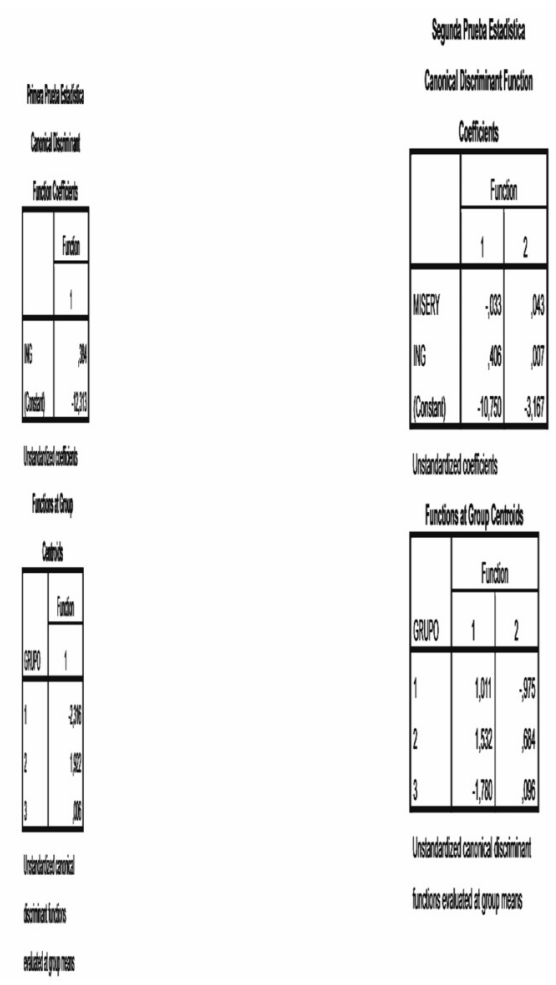




\section{Anexo F. Grupo pronosticado y probabilidades en otros grupos}

\begin{tabular}{|c|c|c|c|c|c|}
\hline Países & $\begin{array}{l}\text { Prueba } 1 . \\
\text { Grupo que } \\
\text { Pertenece }\end{array}$ & $\begin{array}{c}\text { Grupo } \\
\text { Pronostico }\end{array}$ & $\begin{array}{c}\text { Probabilidad de pertenecer } \\
\text { al Grupo } 1 \text { (ALBA) }\end{array}$ & $\begin{array}{c}\text { Probabilidad de pertenecer } \\
\text { al Grupo } 2 \text { (AP) }\end{array}$ & $\begin{array}{c}\text { Probabilidad de pertenecer } \\
\text { al Grupo } 3 \text { (Otros) }\end{array}$ \\
\hline Argentina & 3 & 2 & 0,00132 & 0,52742 & 0,47126 \\
\hline Bolivia & 1 & 1 & 0,66575 & 0,00165 & 0,3326 \\
\hline Brasil & 3 & 2 & 0,00024 & 0,73856 & 0,2612 \\
\hline Chile & 2 & 2 & 0 & 0,98472 & 0,01528 \\
\hline Colombia & 2 & 2 & 0,00082 & 0,59453 & 0,40465 \\
\hline Costa Rica & 2 & 2 & 0,00006 & 0,84663 & 0,15331 \\
\hline Cuba & 1 & 1 & 0,9853 & 0 & 0,01469 \\
\hline Ecuador & 1 & 1 & 0,71537 & 0,00116 & 0,28347 \\
\hline El Salvador & 3 & 3 & 0,37861 & 0,00801 & 0,61338 \\
\hline Guatemala & 3 & 3 & 0,11769 & 0,0377 & 0,84461 \\
\hline Honduras & 3 & 1 & 0,83336 & 0,00039 & 0,16626 \\
\hline México & 2 & 2 & 0,0004 & 0,68265 & 0,31694 \\
\hline Nicaragua & 1 & 1 & 0,939 & 0,00006 & 0,06094 \\
\hline Panamá & 2 & 2 & 0,00001 & 0,92014 & 0,07985 \\
\hline Paraguay & 3 & 3 & 0,05738 & 0,07208 & 0,87055 \\
\hline Perú & 2 & 3 & 0,00218 & 0,45372 & 0,54409 \\
\hline R. Dominicana & 3 & 3 & 0,03009 & 0,11804 & 0,85188 \\
\hline Uruguay & 3 & 3 & 0,00211 & 0,45922 & 0,53867 \\
\hline Venezuela & 1 & 1 & 0,92854 & 0,00008 & 0,07138 \\
\hline
\end{tabular}

\begin{tabular}{|c|c|c|c|c|c|}
\hline Países & \begin{tabular}{|l} 
Prueba 2. \\
Grupo que \\
Pertenece
\end{tabular} & $\begin{array}{c}\text { Grupo } \\
\text { Pronostico }\end{array}$ & $\begin{array}{l}\text { Probabilidad Grupo } 1 \\
\text { (MERCOSUR) }\end{array}$ & $\begin{array}{l}\text { Probabilidad Grupo } 2 \\
\text { (AP) }\end{array}$ & $\begin{array}{c}\text { Probabilidad Grupo } 3 \\
\text { (Otros) }\end{array}$ \\
\hline Argentina & 1 & 1 & 0,8205 & 0,17935 & 0,00015 \\
\hline Bolivia & 3 & 3 & 0,00138 & 0,00086 & 0,99776 \\
\hline Brasil & 1 & 2 & 0,46804 & 0,53127 & 0,00069 \\
\hline Chile & 2 & 2 & 0,0682 & 0,93175 & 0,00004 \\
\hline Colombia & 2 & 2 & 0,22861 & 0,74835 & 0,02304 \\
\hline Costa Rica & 2 & 2 & 0,23269 & 0,76619 & 0,00112 \\
\hline Cuba & 3 & 3 & 0,12967 & 0,00095 & 0,86937 \\
\hline Ecuador & 3 & 3 & 0,00054 & 0,00041 & 0,99905 \\
\hline El Salvador & 3 & 3 & 0,00272 & 0,00311 & 0,99417 \\
\hline Guatemala & 3 & 3 & 0,0528 & 0,05492 & 0,89228 \\
\hline Honduras & 3 & 3 & 0,00167 & 0,00049 & 0,99784 \\
\hline México & 2 & 2 & 0,13515 & 0,83607 & 0,02878 \\
\hline Nicaragua & 3 & 3 & 0,00027 & 0,00007 & 0,99966 \\
\hline Panamá & 2 & 2 & 0,08586 & 0,91261 & 0,00153 \\
\hline Paraguay & 1 & 3 & 0,20615 & 0,18884 & 0,60501 \\
\hline Perú & 2 & 2 & 0,25597 & 0,68679 & 0,05724 \\
\hline R. Dominicana & 3 & 3 & 0,31481 & 0,31934 & 0,36584 \\
\hline Uruguay & 1 & 2 & 0,35834 & 0,61719 & 0,02446 \\
\hline Venezuela & 1 & 1 & 0,96012 & 0,00318 & 0,0367 \\
\hline
\end{tabular}


JHONER PERDOMO. Estadístico, Candidato a Doctor en Ciencias Sociales por la Universidad Central de Venezuela (UCV). Profesor de Estadística en la Escuela de Sociología UCV (2014-2016). Miembro asociado de la American Statistical Association (2008-2015) y Royal Statistical Society (2016). Consultor Independiente en Estadística y en la Prevención del Lavado de Dinero.

LUIS DANIEL ÁlVAREZ VANEGAS. Doctor en Ciencias Sociales. Magister en Ciencia Política y en Educación. Especialista en Sistemas Electorales. Licenciado en Estudios Internacionales, en Comunicación Social y en Educación. Cursante del Postdoctorado en Ciencias Sociales. Cursante de la Especialización en Estudios Políticos y Constitucionales. Actualmente Director de la Escuela de Estudios Internacionales de la UCV. Integrante del Grupo Ávila y del Instituto Cultural Venezolano Israelí.

MAURICIO PHÉLAN C. Sociólogo de la Universidad Central de Venezuela (UCV) y Especialista en Análisis de Datos para las Ciencias Sociales de la misma casa de estudios. Doctor en Sociología por la Universidad de Barcelona, España. Se desempeña como Profesor Titular de la Escuela de Sociología de la Facultad de Ciencias Económicas y Sociales UCV.

SARY LEVY-CARCIENTE. Economist with expertise in the field of financial macroeconomics. PhD in Development Studies, Master in International Economics and Professional Specialization in Administrative Sciences. Board member of the National Academy of Economics Sciences. Dean of the Economics and Social Science Faculty at Universidad Central de Venezuela (2008-2011). www.sarylevy.com

Recibido:01/04/2016

Aceptado: 30/11/2016 



\title{
UNIVERSITY INTERNSHIPS IN SPAIN: WHAT IS MISSING FOR ITS STAKEHOLDERS?

\author{
PRÁCTICAS DE EMPRESA UNIVERSITARIAS EN ESPAÑA: \\ ¿QUÉ ECHAN DE MENOS LOS PROTAGONISTAS?
}

\author{
Francisco Alberto Vallejo Peña \\ Universidad de Málaga, España \\ favallejo@uma.es \\ Juan Herrera Ballesteros \\ Universidad de Málaga, España \\ juanherrera@uma.es
}

\begin{abstract}
Cómo citar / Citation
Vallejo Peña, Francisco Alberto y Herrera Ballesteros, Juan (2016). "University internships in Spain: what is missing for its stakeholders?". OBETS. Revista de Ciencias Sociales, 11(2): 547-566. doi:10.14198/OBETS2016.11.2.07
\end{abstract}

\begin{abstract}
The purpose of this paper is to analyze the performance of the current university internship programs, with a particular focus on the present needs of the main stakeholders: the students and businesses. The study draws on the interpretive perspective of organizational culture (Berger and Luckmann), which stresses the difficulty of integrating subworlds with different codes, practices and habits. The results of a case study on the program run by University of Cadiz are then presented through a qualitative analysis. Otherwise, the conclusions have been compared with those obtained in recent research conducted by Spanish universities (Granada, UNED, Politécnica de Valencia, Politécnica de Madrid, Carlos III and Lleida).
\end{abstract}

Key words: internship evaluation; graduate employment; university-business cooperation; organizational culture.

\section{Resumen}

El propósito de este estudio es abordar el actual desempeño de los programas de prácticas de empresa universitarias, tratando de enfatizar en las actuales necesidades de sus protagonistas: estudiantes y empresas. El trabajo se basa en la perspectiva interpretativa de la cultura organizacional (Berger y Luckmann), que resalta las dificultadas que implica la integración de submundos 
regidos por diferentes códigos, prácticas y hábitos. Para ello se exponen los resultados de un estudio cualitativo basado en un programa desarrollado en la Universidad de Cádiz. Sus conclusiones han sido, a su vez, contrastadas por las obtenidas en otras investigaciones recientes en universidades españolas (Granada, UNED, Politécnica de Valencia, Politécnica de Madrid, Carlos III y Lleida).

Palabras clave: evaluación de prácticas de empresa; empleo universitario; cooperación universidad-empresa; cultura organizacional.

\section{RESEARCH APPROACH}

Internship programs for university students were not regulated until 1981 (Spanish Royal Decree 1491/1981) and their presence in Spanish society was consolidated in the 1990s. The first internship programs arrived at a time when the pressure of unemployment and the complexity of university students' paths into their first job were conducive to strengthening their training and adaptation within the labor market. The sphere of intern placements also arose as a result of social and educational change, with a sudden increase in the number of university graduates in the population, a phenomenon that contributes to the normalization of internships as a transitional phase before employment. The OECD indicated in its Education at a Glance report (as per the version of the Spanish Ministry of Education in 2012) that 30\% the Spanish population aged between 25 and 64 years old were university graduates, a rate that reaches $39 \%$ in the case of 25- to 34-year-olds. The Spanish figure reveals our distance from the EU-27 average (40\% of the population aged 25 to 64), though it has evolved constantly since the 1990s (the figure was 24\% in 1995). However, the same report also underlines the devaluation of our qualifications; in other words, the quantity has not been matched in quality. There has been no miracle.

With the arrival of the new European Higher Education Area (EHEA) in 2010, universities have attempted to respond to the new trends, expanding - formally at least - the sphere of business participation in academic life. Businesses, meanwhile, have entered an era in which they must assume new roles: investing partner, planner and demander of services. The aim is for businesses to go from being merely a peripheral collaborator to become a central part of academic life. This process necessitates a change in attitudes in both institutions so that they enter into a process of cultural assimilation which, in practice, is very complicated. However, though they are two subworlds with different agendas, they share interests (Vallejo Peña, 2010). Business's workforce (students) start training long before they come into contact with the workplace and, at the same time, the modern university cannot design its pro- 
grams of study without considering the emerging demands of business. The cultural change is served: Listen to the other party, before planning, acting and converging (ibid.). Muñiz and Fonseca-Pedrero (2008: 15) also touched on a convergence of interests when they indicated that those "legitimately involved in the evaluation of the university are also outside of the classroom, namely society and its institutions that subsidize the university (...) through public taxes, regardless of whether they have children at university".

In this climate, internship programs must contribute to closing the gap between two worlds as different as university and business. It is a challenging goal, because the transition from one to the other is rarely exempt from abruptness. "Contact with the world of work marks a switch from laboratory training to reality" (Martínez 2003: 234). In addition, the evidence provided by the university system for the advisability of these programs is increasingly compelling. In a study conducted by the Centro de Orientación e Información al Estudiante (the 'Student Guidance and Information Center', COIE), 65\% of professors believe that graduates are not adequately prepared to meet the demands of the business world, and the main reason for this is the lack of a practical dimension to training (COIE 1997: 67-68). In other words, running and improving internship programs - with stronger involvement of universities - would help to end the situation of "the dog chasing its tail". The foundations introduced by the EHEA have also served to remind us that there should be an even greater commitment from all parties to fixing this faulty connection in the education system.

This paper analyzes the results obtained in the internship program of the Francisco Tomás y Valiente Center (Algeciras, University of Cadiz) in the period 2002-2006, on the basis of a qualitative design that interprets the evaluation of the experience by the two main groups involved (students and businesses). The main task is to analyze this critical reflection from the two sides on the contribution of the experience both in terms of work, strictly speaking, and life in general. The study is also approached from the perspective of organizational culture: two subsystems (university and business) merge in a thorny process in the first few years (recruitment, training and work placements for new candidates), generating an inevitable culture shock that eases over time. However, both institutions must formulate procedures that facilitate the integration of the two worlds, given the social significance in a society like ours of the insertion into the workplace of young university graduates.

To this end, below we present the most relevant aspects of the theoretical framework, the methodology of the study, the results of the experience and the main conclusions reached. 


\section{THEORETICAL BACKGROUND}

Previous studies on internships in Spain generally highlight the gulf that exists between the academic system and the needs of businesses. The lack of a genuine climate of cooperation is identified as one of the causes. As Alfonso and Borrego (2009) stress, the reality is that agreements are reached but they do not generate truly mixed workplaces. However, this does not mean that no satisfactory results have been achieved in the last thirty years; in fact, a study recently conducted at the Polytechnic University of Valencia (UPV) by Hervás, Ayats, Desantes and Juliá (2012) indicates that business owners and management value internships very highly, stating that they would sooner employ a candidate who has been an intern in their company than appoint someone more qualified but unknown. This has not gone unnoticed by students, who in a study conducted by the University of Granada highlighted both the need to improve these cooperative programs and the importance of making internships mandatory (García, Fernández, Calero and Luzón, 2011). In short, all of those involved, whether they are business owners, management, university administrators or students, share the perception of internship programs as something essential, and something, therefore, that must be furthered. However, having confirmed the usefulness and purpose of the model, we must deal with the factors that limit its ability to generate added value.

As far as evaluative approaches to the system are concerned, the study published by García Delgado in 2002, Lo que hemos aprendido después de 20 años de prácticas de empresa en España ('What we have learned after 20 years of work placements in Spain') examines the structural defects of our internship programs which, from his point of view, can be summarized as follows:

- Placements are poorly planned, with improvisation predominating.

- Supervisors in the businesses indicate that the universities are barely involved in planning and overseeing the internships; they indicate that it is as if the universities consider their job to be done once the placement has been agreed.

- Measures are required so that students arrive at the workplace with a better idea of how to get the most out of the experience. (García Delgado 2002: 8).

As a result of these deficiencies, cooperation between universities and businesses in internships manifests itself as a system that has huge potential for growth but is still immature. Vilanova and Tarruella (2011) highlight the fact that businesses have given their University of Lleida students the highest rating for willingness (81.4\%) and ability to integrate (75.7\%), but this rating goes 
down to $54.3 \%$ when asked about their skills and $31.9 \%$ in the case of their previous training. The students are even more critical in response to the latter question, with just $16 \%$ believing that their previous training is very good. In this regard, professors also expressed pessimism in a previous study. As mentioned in the study approach, $65 \%$ of professors believe that graduates are not adequately prepared to meet the demands of the business world, claiming the lack of a practical dimension to their training as the main reason (COIE 1997: 68). The message that these figures send out should be a wake-up call for both institutions, which urgently need to build the networks and procedures required to fill this gap in training.

Equally, the new scenario of coexistence and work taken on by students in the business world involves a degree of culture shock, with only partially shared interests and objectives between them and the members of the organization. Vilanova and Tarruela's study (op. cit.) captures the opinions of students who rate the leaders within the business in reverse to their hierarchical position. The workers around them received the best ratings, with middle management receiving slightly lower ratings, and the managers and executives receiving the lowest. This situation reveals that students are affected by the asymmetry of their relationships in the business. The role of the intern is subject to certain dangers in the environment:

One danger is the stereotypes that are entrenched in society - which, like all stereotypes, have some basis in reality - of the intern who is only entrusted with photocopying, data entry, making coffee, etc. and who, ultimately, is used, in the worst sense of the word, as cheap manpower for routine and uninstructive tasks. Other clichés, which fortunately are less widespread, could have a much more damaging effect, such as supervisors training the person who will sooner or later take their job. García Delgado (2002: 7-8).

Unfortunately, symptoms of the degradation of the role of intern have been confirmed, though we should be mindful not to over-generalize the phenomenon. In practice, although these programs are intended to reduce distances between two subworlds as different as university and business, the leap from one to the other is unlikely to be free of abruptness.

Contact with the world of work marks a switch from laboratory training to reality. On many occasions it breaks down myths that become entrenched at university in relation to usefulness, job opportunities and the role to be played in the workplace. (Martínez, 2003: 234).

Another aspect addressed in the recent research is the lack of a more active and involved administration by some universities to monitor and tutor the stu- 
dents. Likewise, in some organizations the figure of the company supervisor tends to be diluted, leading to the students being left unattended. If to the cultural gulf we add a lack of supervision, the dysfunctions in their coexistence are obvious (Ballesteros, Manzano and Moriano 2001; Martínez Martín 2003). García Delgado (2002:8) also indicates that some of his research findings suggest deliberate used of internships as a way to recruit cheap manpower by some businesses.

Spanish universities and their students concur when it comes to identifying its contribution to graduate employment as the main purpose of internships. In this regard, Martínez Martín, following his evaluation of the WorkExperience Program of the University of Granada, argues:

Graduate employment has thus become one of the primary objectives of internship placements. The vast majority of University of Granada students state this when requesting and undertaking placements. They do in fact constitute a good opportunity in that they improve credentials and social networks, and allow the students to enjoy the advantages provided by internal job markets. (Martínez Martín: 2003:232).

The data on employment obtained to date in various studies conducted in Spain reveals clear signs that internships have become a path into graduate employment, though the results vary widely between studies.

The study conducted at UPV by Hervás et al. (2012) concludes that $17.7 \%$ of their students find employment in the company where they were interns. However, the most significant figure presented is on the employability of graduates who were interns (a difference of $9.6 \%$ in their favor over those who did not undertake internships, measured 6 months after completing their degrees). In the case of the University of Granada's evaluation of internships (Martínez Martín, 2003), 28.8\% of interns go on to have a working relationship with the business after the period of collaboration. A similar figure was obtained in the study by Martínez and Valero (1999: 39), who indicate that $32.7 \%$ secured an employment contract. This result is almost identical to the one presented by the internship evaluation conducted at UNED, which reveals that the activity translates into a contract in a third of cases (Ballesteros et al. 2001). In contrast to these studies that demonstrate modest levels of placement, other analyses show a more optimistic outlook, which suggests that there is significant variability in the phenomenon depending on the case being analyzed. This is the case of the Carlos III Foundation of Madrid, where 50\% of graduates from its university obtain stable employment in the business where they were interns (Servicio de Orientación y Planificación Profesional 1996: 30). Similarly, the study by Prof. Delgado states that $72 \%$ of the sample of graduates analyzed 
found employment through the internships (García-Delgado and Pastor, 1999). This disparity in results could be explained by the variety of contexts in local job markets, the networks and contacts made by university centers, and the various possibilities for employment associated with the qualifications offered in each case.

Furthermore, outside of Spain, other studies like those of Smith, Clegg, Lawrence and Todd (2007) in the United Kingdom place the possibility of achieving high academic performance in internship placements over employment aspects. A group of students previously trained in organizational analysis skills demonstrated an excellent ability to identify the strengths and weaknesses of the organization after completing their internship. However, other British studies concluded that there were some deficiencies in the model. Both Callender (2000) and Curtis and Williams (2002) highlight the detrimental effect on academic results that a lack of time devoted to studying can have among students during their internship placement. Moreover, Blasko (2002: 48), in her study conducted in Bristol for the Centre for Higher Education Research and Information (CHERI), warns of the questionable value of short periods of collaboration, since she only finds a link between undertaking internships and graduate employment in the case of long placements (8 months or more).

Attempting to address these difficulties in the collaborations between university and business, we will adopt the interpretative approach of organizational sociology. This envisages business as an agent with little influence on the socialization of individuals; their role is essentially as a secondary agent. Subjects access organizations at an adult age when their personality has already been formed through prior socialization (Berger and Luckmann, 1967). All of this implies that, within the organization, cultures and countercultures are developed with various adaptations to their patterns (Lucas, 2002). This phenomenon is due to the diversity of group interests (social class, level of education, income, profession and ethnicity), which sometimes leads to conflict. Organizations must therefore see themselves as collections of subcultures that are difficult to manage and integrate (Reygadas, 2002).

Moreover, if a particular subsystem (university) tries to integrate itself into a broader cultural system (organizations and business), it must enter into a process of adaptation that will prove to be harsher the stronger the parent culture. These processes require time to adapt, but also management and monitoring, something that is frequently neglected by organizations of all sizes. Universities have not yet fulfilled their potential in the formation of business networks in their natural environment. These networks can create a great deal 
of social value, not just through active management of internships, but also through comprehensive collaborative actions that contribute to closing the gap between the two worlds. Alfonso and Borrego (2009) note that, beyond the internship, we should also integrate professionals into universities' postgraduate courses, create mixed forums and participate in work-linked training programs, which combine training periods with collaborations within businesses.

Work-linked training has a strong tradition beyond our borders with significant development in the United States and Nordic countries. In Spain, notable professional training initiatives have been run, albeit with less impact in universities, though there have been occasional actions, such as the programs implemented by the Autonomous University of Madrid and the University of the Basque Country. The philosophy of this activity consists of integrating candidates into real organizations while strengthening their theoretical-practical training through provision of the required modules, always in keeping with the career offered by business (Sulmont, 2004). The modules or seminars may be taught by the university, the business or both at the same time. External collaborations may also be accommodated. The model has previously been applied in business schools thanks to the participation of companies in their management, and in some cases large corporations even run their own business school with work-linked training programs. This is the case, for instance, of Maersk, who offer a specialized master's degree at their own business school in Copenhagen, training specialists and executives from all over the world.

This said, recognition of the existence of such a culture shock and the lack of progress in their management does not mean that students do not see internships as a positive step for their career prospects. Alfonso and Borrego (2009) argue that students believe internships are the best way into employment, making them more competitive, and that they should begin earlier (first academic years).

\section{METHODOLOGY}

The basic purpose of the case study is to analyze the results obtained in the 'Francisco Tomás y Valiente' University Center's internship program based on a qualitative design that will facilitate the evaluation of the strengths and weaknesses of the activity from the point of view of the main stakeholders in the interaction: students and businesses. These evaluations will, in turn, enable us to reflect on the recent performance and contribution of internships in a broad sense (social value), as well as draw comparisons with the results obtained by similar studies in Spain (already mentioned in the theoretical frame- 
work). After the required reflection on the results obtained, it will be possible to make some suggestions to guide future management of work placements by the agents involved, avoiding dysfunctions and making them more effective. Given the theoretical foundations that underpin the research (interpretative approach), there will be a particular focus on aspects that reveal the culture shock involved, given the differences in the prevailing idiosyncrasies of the two worlds at present (business and university).

To conduct this analysis, two essential sources of qualitative information have been used. First, the institutional information on the internship program gathered by the center itself, and second, the external fieldwork, carried out in the two main companies that collaborate with the organization: Maersk and Cepsa (see Table 1). As for the sources gathered at the university itself, the study drew on the center's record of activities and the internship reports that both parties complete at the end of each placement. In total, 61 student reports and 41 company reports were analyzed, though these sources were used for purely descriptive purposes. Our analysis centers on external fieldwork (businesses), which made use of materials corresponding to the study entitled El análisis de la cultura de una multinacional: el caso Maersk ('Analysis of a multinational's culture: the case of Maersk'; Vallejo Peña, 2007). This includes six discussion groups (one of managers, another of operatives, three by departmental division and another exclusively of interns) and various indepth interviews with specialists and managers of the multinational Maersk - fourteen in total. This information is also complemented with two interviews with Cepsa managers, which were used for the fourth chapter of the monograph, describing the industrial activity of Campo de Gibraltar (Table 1). The two companies accounted for over $60 \%$ of the internships analyzed, hence our particular interest in this fieldwork, despite its limitations in terms of coverage of the target population of the study. These techniques include a discussion group exclusively for interns, while the rest encompass various classifications and categories of management, and technical and operational personnel of the organization who evaluate the company's activity in general (including the internships themselves). Analysis of the data provided by these sources - both internal and external - centered on identifying the predominant discourses and sub-discourses in the testimonies of the stakeholders in their overall evaluation of internship collaborations, attempting, in turn, to compare their views of each problem or circumstance with the perception of the other party: (university versus business). For the implementation of the study, Miguel Vallés' qualitative research manual (1997) was considered a basic methodological source. 


\section{Table 1. Materials used and fieldwork}

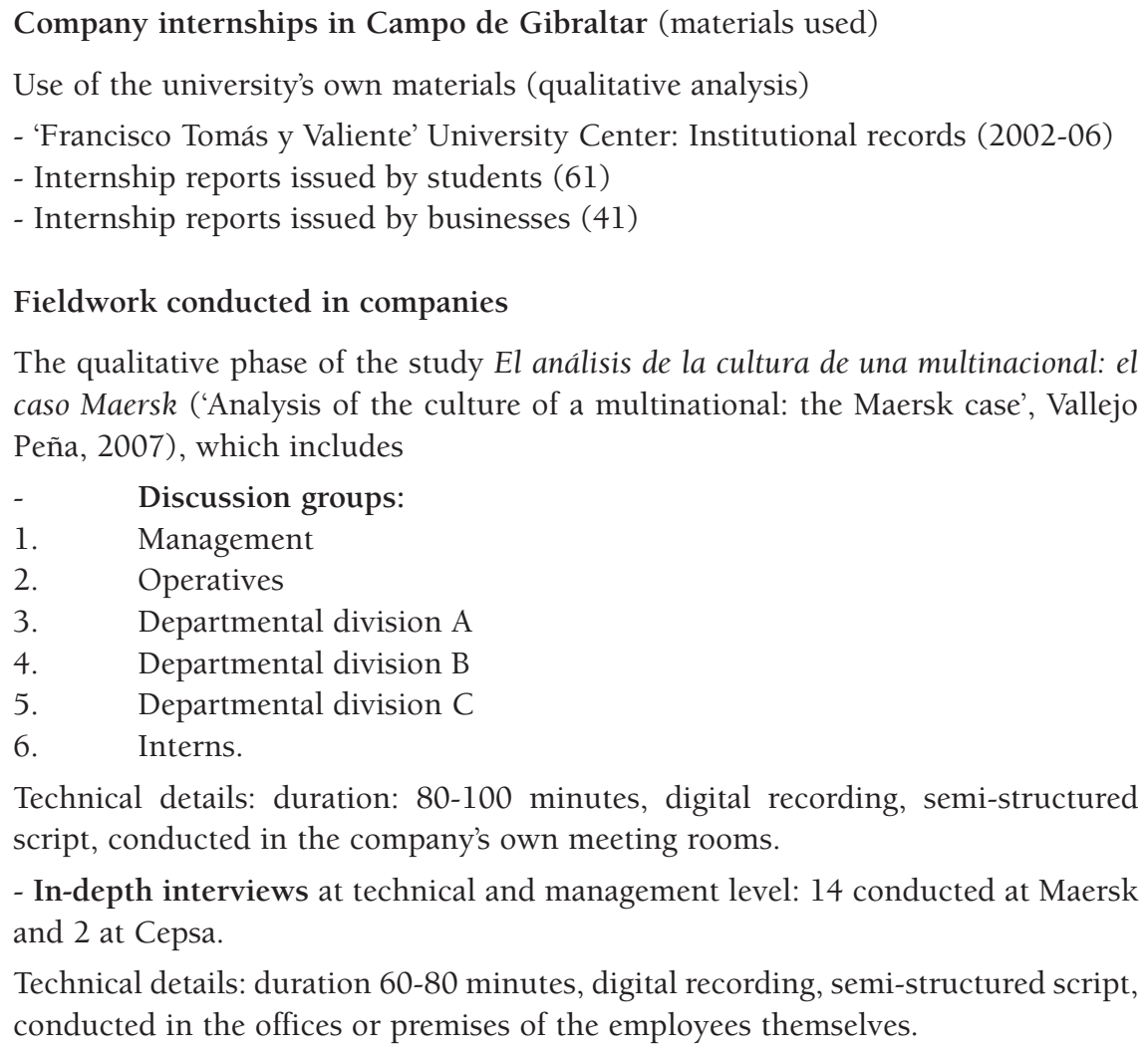

Technical details: duration: 80-100 minutes, digital recording, semi-structured script, conducted in the company's own meeting rooms.

- In-depth interviews at technical and management level: 14 conducted at Maersk and 2 at Cepsa.

Technical details: duration 60-80 minutes, digital recording, semi-structured script, conducted in the offices or premises of the employees themselves.

The University of Cadiz's internships were evaluated using the triangular evaluation system that is currently widespread in Spanish universities, described below. Each work placement organized is evaluated from three perspectives: the university tutor's, the company supervisor's and the student's. To complete and certify each collaboration, these three stakeholders must give their views and therefore evaluate the action as a whole. The three stakeholders must issue a written report at the end of the period in which each of them evaluates the other two parties and the activity as a whole. Finally, after analyzing and digesting the various evaluations, we generate a summary of results in which we attempt to digest the company's views on the contribution of the students and also what the students think about the recipient companies, and naturally, the opinion of both stakeholders on the program as a whole. 
Given the evaluative nature of the research, no hypothesis was put forward. The aims of the study are captured in four basic questions:

- How do the students rate their experience at the company and the program as a whole?

- What do the students want from the partner companies?

- How do the companies view the internship experience?

- What do the companies want from the students and university?

As for the classification of the study from other perspectives of interest, it should be noted that it is a diagnostic, instructive and internal analysis. Diagnostic in the sense that it collects data on the social reality of the activity in order to perform the appropriate evaluations, highlighting strengths and weaknesses; instructive in that it consists of an evaluation whose results may guide the processes to be immediately undertaken by the stakeholders involved; and finally, it is considered internal, given our university background and involvement in the activity under analysis (Trinidad, 2006).

Based on the above, we hope to arrive at a balance that captures the difficulties in the relationship and communication between university and business, as well as the notable achievements and positive aspects of the internship program. Finally, this paper aims to compare its results and conclusions with those obtained by the research conducted by other universities (see theoretical framework), providing a broader overview of the phenomenon.

\section{Results}

\subsection{Some notable figures}

Addressing the vital aspect of the employment of the students who undertook internships. According to the figures provided by the human resources department of Maersk España (a company which hosted over $40 \%$ of our internships), the placement rate of the interns in the company itself was $17 \%$ across the period (2002-2006), taking into account appointments made within six months after the activity. According to figures provided by the university center's records, the rest of the collaborations in private enterprises (50\%) involve a somewhat lower placement rate (13\%). Moreover, collaborations undertaken in the public sector (which accounts for just under $10 \%$ of the total) have not been considered for these measurements, since they are activities with other paths into employment (temporary employment banks, competitive examinations and formal selection processes). The overall student placement rate in the companies where the internships were undertaken stands at around 15\% of 
the collaborations in private enterprises. It should be noted that, in the coordination of the program, indirect appointments were also detected: sometimes the students find work in subsequent months in other businesses which they approach with references or recommendations from the company where they undertook their internship. However, this is an aspect that is difficult to define and quantify, since on occasions the company mediates actively in the appointment, while in others it merely informs students of their options in the local market. In this regard, it should be noted that the detected climate of cooperation was positive, intense and with some good results in terms of informal career guidance (Vallejo Peña 2010).

\subsection{Strengths and weaknesses of the internship program}

Besides what the descriptive data on the program shows, the impressions of the two main stakeholders involved should be examined. The results obtained when asking the students about their impressions and experiences relating the companies and programs, and those of the companies in relation to the students and the university, are summarized below.

a) Impressions of the students in relation to the companies and program:

- The difficulties that supervisors and their companies encounter when it comes to devoting time to students, listening to them and planning their activities. Planning for the integration of interns in small enterprises is poor, and they often resort to improvisation. In the case of the large participating corporations, internships are coordinated and planned, but in the day-to-day, in a context in which urgent tasks override other important aspects, it is difficult to ensure fluid and daily communication with the intern, or to persuade staff to set aside time to train interns. The role of supervisor is often diluted, or in other words it is shared between several people, or there is one formal official supervisor and another real one. Managers themselves confirm some of these difficulties and limitations:

The problem is that the training takes place during working hours and that creates a number of conflicts. Work has to be set aside for it, and there is also a lack of motivation and awareness among staff and difficulty creating a suitable environment for it. (Middle management, service sector, in personal interview).

An intern girl went to ask for help with something and received a sarcastic comment and it was something that caught the attention. (Intern, service sector, in discussion group). 
- The tendency to use internships to cover certain routine and unpopular tasks among employees: filing, photocopying or updating databases. There is also the potential danger that some companies deliberately allow unwanted tasks to accumulate in the hope that the intern students will arrive to "clean up". This is undoubtedly a factor that adds and will continue to add workload to the university students.

- The summer exodus: Summer is an excellent time to do internships in terms of academic organization (there are no classes), so at this time of year university collaborations in companies intensify. However, rotation for annual leave and the slower pace does not help the company show its best side to the university students.

Yes, in summer the company's filled with people doing courses and internships; we have an agreement with the University of Cadiz, but also with other universities. (Manager, industrial sector, in discussion group).

You have to answer the phone and you find that it's a call from the other side of the world asking you for something... you don't know how to reply. (Intern, service sector, in discussion group).

- Difficulties achieving optimum job placement through internships: Students want a stronger connection between the internship program and the organizations' recruitment. The low placement rate in the participating businesses has not gone unnoticed by them. This circumstance creates some difficulties maintaining a high level of motivation in their daily work.

Clearly, if they give you a task that's always the same and it's also something that's only done here... something you're not going to be able make use of if you don't stay here, then you're demotivated and you begin to fade. (Intern, service sector, in discussion group).

b) Impressions of the company in relation to the students and their university:

- Poor language skills (valued highly in the local job market): Companies believe that students lose potential in terms of job placement, and are unable to take on certain roles or tasks that require these skills. Though it is a fairly widespread deficiency, it is even more acute in this case as it is a border region: international business and in particular relations with Gibraltar and Morocco (priority English and French).

Languages are what matters here. It's all very basic and I learned the programs here. Everything like procedures and filing is learned on the job, what's missing is that, English. (Technical employee, service sector, in discussion group). 
- The collaborations have short working hours, which do not always suit the real needs of the company (Monday to Friday, 9 am to 2 pm, or atypically afternoon/evening shifts. No more than 25 hours a week are permitted under the regulations. Some companies are unhappy that they are not able to regulate working hours themselves and that the intern students must have different hours to ordinary employees. The organizations explain the difficulties in adapting the students to deadline- and target-driven professional situations. Likewise, the fact that not all collaborators have the same hours leads to a lack of coordination and extra difficulties.

- The need for excessive supervision in some tasks, due to the gaps in knowledge and skills of some students. A common complaint in companies is that students no longer write as well as they used to. The moment the supervisors have to devote "too much" time to polishing the work of the intern students, they cease to perceive the collaboration as productive. The culture shock caused by the different nature of the activity of the agents (university and business) is added to another factor that widens the distance: the generational gap. In many cases the company describes the collaboration as a zero-sum game.

Here, to run operations, you can't be paternalistic. I can't waste my time explaining a job; I know how it happens and why it happens, and it's not the time to explain it. I'm interrupting a transmitter. The key here is to produce, there's no time to paraphrase. (Technical employee in service-sector company, in personal interview).

- Difficulty posed by finding students trained in the knowledge and skills that the company needs to meet urgent requirements. By linking the rank of university student to the term "qualified", there are high expectations in the companies that, sometimes, are disappointed. They explain the difficulty of fulfilling their demand for internships, since they cannot plan them in the way required by candidates for the job market.

- The company as a moving train: The perception of the dynamics of the business as a subworld that continually tries to respond to its environment and is often unprepared to train and integrate interns properly. A variety of facets of the program are affected by these impressions, the effect on recruitment being the most significant. A large proportion of students still have too many credits left to complete before they complete their degrees and this has been a hindrance to earning a contract at moments of high demand (the company prefers a particular graduate, but is not prepared to wait). 
We have a great ability to improvise. When there's a new program we send a delegation of employees who imbue themselves in the course for a week, then we set up shifts to cover 24 hours in which they are shared out in order to train the rest. So they travel to the course with a great deal of responsibility (...), it's just that we don't have two workforces. (Manager, servicesector company, in discussion group).

Here, when they change a program, they give you a manual and leave you to your own devices; when they give you a new one you might have three hours to figure out how it all works. No one explains anything to you. (Technical employee, service sector, in discussion group).

As for the favorable aspects perceived by those involved, the most frequently mentioned by the companies and students are as follows. Among the companies, there is a widespread impression that the program is a good way to meet new candidates for potential positions at a reasonable cost and without resorting to a more binding employment relationship. It is also believed to be a good tool to meet periods of strong demand for personnel. For the students, the program is an opportunity to have a "first experience of work", it facilitates learning and experiences that are beyond the reach of the classrooms, enables them to build a résumé - at least it's no longer empty - and make some contacts that can guide them on their prospects in the job market. The students highlighted this fact due to the insecurity involved in going out in search of job opportunities with no experience behind them.

\section{DISCUSSION AND CONCLUSIONS}

The findings obtained after analyzing the selected case at the University of Cadiz lead us to share various impressions with those obtained in the collated studies referred to above. There is a shared impression that the culture of internships in businesses is still poor (as underlined by studies like those of Ballesteros et al. (2001), García-Delgado (2002), and Martínez (2003). This circumstance is justified in part by the short period of time since the introduction of the first programs ( 25 years ago), though we must assume that it is also a result of insubstantial and insufficiently interventionist management by universities and in many cases the businesses. As a result, there is still a strong tendency to include the students with the rest of the workers with a lack of awareness that the aim is to foster a means of collaboration beyond labor relations. Furthermore, this does not happen only in SMEs; symptoms are also found - albeit to a lesser extent - in large corporations. This leads to a large number of statements from students alluding to undertaking tasks unrelated to their academic background (which is understandable), or even unrelated 
to their preliminary work plan (less understandable). However, the results of these studies indicate that this does not mean that the "students waste their time", because, in short, all of these "off-script" aspects enable them to gain a realistic experience of the world of work, where there is a big gap between theory and practice, learning methods that have received little stimulation before then (participant observation) and acquiring knowledge and social skills that can only be gained through first-hand experience. These are the reasons for the apparent contradiction that occurs in students who, in repeated reports, criticize the pointlessness of the tasks assigned to them, before underlining the importance and usefulness of company internships, recommending them to their peers.

The areas for improvement of the internship programs suggested by the analysis include their contribution to job placement, frequently highlighted by students. This need is evident at the Francisco Tomás y Valiente center, with a placement rate in the company where the internship was undertaken of $15 \%$, a similar situation to the one evident in the study conducted by Hervás et al. (2012) for UPV, with $17.7 \%$. These figures are by no means widespread across the country (the Carlos III University of Madrid obtained 50\% in 1999, for instance). However, the findings of the studies analyzed all downplay the importance of quantitative aspects and emphasize the importance of quality, seeking suitably structured activities that are meaningful for students in the medium term. Above all, the aim is for internships, within each curriculum, to be a differentiating factor and driver that is linked to other training and/or employment activities in the future.

Research conducted in the same context in the United Kingdom suggests that the academic potential of this experience is not being harnessed, as shown by the program presented by Smith et al. (2007) after previously preparing their students to analyze their organizations (just as one example). However, in respect of the barriers observed in the research conducted by Callender (2000) or Curtis and Williams, no parallels were found in the studies reviewed in Spain (including the one presented in this article). While in the United Kingdom it has repeatedly been observed that students struggle to balance academic studies with their activities in the business, this problem does not manifest itself among our students. In the absence of evidence we can speculate on the possible causes: It is probably due to the fact that our internship periods are short, they take place in the summer months and, furthermore, our students tend to prepare for their examinations at short notice. These are potential hypotheses to verify in later studies.

The results suggest that strengthening the cultural facet will be vital in the development of future programs. The aim is to nurture a cooperative cul- 
ture between universities and businesses, recognizing their interdependence and how they can be mutually beneficial. This cooperation must take place both within the sphere of company internships and from a wider perspective (seminars, exhibitions, research contracts, bilateral projects, among others). This new approach will prevent centers organizing internships with businesses that they are unfamiliar with and which provide little instruction in their dayto-day work, leading to disappointment for the interns. Within these activities we want to stress the need to promote work-linked training actions, both for their value in terms of job placement and for their results. There is little history of these programs in Spain, despite the tradition that exists in the United States and Nordic countries.

All in all, in the current internship program landscape in Spain, the focus is on quality, as anticipated (García Delgado, 2002). The next step, in our view, is a cultural change. The mission of the universities themselves will be essential, since they must devise strategies to cultivate the various methods of collaboration (research, intervention, training, etc), raising awareness among all kinds of businesses, which, necessarily, will be a part of future academic life. In turn, the awareness of the universities themselves must be raised so that they develop a more flexible and open approach. Universities will have to consider a change of direction in their students' language learning, as well as imbue them, in the classroom, with the skills that are currently in demand in businesses, and equip them to work more efficiently as part of a team.

Returning to the interpretive approach of the organizational culture (Berger and Luckmann, 1967), when a subsystem is intended to be integrated within a broader system, the inevitable culture shock must be assumed primarily by the minority group (the university in the case of internships). In other words, without wishing to neglect the responsibilities of businesses, the university must accept its role as a foreign body and lead the way in order to close the gap. Mutual understanding between the two parties, it should be noted, is merely an additional requirement for a business, whose function is production; for the university, however, it is a core function (the training and employment of their students), making it the primary stakeholder. Thus, internship programs - the standard-bearer of university-business relations in the last 20 years - will be an ever greater focus of attention in the coming decades. It is time to learn from previous experiences and apply the results of our evaluations to new planning. In the new age - in all certainty - the pursuit of quality through stronger communication between the two organizations and intensive coordination will be crucial, and in turn this will translate into real and effective working groups. The future of university-business collaborations requires a 
change of culture and mentality on both sides. They are two historical social institutions accustomed to existing at a distance from each other and, at the same time, with the perpetual obligation to understand each other.

\section{SOURCES}

Alfonso, A. and Borrego, I. (2009). "Cooperación Universidad-Empresa en el ámbito educativo para el fomento de la competitividad y el empleo". Actas del XIII Congreso Internacional de Ingeniería de Proyectos, 2274-2285, Badajoz.

Ballesteros, B., Manzano, N. and Moriano, J.A. (2001). "Seguimiento y evaluación en la UNED del sistema de prácticas de alumnos en empresas". Revista Electrónica de Investigación y Evaluación Educativa, 7 (1), available at ; consulted on February 20, 2013.

Becerra, J. (2007). "La empresa denuncia que el proceso de Bolonia no la ha tenido en cuenta". Diario El Mundo, 21-02-2007, available at www.elmundo.es/suplementos/campus/2007/478/1172012409.htmlý; consulted on October 22, 2013.

Berger, P. L. and Luckmann, T. (1967). The Social Construction of Reality. New York: Doubleday.

Blasko, Z. (2002). Access to what: analysis of factors determining graduate employability. Bristol: Hefce.

Callender, C. (2000). Attitudes to debt-school leavers and further education studentes' attitudes to debt and their impact on participation in higher school. Bristol: Hefce.

Centro Universitario Francisco Tomás y Valiente (2006). Memoria de actividades del centro; Informes Institucionales (2002-06). Algeciras: Universidad de Cádiz.

Centro de Orientación e información al Empleo -COIE- (1997). La Tendencia de la oferta de empleo en las empresas de Granada. Una aproximación a las carencias formativas de la población universitaria y a las posibilidades latentes de creación de empleo en la provincia. Granada: Universidad de Granada.

Curtis, S. and Williams, J. (2002). "The reluctant workforce: undergraduates' part-time employment". Education and Training, 44 (1): 5-10.

García, A., Fernández, M., Calero, M. and Luzón, G. (2011). Orientaciones profesionales en el Área de la Ingeniería Química. Girona: Universitat de Girona, available at; consulted on November 30, 2013.

García Delgado, J. (2002). "Lo que hemos aprendido después de 20 años de prácticas de empresa en España". Boletín de la Red Estatal de Docencia Universitaria, 2(1), $13-20$

García Delgado, J., and Pastor, M. (1999). Guía para una buena práctica de las prácticas de empresa. Madrid: Fundación Universidad-Empresa.

Hervás, A., Ayats, J., Desantes, R. and Juliá, J. (2012). "Las prácticas en empresa como uno de los ejes vertebradores de la empleabilidad". Revista Iberoamericana de Educación Superior, 3(8), 3-33.

Kotler, P. (2000). El marketing más eficaz. Deusto: Planeta. 
Lucas, A. (2002). Sociología de las Organizaciones. Madrid: McGraw-Hill.

Martínez, A. M. and Valero, F. (1999). Evaluación del impacto de las prácticas en empresas, Vicerrectorado de Fomento y Relaciones Universidad-Empresa. Granada: Universidad de Granada.

Martínez Martín, R. (2003). "La inserción laboral de los universitarios a través de las prácticas de empresas". Revista Española de Investigaciones Sociológicas, 101, 229-254.

Ministerio de Educación, Cultura y Deporte (2012). Panorama de la Educación. Indicadores de la OCDE 2012 (Informe Institucional). Madrid: Subdirección General de Documentación y Publicaciones.

Muñiz, J. and Fonseca-Pedrero, E. (2008). "Construcción de instrumentos de medida para la evaluación universitaria". Revista de Investigación en Educación, 5, 13-25.

Reygadas, L. (2002). Ensamblando culturas: diversidad y conflicto en la globalización de la industria. Barcelona: Gedisa.

Servicio de Orientación y Planificación Profesional (1996). Estudio de inserción laboral de los titulados de la Universidad Carlos III de Madrid. Madrid: Fundación Carlos III.

Smith, K., Clegg, S., Lawrence, E. (2007). "The challenges of reflection: students learneing from work placements". Innovation in Education and Teaching International, 44 (2), 131-141.

Sulmont, L. (2004). "La universidad en la era virtual y el desarrollo de dispositivos de formación". Revista Iberoamericana de Economía del Desarrollo, 7(1/2), 163-176.

Trinidad, A. (2006). "La evaluación de organizaciones prestadoras de servicios de bienestar social". Revista Internacional de Organizaciones, 0, 78-94.

Vallejo Peña, A. (2007). El análisis de la cultura de una multinacional: el caso Maersk. Granada: Comares.

Vallejo Peña, A. (2010). "Las prácticas de empresa ante el nuevo Espacio Europeo de Educación Superior". Aula de Innovación Educativa, 192, 49-51.

Vallés, M. (1997). Técnicas cualitativas de investigación social. Madrid: Síntesis

Vilanova, A. and Tarruella, A. T. (2011). "Estudio evaluativo y competencial de las prácticas profesionalizadoras en la titulación de Empresariales y Administración y Dirección de Empresas". Revista d Innovació Docent Universitaria, 3, 1-10.

Acknowledgments: for their invaluable assistance, Escuela de Estudios Jurídicos y Económicos del Campo de Gibraltar "Francisco Tomás y Valiente", Maersk España, S.A. and Cepsa-Campo de Gibraltar (data collection and interviews).

FRANCISCO ALBERTO VALLEJO PEÑA. Doctor en Sociología por la Universidad de Granada (2003), en la que presentó su Tesis Doctoral Organizaciones complejas y cultura: el caso de Maersk España. Su labor como docente e investigador se ha desarrollado principalmente en la Universidad de Málaga, en la que ingresó en 2005, aunque también ha completado cursos académicos en las Universidades de Cádiz y Jaén, además de colaboraciones puntuales 
con la Universidad Abdelmalek Essaadi (Norte de Marruecos; 2006, 2008) y Nuremberg $(2005,2006)$. Sus asignaturas de mayor dedicación han sido sociología del trabajo y de las organizaciones, sociología de la educación y métodos y técnicas de investigación social. El autor ha estado dedicado gran parte de su carrera a la cooperación internacional, con experiencia en El Salvador y Marruecos. En su labor como investigador, sus líneas más destacadas son cultura de empresa, análisis de organizaciones y sociología del trabajo; a las que ha contribuido con publicaciones de artículos en algunas de las revistas nacionales de mayor impacto en dichas ramas.

JUAN HERRERA BALLESTEROS. Es Profesor en el Dpto. de Economía y Admón. Empresas (UMA). Licenciado en Ciencias del Trabajo por la Universidad de Málaga. Master en Sociología Aplicada. Actualmente es Doctorando del Dpto. de Derecho del Estado y Sociología de la Universidad de Málaga (UMA), donde desarrolla la Tesis "Factores que condicionan la cooperación inter-empresarial en los Sistemas Productivos Locales. Estudio de caso", cuya lectura está prevista en 2017. Sus principales líneas de investigación son sociología de las organizaciones, del trabajo e industrial y redes sociales.

Recibido: 13/03/2015

Aceptado: 09/02/2016 
NOTAS DE INVESTIGACIÓN RESEARCH NOTES 



\section{CONFIABILIDAD Y VALIDEZ DE UN INSTRUMENTO QUE MIDE PERCEPCIONES DE SALUD OCUPACIONAL EN MIGRANTES DE HUEHUETOCA, ESTADO DE MÉXICO}

RELIABILITY AND VALIDITY OF AN INSTRUMENT THAT MEASURES PERCEPTIONS OF OCCUPATIONAL HEALTH IN MIGRANT HUEHUETOCA, STATE OF MEXICO

Javier Carreón Guillén Universidad Nacional Autónoma de México, México javierg@unam.mx

Miguel Bautista Miranda Universidad Nacional Autónoma de México, México mbautistam@unam.mx Cruz García Lirios Universidad Autónoma del Estado de México, México garcialirios@uaemex.mx Guillermina Hernández Romero Universidad Autónoma del Estado de México, México ghernandezr@uaemex.mx
Francisco Rubén Sandoval Vázquez Universidad Autónoma del Estado de Morelos, México frsandovalv@uaem.mx Gabriel Pérez Crisanto Universidad Autónoma Metropolitana, México gperezc@uam.mx Oscar Valdés Ambrosio Universidad Autónoma de la Ciudad de México, México ovaldeza@uacm.mx

Cómo citar / Citation

Carreón Guillén, Javier; Bautista Miranda, Miguel; García Lirios, Cruz; Hernández Romero, Guillermina; Sandoval Vázquez, Francisco Rubén; Pérez Crisanto, Gabriel y Valdés Ambrosio, Oscar (2016). "Confiabilidad y validez de 
un instrumento que mide percepciones de salud ocupacional en migrantes de Huehuetoca, Estado de México". OBETS. Revista de Ciencias Sociales, 11(2): 569-581. doi:10.14198/OBETS2016.11.2.08

\title{
Resumen
}

Se realizó un estudio no experimental, trasversal y exploratorio con una selección no probabilística de 120 trabajadores migrantes de una localidad del Estado de México con la finalidad de establecer la confiabilidad y la validez de un instrumento que midió ocho dimensiones de la salud ocupacional. A partir de la estimación de parámetros de confiabilidad y validez alfa $=0,771$; $2=135,23(35 \mathrm{gl}) \mathrm{p}=0,000 ; \mathrm{KMO}=0,793: 23 \%$ y $20 \%$ de la varianza explicada para el primer y segundo factor se encontraron correlaciones positivas y significativas entre variables que explicarían la salud ocupacional conformada por expectativas de lecto-escritura con oportunidades esperadas ( $\mathrm{r}=$ $0,687 ; p=0,001)$, éstas últimas con capacidades $(r=0,667 ; p<0,05)$ y éstas con bienestar subjetivo $(r=0,578 ; \mathrm{p}<0,05)$. A partir de la revisión de la literatura se advierte la inclusión de variables normativas y valorativas que explicarían cuatro rutas lógicas de salud ocupacional.

Palabras claves: adaptación, asimilación, selectividad, identidad, salud.

\begin{abstract}
A non-experimental, cross-sectional and exploratory study was conducted with a nonrandom selection of 120 migrant workers from a town in the State of Mexico in order to establish the reliability and validity of an instrument which measured eight dimensions of occupational health. From the estimation of parameters of reliability and validity alpha $=0.771 ; 2=135.23(35 \mathrm{gl})$ $\mathrm{p}=0.000 ; \mathrm{KMO}=0.79323 \%$ and $20 \%$ of the variance explained for the first and second factor significant positive correlations between variables that explain occupational health made up expectations with expected literacy opportunities $(r=0.687$ were found; $p=0.001)$, the latter with capacities $(r=$ $0.667 ; \mathrm{p}<0.05)$ and these with SWB $(\mathrm{r}=0.578 ; \mathrm{p}<0.05)$. From the literature review including valuation standards and four logical variables that explain routes warns occupational health.
\end{abstract}

Keywords: adaptation, assimilation, selectivity, identity, health.

\section{INTRODUCCIÓN}

El objetivo del presente trabajo es establecer la confiabilidad y la validez de un instrumento que mide percepciones en torno a la salud ocupacional en una muestra no probabilística de migrantes en una localidad del Estado de México.

Con toda claridad se puede advertir que prevalecen dos diferentes contextos relativos al denominado Estado de bienestar y el Estado posburocrático. El primero caracterizado por incentivos fiscales que buscan incidir o fortalecer la productividad, pero que generan una mayor demanda en horas de trabajo, en relación a condiciones precarias de los trabajadores y sus efectos a la salud: somática y emocional. En contraste, el Estado posburocrático que supo- 
ne un interés público en los trabajadores mediante una administración de la calidad de los procesos, así como la adhesión a normas y responsabilidad social; justificación de costos, previsión de reglas y procedimientos alusivos a la planeación de resultados (García, 2011).

Ambos contextos, el paradigma del bienestar y el modelo posburocrático se orientan a la salud pública de los trabajadores, pero solo en el sistema posburocrático es posible la reducción de riesgos laborales y el incremento del salario, ya que a mayor productividad se genera una mayor y mejor distribución del ingreso (Barrios y Peravic, 2006).

Los resultados reportados por la literatura muestran que: 1) El aprendizaje del idioma permite el procesamiento de la información concerniente a los riesgos del trabajo. 2) El abatimiento del analfabetismo genera el establecimiento de necesidades de los trabajadores. 3) La promoción de los derechos laborales favorece el clima organizacional de carácter productivo. 4) La relación equilibrada entre oportunidades y capacidades conlleva a una mejor calidad de vida, y 5) La reducción de estrés propicia un mayor compromiso y satisfacción en los trabajadores (García, 2011).

Es evidente la ausencia de estudios relativos a los efectos culturales entre residentes y migrantes con respecto al empleo y la salud ocupacional. Por consiguiente, es menester un diagnóstico integral en el manejo del idioma, así como la alfabetización de los migrantes, la promoción de los derechos laborales, la adquisición de capacidades y el compromiso laboral con respecto a los empleos que suponen niveles de insalubridad y sus probables afectaciones somáticas y psicológicas.

El Estado de bienestar, para los propósitos del presente proyecto, es un modelo económico que permite dos objetivos: 1) los trabajadores en lo general asumen que su salario real no crece en función de su esfuerzo o del tiempo socialmente necesario para llevar a cabo una determinada faena -función básica en el empleo la cual supone riesgos: somáticos, psicológicos y laborales-a cambio el Estado de bienestar se compromete a implementar una política laboral que consiste en equidad con acceso a los servicios sociales. Por consiguiente, los empresarios de servicios de alto riesgo asumen estas políticas como un estímulo fiscal, ya que el Estado introduce estrategias fiscales orientadas a incentivar la productividad y la innovación, estos incentivos fiscales no se traducen en una mejora de las condiciones laborales y de salud pública de los trabajadores (García y Muñoz, 2013).

Precisamente, se sabe que la salud ocupacional consiste en un enfoque multidisciplinario que promueve y protege a los trabajadores mediante la previsión de los accidentes de trabajo y las enfermedades profesionales derivadas inherentes al proceso de trabajo. 
Por lo tanto, el presente proyecto: 1) Explora las condiciones físicas, económicas, laborales, familiares y psicológicas de los trabajadores migrantes. Tal diagnóstico permitirá conocer los efectos de las políticas públicas en material laboral y sobre todo de salud, ello en ámbitos de alto riesgo. 2) Describir los estilos de vida tanto familiares como laborales de los migrantes empleados en oficios de limpieza y mantenimiento. En esta fase será posible observar los imponderables que la literatura cita con respecto a: el idioma, el analfabetismo, la corrupción y la ausencia de una cultura fincada en el derecho, no sólo imputable a los trabajadores sino a quienes administran sus funciones. 3) Explicar las diferencias entre la calidad de vida (salarios, educación, acceso a los servicios de salud, patrimonio, remesas) y bienestar subjetivo (estrés, ansiedad, adicciones, enfermedades).

El Estado benefactor en México, consiste en políticas públicas de regulación de riesgos y compensaciones en el caso de accidentes o enfermedades profesionales derivadas de la actividad laboral. A partir de estas políticas públicas, los estudios relativos a la salud ocupacional identifican programas y estrategias de prevención no siempre efectivas, como es el caso de:

a) Idioma en el cual estudios con migrantes latinos en territorio canadiense, principalmente en la provincia de Quebec. Desde un enfoque multicultural, estos antropólogos-sociólogos, encontraron como principal límite al desempeño y la productividad laboral a la comprensión y manejo del idioma franco-inglés. Las políticas propuestas de inclusión social consistentes en la formación de habilidades culturales, ello con la finalidad de que los migrantes se fueran adaptando a la cultura dominante. No obstante que la productividad se incrementó con el manejo del idioma y la adquisición de las capacidades culturales, las desigualdades persistieron (Blanch, Sahagun y Vervantes, 2010).

b) El analfabetismo como un obstáculo para la promoción y atención de la salud ocupacional en Cincinnati, Oh. Las habilidades de lecto-escritura son limitantes en la formación de las capacidades culturales. A partir de la hipótesis en torno a la cual, la búsqueda y permanencia de un determinado tipo de empleo afecta directamente la salud del trabajador (enfermedades cardiovasculares, cerebro-musculares, renales-hepáticas y crónico-degenerativas); encontraron una relación directa entre los empleos de alto riesgo, tales como: los del sector servicios y específicamente los de limpieza, con respecto al nivel de ansiedad, glucosa, presión arterial y arritmia cardiaca. Es decir, entre más riesgoso es el trabajo, más vulnerable es la persona que no puede o no sabe leer y escribir sus padecimientos o preocupaciones derivadas de su función (Melero y Ramírez, 2011). 
c) Derechos de acceso a los servicios de salud. La relación entre el bienestar laboral y la promoción de la salud en ámbitos de alto riesgo, entendiendo que el bienestar laboral es resultado de un diálogo entre trabajadores y empleadores; encontrando diferencias significativas entre quienes están organizados en sindicatos y quienes no están afiliados a ninguna agrupación, una mayor calidad de vida para los del primer grupo, ello sin importar su estatus migratorio o bien el tipo de empleo y función que desempeña (García, Carreón, Hernández y Rivera, 2015).

d) Exclusión social, en el caso específico de México, se han llevado a cabo estudios en los que intentan demostrar que al ser la migración una condición de exclusión, afecta directamente la dinámica familiar. Es el caso de una investigación que realizaron en el sureste de México, con comunidades migrantes tzotziles, los cuales laboraron en la Ciudad de México. Los resultados de su investigación muestran que los discursos de discriminación y estigma afectaron su desempeño y en algunos casos los orilló a la ideación suicida (pensamientos de automutilación y castigo). Los autores recomienda llevar a cabo políticas de inclusión social con base en el interculturalismo o diálogo entre grupos discriminados y discriminantes; para lograr acuerdos de beneficio mutuo tales como: la administración de talentos y saberes (Martínez, Pando, León, González, Aldrete y López, 2015).

e) Oportunidades y capacidades. Desde un enfoque liberal y cooperativo, el abatimeinto de la pobreza y llevar a cabo políticas de microcrédito y microfinanciamiento en comunidades migrantes. Se encontraron diferencias notables de género, con respecto a los diferentes apoyos y a los pagos de los créditos. Las mujeres resultaron ser mejores administradoras que los varones, al emprender proyectos e incluir a otras mujeres en dichas actividades. En contraste los hombres consumían los apoyos económicos y no se responsabilizaban en cubrir los adeudos contraídos. Por consiguiente, el enfoque de capacidades se orientó hacía las madres solteras y migrantes que, al final de cuentas, resultaron ser más emprendedoras con respecto a otros grupos. En términos de políticas públicas este modelo ha sido muy exitoso en contextos denominados posburocráticos del Estado de bienestar.

f) Estrés y bienestar subjetivo. Los empleos de alto riesgo no solo generan estrés en los trabajadores, sino además les produce infelicidad e insatisfacción; por consiguiente, el grado de compromiso laboral en contextos de alto riesgo e insalubre disminuye en la medida en que las demandas se incrementan y los incentivos y las condiciones son precarias. La instauración de políticas públicas de desarrollo humano concernientes a la reducción de la jornada laboral, el aumento de prestaciones y el establecimiento de acuerdos que conlleven a la atención debida del estrés (Vieco y Abello, 2014). 
Formulación: ¿Las correlaciones entre las variables esgrimidas en qué sentido evidencian un nivel de salud ocupacional?

Hipótesis nula: Las correlaciones entre las variables son significativas evidenciando un sentido positivo de la salud ocupacional.

Hipótesis alterna: Las correlaciones entre las variables evidencian un proceso diferente a la salud ocupacional.

\section{METODOLOGÍA}

Diseño. Se llevó a cabo un estudio no experimental, transversal y exploratorio.

Muestra. Se realizó una selección no probabilística de 120 trabajadores migrantes del sector maquilador y servicios de Huehuetoca, Estado de México.

Instrumento. Se aplicó la Escala de Percepción de Salud Ocupacional de Carreón (2016) el cual incluye dimensiones relativas a expectativas en torno a los efectos del aprendizaje del idioma, lecto-escritura, acceso y derecho a la salud, estigma, oportunidades, capacidades, calidad de vida y bienestar subjetivo relacionados con el estatus migratorio y el tipo empleo. Cada uno de los ítems de la escala incluyen cinco opciones de respuesta que van desde "nada probable" hasta "muy probable".

Procedimiento. Se utilizó la técnica Delphi para la homogenización del significado de las palabras incluidas en los ítems. Se estableció por escrito la garantía de confidencialidad de la encuesta, se les informó a los encuestados que los resultados del estudio no afectarían su estatus académico. La aplicación de los cuestionarios se realizó en el vestíbulo de la biblioteca de la universidad. La información fue procesada en el Paquete Estadístico para Ciencias Sociales (SPSS por sus siglas en inglés). Se estimó la confiabilidad con alfa de Cronbach, la adecuación con KMO, la esfericidad con la prueba de Bartlett, la validez con pesos factoriales -análisis factorial de componentes principales con rotación varimax-. Las correlaciones se estimaron con el parámetro $\mathrm{r}$ de Pearson.

\section{RESULTADOS}

La confiabilidad general $($ alfa $=0,771)$ se configuró a partir de la consistencia interna de las escalas (alfa mínima $=0,702$ hasta alfa máxima $=0,791$ ). Es posible advertir, considerando la varianza explicada, que sólo el factor del idioma y lecto-escritura cumplen con el requerimiento mínimo del 20\% (véase tabla 1). 
Tabla 1. Descriptivos, confiabilidad y validez del instrumento

\begin{tabular}{|c|c|c|c|c|c|c|c|c|c|c|c|c|}
\hline Clave & Ítems & $\mathrm{M}$ & $\mathrm{DE}$ & Alfa & $\mathrm{F} 1$ & F2 & F3 & F4 & F5 & F6 & F7 & F8 \\
\hline & Subescala de expectativas lingüisticas & & & 0,702 & & & & & & & & \\
\hline EL1 & $\mathrm{Al}$ aprender otro idioma tendré un mejor salario & 1,34 & 0,32 & 0,783 & 0,346 & & & & & & & \\
\hline EL2 & Al dominar el idioma obtendré un mejor empleo & 1,36 & 0,54 & 0,741 & 0,436 & & & & & & & \\
\hline EL3 & $\mathrm{Al}$ aprender otro idioma podré migrar & 1,25 & 0,75 & 0,732 & 0,513 & & & & & & & \\
\hline \multirow[t]{2}{*}{ EL4 } & Al hablar otro idioma accederé a créditos & 1,57 & 0,32 & 0,742 & 0,467 & & & & & & & \\
\hline & Subescala de expectativas lecto-escritoras & & & 0,731 & & & & & & & & \\
\hline ELE1 & Al leer otro idioma obtendré mejores créditos & 1,05 & 0,83 & 0,752 & & 0,468 & & & & & & \\
\hline ELE2 & Al escribir otro idioma conseguiré un mejor empleo & 1,94 & 0,85 & 0,741 & & 0,356 & & & & & & \\
\hline ELE3 & Al leer otro idioma podré tener un aumento salarial & 1,36 & 0,36 & 0,752 & & 0,476 & & & & & & \\
\hline \multirow[t]{2}{*}{ ELE4 } & $\mathrm{Al}$ escribir otro idioma pediré un mejor puesto & 1,28 & 0,26 & 0,756 & & 0,312 & & & & & & \\
\hline & Subescala de expectativas de salud & & & 0,757 & & & & & & & & \\
\hline ES1 & Al tener prestaciones trabajaré más tiempo & 1,97 & 0,71 & 0,721 & & & 0,495 & & & & & \\
\hline ES2 & $\mathrm{Al}$ tener un seguro médico buscaré otro empleo & 1,70 & 0,46 & 0,742 & & & 0,586 & & & & & \\
\hline ES3 & Al tener prestaciones ganaré menos dinero & 1,67 & 0,36 & 0,773 & & & 0,542 & & & & & \\
\hline \multirow[t]{2}{*}{ ES4 } & $\mathrm{Al}$ tener un seguro médico formaré una familia & 1,46 & 0,26 & 0,709 & & & 0,693 & & & & & \\
\hline & Subescala de percepciones de estigma & & & $\mathbf{0 , 7 3 2}$ & & & & & & & & \\
\hline PE1 & Al ser migrante me verán como delincuente & 1,06 & 0,22 & 0,746 & & & & 0,413 & & & & \\
\hline PE2 & Al migrar me expongo al tráfico de personas & 1,58 & 0,25 & 0,752 & & & & 0,476 & & & & \\
\hline PE3 & Al ser migrante soy vulnerable a la xenofobia & 1,48 & 0,15 & 0,781 & & & & 0,653 & & & & \\
\hline \multirow[t]{2}{*}{ PE4 } & Al migrar me insultarán por mi color de piel & 1,49 & 0,38 & 0,773 & & & & 0,321 & & & & \\
\hline & Subescala de expectativas de oportunidades & & & 0,791 & & & & & & & & \\
\hline EO1 & Al ser migrante reduciré mis opciones de empleo & 1,32 & 0,82 & 0,732 & & & & & 0,721 & & & \\
\hline $\mathrm{EO} 2$ & Al migrar sólo tendré empleo informal & 1,42 & 0,94 & 0,751 & & & & & 0,783 & & & \\
\hline $\mathrm{EO} 3$ & Al ser migrante estaré desempleado & 1,02 & 0,67 & 0,731 & & & & & 0,432 & & & \\
\hline \multirow[t]{2}{*}{ EO4 } & Al migrar me expondrá a riesgos & 1,96 & 0,73 & 0,752 & & & & & 0,745 & & & \\
\hline & Subescala de expectativas capacidades & & & 0,773 & & & & & & & & \\
\hline $\mathrm{EC} 1$ & Al migrar aprenderé otros oficios & 1,72 & 0,21 & 0,784 & & & & & & 0,843 & & \\
\hline $\mathrm{EC} 2$ & $\mathrm{Al}$ ser migrante tendré más experiencia laboral & 1,25 & 0,46 & 0,793 & & & & & & 0,856 & & \\
\hline $\mathrm{EC} 3$ & Al migrar aprenderé a usar maquinas & 1,46 & 0,57 & 0,714 & & & & & & 0,732 & & \\
\hline \multirow[t]{2}{*}{$\mathrm{EC} 4$} & Al ser migrante tendré más oportunidades laborales & 1,04 & 0,43 & 0,786 & & & & & & 0,543 & & \\
\hline & Subescala de calidad de vida & & & 0,732 & & & & & & & & \\
\hline CV1 & Al migrar ya no dependeré de mis familiares & 1,01 & 0,46 & 0,754 & & & & & & & 0,632 & \\
\hline $\mathrm{CV} 2$ & Al ser migrante ya no estaré desempleado & 1,92 & 0,38 & 0,752 & & & & & & & 0,567 & \\
\hline $\mathrm{CV} 3$ & Al migrar ya no estaré endeudado & 1,20 & 0,51 & 0,746 & & & & & & & 0,683 & \\
\hline \multirow[t]{2}{*}{$\mathrm{CV} 4$} & Al ser migrante ya no seré criticado por mis amigos & 1,27 & 0,48 & 0,773 & & & & & & & 0,413 & \\
\hline & Subescala de bienestar subjetivo & & & 0,751 & & & & & & & & \\
\hline BS1 & Al migrar seré más feliz & 1,73 & 0,63 & 0,763 & & & & & & & & 0,431 \\
\hline BS2 & Al ser migrante tendré más experiencia & 1,46 & 0,62 & 0,767 & & & & & & & & 0,456 \\
\hline BS3 & Al migrar conoceré más personas & 1,27 & 0,41 & 0,772 & & & & & & & & 0,652 \\
\hline BS4 & Al ser migrante podré elegir más cosas & 1,39 & 0,36 & 0,779 & & & & & & & & 0,476 \\
\hline
\end{tabular}

Método de extracción: componentes principales -análisis factorial con rotación varimax-, adecuación y esfericidad $2=135,23(35 \mathrm{gl}) \mathrm{p}=0,000 ; \mathrm{KMO}=0,793 . \mathrm{F} 1=$ expectativas del idioma ( $23 \%$ de la varianza total explicada), F2 = expectativas lecto-escritoras ( $20 \%$ de la varianza total explicada), F3 = expectativas de salud ( $17 \%$ de la varianza total explicada), $\mathrm{F} 4=$ percepciones de estigma ( $15 \%$ de la varianza total explicada), F5 = expectativas de oportunidades ( $13 \%$ de la varianza total explicada), F6 = expectativas de capacidades ( $11 \%$ de la varianza total explicada), F7 = calidad de vida ( $7 \%$ de la varianza total explicada), F8 = bienestar subjetivo ( $3 \%$ de la varianza total explicada). Cada ítem se responde con alguna de cinco opciones: $0=$ "nada probable" hasta 4 = "muy probable".

Fuente: Elaborada con los datos del estudio 
La confiabilidad y la validez, requerimientos para análisis multivables, incluyeron valores cercanos al cero y por tanto espurios en cuanto a la explicación del constructo de salud ocupacional percibida.

Por consiguiente, la inclusión de otros factores también es posible observarlo en las correlaciones entre los factores, ya que al ser cercanas a cero o a la unidad evidencian la inclusión de otros factores en el proceso de salud ocupacional (véase tabla 2).

Tabla 2. Correlaciones entre los factores

\begin{tabular}{|c|c|c|c|c|c|c|c|c|}
\hline & $\mathrm{F} 1$ & F2 & F3 & $\mathrm{F} 4$ & F5 & F6 & F7 & F8 \\
\hline $\mathrm{F} 1$ & 1,000 & & & & & & & \\
\hline $\mathrm{F} 2$ & 0,432 & 1,000 & & & & & & \\
\hline F3 & $0,576^{*}$ & $0,567 *$ & 1,000 & & & & & \\
\hline F4 & 0,687 & 0,657 & 0,568 & 1,000 & & & & \\
\hline F5 & $0,832^{*}$ & $0,687 * * *$ & $0,679 * * *$ & $0,453^{*}$ & 1,000 & & & \\
\hline F6 & $0,941 * *$ & 0,543 & $0,544 * * *$ & $0,445^{* * *}$ & $0,667^{*}$ & 1,000 & & \\
\hline F7 & 0,436 & $0,453^{*}$ & $0,567^{*}$ & 0,556 & 0,469 & 0,325 & 1,000 & \\
\hline F8 & $0,542^{*}$ & $0,457 * *$ & 0,658 & $0,576^{* * *}$ & $0,504 *$ & $0,578^{*}$ & 0,587 & 1,000 \\
\hline
\end{tabular}

$\mathrm{F} 1=$ expectativas del idioma, $\mathrm{F} 2=$ expectativas lecto-escritoras, $\mathrm{F} 3=$ expectativas de salud F4 = percepciones de estigma, F5 $=$ expectativas de oportunidades, F6 $=$ expectativas de capacidades, F7 = calidad de vida, F8 = bienestar subjetivo Fuente: Elaborada con los datos del estudio

De este modo, el factor de expectativas del idioma con respecto a las capacidades esperadas $(r=0,941 ; p=0,01)$ muestra que una colinealidad que supone la medición de la misma dimensión relativa a la salud ocupacional. Es el mismo caso de las expectativas lingüísticas con las oportunidades esperadas $(r=0,32 ; p=0,05)$. Es decir que la multicolinealidad entre los factores de idio$\mathrm{ma}$, de oportunidad y de capacidad miden un mismo proceso alusivo a la salud ocupacional de migrantes en el sector servicios.

En los casos de correlaciones entre las expectativas lecto-escritoras con respecto a las oportunidades percibidas, es posible advertir una trayectoria que explicaría la búsqueda, permanencia y ascenso de la salud ocupacional siempre que los migrantes esperan aprender otro idioma que les permita más oportunidades laborales. Esta lógica se refuerza con la correlación entre la salud per- 
cibida y las oportunidades esperadas $(\mathrm{r}=0,679 ; \mathrm{p}=0,001)$ y también en el caso del factor de oportunidades con el de capacidades $(r=0,667 ; p=0,05)$.

Es decir que la salud ocupacional parece ser explicada por una trayectoria de relaciones de dependencia entre los factores de lecto-escritura, salud, oportunidades y capacidades percibidas. Se trata de un constructo de segundo orden en el que los cuatro factores están circunscritos como una ruta lógica de expectativas.

\section{DISCUSIÓN Y CONCLUSIÓN}

El presente trabajo evidenció la confiabilidad y la validez de un instrumento que mide expectativas de salud ocupacional en el que se incluye ocho dimensiones relativas al idioma, lecto-escritura, salud, estigma, oportunidades, capacidades, calidad de vida y bienestar subjetivo.

Sin embargo, las correlaciones entre los factores muestra una trayectoria de relaciones de dependencia explicativa de la salud ocupacional como un proceso que parte del aprendizaje de habilidades lecto-escritoras y culmina con expectativas derivadas del aprendizaje de otras habilidades acordes a las oportunidades esperadas.

García, Carreón, Hernández y Morales (2014) demostró que el compromiso laboral está circunscrito a un proceso que va de la confianza hasta satisfacción. Se trata de un proceso opuesto al encontrado en el presente trabajo, el cual parte del supuesto según el cual las correlaciones entre las variables explican un sentido positivo de la salud ocupacional.

Precisamente, una línea de investigación alusiva a las emociones organizacionales explicaría una variabilidad de la salud ocupacional al considerarla como resultado de las relaciones personales más que el cumplimiento de objetivos y la consecución de metas.

García, Carreón, Hernández, Bustos, Bautista, Méndez y Morales (2013) demostraron que la cultura organizacional, entendida como un proceso de valores y normas, estriba en la influencia de la socialización primaria y secundaría sobre el desempeño laboral. En un sentido diferente, la salud ocupacional como resultado de la cultura labora consistiría en una serie de creencias relativas a las normas de higiene, la prevención de enfermedades y accidentes, pero en un sentido de colectividad organizacional.

Tal línea de investigación se complementaría con la establecida en el presente estudio, ya que las oportunidades laborales corresponden con los valores familiares y gremiales en la medida en que los migrantes tienden redes laborales que son consecuencia de los usos y costumbres culturales. 
Respecto a la calidad de vida y el bienestar subjetiva relacionados con la salud ocupacional, es posible advertir que su correlación esgrime un proceso alusivo a los efectos de la cultura organizacional sobre los grupos a los que los empleados pertenecen.

García, Carreón, Hernández y Rivera (2015) demostraron que la calidad de vida está vinculada con el clima de relaciones más que el clima de tareas al interior de una organización. En este sentido, el estigma que a los migrantes se les atribuye afecta no sólo su calidad de vida o su bienestar subjetivo, sino además su salud ocupacional.

En el presente trabajo, el estigma percibido se vinculó significativamente con las capacidades y el bienestar subjetivo. A medida que se incrementan las percepciones de estigma, aumentan las expectativas de capacidades y el bienestar subjetivo. Es decir, lejos de inhibir la salud ocupacional de los migrantes, la discriminación a la que están expuestos incentiva el aprendizaje de habilidades relativas a sus oportunidades de empleo.

Por consiguiente, el modelo de salud ocupacional a contrastar incluiría cuatro trayectorias en donde no sólo se pondera el efecto de la migración sobre la salud ocupacional, la calidad de vida y el bienestar subjetivo de los trabajadores, sino además se constatarían las cuatro hipótesis culturales de adaptación, asimilación, selección e identidad reportadas por el estado del conocimiento.

De este modo

Trayectoria explicativa de la adaptación cultural: Migración $\rightarrow$ aprendizaje del idioma $\rightarrow$ lecto-escritura $\rightarrow$ estigma $\rightarrow$ bienestar subjetivo. Se trata de un proceso que inicia con la migración de los trabajadores, su adaptación cultural indicada por el aprendizaje del idioma, la lecto-escritura, la convivencia con la xenofobia y la percepción de una mejor vida comparada con su lugar de origen en donde a menudo están desempleados, endeudados y dependientes de la agricultura local-estacional.

Trayectoria explicativa de la asimilación laboral: Migración $\rightarrow$ estigma $\rightarrow$ oportunidades $\rightarrow$ capacidades $\rightarrow$ bienestar. Se trata de un proceso en el que una vez consumada la migración a través de las redes laborales, la salud ocupacional es producto del estigma percibido -los migrantes trabajan las actividades que los oriundos desprecian- el cual incide en oportunidades de alto riesgo que a menudo demandan capacidades de resiliencia, pero que al final generan expectativas de bienestar porque el empleo precario e informal es considerado mejor que el desempleo.

Trayectoria explicativa de la selección de talentos: Migración $\rightarrow$ oportunidades $\rightarrow$ capacidades $\rightarrow$ calidad de vida. Es un sendero que establece relaciones 
de dependencia entre la migración, las oportunidades que corresponden a capacidades específicas y actualizadas en cuanto habilidades y conocimientos que escasez en la fuerza laboral local y estarían vinculado con una alta calidad de vida desde el lugar de origen del migrante. A menudo se trata de talentos con una alta especialización académica que estudian en el país receptor y son contratados por las organizaciones de acogida.

Trayectoria explicativa de la identidad cultural: Migración $\rightarrow$ capacidades $\rightarrow$ calidad de vida $\rightarrow$ bienestar subjetivo. Es un proceso en el que convergen las redes familiares y laborales en el desarrollo de habilidades y conocimientos en torno a los cuales se refleja una alta calidad de vida y bienestar subjetivo, ya que el migrante está debidamente circunscrito a un grupo que lo inserta en el país receptor y en su dinámica laboral.

Las cuatro rutas explicativas complementan los hallazgos del presente estudio con los aportes de la literatura, avizorando líneas de investigación circunscritas a la salud ocupacional, sus determinantes y sus efectos en las redes migratorias y sus estilos de vida.

\section{REFERENCIAS}

Barrios, Sara y Peravic, Tatiana. (2006). "Promoción de la salud y un entorno laboral saludable." Revista Latinoamericana de Enfermería, 14 (1), 1-10

Blanch, Josep., Sahagun, Miguel y Vervantes, Genis. (2010). "Estructura laboral del cuestionario de condiciones de trabajo." Revista de Psicología del Trabajo y las Organizaciones, 26 (3), 175-189

García, Constanza y Muñoz, Alba. (2013). "Salud y trabajo de docentes de instituciones educativas distritales de la localidad uno de Bogotá." Avances de Enfermería, 31 (2), $30-42$

García, Cruz. (2011). "Estructura de las actitudes hacia los hospitales." Psicología y Salud, 21 (1), 57-64

García, Cruz., Carreón, Javier., Hernández, Jorge y Rivera, Bertha. (2015). Confiabilidad y validez de un instrumento que mide la dimensión sociopolítica de la calidad de vida." Psicumex, 1 (2), 79-92

García, Cruz., Carreón, Javier., Hernández, Jorge. y Morales, María. (2014). "Contraste de un modelo de compromiso laboral en centros de salud pública." Acta Universitaria, 24 (1), 48-59

García, Cruz., Carreón, Javier., Hernández, Jorge., Bustos, José., Bautista, Miguel., Méndez, Agustín y Morales, María. (2013). "Compromiso laboral en el Trabajo Social del sector salud." Medicina, Salud y Sociedad, 4 (1), 39-8

Martínez, Rebeca., Pando Manuel., León, Silvia., González, Raquel., Aldrete, María. y López, Luis. (2015). "Validez y confiabilidad de la escala de salud mental positiva." Revista Psicogente, 18 (33), 78-88 
Melero, Rosa. y Ramírez, Jesús. (2011). "El distintivo igualdad en la empresa: Una certificación en igualdad de oportunidades." Intangible Capital, 7 (2), 410-427

Vieco, Germán, y Abello, Raymundo. (2014). "Factores psicosociales de origen laboral, estrés y morbilidad en el mundo." Psicología desde el Caribe, 31 (2), 354-385

CRUZ GARCÍA LIRIOS. Realizó estudios de doctorado en Psicología Social y maestría en Trabajo Social, Universidad Nacional Autónoma de México. Es licenciado en Psicología Social por la Universidad Autónoma Metropolitana. Profesor de asignatura en el Instituto Politécnico Nacional, Universidad Autónoma del Estado de México y Universidad Autónoma del Estado de Morelos. Línea de investigación en "Gobernanza de la Educación y Salud Pública en Organizaciones de la Sociedad Civil”.

JAVIER CARREÓN GUILLÉN. Doctor en Administración por la Facultad de Contaduría y Administración de la Universidad Nacional Autónoma de México. Profesor de Carrera en la Escuela Nacional de Trabajo Social de la UNAM, y adscrito al Sistema Nacional de Investigadores. Línea de investigación: "Encuadre de la prensa en torno a la violencia sociopolítica en México. Análisis transcultural de la ciudad de Bogotá (Colombia), Caracas (Venezuela) y Distrito Federal (México)"

JORGE HERNÁNDEZ VALDÉS. Doctorante en Trabajo Social, Universidad Nacional Autónoma de México. Secretario Académico de la Escuela Nacional de Trabajo Social de la UNAM, así como Profesor de Carrera de la misma institución, desarrolla las líneas de investigación sobre "migración, jóvenes y masculinidades"

JOSÉ MARCOS BUSTOS AGUAYO. Licenciado, maestro y doctor en Psicología por la Facultad de Psicología de la UNAM. Es Profesor Titular "C" en la FES Zaragoza, Docente en la UNAM durante 35 años. PRIDE nivel D. Tutor principal del doctorado en psicología y de las maestrías en psicología ambiental y trabajo social, de la UNAM y del doctorado en Educación en la Universidad INACE. Ha publicado más de 60 trabajos de investigación en revistas y capítulos en libros. Coeditó el libro Concepciones de la interacción social en el niño (2001 y 2006). Se encuentra en preparación de los libros Psicología ambiental: análisis de barreras para la sustentabilidad y Nuevas tendencias de la psicología de la conservación ambiental e Investigaciones psicoambientales en preescolares. Ha presentado más de cien ponencias en congresos mexicanos e internacionales. 
MARÍA LUISA QUINTERO SOTO. Profesora e Investigadora de Tiempo Completo en la UAEM, ocupa el cargo de Coordinadora de Investigación y Estudios Avanzados. Doctora en Ciencias Sociales, por la Universidad Iberoamericana, graduada con mención honorífica. Desde el 2006 a la fecha es Miembro del Sistema Nacional de Investigadores nivel II del CONACYT. Ha publicado más de 80 artículos de revistas y capítulos de libros, así como 45 libros, ha sido ponente nacional e internacional.

FRANCISCO RUBÉN SANDOVAL VÁZQUEZ. Doctor en Ciencias Políticas, Universidad Nacional Autónoma de México. Profesor de Tiempo Completo, Universidad Autónoma del Estado de México. Línea de investigación en "Gobernanza del Desarrollo Comunitario Sustentable".

Recibido: 07/04/2016 Aceptado: 30/11/2016 

CRÍTICA DE LIBROS BOOK REVIEWS 



\author{
Crítica de libro: \\ ANTONIO ALAMINOS CHICA, \\ FRANCISCO JOSÉ FRANCÉS GARCÍA, \\ CLEMENTE PENALVA VERDÚ Y \\ ÓSCAR ANTONIO SANTACREU FERNÁNDEZ
}

ANÁLISIS MULTIVARIANTE PARA

LAS CIENCIAS SOCIALES I

ÍNDICES DE DISTANCIA, CONGLOMERADOS

Y ANÁLISIS FACTORIAL

CUENCA (ECUADOR): PYDLOS EDICIONES, 2015

ISBN: 978-9978-14-315-5

\title{
Antonio Alaminos Fernandez \\ Universidad de Alicante, España Antonio.alaminos@ua.es
}

\begin{abstract}
Cómo citar / Citation
Alaminos-Fernández, Antonio Francisco (2016). "Crítica de libro: Antonio Alaminos Chica, Francisco José Francés García, Clemente Penalva Verdú y Óscar Antonio Santacreu Fernández. Análisis multivariante para las Ciencias Sociales I. Índices de distancia, conglomerados y análisis factorial". OBETS. Revista de Ciencias Sociales, 11(2): 585-589.

doi:10.14198/OBETS2016.11.2.09
\end{abstract}

La producción de manuales introductorios al análisis estadístico, y en especial los asociados con programas informáticos, han crecido de forma casi exponencial en las últimas décadas. En parte, como consecuencia de la difusión de paquetes estadísticos, para los que muchos textos cumplen con la función de manuales de usuario. En este tipo de libros, los análisis dependen en gran medida de las posibilidades del programa de referencia que se emplee. Hasta el punto de que tanto la presentación de los menús como las opciones estadísticas que considere el programa (algoritmos, por ejemplo o métodos de ajuste) determinan 
la estructura o la lógica de estos libros. Se caracterizan la mayoría de ellos por tomar un único paquete de análisis estadístico y hacer girar tanto los contenidos como los ejemplos en torno a él, apoyándose para exponer los comentarios e interpretación estadística sobre los resultados que muestre el programa. Hasta cierto punto, el manual se hace dependiente del programa de una forma tan estrecha que una versión posterior del paquete estadístico hace obsoleto el texto y su planteamiento. Por ejemplo, los manuales de análisis estadísticos vinculados a la versión 12 de un programa, es muy probable que se vuelvan incomprensibles en la versión 18 de ese mismo programa. Las modificaciones en los menús o en la forma de exponer los resultados, no permitirían al lector tomar el libro como referencia de la nueva versión.

Así mismo, con frecuencia, al apoyarse sobre la clasificación de los procedimientos de análisis que emplee un programa concreto, se oculta la conexión y transversalidad existentes en la mayoría de ellos. También se simplifica la diversidad de planteamientos existentes para interpretar la lectura de la relación existente entre los datos.

El manual Análisis Multivariante para las Ciencias Sociales I, Índices de Distancia, Conglomerados y Análisis Factorial de los profesores Antonio Alaminos, Francisco Francés, Clemente Penalva y Oscar Santacreu refleja con claridad la experiencia docente e investigadora que acumulan en el empleo de los procedimientos de análisis estadístico aplicado a la investigación social. Los autores son reputados especialistas en métodos y técnicas de investigación en Ciencias Sociales, cosa que avala tanto su producción académica como su orientación en la docencia. Así, el profesor Antonio Alaminos es catedrático de Sociología Matemática e imparte docencia desde hace más de 30 años en técnicas de investigación social, análisis y prospectiva electoral. El profesor Francisco José Francés García imparte la docencia en asignaturas como "Técnicas de Investigación Social para el Trabajo Social" o "Análisis de Datos para el Trabajo Social". El tercer autor por orden de firma es el profesor Clemente Penalva Verdú responsable docente de asignaturas como "Análisis de Información Cualitativa y "Técnicas de Investigación Social en Comunicación". Por último, el profesor Óscar Antonio Santacreu Fernández imparte las asignaturas "Análisis de Datos I" y "Sociología Matemática".

El libro forma parte de una colección de 5 manuales en los que se recogen cuatro aproximaciones diferentes a la investigación social: la cualitativa, el análisis de contenido, la investigación participativa y el análisis cuantitativo de encuestas y otros tipos de datos estadísticos. La colección ha sido editada como colaboración de dos grupos de investigación internacionales. Por un lado PYDLOS, de la Universidad de Cuenca (Ecuador) y por otro OBETS perteneciente a la Universidad de Alicante (España). 
El libro contiene algunas novedades interesantes en lo que se refiere al panorama antes mencionado. En primer lugar, toma como referencia de ejemplo dos programas de análisis estadísticos diferentes: IBM SPSS y Systat. El empleo de dos programas permite considerar las similitudes y diferencias en los planteamientos, métodos de ajuste y opciones posibles. El lector se sorprenderá de que opciones ausentes en uno, son vitales en el otro y viceversa. Así, en el caso del análisis de aglomerados, Systad ofrece opciones de gran utilidad que están (en la versión considerada) ausentes del SPSS. Y viceversa, la incorporación de algoritmos procedentes de Big Data Analysis al SPSS ofrece funcionalidades especiales. El libro ofrece unas orientaciones y comentarios importantes respecto a los límites y posibilidades de algunos de estos algoritmos. No por estar disponibles en los programas de análisis estadístico existen garantías respecto a su eficacia o significado de los resultados. En ese sentido, el libro se enriquece de la comparación entre las estrategias alternativas que plantean los dos programas. En especial, la potencialidad gráfica, que durante muchos años fue el talón de Aquiles del programa SPSS ya desde la década de los 80 .

Asimismo, un elemento significativo es la adopción de una estrategia de análisis e interpretación basada en el empleo del concepto de distancia o similaridad. La interpretación de la relación como distancia es una herramienta muy potente para el análisis de datos. Un ejemplo de ello es el análisis factorial. Ciertamente es un procedimiento de medición, pero también y en su base estadística, es un método de agrupación de variables según su proximidad, estimada mediante la correlación o covarianza.

En este texto presentamos tres estrategias de medición multivariante, que son útiles tanto para mediciones de características que se pueden percibir directamente, como de estados subjetivos. Nos centraremos en su empleo para medir (por ejemplo, estados subjetivos de los individuos), permitiendo construir, por ejemplo, un índice. Resulta evidente, una vez que hemos logrado asignar una cifra a cada individuo o caso (su valor en un índice), ya es decisión del investigador si las empleará para agrupar los casos en tipologías o usar su magnitud para relacionarla con otras magnitudes medidas en otras variables. (Página 12).

En ese sentido, el libro articula la presentación de las estrategias de análisis sobre la base de distancias o similitudes, y a partir de ellas, todas las variantes existentes. Insiste con acierto este libro en despejar el camino que conecta los diferentes métodos de análisis estadístico. Con frecuencia, estos son clasificados según su finalidad y no en función a los procedimientos. Un análisis discriminante no deja de ser un análisis de optimización de aglomerados empleando variables independientes. Los análisis de segmentación y de elaboración de perfiles, no dejan tampoco de ser estrategias de agrupación. En ese sentido, 
la intención de los autores es desencapsular los métodos de ese encierro conceptual que implica mencionarlos por sus finalidades, permitiendo una mayor flexibilidad analítica.

Es importante que el investigador comprenda que la mayoría de los procedimientos estadísticos están interconectados entre sí. Podemos llamarlos de forma diferente por motivos varios. Así es habitual que sea la finalidad inicial para la que se establecieron la que los diferencia y les da nombre. Sin embargo, con un análisis factorial (por ejemplo), una vez efectuado, se pueden atribuir magnitudes a los sujetos. A partir de ellas se les puede clasificar o efectuar otras muchas operaciones. Una vez que hemos "medido" los sujetos respecto a algo, las demás operaciones son derivadas de esa labor esencial. Por eso, existen muchas vías alternativas (procedimientos estadísticos) que pueden dar respuesta a una misma pregunta. (Página 13)

El libro considera dos técnicas principales: el análisis factorial y el análisis de aglomerados. Para ello, previamente, desarrolla los conceptos de distancia y proximidad, o también disimilitud y similitud. Se recorren los diferentes tipos de índices empleados para estimar las distancias, aplicándolos tanto a las distancias entre casos como a las distancias entre variables. Es interesante este planteamiento en el que variables y casos son sometidos a una perspectiva analítica semejante. Así, la lógica de agrupar variables según su proximidad es equivalente a lo lógica de agrupar casos según su proximidad.

Muchos procedimientos estadísticos, tales como el análisis factorial, el análisis de conglomerados, o el escalamiento multidimensional tienen como punto de partida la matriz que define las distanciasl o las proximidades entre pares de casos o variables. A partir de dichas matrices de distancias, se procede a formar los conglomerados, se extraen los factores o se identifican las estructuras y dimensiones presentes en los datos. (Página 14).

El desarrollo y explicación de las condiciones de uso de las diferentes medidas de distancia es muy claro y se acompaña de ejemplos de uso que ilustran la exposición. Una mención especial, por su relevancia es el apartado referido a la normalización y estandarización de variables. Es un apartado poco tratado en la mayoría de los manuales y que sin embargo, muestra un elevado potencial de uso. Tanto las diferencias entre normalizar y estandarizar, como los procedimientos que se pueden emplear y las consecuencias sobre los datos son de extremado interés.

A la presentación de las medidas de distancia y proximidad le siguen dos capítulos referidos al análisis factorial y a los análisis de clúster jerárquicos y no jerárquicos. Una idea destacable es el empleo de los mismos datos referidos a América Latina, tanto para ilustrar el análisis factorial como el de aglomerados. 
Así, en el primero de los casos se evalúa el peso de diferentes indicadores empleados para calcular un índice de democracia entre los países de la región. Con ello, se determina la influencia de cada uno de ellos en la construcción de un índice resumido. Utilizando los mismos datos, y a partir de los valores de los indicadores de cada país, se efectúa el análisis de aglomerados. En ese sentido, se ilustra claramente la potencialidad de la noción de distancia para el tratamiento de variables y casos. En ese sentido, el libro en consideración aporta una visión más amplia y alternativa a la que es usual en este tipo de manuales, rompiendo con la dependencia clasificatoria de un único programa de análisis estadístico, y la restricción de opciones analíticas que ello supone. El empleo de un único programa de análisis estadístico empobrece notablemente la capacidad de análisis de los investigadores, induciéndolos a pensar que solamente cabe hacer lo que ese programa indica, y únicamente en la forma en que lo propone. Cabe dar la bienvenida a libros que se desprenden de la naturaleza de manual de usuario y abren al lector las diferentes posibilidades que realmente existen en lo que se refiere a las estrategias de análisis de datos.

ANTONIO ALAMINOS FERNÁNDEZ. Grado en Publicidad y RRPP (Universidad de Alicante), Bachelor en Circumpolar Studies (University of Nordland), master Internacional en Paz, Conflicto y Desarrollo (Universitat Jaume I), y Titulado en Musica, especialidad Violin y Viola. Ultima publicacion: Antonio Alaminos (2016) Music and Society, Alicante, Editorial Compas. Especialista en la investigacion de la musica y sus efectos: Emociones, valores y emociones. Areas: Musica y movimientos sociales, diplomacia de las celebridades, publicidad y musica ambiental. Actualmente es investigador del programa "Musica y Sociedad" en la Universidad de Alicante. Editor de la revista "Musica y Sociedad" (Universidad de Alicante) y de la coleccion de monograficos "Musica y Sociedad" editada por el Observatorio Europeo en Tendencias Sociales. 



\section{NORMAS EDITORIALES E INSTRUCCIONES PARA COLABORACIONES}

A continuación se ofrece un resumen de las normas editoriales e instrucciones para colaboraciones. Se recomienda consultar la última versión disponible en la dirección http://revistaobets.ua.es Instrucciones para el envío de originales

1. OBETS. Revista de Ciencias Sociales tiene como objetivo la difusión de estudios de naturaleza académica que permitan un mejor conocimiento de la sociedad contemporánea. En este sentido

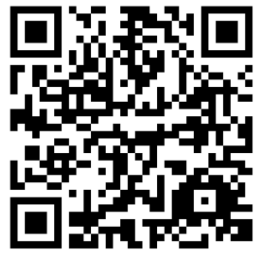
está abierta a la publicación de resultados de investigación empírica, metodológica o teórica de ámbito nacional e internacional, en un amplio abanico de temas inscritos en el ámbito de la Sociología y Ciencias Sociales, como estudios de opinión pública, metodología, demografía, estructura y cambio social, ciencia política, teoría sociológica, antropología o psicología social. Se dará prioridad a trabajos que comuniquen resultados de investigaciones académicas originales y que observen la estructura IMRyDC+B (introducción, metodología, resultados y discusión, conclusiones, y bibliografía actualizada).

2. Los trabajos, que podrán estar escritos en español, inglés, portugués o valenciano/ catalán deberán ser remitidos en formato digital, como archivo adjunto en formato .rtf o .doc a través de la página de envíos en la web de la revista. La recpción de artículos está abierta durante todo el año, a excepción del mes de agosto.

3. En cada edición se aceptan artículos que han sido positivamente evaluados al menos durante el mes anterior al de edición.

4. La extensión de los artículos que se remitan a la revista tendrán una extensión no superior a 10.000 palabras. Las notas de investigación (informe de hallazgos, aportaciones, etc.) tendrán una extensión máxima de 7.000 palabras. Las recensiones o críticas de libro no pueden superar las 3.000 palabras, y debe especificarse en ellas el autor, el título, la editorial, el lugar y la fecha de publicación de la obra objeto de recensión, así como el nombre, los apellidos y la dirección de contacto del autor de la crítica. Sólo se aceptarán recensiones de libros publicados en los últimos 3 años.

5. Los trabajos se enviarán en el siguiente formato

1. Tipo de letra Times New Roman, tamaño 12. Espacio sencillo, tamaño de página DIN A4.

2. Los diferentes apartados irán en negrita, en mayúsculas sólo la primera letra y con el mismo tipo y tamaño de fuente que el cuerpo del texto.

3. Los párrafos irán sangrados en la primera línea.

4. Las palabras en idioma diferente al original del trabajo deben ir en cursiva.

5. Las citas textuales deben ir entrecomilladas cuando sean inferiores a tres líneas. Si tienen más de 3 líneas irán sin entrecomillar y sangradas por el margen izquierdo, indicando en todo caso entre paréntesis el apellido del autor o autores del texto, el año de publicación y la página. Por ejemplo: (Ramírez, 2009: 10). Si hay más de dos autores pero menos de seis, se citarán todos ellos la primera vez y las veces siguientes se usará la expresión "et al.". Si son más de seis autores, se usará "et al." desde la primera mención. 
6. Para la bibliografía, al final del trabajo, deberá utilizarse el estilo APA (American Psychological Association). A continuación se ofrecen algunos ejemplos de formato:

\section{Libros y capítulos:}

Anwar, M. (1979). The Myth of Return: Pakistanis in Great Britain. London: Heinemann.

Esser, H. (2003). "What substance is there to the term 'Leitkultur'?". En R. Cuperus, K. A. Duffek y J. Kandel (Eds.), The challenge of diversity. European social democracy facing migration, integration and multiculturalism. Innsbrück/Vienna: Studienverlag, 47-58.

\section{Revistas:}

Berry, J. W. (1970). "Marginality, stress, and ethnic identification in an acculturated Aboriginal community". Journal of Cross-Cultural Psychology, 1, 17-22. Para documentos online, debe indicarse la fecha de consulta. Cuando se incluyan varias referencias de un mismo autor/a, es necesario indicar el nombre del autor en cada título y no usar guiones/rayas.

7. Las imágenes y diagramas se incluirán en el texto. En función de la resolución y calidad de dichas imágenes, la redacción puede solicitar el envío posterior de los archivos de imagen originales como condición para su publicación.

8. Los trabajos deben incluir, tanto en la lengua del artículo como en inglés, los siguientes elementos básicos: título, resumen de no más de 100 palabras, y entre 4 y 8 palabras clave separadas por punto y coma. Si el idioma del trabajo es el inglés, se incluirán estos elementos en inglés y en español. Para aquellos textos cuyo idioma sea diferente del inglés se debe enviar, además del abastract de 100 palabras, un abstract extendido en inglés del orden de 1000 a 1500 palabras en el que se describa con algo más de profundidad los métodos, datos, hallazgos e implicaciones del trabajo.

6. Los artículos han de ser inéditos. Dicha condición debe indicarse durante el proceso de envío al completar la lista de comprobación en la plataforma de la revista.

7. Las propuestas de contribuciones enviadas a la revista OBETS no pueden ser enviadas simultáneamente a ninguna otra publicación.

8. Todo original se somete al arbitraje por pares académicos. Con la finalidad de garantizar la imparcialidad en la selección de los artículos para publicar, se observa el anonimato tanto de autores como de evaluadores. Para proteger este anonimato, se respetará el siguiente formato en los trabajos enviados:

1. Una primera página en la que constará, únicamente, el título (en mayúsculas la primera letra y el resto en minúsculas), el nombre y apellidos de los autores, el centro de trabajo, dirección postal y correo electrónico, y teléfono y fax en su caso.

2. Una segunda página que contenga, nuevamente, el título, un resumen de no más de 100 palabras, y entre 4 y 8 palabras clave, separadas por punto y coma. Tanto el título como el resumen y las palabras clave deben aparecer en la lengua del trabajo y en inglés. 
3. El texto del trabajo (incluyendo el abstract extendido en inglés) en la página tercera y siguientes.

\section{Proceso de selección de originales}

1. Las obras recibidas pasarán por el siguiente proceso en el que cada paso requiere la superación del anterior:

1. Notificación de acuse de recibo.

2. Clasificación temática del artículo (UNESCO). Al menos dos miembros del Consejo Editorial comprobarán que el trabajo cumpla los estándares editoriales de un texto académico en el ámbito temático de la revista. Si hay al menos una valoración positiva, el trabajo pasará a la siguiente fase, y en caso contrario será notificado de manera justificada a los autores.

3. Revisión de aspectos formales y estilos, con notificación y devolución al autor en caso de existir errores.

4. Comprobación de la anonimización del artículo.

5. Revisión por dos personas evaluadoras externas, de acuerdo con criterios de

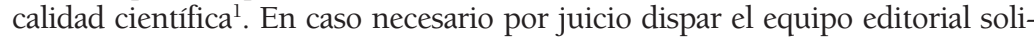
cita la contribución de un tercer evaluador/a. El formulario de evaluación está disponible en la web de la revista e incluye:

1. Evaluación de la originalidad y contribución científica.

2. Evaluación de la claridad y coherencia de objetivos, hipótesis, metodologías y conclusiones del trabajo.

3. Evaluación de la pertinencia y actualización de la bibliografía.

4. Evaluación de los aspectos formales (redacción, citas, organización del texto, tablas, gráficos, etc.).

5. Recomendación final sobre el trabajo y, en su caso, sugerencias de modificación o razones para no publicación.

6. Envío al autor del informe de revisión con la decisión correspondiente (aceptación, aceptación pendiente de rectificaciones, rechazo) de forma motivada en un plazo máximo de 6 meses desde la recepción del artículo.

2. En el caso de que un artículo sea aceptado para su publicación, se solicitará al autor/a la firma de un documento de cesión de derechos a fin de que sea publicado en la revista bajo licencia Creative Commons Reconocimiento 3.0 España (CC BY 3.0). De igual modo, las pruebas de imprenta serán enviadas al autor/a en formato PDF cuando estén disponibles y deberán ser devueltas a la secretaría de la revista en el plazo máximo de una semana, con las oportunas correcciones.

3. El proceso de evaluación suele tomar unos 4-6 meses. Al tratarse de una revista semestral, una vez aceptado un artículo la publicación final puede llevar por lo general hasta 6 meses más.

4. Para cualquier duda o aclaración, puede llamarse al teléfono 965909615 ( $\mathrm{M}^{\mathrm{a}}$ Carmen Albert), de $10 \mathrm{~h}$ a $14 \mathrm{~h}$, de lunes a viernes, o bien mandar un correo electrónico a la siguiente dirección: revistaobets@ua.es

\footnotetext{
${ }^{1}$ Centro de Información y Documentación Científica (CINDOC) CSIC. Madrid, 2001.
} 


\section{Principios éticos de publicación}

La publicación de artículos en una revista con revisión por pares es un reflejo directo de la calidad del trabajo de sus autores, y del compromiso y cualificación de los investigadores que actúan como revisores. Por ello OBETS. Revista de Ciencias Sociales es una publicación comprometida con los principios éticos de la actividad científica en los siguientes términos:

\section{Publicación y autoría}

Todos los artículos deben incluir un listado de referencias, así como indicar si han recibido apoyo económico. Los trabajos deben estar libres de plagio o fraude científico, cuyos supuestos ${ }^{2}$ se enumeran de manera no exhaustiva a continuación:

- Plagio: copia literal sin entrecomillar y citar la fuente; copia sustancial (materiales de investigación, procesos, tablas...); parafrasear o reproducir ideas sin citar la fuente y/o cambiando el significado original; reutilizar y enviar textos propios ya publicados sin indicar la fuente y el parafraseo abusivo incluso citando la fuente.

- Fraude científico: no reconocimiento de todos los investigadores/as participantes en la elaboración del trabajo, el envío simultáneo a varias publicaciones, la división de un trabajo en partes diferentes que comparten las mismas hipótesis, población y métodos, así como la utilización de datos falsos o no probados. Finalmente, los autores/as deben declarar a la revista los potenciales conflictos de interés cuando envían un trabajo.

\section{Responsabilidad de los autores}

- El envío de trabajos a OBETS supone la lectura y aceptación de las normas editoriales y de publicación de la revista, incluida la participación en un proceso anónimo de evaluación por pares.

- Todos los autores que firman un trabajo deben haber contribuido de manera significativa a su elaboración y deben estar de acuerdo con el resultado final y con el envío del trabajo para su evaluación.

- Los trabajos deben reconocer a todos los autores que han participado en su elaboración.

- Los datos utilizados en el artículo deben ser reales y auténticos.

- Los autores asumen la obligación de corregir y/o retractarse ante posibles errores detectados posteriormente.

- Los artículos han de ser inéditos y no pueden ser enviados simultáneamente a ninguna otra publicación.

\section{Proceso de revisión}

Todos los artículos enviados a la revista se someten a un proceso de revisión por pares con las siguientes características:

- La selección de los revisores se realiza en función de normas y principios previos basados tanto en su cualificación como en la calidad de su producción científica.

\footnotetext{
${ }^{2}$ Fuente: http://www.ethics.elsevier.com/
} 
- El proceso de revisión será totalmente anónimo tanto para los autores como para los revisores. Los artículos y sus revisiones serán tratados confidencialmente.

- Los revisores consideran, entre sus criterios de evaluación, el respeto a los principios éticos esenciales en la investigación científica.

- Los juicios expresados en las revisiones deben ser objetivos.

- Tanto autores como revisores deben revelar las relaciones y fuentes de financiación que puedan generar potenciales conflictos de intereses.

\section{Responsabilidades de los editores}

- El equipo editorial tiene la responsabilidad y autoridad para aceptar o rechazar un artículo basándose en las revisiones.

- El equipo editorial revelará en su caso las relaciones o fuentes de financiación que puedan ser potencialmente consideradas como conflictos de intereses respecto a los artículos que rechaza o acepta.

- Sólo se aceptarán los artículos en los que existe una evidencia cierta sobre el cumplimiento de las normas editoriales

- El Consejo de Redacción de OBETS. Revista de Ciencias Sociales se reserva el derecho de retirar cualquier trabajo recibido, aceptado o ya publicado en caso de constatarse plagio, falsificación o publicación duplicada, así como los diversos supuestos de fraude científico anteriormente enumerados. Del mismo modo, promoverá la publicación de correcciones o retractaciones frente a errores detectados.

- El equipo editorial se compromete a preservar el anonimato de los revisores de manera que nunca puedan asociarse con los artículos revisados.

\section{Cuestiones éticas de publicación}

El equipo editorial se compromete a:

- Vigilar y preservar los principios éticos de publicación

- Mantener la integridad del expediente académico

- Evitar la publicación de material plagiado o elaborado de manera fraudulenta

- Estar abierto a la publicación de correcciones, clarificaciones, retractaciones y disculpas siempre que sea necesario

- Ofrecer apoyo en el proceso de retractación de artículos

- Realizar todas las acciones necesarias para cumplir los estándares de compromiso intelectual y ético

\section{Aviso legal}

A efectos de lo estipulado en los artículos 138-143 de la Ley de Propiedad Intelectual, la publicación de un trabajo que atente contra dichos derechos será responsabilidad del autor/a. El equipo editorial de OBETS. Revista de Ciencias Sociales no se hace responsable, en ningún caso, de la credibilidad y autenticidad de los trabajos. Del mismo modo, las opiniones y hechos expresados en cada artículo son de exclusiva responsabilidad de sus autores/as y OBETS. Revista de Ciencias Sociales no se identifica necesariamente con ellos. Los autores conservan el copyright de su artículo sin restricciones. 



\section{EDITORIAL STANDARDS AND INSTRUCTIONS FOR CONTRIBUTORS}

Summary of guidelines for submitting manuscripts. Please check the latest version in http://revistaobets.ua.es

\section{Guidelines for submitting manuscripts}

1. The journal OBETS. Revista de Ciencias Sociales (OBETS. Journal of Social Sciences) aims at the dissemination of academic nature studies that allow a better understanding of contemporary society. In this sense it is open to the publication of results of empi-

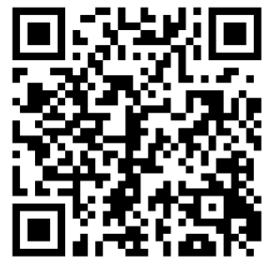
rical, methodological or theoretical research at national and international level, in a wide range of subjects enrolled in the field of sociology and social sciences, as public opinion surveys, methodology, demographics, structure and social change, political science, sociological theory, anthropology or social psychology. Priority will be given to works that communicate results of original academic research and to use the IMR\&DC+B structure (introduction, methods, results and discussion, conclusions, and updated bibliography).

2. Papers may be written in English, Italian, Portuguese, Spanish or Valencian/Catalan. They must be submitted in digital format as an attachment, in .Rtf or .Doc format through the submission page on the website of OBETS Journal. Receipt of items is open all the the year, except August.

3. For each edition are accepted only articles that have been positively evaluated at least during the month prior to the edit month.

4. The length of papers should not exceed 10000 words. The research notes (report on findings, contributions, etc.) should not exceed 7000 words. The book reviews cannot exceed 3000 words, and should include the author, title, publisher, place and date of publication of the book. The full name and address of Contact of the author of the critique must also be included. We only accept reviews of books published in the last 3 years.

5. The works will be sent in the following format

1. Font Times New Roman, font size 12. Single space, page size A4.

2. Section headers in bold. Capitalize only the first letter, and with the same type and font size that the text body.

3. Paragraphs indented on the first line.

4. The words in a language other than the original work in italics.

5. Textual citations must be quoted if they are less than three lines. If you have more than three lines shall be indented by the left margin without quotation marks. In any case, indicate in parentheses the surname of the author or authors of the text, the year of publication and page. For example: (Ramírez, 2009: 10). If there are more than two authors but less than six, all of them will be cited the first time and the time following use the expression "et al.". If more than six authors, use "et al." from the first mention. 
6. The bibliography at the end of the work shall use APA style (American Psychological Association). Please find below some examples of format:

Books and chapters:

Anwar, M. (1979). The Myth of Return: Pakistanis in Great Britain. London: Heinemann.

Esser, H. (2003). "What Is There Substance to the term 'Leitkultur'?". In R. Cuperus, KA Duffek and J. Kandel (Eds.), The challenge of diversity. European Social Democracy Facing Migration, integration and multiculturalism. Innsbruck / Vienna: Studienverlag, 47-58.

Journals:

Berry, J. W. (1970). "Marginality, stress, and ethnic identification in an acculturated Aboriginal community". Journal of Cross-Cultural Psychology, 1, 17-22.

For documents online, you must indicate the accessed date.

When several references of a same author are included, it is necessary to indicate the name of the author in each title instead of using hyphens/dashes.

7. Pictures and diagrams should be included in the text. Depending on the resolution and quality of the images, the Journal can ask for the original image files as a condition for the publication.

8. Papers should include the following basic elements, both in the language of the article and in English: title, an abstrat no longer than 100 words, and between 4 and 8 keywords separated by semi-coma. If the working language is English, these elements should be included in English and Spanish. If the paper is written in a language other than English, in addition to the 100 words abstract, an extended English abstract must be included, on the order of 1000-1500 words, going into some depth about the papers methods, data, findings and implications.

6. Articles must be unpublished. That condition should be declared during the sending process, when completing the checklist in the Journal webside.

7. Proposals for contributions sent to the OBETS journal may not be sent simultaneously to any other publication.

8. All original is submitted to arbitration by academic peers. In order to ensure impartiality in the selection of articles to publish, the journal observes the anonymity of authors and evaluators. To protect the anonymity, please respect the following format in contributions:

1. A first page that contain only the title (capitalize the first letter and the rest in lower case), the name of the authors, the workplace, and email address, telephone and fax.

2. A second page containing, again, the title (but not the name of author/s), an abstract no longer than 100 words, and between 4 and 8 keywords, separated by semi-coma. Title, abstract and keywords should appear in the original language and in English. 
3. The text of the work (including the extended English abstract) will follow in the third and following pages.

\section{Selection process of manuscripts}

1. The works received will go through the following process in which each step requires overcoming previous

\section{Acknowledgement Notice}

2. Subject classification of the article (UNESCO). At least two members of the Editorial Board will check the compliance of the article with editorial standards of an academic text in the subject area of the journal. If there is at least a positive assessment, the article proceeds to the next phase; otherwise it will be justifiably notified to authors.

3. Review of formal aspects and styles, with notice and return to the author in case of errors.

4. Verification of the anonymization of the article

5. Review by two external evaluators, according to scientific quality criteria ${ }^{1}$. If necessary by disparate evaluations, editorial team requests the contribution of a third evaluator. The evaluation form (available on the website of the journal) includes:

1. Evaluation of the originality and scientific contribution.

2. Evaluation of the clarity and consistency of objectives, hypothesis, methodologies and conclusions.

3. Evaluation of the adequacy and updating of the bibliography.

4. Evaluation of the formal aspects (writing style, quotes, text organization, Tables, graphics, etc).

5. Final recommendation on the work and, where appropriate, suggestions for change or reasons for non-publication.

6. The author(s) will be notified with the relevant decision (acceptance, acceptance pending revisions, reject) on a reasoned way within a maximum period of 6 months.

2. When an article is accepted for publication, the author will be asked to sign a transfer of rights document in order to allow the journal to publish the article under a Creative Commons Attribution 3.0 Spain license (CC BY 3.0). Similarly, proofs will be sent to the author in PDF format when they are available and they must be returned to the secretariat of the journal within one week, with appropriate corrections.

3. The evaluation process is expected to last about 4-6 months. Since Obets Journal is semmianual, the final publication of the article once accepted usually can take up to 6 more months.

4. For any questions or doubts, please send an email to the following address: revistaobets@ua.es

${ }^{1}$ Centre for Scientific Information and Documentation (CINDOC) CSIC. Madrid, 2001. 


\section{Publication ethics and malpractice statement}

The publication of articles in a peer-review journal is a direct reflection of the quality of the work of their authors, and the commitment and qualifications of the researchers who act as reviewers. Therefore OBETS. Revista de Ciencias Sociales is a publication committed to the ethical principles of scientific activity in the following terms:

\section{Publication and authorship}

All manuscripts must include a list of references, and indicate whether they have received financial support. Works must be free of plagiarism or scientific fraud. Illustrative cases ${ }^{2}$ of plagiarism and scientific fraud can be consulted in a non-exhaustive list below:

- Plagiarism: literal copy without quoting and referencing the source; substantial copying (research materials, processes, tables...); paraphrasing or reproducing ideas without citing the source and/or changing the original meaning; text-recycling (reusing a published own text) without indicating the source, and abusive paraphrasing even quoting the source.

- Scientific fraud: no recognition of all the participating researchers in the study, simultaneous submission to several publications, the division of a work in different parts ('slices') that share the same hypotheses, population and methods, as well as the use of false or unproven data. Finally, the authors should disclose potential conflicts of interest to the journal when a manuscript is sent.

2. Responsibility of the authors

- The manuscripts submission to OBETS involves reading and acceptance of the journal publishing guidelines, including participation in an anonymous peerreview process.

- All authors signing a work must have contributed significantly to its development and must agree both with the end result and with the manuscript submission for evaluation.

- Manuscripts must acknowledge all authors who have participated in their elaboration.

- Data used in the article must be real and authentic

- The authors assume the obligation to retract/correct when possible errors are later detected.

- Articles must be original and cannot be sent simultaneously to any other publication.

\section{Review Process}

All articles submitted to the journal are subjected to a peer review process with the following characteristics:

- The selection of reviewers is done according to rules and principles based on both their qualification and the quality of their scientific production.

- The review process will be totally anonymous both for authors and for reviewers. Manuscripts and reviews will be treated confidentially.

\footnotetext{
${ }^{2}$ Source: http://www.ethics.elsevier.com/
} 
- Reviewers will take into account for their evaluation criteria the respect for the ethical principles that are essential in scientific research.

- The judgments expressed in the reviews should be objective.

- Authors and reviewers should disclose all relationships and funding sources that could generate potential conflicts of interest.

\section{Responsibilities of Editors}

- The editorial board has the responsibility and authority to accept or reject a manuscript based on the peer reviews.

- The editorial board will reveal any relationships or funding sources that could potentially be considered conflicts of interest regarding the rejection or the acceptance of manuscripts.

- The journal only accepts manuscripts when reasonably certain of compliance with editorial standards.

- The Editorial Team reserves the right to remove any received, accepted or already published work where plagiarism, falsification, duplicate publication or scientific fraud is found. Similarly, it will encourage the publication of retractions or corrections to errors detected.

- The editorial team is committed to preserve the anonymity of the reviewers so that they can never be associated with the reviewed manuscripts.

\section{Publishing ethical Issues}

The editorial board is committed to:

- Monitoring and maintaining the publishing ethics

- Maintaining the integrity of the academic record

- Avoid publishing plagiarized or fraudulently prepared material

- Be willing to publish corrections, clarifications, retractions and apologies when needed

- Provide support in the process of retracting articles

- Perform all actions required to meet the standards of intellectual and ethical commitment

\section{Disclaimer}

Regarding the provisions in articles 138-143 of the Spanish Law on Intellectual Property, the publication of a work prejudicial to those rights shall be the responsibility of the author. The editorial team of OBETS. Revista de Ciencias Sociales is not responsible, in any case, for the credibility and authenticity of the works. In the same way, the opinions and facts expressed in each article are the sole responsibility of the authors and OBETS. Revista de Ciencias Sociales does not necessarily agree with them. The authors hold the copyright of their articles without restrictions. 
